\title{
EVIDENCE-BASED DESIGN UTILIZED IN HOSPITAL ARCHITECTURE AND CHANGING THE DESIGN PROCESS: A HOSPITAL CASE STUDY
}

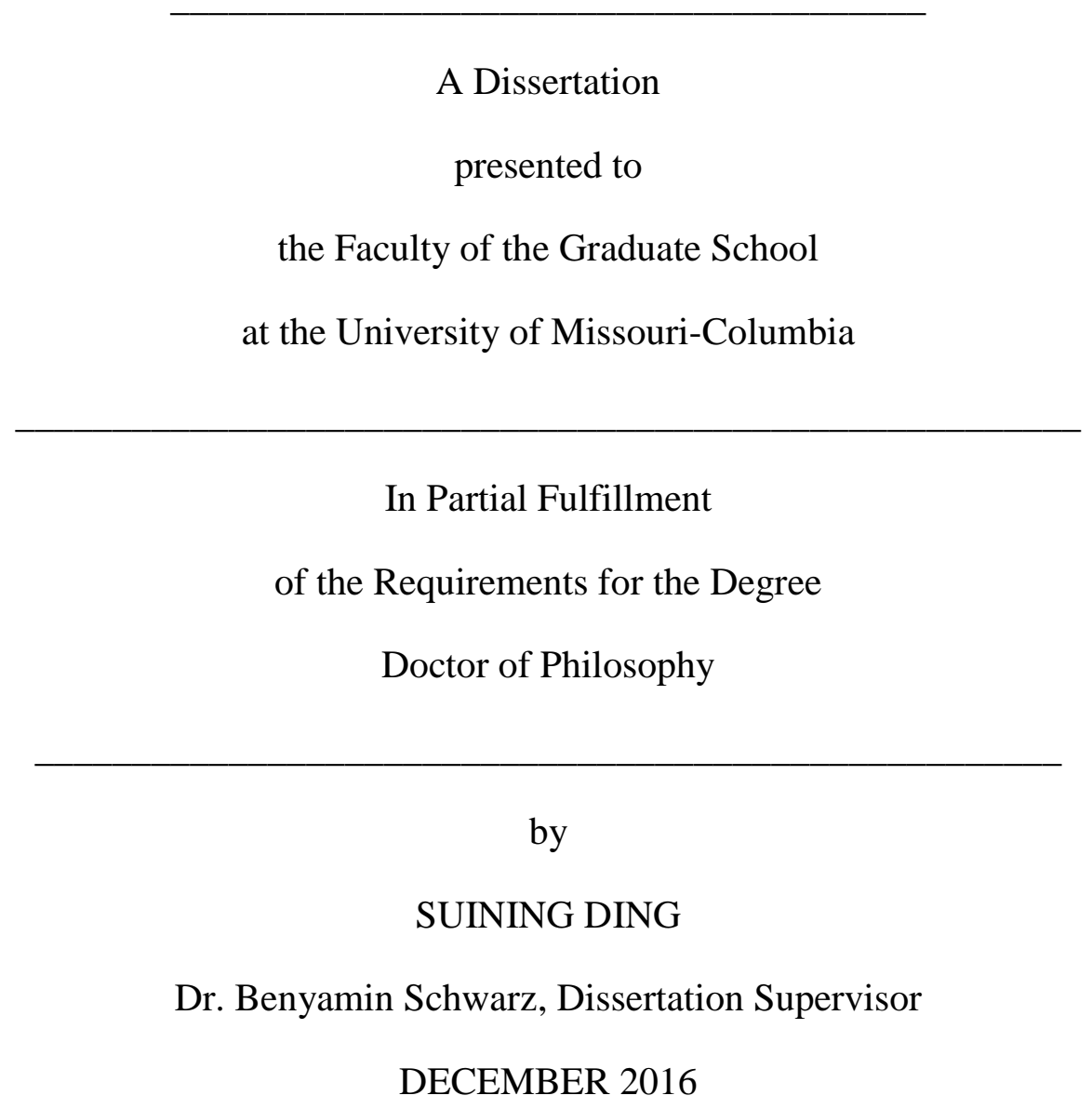


(C) Copyright by Suining Ding 2016

All Rights Reserved 
The undersigned, appointed by the dean of the Graduate School, have examined the dissertation entitled

\section{EVIDENCE-BASED DESIGN UTILIZED IN HOSPITAL ARCHITECTURE AND CHANGING THE DESIGN PROCESS: A HOSPITAL CASE STUDY}

presented by Suining Ding,

a candidate for the degree of doctor of philosophy,

and hereby certify that, in their opinion, it is worthy of acceptance.

Professor Benyamin Schwarz, PhD

Professor Ruth Tofle, $\mathrm{PhD}$

Professor Deanna Sharpe, $\mathrm{PhD}$

Professor Jane Bostick, PhD 


\section{ACKNOWLEGEMENTS}

I consider my doctoral studies as a shared experience of intellectual and professional growth. Through this process, I was fortunate to have the opportunity to study with great mentors who have provided encouragement, guidance, and support. I am honored and privileged to have worked with Dr. Benyamin Schwarz, who recognized my passion for healthcare design research and challenged me to think critically; he is a genuinely conscientious mentor and professor who maintain the high standard and quality of academic inquiry. I am greatly indebted to Dr. Ruth Tofle, for her effort and time as the Chair for the breadth and depth of learning in the Department of Architectural Studies and her personal encouragement for my doctoral studies as a mentor. I am very grateful to Dr. Jane Bostick, whose professional insight into the field of nursing has led me to a deeper understanding of the needs for research informed healthcare design. Finally, I want to express my heartfelt appreciation to Dr. Dianna Sharpe, who has great enthusiasm and interest in my research for reviewing my dissertation.

This research could not have taken place without the open door that Grand River Hospital afforded me. Their leadership and focus on patient safety and outcomes give me a new appreciation and new perspective for what healthcare design can be. I also want to express my gratitude to Sackerber Architects, for helping and supporting my research. Their approach to healthcare design convinced me that the design should be both analytical and intuitive. I wish to thank all the participants in this study, who have made my intellectual inquiry robust and thorough by sharing their experience and opinions.

Finally, I would like to acknowledge the unconditional support, patience, and much more, contributed by my family. 
TABLE OF CONTENTS

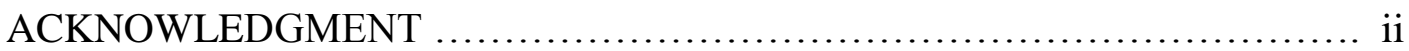

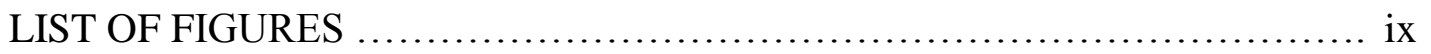

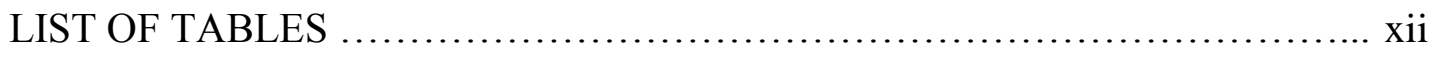

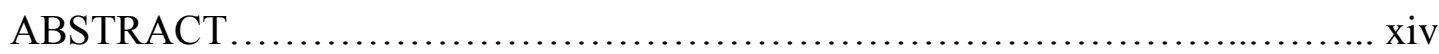

Chapters

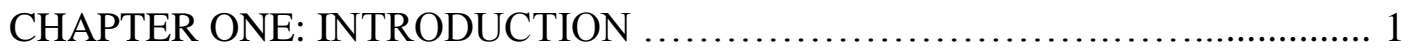

Statement of the Problem.......................................... 1

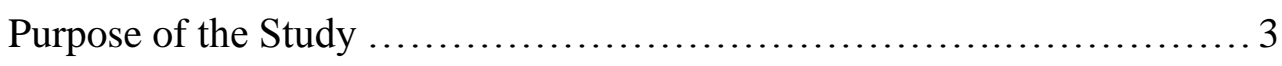

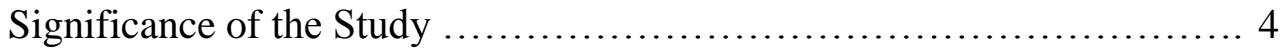

Theories and Theoretical Perspective .............................. 5

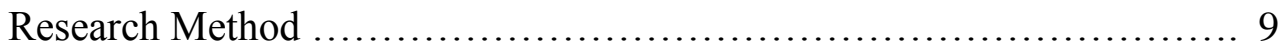

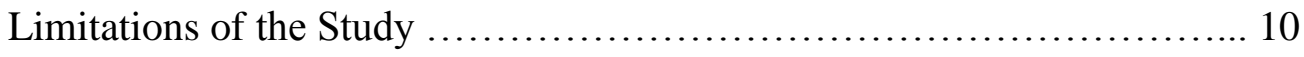

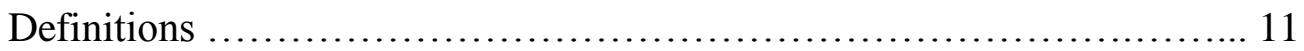

The Organization of the Remained of the Study ....................... 15

CHAPTER TWO: CRITICAL REVIEW of THE EVOLUTION OF HOSPITAL ARCHITECTURE and THE NEW WAVE EVIDENCE-BASED DESIGN ............................ 17

The Ancient ............................................................. 18

The Medieval .................................................... 20

The Renaissance ................................................ 21

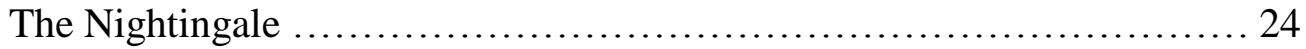


The Minimalist Megahospital .....................................26

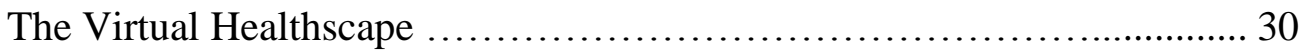

The New Wave - Evidence-based Design (EBD) .......................33

CHAPTER THREE: LITERATURE REVIEW ........................... 35

Review of Related Research in Evidence-based Design ................ 35

Analytical and Critical Review of Theories Relevant to this

Research ................................................................................ 38

Positive Theory and Normative Theory ........................39

Procedural Theory, Design Process, and

Substantive Theory ............................................ 42

Summary of Important Theories for This Research ................ 46

Lean-led Design and Lean Six Sigma .................................. 47

Environment-Behavior Studies in Healthcare Environment and

EB Attributes .......................................................... 52

Environmental Stress......................................58

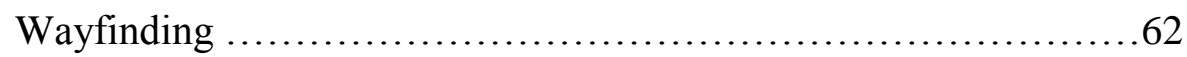

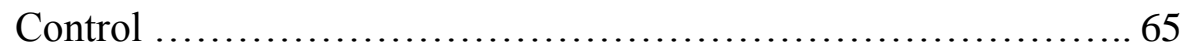

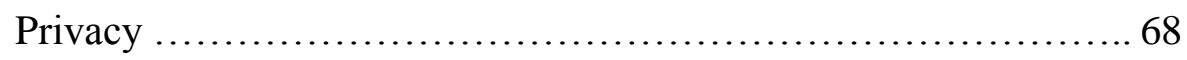

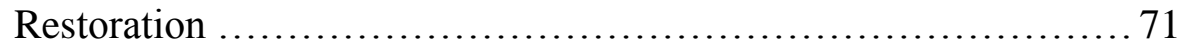

Conceptual Framework for the Study ............................. 73

CHAPTER FOUR: RESEARCH METHODS $\ldots \ldots \ldots \ldots \ldots \ldots \ldots \ldots \ldots \ldots \ldots \ldots . \ldots 77$

Philosophical Assumptions ......................................77

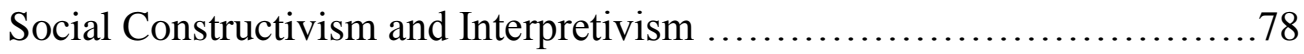




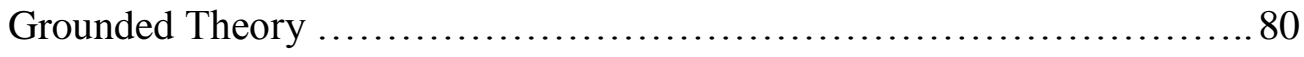

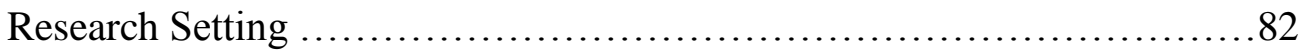

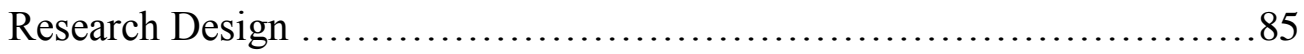

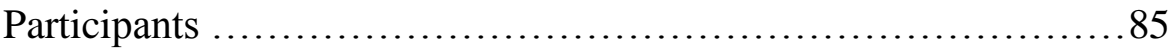

Ethical Considerations ...................................... 86

Permission to Conduct the Case Study ......................... 87

Document Reviews ........................................... 88

Direct Observations ......................................... 89

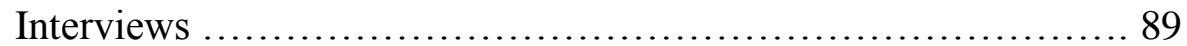

Data Analysis Strategies ............................................ 92

Initial Open Coding ......................................... 95

Memo-Writing .......................................... 97

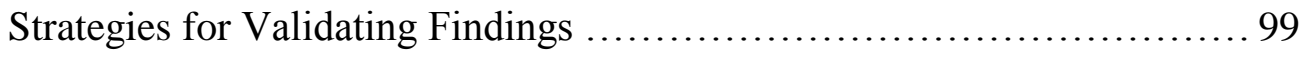

CHAPTER FIVE: FINDINGS ......................................... 101

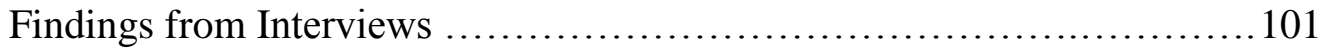

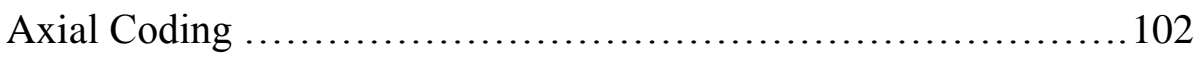

Selective Coding .......................................... 105

Diagram of Selective Coding for Interviews Regarding Research Question \#1................................106

Storyline Memos for Interviews Regarding Research Question \#1..........................................108

Evidence-based Design ............................. 109

Design Research ...............................111 
Collaborations

Design Innovation ................................... 118

Best Possible Outcomes ........................122

Post-Occupancy Evaluation ....................... 126

Diagram of Selective Coding for Interviews Regarding Research Question \#2 .................................129

Storyline Memos for Interviews Regarding Research Question \#2

Visioning Sessions and Design Guiding

Principles

Programming Process

Schematic Design Process

Research Evidence Interpretation and Implementation

Decision-Making Process

Contractors' Roles in Design Process

Post-Occupancy Evaluation Feedback

Session and Publication

Findings from Observations: Research Evidence Implemented in the Design of Grand River Hospital

Healing Environment and Positive Distractions

Privacy

Supervision and Control

Infection Control ............................................... 162

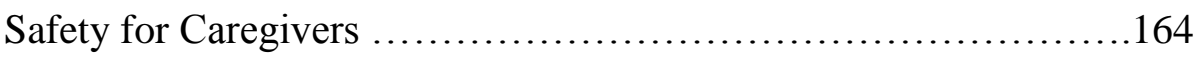

Safety for Patients ............................................ 165 
Patient-centered Care and Restoration

Connecting with Natural Daylight and Window Views............ 174

Walking Distance - Efficiency .......................... 175

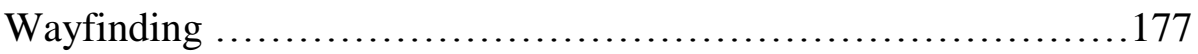

Summary of Research Evidence Implemented in the

Design of Grand River Hospital

Findings from Document Reviews (Data Triangulated by Interviews)......181

Research in Practice at Sackerber Architects .....................186

Functional Performance Evaluation (FPE) at Sackerber

Architects ............................................. 190

Parametric Modeling Tool .....................................199

Institute of Design Research and Evaluation (IDRE) ..............202

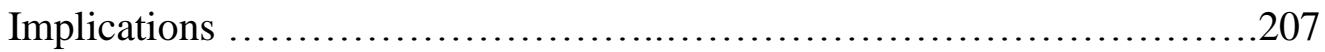

Redefined Model of Design Process by Integrating

Evidence-based Design ...................................208

Description and Explanation of Redefined Design Process .........212

Design Research ..................................213

Research, Evidence Generation in Practice, and New

Skill Set .........................................214

Prediction and Evaluation - Building Mock-ups ...........215

User Participations ..................................218

Technology .........................................219

Cyclical Process not a Linear Process ....................220

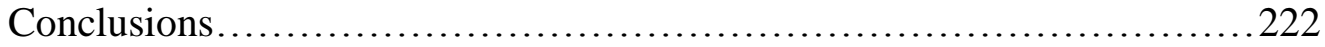


Research-Informed Design and Research-Confirmed Design and

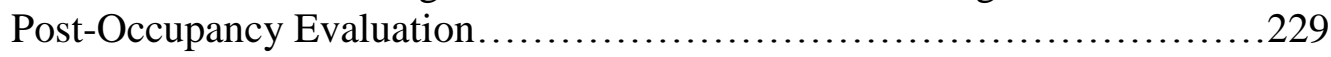

Environment-Behavior Studies and Theory Development.....................2236

Sustaining the Legacy of Florence Nightingale's Environmental Theory and Further Advance E-B Studies in Healthcare Environment.........243

Interdisciplinary Team Approach .....................................245

Research Meets Design in Practice .........................................246

Recommendations of Evidence Generation for Evidence-based

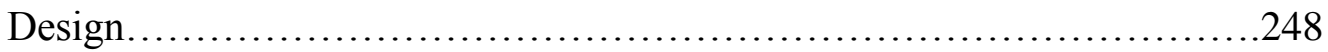

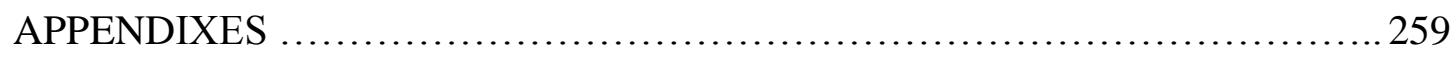

Appendix I: Interview Contacts and Schedule ............................... 259

Appendix II: Interview Protocols ...................................... 260

Appendix III: Observation Protocol ...................................266

Appendix IV: Sample of Observation Sheet ............................ 267

Appendix V: Informed Consent Form ................................2271

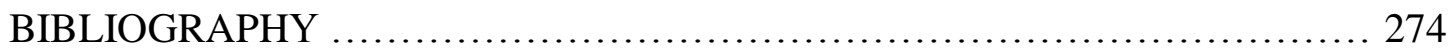

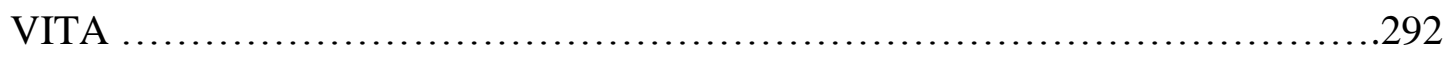




\section{LIST OF FIGURES}

Figure

Page

Figure 3.1: Diagram of Behavioral Science and Environmental Design

Theory Adopted from Lang $(1987$, p.24) ..........................40

Figure 3.2: A General Model of Design Praxis Adopted from

Lang $(1987$, p.45) ...........................................44

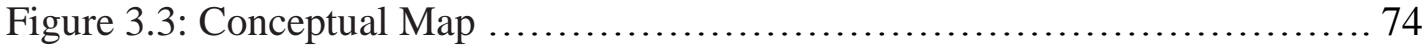

Figure 4.1: Grand River Hospital Medical Campus Site Plan .................... 84

Figure 5.1: Selective Coding Diagram for Research Question \#1 Regarding

Research Evidence Interpretation and Implementation in

Evidence-based Design ..................................... 108

Figure 5.2: Typical Floor Plan of Nursing Unit in the Tower $\ldots \ldots \ldots \ldots \ldots \ldots \ldots \ldots \ldots$

Figure 5.3: Typical Patient Room Layout with a Nurse Alcove,

Family Zone and a Hand-washing Sink ...........................124

Figure 5.4: Typical Decentralized Nurse Station and Medication Room ........... 125

Figure 5.5: Selective Coding Diagram for Research Question \#2 Regarding

Programming Process, Design Process, and Decision-Making

Process in Evidence-based Design .............................131

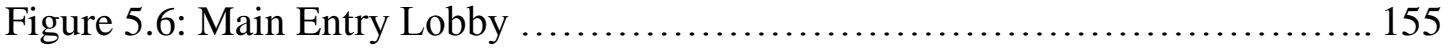

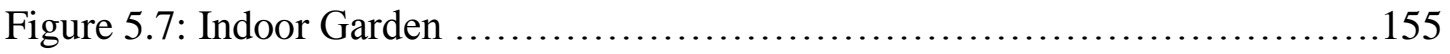

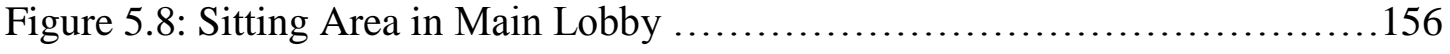

Figure 5.9: Main Lobby at Grand River Hospital ........................... 156

Figure 5.10: Private Patient Room Showing Headwall ........................ 157

Figure 5.11: Family Space in Private Patient Room .......................... 158

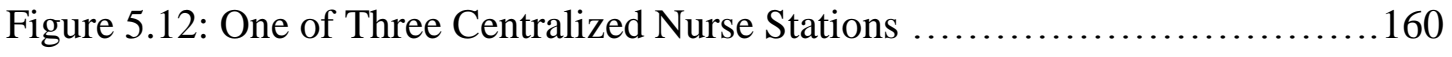


Figure 5.13: Decentralized Nurse Alcove Outside Patient Room 160

Figure 5.14: Hand-washing Sink in Patient Room 162

Figure 5.15: Antibacterial Hand Sanitizers in Patient Room 162

Figure 5.16: Hand-Wash Sink in Corridor 162

Figure 5.17: Ceiling Lift in Patient Room 164

Figure 5.18: Standardized Exam Room in Emergency Department 167

Figure 5.19: Hand Railing Installed in a Slightly Curved Corridor 169

Figure 5.20: Art Works in hallway 170

Figure 5.21: Piano at the Corner of Lobby for Healing Art Program .... 170

Figure 5.22: The Chapel in Grand River Hospital 171

Figure 5.23: Meeting Room for Families and Medical Staff 172

Figure 5.24: Big Mural Installed in the Waiting Area/Family Lounge in Emergency Department

Figure 5.25: Touch Screen Machine for Children in Waiting area/Family Lounge.. 173

Figure 5.26: Big Window View at the End of Hallway in Nursing Unit 174

Figure 5.27: Built-in Bench in Hallway in Nursing Unit 175

Figure 5.28: Decentralized Supply Space 176

Figure 5.29: Research-Informed Design and Research-Confirmed Design

Diagram 188

Figure 5.30: Process Model of Research in Practice at Sackerber Architects 189

Figure 5.31: Process of Functional Performance Evaluation (FPE)

Figure 5.32: Deeper Dive Studies - Functional Performance Evaluation (FPE) ..... 194

Figure 5.33: Field Research (Site Visit) Framework 196

Figure 5.34: Integrating Research in Practice in Design Process Diagram at Sackerber Architects 198 
Figure 5.35: The Model of Redefined Design Process by Integrating Evidence-based Design ........................................ 210

Figure 6.1: Diagram of Cyclical Design Process - Starts with Research and Ends with Research 


\section{LIST OF TABLES}

Table

Page

Table 3.1: Two Primary Approaches in Lean Six Sigma

(Source: Novicoff, 2013)

Table 3.2: Traditional versus Lean-Led Architectural Design Philosophies

(Source: Grunden and Hagood, 2012)

Table 3.3: Environment-Behavior Attributes with Supporting Empirical EB

Studies Literature

Table 4.1: List of Interviewees and Their Occupations ...................... 92

Table 4.2: Sample of Open Coding for Interviews ............................ 97

Table 4.3: Memo about Design Charrette/Workshop................................ 98

Table 5.1: Axial Coding for Research Question \#1 Regarding Research

Evidence Interpretation and Implementation in Evidence-based

Design

Table 5.2: Axial Coding for Research Question \#2 Regarding Design Process and Decision-Making Process in Evidence-based Design 105

Table 5.3: Summary of Post-Occupancy Feedback Session for Grand River Hospital

Table 5.4: Design Guiding Principles for Grand River Hospital

Table 5.5: Open Coding for Observations

Table 5.6: Findings from Observations (Confirmed by Interviews)

Table 5.7: Open Coding for Document Reviews

Table 5.8: Findings from Document Reviews (Confirmed by Interviews)

Table 5.9: Design Metrics and Performance Metrics for Research in Practice at Sackerber Architects 190

Table 5.10: 12 Key Categories for Functional Performance Evaluation 194 
Table 5.11: Publications, Tools and Resources at IDRE .204

Table 5.12: Research Evidence Compiled by Institute of Design Research

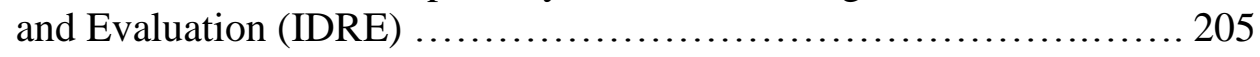

Table 5.13: The Evidence-based Design Process - Eight Steps (Source: EDAC Advocate Brochure 2016) ..........................209

Table 6.1: Data Collection Methods in FPE and POE .............................234

Table 6.2: Activities and Methods for Evidence Generation ......................250 


\title{
Evidence-based Design Utilized in Hospital Architecture and Changing the Design Process: A Hospital Case Study
}

\author{
Suining Ding
}

Dr. Benyamin Schwarz, Dissertation Supervisor

\begin{abstract}
As a new paradigm in healthcare design in the $21^{\text {st }}$ century, evidence-based design (EBD) has played a critical role in the changing hospital architectural design process and shaping new images of hospital architecture. Evidence-based design is research informed, and its results affect not only patients' clinical outcomes but also medical facility operational efficiency and its staff retention and satisfaction. This research investigated how EBD was implemented in hospital architectural design and how traditional design process was modified to incorporate credible research evidence through a case study at Grand River Hospital in the United States. This study took a qualitative approach with grounded theory methodology. The methods used for this research were multiple sources of data collection through document reviews, observations, and interviews. Findings revealed that the investigation for EBD needs to focus on environment-behavior studies especially in the development of explanatory theory. This study also recommended a modified cyclical design process model for integrating EBD. This redefined design process model requires collaborations with all stakeholders by adding visioning sessions, multiple design charrettes, mock-ups, and the functional performance evaluation to help to implement research evidence and make design decisions to achieve the best possible outcomes.
\end{abstract}




\section{CHAPTER ONE: INTRODUCTION}

\section{Statement of the Problem}

Nursing units in hospitals in the United States have evolved through history and experienced radical transformations. These radical changes are reflected in different hospital configurations and environmental features in different periods of time. As a new paradigm in healthcare design in the $21^{\text {st }}$ century, evidence-based design (EBD) has played a critical role that modified or changed the hospital architectural design process and generated new configurations of hospital architecture.

Evidence-based design is a new strategy and a growing trend in hospital architectural design in the United States in the $21^{\text {st }}$ century (Cama, 2009; D. K. Hamilton \& Watkins, 2008; McCullough, 2009). It is a developing field of study that holds great promise for benefiting stakeholders including patients, families, physicians and nurses as well as other healthcare staff and organizations (R. S. Ulrich, Berry, Quan, \& Turner Parish, 2010). Evidence-based design has been formally defined as "the process of basing decisions about the built environment on credible research to achieve the best possible outcomes" (The Center for Health Design, 2008). A study conducted by the Center for Health Design surveyed more than 1,000 participants from different stakeholders in 2010. The results from the study show that $47 \%$ of the participants in a design team use research evidence to make design decisions "on a regular basis" and $24.1 \%$ of the participants in a design team "sometimes" use EBD. More than $80 \%$ of respondents from all stakeholders stated they "regularly" or "sometimes" used design research to make their decision. Evidently, the notion of evidence-based design has been accepted by the 
general public in the United States even though EBD has not been fully implemented in healthcare design practice.

Indeed, the era of research-informed design has already brightened the hospital architectural design field. The Center for Health Design identified more than 1200 credible studies with specific environmental design relevance and characteristics in 2008 and there is continually more published research evidence since then. This credible research evidence is available to be implemented in hospital architecture through the appropriate design process. However, very few studies in the body of knowledge of EBD have been found regarding the linkage between credible research and healthcare design practice, particularly regarding how research evidence is interpreted and then implemented in design concepts. As Hag and Pati (2010) state, the interaction between the primary change agent (the designer) and research evidence is a crucial component of evidence-based design that has not attracted much attention, yet (Haq \& Pati, 2010).

In fact, the relationships between the physical environment and medical outcomes have been confirmed by the study carried out by Rubin et al. (1998). Rubin et al.'s study confirms "there is suggestive evidence that aspects of the designed environment exerts significant effects on clinical outcomes for patients" (Rubin, Owens, \& Golden, 1998). In addition, a vast number of studies have confirmed the impact of the physical environment on patient medical outcomes and staff efficiency in hospital settings (R. Ulrich, 1984; R. S. Ulrich, 1991, 2001; R. S. Ulrich et al., 2008; Urlich, Zimring, Quan, Joseph, \& Choudhary, 2004). Therefore, there is a growing body of evidence that links the physical environment with safety and quality outcomes for patients and staff. Although existing studies have also emphasized the linkage between the physical environment and health 
outcomes and overall performance through case studies, such as Pebble Project

conducted by The Center of Health Design (Joseph \& Kirk Hamilton, 2008), it is not the goal of Pebble Project to examine the linkage between credible research evidence and architecture design practice. Therefore, what remains to be explored is to assess and understand how credible research is implemented in the design concept and how design decisions are made in an evidence-based design process.

\section{Purpose of the Study}

The design process traditionally consists of four phases: programming/conceptual design, schematic design, design development, and construction documents. Joseph et al. (2008) outlines a cyclical framework for the evidence-based design process for the Pebble Project research. This cyclical framework for the EBD process is presented as: 1) identifying available research evidence-literature, existing knowledge, and original data collection; 2) critically analyzing research evidence; 3) design innovations; and 4) conducting research studies to assess the effect of design innovations (Joseph \& Kirk Hamilton, 2008). What remains unknown, however, is how these EBD steps are incorporated into a traditional design process.

In order to provide practical recommendations for future healthcare design practice and be able to implement research evidence in design practice effectively, it is absolutely necessary to have a fuller and deeper understanding about the design process that implements credible research evidence. Whether the current design process has had a major overhaul of traditional design methods or it just added elements to incorporate the research-based model into the traditional process, these can be assessed and examined by 
this case study in Grand River Hospital (a pseudonym for the facility) in the United States.

It has been a promising path forward in healthcare design that design decisions should be made based on evaluation of creditable research evidence (D. K. Hamilton \& Watkins, 2008). Evidence-based design has also become a major driving force to shape hospital architecture configurations and environmental features. Yet, as in any field, execution typically lags behind theory and research (R. S. Ulrich et al., 2010). Since evidence-based design is a new paradigm in architectural design practice, little information has been found regarding how credible research is evaluated, interpreted, and implemented in healthcare design practice to achieve the best possible outcomes. The purpose of this study is to investigate how evidence-based design has been implemented in hospital architecture as well as how the traditional design process has been modified or changed in order to incorporate credible research evidence. The research questions for this study are:

1. How is credible research evidence interpreted and implemented in the hospital architecture design process?

2. How does implementation of evidence-based design change the programming process, design process, and the decision-making process of healthcare design?

\section{Significance of the Study}

The significance of this study is that it bridges the gap between research evidence and design practice by recommending a redefined model of design process that incorporates evidence-based design as well as recommendations for future research in 
theory and practice in evidence-based design. With a better understanding of the evidence-based design process through a case study at Grand River Hospital, I gained insights from different stakeholders regarding how a traditional design process was modified and how research evidence was interpreted, implemented, and evaluated. Gathering evidence is an easy part of basing decisions on research findings. The most difficult part is to use critical thinking to make an objective interpretation of the implications of research for the specific design situations (D. K. Hamilton \& Watkins, 2008). Hamilton (2008) states that the result of critical interpretation is an understanding of what the research suggests as a promising avenue for design. The designer will then convert these implications into design concepts that fall within the chain of logic from evidence to interpretation and then to design concept (D. K. Hamilton \& Watkins, 2008). Therefore, understanding how research evidence is evaluated, interpreted, and implemented in the design process makes this study particularly significant. The findings of this research fill in the gap in the body of knowledge of evidence-based design and lead to better design decisions and increased rigor of design practice.

\section{Theories and Theoretical Perspective}

Several theories are applicable when identifying a theoretical perspective for research in the areas of implementing evidence-based design and hospital architectural design process. A fundamental theory at the heart of any study concerning environmentbehavior is Rapoport's exoplanetary theory (Rapoport, 1982, 2000). Other theories that have implications for this study are Lang's (1987) theories: positive theory, normative theory, procedural theory, and substantive theory. 


\section{Explanatory Theory, Positive Theory, and Normative Theory}

Scholars in architectural research often reference theories to many different terms with different definitions including explanatory theory, positive theory, normative theory, procedural theory, and substantive theory (Hillier, 1996; Lang, 1987; Rapoport, 2000). Because this research focuses on understanding a healthcare architectural design process that implements evidence-based design (EBD) and uses scientific research evidence to inform design decisions, theories relevant to architectural research, specifically relevant to design methodology and design process as well as environment-behavior studies, are important to this study. These theories include explanatory theory, positive theory, normative theory, procedural theory, and substantive theory.

Rapaport (1982) defines explanatory theory:

... there is explanatory theory, which is based on research and supported by empirical data and which leads to understanding and prediction, and then there is "theory", which is really nothing more than opinion, ideology, and the like... the construction of explanatory theory cannot begin until there is sufficient empirical data to suggest directions and to constrain such theory construction. (p. 241)

Behavioral science contributes in several ways to architectural theory. Two major ways that behavioral science contributes to architectural theory consist of 1) theories and models that enhance understanding of the design process and the relationship between people and the physical environment; and 2) research methods (Lang, 1987). Two kinds of theories are commonly discussed in architectural research, including positive theory and normative theory. Scholars distinguish between positive theories as analytic and predictive and normative theories as creative (Hillier, 1996; Lang, 1987). In general, a positive theory is a theory that attempts to explain how the world works and explain a phenomenon or a group of phenomena, while a normative theory provides a value-based 
view about what the world ought to be like or how it ought to work; positive theories express what is, while normative theories express what ought to be (Lang, 1987).

\section{Procedural Theory and Substantive Theory}

Positive theory and normative theory in the design fields consist of two components, procedural theory and substantive theory, although both procedural theory and substantive theory are professed in normative theory (Lang, 1987). What are substantive theory and procedural theory? Lang (1987) defines these two theories as the following:

Procedural theory is concerned with descriptions and explanations of the processes whereby the built environment, interiors, building, and landscapes are designed. It is concerned with design methodology, the study of the process of designing. (p. 33)

Substantive theory in architecture is concerned with descriptions and explanations of the physical nature of the built environment, its materials and structure, and with what it affords organisms. (p. 73)

Johnson (1994) summarized procedural theory and substantive theory as:

"Procedural issues are concerned with praxis and process, and deal with creativity, analysis, synthesis, evaluation, and research. Substantive issues are concerned with phenomena, environmental qualities and functions, esthetics, behavior and the determination of the emphasis on these" (p. 19).

Based on critical review of theories that are relevant to this research, it is clear that positive explanatory theory is very important to this study. The reason is that evidence-based design is using credible research evidence to inform design decisions to achieve the possible best outcomes. Thus, developing positive explanatory theory that is descriptive and predictive in environment-behavior studies is critical for evidence-based 
design. The procedural theory is also very important to this study. The reason is that this research focuses on the design process and decision-making regarding evidence-based design. Like Lang (1987) defined, procedural theory is concerned with the design process and design methodology. Thus, procedural theory is extremely important in this study. Lang (1987) also states that a thoughtful and sensitive design process cannot be done well without good substantive theory. Therefore, both procedural theory and substantive theory are equally important to this study.

Theories are an essential part of the framework used to organize specific social phenomena within social sciences. A theoretical perspective can be defined as a hypothetical model that provides explanation for a given point of view. Researchers increasingly use a theoretical lens or theoretical perspective in qualitative research, which provides an overall orienting lens for the research questions (Creswell, 2009). Creswell (2009) further indicates that this theoretical lens becomes an advocacy perspective that shapes the types of questions asked, informs how data are collected and analyzed, and provides a call for action or change (p. 62). Additionally, like Creswell (2009) states, inquiries should employ theory as a broad explanation for behavior and attitudes in qualitative research. Theories may also be a theoretical lens or theoretical perspective that raises research questions (Creswell, 2009, p. 70). Thus, theories described above can be seen as theoretical perspectives that address the environment-behavior studies in which credible research evidence is generated to achieve the best possible outcomes in healthcare environment. These theoretical perspectives also address the architectural design process and architectural theory creation. Creswell (2009) writes that data interpretations could be in many forms. It could be the researcher's personal 
interpretation that is brought from her or his own experience or it could also be a meaning derived from a comparison of the findings with information gleaned from theories (Creswell, 2009). For this study, the interpretation is a meaning derived from a comparison of the findings with information that was obtained from the theoretical perspectives described above. These theoretical perspectives explain particular features of a phenomenon in environment-behavior studies and thus contribute to a better understanding of the phenomenon in EB studies, especially in architectural research. More detailed analytical and critical review of these theories will be discussed in Chapter 3: Literature Review.

\section{Research Method}

According to Yin, when the research question is "how" and "why", the research would be explanatory and likely to lead to the use of case studies as preferred research methods (Yin, 2009). Case studies are a strategy of inquiry in which the researcher explores in-depth a program, event, activity, or process. Cases are bounded by time and activity, and researchers collect detailed information using a variety of data collection procedures over a sustained period of time (Stake \& Savolainen, 1995). Given the nature of research questions, the research method for this study is a case study in Grand River Hospital in the United States.

This study took a qualitative approach with grounded theory methodology. The methods used for this research were multiple sources of data collection through document reviews, observations, and interviews. More detailed procedures of data collection will be described in Chapter 4: Research Methods. Data was collected from interviews with each 
of the participants who were involved in the design of Grand River Hospital. Data was also collected from document reviews of published articles and documents obtained from the architect. In addition, data was collected from direct observations of physical features that were designed by using credible research evidence. This allowed me to compile an abundant amount of information that is coded and analyzed to understand and evaluate the current practice for evidence-based design at this healthcare facility. As part of the grounded theory methodology, and due to the extensive amount of information that has been obtained for this study, a three-stage coding paradigm was used to organize and analyze the data. The three stages of data coding are open coding, axil coding, and selective coding. According to Strauss and Corbin (1990), coding represents the operations by which data are broken down, conceptualized, and put back together in new ways. The coding process is a central process by which theories are built from data. Cresswell (2009) states that theory also appears as an end point of qualitative study, a generated theory, a pattern, or a generalization that emerges inductively from data collection and analysis. Grounded theorists generate a theory grounded in the view of participants and place the theory as the conclusion of the study (Creswell, 2009). For this study, data interpretation took the grounded theory approach to generate a new theory or pattern of meaning, which was "grounded" in the actual data collected from multiple sources of evidence.

\section{Limitations of the Study}

There were a couple of limitations to this study that were inherent in the design of the research. This research was conducted on one single hospital case study in the United 
States. Although there are enough participants $(\mathrm{N}=26)$ in this study to reach data saturation and reveal findings and draw conclusions, it is just one case study. Future research could include more hospital case studies in different regions of the United States that follow the same research protocols. I received help from Grand River Hospital and its research and innovation center. They helped to recruit participants for interviews. Thus, some participants were randomly selected, and some participants were not randomly selected but selected from referral and recommendation of participants themselves.

\section{Definitions}

Architects/Designers/Design Team: For this study, these terms refer to the architects and designers who worked on Grand River Hospital. Sackerber Architects (a pseudonym) is the architectural design firm.

BIM: Building Information Management is computer software that is used for a process involving the generation and management of digital representations of physical and functional characteristics of buildings.

Consultants: For this study, this term refers to a programming consulting company (Wayfinding Design Consulting Company), a project management consulting company (LDJ Global Project and Development Service Company - a pseudonym), a landscape design consulting company, and an ecological consulting company that worked on Grand River Hospital. 
Contractors: For this study, this term refers to the two construction companies that worked on Grand River Hospital. One is Zbranden Construction (a pseudonym) and the other one is McLaughlin Construction (a pseudonym). Zbranden Construction is a local construction company.

Center for Health Design: Center for Health Design is a non-profit organization of passionate healthcare designers and professionals who are dedicated to improving the quality of healthcare through design of built environment. The center was founded in 1993 with a vision for creating healthcare facilities that promote healthier environments for patients and staff. The mission of the center is to lead the way in transforming healthcare facilities to safer and healthier places through design research, education, and advocacy.

EBD: Evidence-based Design has been formally defined as "the process of basing decisions about the built environment on credible research to achieve the best possible outcomes" (The Center for Health Design, 2008).

EDAC: Evidence-based Design Accreditation and Certification is an exam that tests the candidates on evidence-based design in healthcare, the research process, the pre-design process, construction, and occupancy. The exam tests the candidates' ability to practice the EBD process, not the evidence itself.

EDRA: Environmental Design Research Association is a non-profit organization and is an international, interdisciplinary organization founded in 1968 by design professionals, social 
scientists, students, educators, and facility managers. EDRA's mission is to advance and disseminate environmental design research, thereby improving understanding of the interrelationships between human behavior and their built environment in order to create environments that are responsive to human needs.

HCAHPS: HCAHPS stands for Hospital Consumer Assessment of Healthcare Providers and Systems. The intent of HCAHPS is to provide a standardized survey instrument and data collection methodology for measuring patients' perspectives on hospital care. The HCAHPS survey contains a core set of questions that can be combined with a broader, customized set of hospital-specific items. The methodology and the information it generates are available to the public.

HERD: Health Environments Research and Design journal is an international, peerreviewed journal that features research and methodology papers, theory articles, case studies, and book reviews focused on the effects of heath environments and design on patient and organizational outcomes. HERD has been an advocate for research informed design or evidence-based design (EBD).

IPD: Integrated Project Delivery is a project delivery approach that integrates people, systems, business structures, and practices into a process that collaboratively work together to bring talents and insights of all participants to optimize project results, increase value to the owner, reduce waste, and maximize efficiency through all phases of design, fabrication, and construction. IPD teams can include members well beyond the basic triad of owner, architect, and contractor. 
IDRE: Institute of Design Research and Evaluation (a pseudonym) is a non- and unbiased research unit within Sackerber Architects. This research unit conducts and disseminates evidence-informed research that allows their design to create operationally efficient and effective healthcare architecture. This research unit also conducts PostOccupation Evaluation and takes deeper dive for functional performance evaluation (FPE).

Lean-led Architectural Design: This is a systematic approach to healthcare architectural design that focuses on defining, developing, and integrating safe, efficient, waste-free operational processes in order to create the most supportive, patient-focused physical environment possible (Grunden \& Hagood, 2012).

Lean Six Sigma: Lean Six Sigma is a methodology that relies on a collaborative team effort to improve performance by systematically removing waste. It combines lean and Six Sigma to eliminate the eight kinds of waste: time, inventory, motion, waiting, over production, over processing, defects, and skills. This methodology has been used in hospital management and design in recent years.

LEED: Leadership in Energy and Environmental Design was developed by the United States Green Building Council. It includes a set of rating systems for the design, construction, operation, and maintenance of green buildings, homes, and neighborhoods that aims to help building owners and operators be environmentally responsible and use resources efficiently. 
Owners/Users/End-Users: For this study, these terms refer to Grand River Hospital leadership, and Grand River Hospital facility planning personnel, nurses, physicians, and patients who were involved in the design of Grand River Hospital.

Project Manager: For this study, this term refers to the consultant (LDJ Global Project and Development Service Company) and Sackerber Architects who worked on Grand River Hospital as project managers.

\section{Organization of the Remainder of the Study}

This first chapter has given a general background about evidence-based design, the purpose and significance of the study, the theoretical perspective, and a brief description of research methods for this study. The second chapter involves a critical review of the evolution of hospital architecture and the new wave - evidence-based design - in order to provide a backdrop for this research. The third chapter provides a literature review regarding current research in evidence-based design, analytical and critical review theories that are important to this research, explanatory theory, positive theory and normative theory, procedural theory and substantive theory, design process, Lean-led architectural design and Lean Six Sigma, and environment-behavior studies in healthcare environment, as well as a conceptual map. A detailed explanation of the research methodology is found in the fourth chapter. This includes the philosophical assumptions for the study, and the qualitative background and grounded theory methods applied to the research and to the data analysis. Open coding and memo writing as data analysis strategies are described in Chapter 4. Chapter 5 details findings through the three-stage coding processes including axial coding and selective coding. Story memos and diagrams are utilized to extract themes from the data. 
Then it moves on to explain what was found and interpreted through the interview process and findings from observations as well as findings from document reviews. A redefined design process model is proposed in the fifth chapter. Finally, Chapter 6 provides discussions about the implications from findings and new insights revealed. The appendix following this study will include documents and the bibliography relative to this research. 


\section{CHAPTER TWO: CRITICAL REVIEW of THE EVOLUTION Of HOSPITAL ARCHITECTURE and THE NEW WAVE - EVIDENCE-BASED DESIGN}

A hospital as a place and as an institution interweaves so many aspects of people's lives. First and foremost, hospitals are places of healing, where healthcare professionals perform their daily activities in attempts to restore patients to health in a healing environment. But, hospitals are also institutions where medical advances, technology, healthcare profession movements, social expectations, and healthcare business trends intersect and sometimes collide. Therefore, a brief look at hospital history and hospital evolution seems necessary for this study. Two fine volumes have served as the framework for the following discussion of the evolution of hospital architecture:

Healthcare Architecture in an Era of Radical Transformation by Stephen Verderber and David Fine (2000) and The Hospital: A Social and Architectural History by John Thompson and Grace Godin (1975). The following discussion cannot do justice to their in-depth inquiry in these two fine volumes; rather, the following brief discussion of the evolution of hospital architecture and the new wave - evidence-based design - is meant to provide a backdrop for this research.

Healthcare architecture has evolved through history and experienced radical transformations. Verderber and Fine (2000) elaborate the development of healthcare architecture from the 1960s to early 1990s in their book Healthcare Architecture in an Era of Radical Transformation ${ }^{1}$. They identified six periods in the history of healthcare

\footnotetext{
${ }^{1}$ Thompson and Goldin (1975) articulate the hospital architectural history from ancient time to 1960s in their book "The Hospital: A Social and Architectural History." The book remains a major and comprehensive work on the origins and evolution of the hospital in Western culture, dating from the Greek Asclepia to the modern machine hospitals of 1960s. It remains a seed work for hospital history literature that documents the evolution of hospital design. Verderber and Fine's book continues the same framework
} 
architecture that capture significant developments through the centuries. They label these six periods as the Ancient, the Medieval, the Renaissance, the Nightingale, the Modern Megahospital, and the Virtual Healthscape ${ }^{2}$ (Verderber \& Fine, 2000). In the following sections, each of these six periods is critically reviewed by examining the evolution of hospital building types in different periods of history. In the meantime, advances in medical sciences and innovations in building sciences, as well as the development of a new paradigm and new theory, that have significantly influenced the transformation of hospital architecture are discussed. In addition, the future trends and innovations in healthcare architectural design are explored. Lastly, evidence-based design as a new wave is critically reviewed and added as a new wave to the six waves of healthcare architecture.

\section{The Ancient}

The historical development of healthcare architecture is a long process that is influenced by many different driving forces ranging from a wide spectrum. Throughout western history, the place where the sick were cared for has transformed. These "healing" environments have ranged from the home to the church and then developed to what we now understand as hospitals (Burpee, 2009; Sternberg, 2009; Thomson \& Goldin, 1975). Verdeber and Fine (2000) define the first wave that was expressed in the healing practices of the ancient Egyptians, the Greeks, and Middle Eastern and Eastern cultures. Verderber and Fine (2000) note:

in Thompson and Goldin's (1975) book and elaborates the history of healthcare architecture from the 1960s to 1990 s.

${ }^{2}$ There is certain degree of overlap among these periods (Verderber \& Fine, 2000). 
The private room first appeared nearly three thousand years ago in the Greek Asclepion. The shift from the first to the second wave generally coincided with the fall of Greece and the rise of Rome, and the second wave lasted until Rome's fall, in about A.D. 340. (p. 10)

The ancient Greeks and Romans did not have hospitals. The itinerant doctors moved from town to town, treating the patients in their homes. On the other hand, patients who were considered terminally and chronically ill visited temples for the Greek god of healing, Asclepius, for their care. These temples were built far from the heat, noise, dirt, and dust of the towns, always at freshwater sources, usually with a magnificent view of the sea. Patients were treated with healthy diet, pure water, music, sleep and dreams, social interactions, and above all, prayer (Sternberg, 2009, p. 220).

Evidentially, the concept of the healing environment and the notion of physical environment contribute to the therapeutic and healing process and well-being date back to ancient Greece. In the nursing literature, the key importance of physical environment was first highlighted by Nightingale (Nightingale, 1863). Later, in 1860, Florence Nightingale extolled ventilation and fresh air along with the elimination of unnecessary noise, proper lighting, warmth, and clean water in nursing units (Nightingale, 1863). It is obvious that the concept of the healing environment and the notion of physical environment contribute to the healing process and well-being originated in ancient Greece and was influential to Nightingale's nursing practice.

In recent studies, nature as a positive distraction and as an effective stressreducing factor has been addressed and confirmed by many authors (Marcus, 2007; Sternberg, 2009; R. Ulrich, 1984; R. S. Ulrich, 1981). It is a fact that the notion of integrating nature settings in a hospital dates back to ancient Greece. There is a rapidly 
expanding body of research that has tested the old belief that visual contacts with nature have restorative or stress-reducing influences (R. S. Ulrich \& Parsons, 1992). Clearly, recent research has given the scientific base to the old believed notion.

Regarding the plan layout for the patients in the Ancient period, Thompson and Goldin (1975) write, in general, early hospitals used what we call derived plans, which originally evolved for other purposes and were adapted to nursing. For example, the Roman military hospital or valetudinarium was a regular barracks adapted for sick and wounded soldiers. Very much later, functional hospital forms were deliberately created in response to medical or nursing needs, which we call designed plans. In addition, transitional forms are possible, in which some elements of deliberate design may be seen to modify a recognizably derived plan (p.5).

\section{The Medieval}

During the Middle Ages, the Catholic Church arose as the most powerful provider of hospital care (Verderber \& Fine, 2000). Hospitals were often located on the edge of villages or cities throughout the fifth through thirteenth centuries. The populations often grew to surround the hospitals, and these hospitals were the origins of the modern medical center (Verderber \& Fine, 2000, p. 11). The Plan of St. Gall Monastery in Switzerland speaks eloquently of distinctions among persons. The first distinction is that between monks and layman, masters and servants. The second distinction documented by this plan is that between rich and poor pilgrims. The third distinction observed in this plan is that between inpatients and outpatients. The fourth distinction to be observed in this plan is that between sick and well (Thomson \& Goldin, 1975). These distinctions can 
be seen as the early form of department groupings or "zones" with unique functional planning later in the Renaissance time.

Open ward plans were popular during the Middle Ages. The relationship of ward to chapel can be seen from many open ward and chapel arrangements all over the hospital. Patients were treated in large open wards, where they heard mass each day because faith remained the main healthcare offering. Perhaps this is the reason for the popularity of the large open wards because religious feelings would be even more intense among the ill. To see the host lifted was paramount for patients or at least to hear the words of the Mass (Thomson \& Goldin, 1975).

Another popular hospital building type in Middle Ages was the cross ward. It is the same logic as an open ward; cross ward plans led to a better solution. If the altar was placed in the middle of a cross and each arm of the cross is the size of the original ward, four times as many patients would be able to hear and see the same Mass (Thomson \& Goldin, 1975, p. 30).

\section{The Renaissance}

The open ward plans continued to carry over into the Renaissance period. The hospitals in the Renaissance time were most likely to be seen as symmetrical, axial configurations and regimented facades, and they lasted from 1650 to the late nineteenth century (Verderber \& Fine, 2000). An example of an open ward in the Renaissance period is Glasglow Lunalic Asylum, Scotland (1810), which is a panoptical cross ward. There are three main virtues for this building: 1) It maintains the religious purpose while 
meeting the needs of expansion for a larger volume of patients; 2) It facilitates ventilation through the center tower; and 3) It eases surveillance for nurses.

There are many more examples of open ward plans and symmetrical configuration hospitals in the Renaissance period. Julius Hospital, Wurzburg, Germany (1576) is an example of derived plans with symmetrical façade; St. Thomas Hospital, London, England (1693-1709) is an example of a derived plan with a courtyard plan. In every ward of St. Thomas Hospital, they followed the charge to treat patients equally no matter whether they were rich or poor. In addition to open ward plan and symmetrical configuration characteristics, Renaissance hospitals included daylight, fresh air, fireplaces, and gardens.

In the late 1700s, a re-evaluation of the hospital form was prompted by Louis XV in Paris, who developed a committee charged with creating standards for fundamental reform of the basic hospital typology. This change was prompted in part by the new recognition of clean air and hygienic conditions as agents of health, especially within hospital environments. The reformers believed that health primarily came not from medical solutions but from creating a pure, natural environment that provided clean air. One of the architectural proposals was a pavilion system ${ }^{3}$ (Burpee, 2009). The pavilion system became a very influential form; the first was Hôpital Lariboisiere, built between 1839 and 1854 in Paris by M.P. Gauthier.

During the Renaissance period, especially late Renaissance time, many advances in medical sciences and building sciences emerged. The progress of knowledge had been

\footnotetext{
${ }^{3}$ Pavilion in this sense means an open ward, but of limited extent; ventilated on both long sides by windows, on both short sides by doors; connected to a corridor that serves similar pavilions, but selfcontained with its own service rooms. This type of ward came into use in the middle of the nineteenth century. For a hundred years, the pavilion was the dominant ward form (Thomson \& Goldin, 1975).
} 
a driving force that significantly influenced the evolution of hospital building types and configurations. For example, the advances in medical sciences included steam sterilization and clean surgical tools in 1865; specific bacillus caused diseases such as TB in 1882 and vaccination produced immunity in 1885 (Straus \& Straus, 2006). This advanced knowledge in medical sciences has changed healthcare architecture image and its configurations drastically. In addition, advances in building sciences also have caused radical transformations in healthcare architecture; for example, rolled iron beams in the 1850s, elevator in Crystal Palace Expo in 1853, steel frame building in the 1900s, and air conditioning in the 1960s. All these innovations in building sciences have played important roles in shaping new images of healthcare architecture.

However, different opinions exist among scholars regarding what driving forces have caused the change of hospital building type (Adams, 2008; Forty, 1980; Sternberg, 2009). Historians of medicine frequently explain the transformation from the open ward pavilion hospital to private or semi-private patient room with reference to the germ theory, particularly to Robert Koch's discovery in 1870s that specific bacilli caused particular diseases. Sternberg (2009) writes from her medical doctor perspective that the evolution of hospital design from ancient times has paralleled the course of infectious diseases and the knowledge of germ theory that helped to prevent and cure them (p. 219). Yet, the suggestion that the germ theory meant the end of the pavilion-plan hospital is unconvincing to some of the scholars; for instance, Adams indicated the disagreement in her book Medicine by Design (Adams, 2008). Pavilion-plan hospitals continued to be built into the 1930 s after the germ theory was introduced in 1870 s, while at the same time private or semi-private patient rooms were also built. 
One of the opinions regarding scientific discoveries was proclaimed by Thompson and Goldin (1975). They state in their book that nineteenth-century scientific advances, real breakthroughs in understanding the causes of disease, were not fully understood in their time and they were not translated into the changes in hospital design until the twentieth century (Thomson \& Goldin, 1975). This statement explains why the Nightingale ward, which will be reviewed in the next section, appeared and lasted for so long after the discovery of germ theory. Although many new discoveries and experiments regarding vaccines and bacteria have been published, it took a long time for the new principles to be understood, and people continued to plan and design pavilion hospitals without implementing the germ theory evidence into the design (Thomson \& Goldin, 1975).

\section{The Nightingale}

Verderber and Fine (2000) state that the fourth wave originated in Florence Nightingale's work in her two books, Notes on Nursing (1858) and Notes on Hospital (1863). Florence Nightingale (1820-1910) was a very influential figure in nursing history and is applauded for her intuitive, observational approach. She recognized that cleanliness within the hospital ward correlated to patient survival, a quarter century before Louis Pasteur formally proposed his germ theory of disease. During the Crimean War of the 1850s, she was able to decrease the death rate of wounded soldiers remarkably. Nightingale is praised highly as the mother of modern nursing, and her humanist approach influenced hospital design far beyond her time (Burpee, 2009; Straus $\&$ Straus, 2006). 
Nightingale's work had far-ranging implications for the next hundred years of hospital planning and design. Her principles and guidelines for hospital reform concerned the aspects of the maximum allowable width and length of a ward, the size of windows and their placement in relation to the bed, the overall ambiance, the ventilation and heating systems, and the use of specific materials and colors (James \& Tatton-Brown, 1986; Verderber \& Fine, 2000). A Nightingale hospital is also called a pavilion hospital that is a designed plan. One of the typical examples of a Nightingale hospital is Herbert Hospital in Woolwich, England, built in 1859-1864. The pavilions were connected by a central corridor that was kept to one story so as not to cast unnecessary shadows on the ground (Thomson \& Goldin, 1975, p. 165).

Nightingale's principles were based in large part on the need to expose the interior space of patient wards in abundant natural daylight. However, once the technological innovations were introduced in hospitals in the late 1880s, such as the electric light bulb and the Otis Elevator, those concepts of a Nightingale ward were increasingly compromised. It became very common that Urban Nightingale wards were sometimes situated back to back on each patient floor and stacked up twelve to fifteen stories, which disregarded Nightingale's requirement for light from at least two sides in each ward. The high-rise urban hospital was necessary because of the dramatic increase in land cost in urban centers (Verderber \& Fine, 2000, p. 13). These are the evidences of technological innovations and economic factors that have caused changes in the Nightingale ward building type. Obviously, there is no privacy for the patient in the Nightingale ward. However, supervision and efficiency rank highly in the Nightingale ward. A study carried out by Ann Noble and Rodger Dixon in 1977 showed that 
Nightingale wards scored highest marks at the levels of patient satisfaction, absence of boredom, ease of supervision, and job satisfaction (James \& Tatton-Brown, 1986).

Today, many scholars criticize the Nightingale ward from the patient-centered care perspective (Verderber \& Fine, 2000). They argue that the Nightingale ward no longer meets the needs of modern healthcare because it lacks privacy (Chaudhury, Mahmood, \& Valente, 2005; Leino-Kilpia et al., 2001). The debate on privacy in a patient room was an ongoing topic. Literature review indicates that the debate of privacy in patient rooms has a long history dated back to 1788 between Dr. Hoffmann and Dr. Strack (Thomson \& Goldin, 1975, pp. 226-230) and the debate was ongoing for modern hospital design. Since the value of single-bed rooms has been acknowledged by the AIA after extensive research and has been included in the Guidelines for Design and Construction of Health Care Facilities (AIA, 2006), now all patient rooms have been designed for single occupancy in modern healthcare facilities. In recent years, research also has confirmed all the benefits that private patient rooms can bring to patients. However, the spirit of the Nightingale ward still influences the design of healthcare architecture today, which is evidenced by the integration of decentralized nurse's stations to have effective supervision and control over patients, which is the benefit from an open ward.

\section{The Minimalist Megahospital}

Verderber and Fine (2000) define the hospitals in the decades following the end of World War II (the 1940s - the 1990s) as Minimalist Megahospitals. During this period of time, hospitals grew more specialized, containing newly formed departments, 
groupings, or "zones," each with unique functional planning requirements for diagnosis, treatment, surgery, administration, meals, and other support functions. The hospital also grew exponentially in size and spatial complexity during this period (Verderber \& Fine, 2000, p. 13). ${ }^{4}$ Advances in building sciences, such as the long-span structural systems and sophisticated heating, ventilation, and air conditioning (HVAC) systems encouraged the abandonment of the obsolete Nightingale wards in favor of large "block hospitals" with vast windowless regions at the center of each floor, such as race track building type.

After World War II, the medical establishment accepted International Style modernism with open arms. At that time, it was implicitly assumed among architects and their clients that there was an acceptable modern aesthetic and an unacceptable historicist one (Verderber \& Fine, 2000). Thus, the International Style dominated mainstream of healthcare architecture over the next forty years. In the United States, the dominant internal configuration for a hospital nursing unit throughout the 1950s was the doubleloaded corridor typology; for example, Bellevue Hospital in New York City. By the early 1960s, however, the exploration on hospital typologies that led to high efficiency emerged. Therefore, the double-loaded corridor had given way to a racetrack plan. The racetrack plan was created by pulling apart the room blocks along the two sides of the corridor and inserting core supporting amenities in the center (Verderber \& Fine, 2000). The Radial building typology appeared due to the struggle among staff efficiency - the minimization of distances that staff must walk on the nursing unit and the maximization of direct visual contact with patients from the nurses' station. The radial concept, the most radical advance in nursing unit design in the 1960s, was by no means the only

\footnotetext{
${ }^{4}$ The remaining part of hospital architectural history after 1960s was not documented until Verderber and Fine published their book Healthcare Architecture in an Era of Radical Transformation in 2000. It is an excellent addition to the existing hospital history literature.
} 
alternative to the traditional racetrack hospital configuration. The Sawtooth layout emerged, which positioned patient rooms outboard and turned every second room at a forty-five degree angle to the main racetrack corridor loop. The triangulation of the nursing unit, which also first appeared in the mid-1960s, was justified largely on the basis of the Yale Index research. ${ }^{5}$ It was found a highly efficient, effective configuration from the standpoint of nursing staff (Verderber \& Fine, 2000). The block hospitals of the 1960s gave way to further experimentation with the massing and compositional attributes of acute-care hospitals. According to Verderber and Fine (2000), the hospital was considered a "Healing Machine" with the exploration of different building types to lead to high efficiency during that period.

However, this type of healthcare facility (healing machine) traditionally has emphasized the functional delivery of healthcare. Little thought was given to the qualities of the building, such as natural daylight and meaningful connections to natural environment. As a result, many healthcare facilities just emphasized providing enough spaces for laboratories or doors wide enough to accommodate the beds without the considerations of any psychological or social aspects that would be supportive of a patient's recovery. A consequence of this perspective has been that psychological and social needs of patients have been largely disregarded and ignored in the design of healthcare facilities, and are often marginalized in creating visitor and staff spaces (R. S. Ulrich, 2000).

Therefore, healthcare architectural design started moving away from "healing machine" in the 1980s. The early examples of the hospital started breaking away from the

\footnotetext{
${ }^{5}$ Yale Index research is an examination in depth of how one typical ward building - the Memorial Unit of the Yale New Haven Hospital works (Thompson \& Goldin, 2975).
} 
International Style. Postmodernism became popular and home-like residential style was favorable. Architects and healthcare designers started the process of rethinking healthcare design. There are many criticisms on the healing machine, including isolation from context, inflexibility, monumental scale, obsession with high technology, and insensitive to patient and family needs. Architects and designers started reinventing the hospital after 1980. New types of healthcare facilities emerged, including outpatient health-screening centers, mobile health units, community mental health centers, health education programs and centers, long-term rehabilitation centers and home care programs, and subsidized long-term care facilities for the aged.

A Theory of Supportive Design emerged in the 1990s as the result of Roger Ulrich's study by gathering the evidence from multiple studies that seemed to have findings influenced by the physical environment. He interpreted the implications of these studies to suggest a theory that designers could use in the development of supportive designs for healthcare settings (D. K. Hamilton \& Watkins, 2008). His work has been influential, and it has been a catalyst of Evidence-based Design (EBD). In the context of Theory of Supportive Design, healthcare design should do more than produce health facilities that are satisfactory in terms of functional efficiency, marketing, project cost, and building codes. Another more important and more critical role for designers is to promote wellness by creating a physical environment that is "psychologically and socially supportive" (Ruga, 1989; R. S. Ulrich, 2000). It is expected that the effects of supportive design not only are complementary to the healing effects of drugs and other medical technology and foster the recovery process, but also have patient-centered or 
supportive characteristics that help patients cope with the stress that accompanies illness (R. S. Ulrich, 1991, 2000, 2001).

\section{The Virtual Healthscape}

The sixth wave of healthcare architecture - the virtual healthscape - emerged around 1990. The reaction against the minimalist megahospital has been a move toward residential imagery and residential-like design principles for hospitals (Verderber \& Fine, 2000, p. 14). In the 1990s, "Residentialism" found ways to make the hospital room more home-like through the use of natural materials, increased privacy, and reduced noise (Grunden \& Hagood, 2012). "Residentialism" became the dominant theme during that time. The origin of the sixth wave is based on two main areas of influence: the information technology revolution and the cost-containment movement (Verderber \& Fine, 2000). The significant impact of these changes on healthcare architecture would not be fully seen until the rise of the Internet and the World Wide Web in the early 1990s.

Virtual healthscape, the term used by Verderber and Fine (2000), describes the latest wave in healthcare and denotes an unprecedented degree of personal, medical, and technological empowerment. One can choose the means by which one accesses and receives information and care (Verderber \& Fine, 2000, p. 330). Clearly, the era of digital healthcare was in full bloom at the close of the century. According to Verderber and Fine (2000), there are six trends within the contemporary healthcare architecture that serve as the conclusions to the arguments made in their book. These trends include: 
1) Home-based care and the rise of the "health village" whereby the individual can access care in more decentralized settings rather than centralized medical center-based care.

2) Moving from highly centralized medical centers toward networks of providers in the integrated delivery system.

3) The shift from provider-centered care to patient-centered care continues.

4) Creating a sustainable healthcare landscape based on principles of renewability, flexibility, mobility, appropriate construction technologies, and conversation methodologies.

5) Incorporating and sustaining the natural environment as a modality in the design.

6) Interdisciplinary approaches to address complex health and environmental design, and other design-related issues.

These six trends are the foundation and departure point for an expanded discussion (Verderber, 2010, p. 103). In addition to what Verderber and Fine have concluded for the future trends, additional movements of healthcare design should be discussed and explored. The movements include "Green" buildings that emerged with the acceptance of LEED certification, and the "Lean" healthcare approach, which shows that a detailed process design can produce more useful and safer hospitals. Another key development is Integrated Project Delivery (IPD). With IPD in healthcare design, the work is carried out under a single contract covering the owner, architect, contractor, subcontractors, and others. IPD provides a way to collaborate and align the team in pursuit of the project goal (Grunden \& Hagood, 2012). Other new approaches include 
patient-centered care, design for efficient workflow, focus on quality care and patient safety, focus on environmental impact and operating cost, alternative care sites for longterm care, assisted living and home care, as well as evidence-based design. Among all of these movements and new approaches, evidence-based design (EBD) certainly is a major one. It has been a promising path forward in healthcare design that design decisions should be made based on the evaluation of credible evidence (D. K. Hamilton \& Watkins, 2008). Evidence-based design is advocated by many scholars and it has also become a main driving force to shape hospital architecture configurations and environmental features (Cama, 2009; D. K. Hamilton \& Shepley, 2010; Malkin, 2008; Marberry, 1995; McCullough, 2009; R. S. Ulrich et al., 2010; C. Zimring \& Bosch, 2008; C. Zimring, Joseph, \& Choudhary, 2004). There is increasing scientific evidence in the past decades that poor design works against the well-being and well-designed physical environment that promotes patients' medical outcomes (Rubin, Owens, \& Golden, 1997; R. Ulrich, 1984; R. S. Ulrich, 1999b; R. S. Ulrich et al., 2008).

The field of EBD has been developed during the last quarter century to apply scientific knowledge and methods to help guide healthcare facility design that reduces the stress of facility users, improves safety and productivity, reduces resource waste, and enhances sustainability (Berry et al., 2004). A study carried out by the Center for Health Design confirmed that the notion of EBD has been accepted by the general public and it has been used as an innovative approach by many architectural design firms. Therefore, evidence-based design is a new strategy and a growing trend in hospital architectural design in the United States in the $21^{\text {st }}$ century (Cama, 2009; D. K. Hamilton \& Watkins, 2008; McCullough, 2009). 


\section{New Wave - Evidence-based Design (EBD)}

After critically reviewing six periods of healthcare architecture, logically, a new period of healthcare architecture should be added as a new chapter to the six waves. This new period is Evidence-based Design (EBD) as a new paradigm in healthcare architectural design in the $21^{\text {st }}$ century. It is a developing field of study that holds great promise for benefiting stakeholders, including patients, families, physicians, and nurses as well as other healthcare staff and organizations (R. S. Ulrich et al., 2010). Over the past decades, EBD has emerged as a novel approach to healthcare architectural design practice. This approach attempts to have a closer match between design intentions and medical and organizational outcomes because design decisions are based on credible research evidence. In short, evidence-based design is research-informed. Its results not only affect patient clinical outcomes, but also medical facility operational efficiency and staff retention and satisfaction.

Over these years, considerable attention has been given to the research in evidence-based design, which is a key step in the traditional design process model. Hag and Pati (2010) identified three research areas in which EBD research activities have occurred. The first research area is the collation of available research evidence, such as that organized by the Center for Health Design (R. S. Ulrich et al., 2008; C. Zimring et al., 2004). The second research area focused on developing the business case for EBD, amply exemplified in several studies (Berry et al., 2004; C. Zimring, Augenbroe, Malone, $\&$ Sadler, 2008). The third research area is to identify knowledge gaps and to fund empirical research efforts in those areas such as the research grants administered by The 
Center for Health Design (Haq \& Pati, 2010). Clearly, lots of research has been conducted in different areas in the domain of evidence-based design.

However, there are still many research areas in EBD that need to be examined and explored. One of the research areas that need immediate attention and action is how architects and designers interact with research findings and how design decisions are made in the design process when they interpret and implement research findings. This research is significant because it addresses this important research area. EBD requires a new skill set for architects and designers. In addition to extensive experience and deep domain knowledge in healthcare design, the evidence-based design approach demands the integration of credible research evidence into design decision making. This has caused a radical transformation in design behavior and modifications in the design process. EBD requires architects and designers to be able to interact with scientific research evidence, evaluate the research evidence, interpret it, and implement it in design solutions. Therefore, evidence-based design is a new wave and new paradigm that not only requires a new skill set for architects and designers, but also requires a broad spectrum of research evidence in healthcare settings. 


\section{CHAPTER THREE: LITERATURE REVIEW}

\section{Review of Related Research in Evidence-based Design}

Many scholars have referenced or compared evidence-based design (EBD) with evidence-based medicine (EBM) in their articles (Haq \& Pati, 2010; Stankos \& Schwarz, 2007; Viets, 2009). Hamilton (2008) indicated that EBD is derived from Evidence Based Medicine. Evidence-based medicine (EBM), on the other hand, was defined as "a systematic approach to analyzing published research as the basis for clinical decision making." Then, in 1996, the term was more formally defined by Sacket et al., who stated that EBM was "the conscientious and judicious use of current best evidence from clinical care research in the management of individual patients" (Claridge \& Fabian, 2005). In evidence-based medicine, it is extremely important to use randomized controlled trials (RCT), which is a key component of today's EBM practice as a basis for determining the efficacy of various medical treatments. ${ }^{6}$

In comparison with EBM, scholars have suggested that a systematic review of existing and future studies were essential in evidence-based design (Stankos \& Schwarz, 2007). In EBD, the relationships between physical environment and medical outcomes have been confirmed by the study carried out by Rubin et al. (1998). Rubin et al.'s study confirmed "there is suggestive evidence that aspects of the designed environment exerts significant effects on clinical outcomes for patients" (Rubin et al., 1998). In addition, a vast of number of studies have also confirmed the impact of the physical environment on patient medical outcomes and staff efficiency in hospital settings (R. Ulrich, 1984; R. S.

\footnotetext{
${ }^{6}$ Randomized Controlled Trials (RCT) were advocated by Archie Cochrane in the early 1970s as a source of more reliable evidence than other types of information. With Cochrane's contribution, a considerable body of reliable research was available to form the foundation of EBM.
} 
Ulrich, 1991, 2001; R. S. Ulrich et al., 2008; Urlich et al., 2004). Therefore, there is a growing body of evidence that links the physical environment with safety and quality outcomes for patients and caregivers. However, scholars have suggested that a metaanalysis was needed in order to enable designers to choose the appropriate type of evidence from research to improve the accuracy of predictions in environmental design (Pati, 2011a; Stankos \& Schwarz, 2007).

Today, as designers have become increasingly aware of the relationship between research and design, the term "evidence-based design" has become a well-known and commonly used term in healthcare architectural practice. The question may be asked, "How has evidence-based design been implemented in healthcare architectural design practice?" In fact, some challenges regarding EBD have been raised by scholars (Haq \& Pati, 2010; Pati, 2011a; Stankos \& Schwarz, 2007; Viets, 2009). These questions should come as no surprise in light of the history and development of EBM.

Hag and Pati (2010) state that the existing research focus, however, overshadows another essential component of the EBD approach. Hag and Pati (2010) compared evidence-based design (EBD) with evidence-based medicine (EBM) and suggested that research needed to focus on designers' skill set and design behavior. How do designers interact with scientific research evidence, assess the application of research findings in design decisions, and in some instances engage in empirical research? The medical practitioner was intended to be the primary agent in EBM. The counterparts in EBD, which is derived from EBM, are the architects and design practitioners. Both EBM and EBD represent the sharp end in their respective practices (Haq \& Pati, 2010). As a result, Hag and Pati (2010) conducted a study in an architectural design studio in a university to 
examine how designers interact with research evidence (Haq \& Pati, 2010). The research finding suggested to optimize the research-design relationship. Their research implication warrants some major considerations in four domains: 1) a knowledge structure that is easy to comprehend in EBD; 2) design phases that can complement research evidence; 3) designers have the descriptions and explanations of the context regarding research evidence; 4) a design-friendly vocabulary for EBD. Hag and Pati’s (2010) study was conducted in an academic studio stetting with a small sample of 12 students. Future efforts should focus on increasing generalizability by expanding the study to more institutions and enhancing validity by conducting future studies in professional design firms (Haq \& Pati, 2010).

Many publications by the environment-behavior study community have indicated an emerging need and a long-standing concern for the design profession to integrate research in their design decisions (Alexander, 1964; Alexander, Ishikawa, \& Silverstein, 1977; Archer, 1970; Bazjanac, 1974; Lang, 1987; Zeisel, 1981). As a result of attention to this need of integration of research in design, enhancing academic research became a major focus and it has drawn many scholars to conduct environment-behavior research.

Previous studies also addressed issues in architectural theory development. The nature of the design is its creative activities. Architectural theories should propose solutions in the form of analytic-normative complexes of theoretical ideas (Hillier, 1996). Thus, the normative statements in the form of prescriptions for particular environment attributes need to be supported by better understanding and explanation. In other words, "explanatory theory needs to precede normative statements that should be based on such explanatory theory" (Rapoport, 1987, p. 12). One challenge for EBD is theory building 
and theory development as many scholars have stated. Tofle et al. (2004) wrote, "If we want to have evidence-based guidelines, we need to understand what particular colors are supposed to do, and why, before we can proceed to implement them in a healthcare setting and before we can judge whether these colors do it well" (Tofle, Schwarz, Yoon, Max-Royale, \& Des, 2004, p. 69). This statement is supported by Rapaport's (1987) argument: "The validity of objectives must be evaluated before one evaluates whether objectives have been achieved" (p. 12).

The challenges for EBD are not only in theory building and research but also in practice. Hag and Pati (2010) stated that an essential component in EBD research that has received little attention is how designers interact with research evidence in practice. Similarly, as I indicated earlier, what remains to be explored is to assess and understand how credible research is implemented in the design concept and how design decisions are made in the evidence-based design process. Since procedural theory is concerned with descriptions and explanations of the processes whereby the built environment is designed, and it is concerned with design methodology and the study of the process of designing (Lang, 1987), developing procedural theory seems equally important as developing positive explanatory in evidence-based design.

\section{Analytical and Critical Review of Theories Relevant to this Research}

Theory is an ambiguous term that has been given different definitions. These definitions are not universally agreed upon even though theory has played a central role in the development of knowledge. It has been said, "A theory is a system of ideas or statements that is believed to describe and explain a phenomenon or a group of 
phenomena" (Lang, 1987, p. 13). "Theories are sets of interrelated high-level principles or concepts that can provide an explanatory framework for a broad range of phenomena in a domain" (Rapoport, 2000, p. 112). "Theory is a set of principles that guides the architects in making decisions about complex problems that arise in translating a brief into the design of a building" (Gutman, 1972). "Theory is of practice, and must stand and fall with its practicality, provided that the mode and contexts of its applications be suitably specified" (A. Kaplan, 1973). Scholars in the architectural research field often reference theories to many different terms with different definitions including explanatory theory, positive theory, normative theory, procedural theory, and substantive theory (Hillier, 1996; Lang, 1987; Rapoport, 2000). ${ }^{7}$

The goal of this research is to have a deeper and better understanding of how evidence-based design (EBD) is integrated into the healthcare architectural design process and how research evidence is used to inform design decisions. As such, in the following sections, theories relevant to architectural research, specifically relevant to healthcare design process research and evidence-based design, are analytically and critically reviewed. These theories include positive theory, normative theory, procedural theory, and substantive theory. In the meantime, critical issues in the development, use, and evaluation of these theories are discussed. Finally, the degree of importance of each theory to this research is analyzed.

\section{Positive Theory and Normative Theory}

\footnotetext{
${ }^{7}$ There are many other theories, such as scientific theory and descriptive theory. Given the inconsistent definitions of theory, Kuhn abandons the term theory because of its implication of limited scope and substitutes the concept with what he calls "disciplinary matrix" (Kuhn, 2012, p. 181). The theories discussed here are relevant to architectural research particularly relevant to this study.
} 
Behavioral science contributes in several ways to architectural theory. The following diagram (Figure 3.1) depicts the relationship of behavioral science, architectural theory, and practice. This diagram is adopted from Lang's (1987, p. 24) diagram of behavior science and environmental design theory. Architectural theory includes positive theory and normative theory. Both positive theory and normative theory include procedural theory and substantive theory. ${ }^{8}$ It should be noted that in normative theory both procedural theory and substantive theory are professed. In contrast to positive theory, normative theory is concerned with different positions that have been taken or might be taken on what the built environment and the design process should be (Lang, 1987, p. 19). The positive theory component includes principles of environmentbehavior, while the normative theory component includes aesthetic or compositional principles.

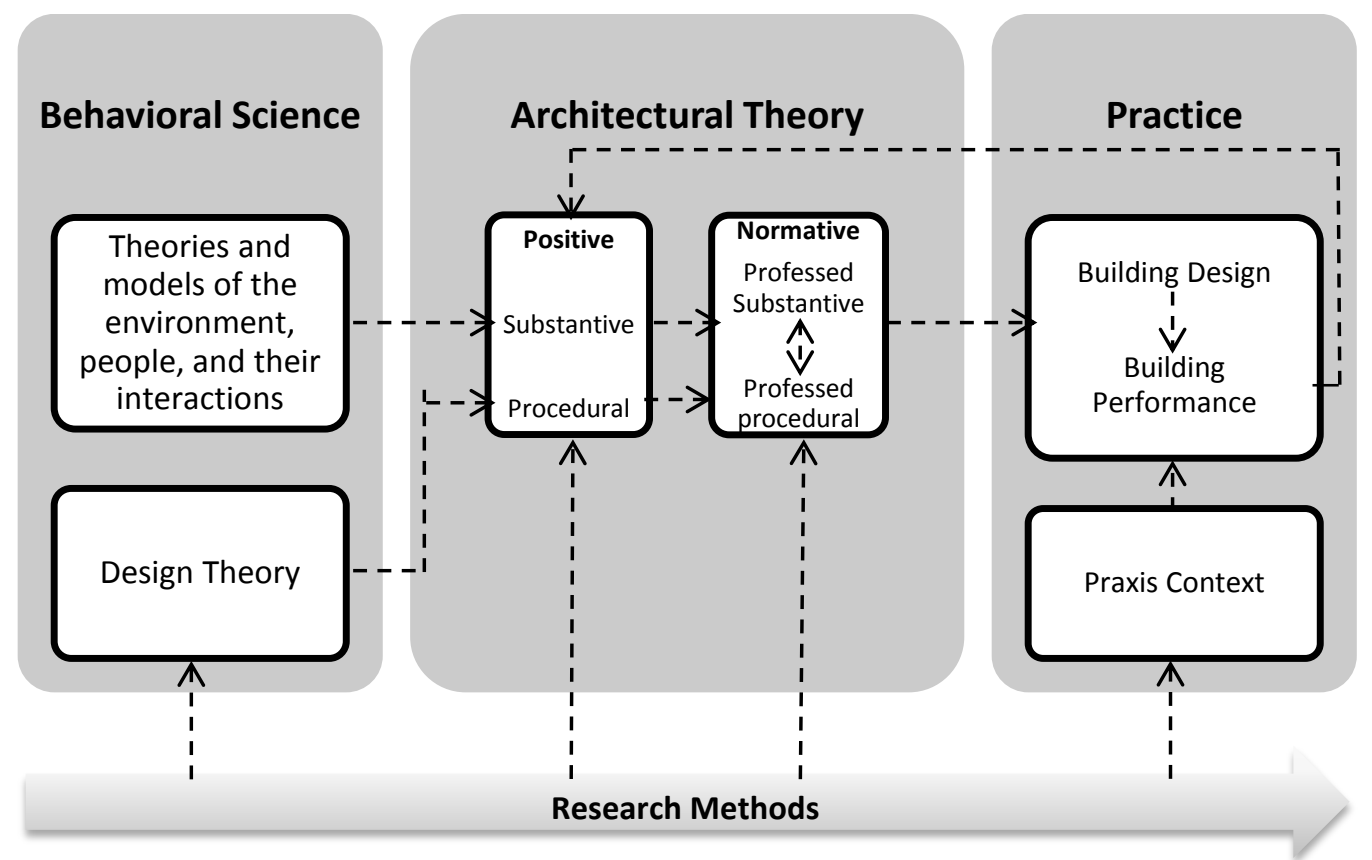

Figure 3.1: Diagram of Behavioral Science and Environmental Design Theory Adopted from Lang (1987, p.24)

\footnotetext{
${ }^{8}$ Substantive Theory and Procedural Theory will be discussed in detail in the next section.
} 
According to Lang (1987), theories in science (positive theories) are sets of general, abstract ideas through which we understand and explain the phenomena the world offers to our experience. They deal with how the world is, not how it might be. Normative theories, on the other hand, consist of statements about what ought to be (Lang, 1987). Although it has been said that it is important to develop the positive theory in the design field, given the nature of the design process that utilizes creativity and intuition, Lang (1987) elaborated how designers use normative theories in the design process:

Designers' normative position is based on what they know and believe about the world and how the design process should be conducted. Normative positions are shaped by designers' world views, which are shaped, in turn, by the cultures - the broad societal and narrower professional cultures - to which they belong. Models of world views and the processes by which they are developed are important in understanding the normative stances an architect takes with regard to perceptions of a good world and perceptions of how environmental design praxis should be carried out. (p. 24)

The relationship between positive theory and normative theory can be seen more clearly by the explanations from Johnson (1994). He explained:

The logic normative theory is not that of science because science does not deal with creation. Rather, normative theories are built on positive ones even though the professed normative position of a designer often differs from its behavioral correlate - practice. (p.19)

Therefore, how architects and designers use normative theory and positive theory depends on designers' personal experience and background as well as how the designers understand theories. Although using the same theory, completely different design solutions may result from different architects and designers.

In his article, Pati (2011a) addressed another challenge in EBD, which was the lack of a commonly agreed-on mechanism to evaluate evidence for use in design decision 
making. Among the key areas of the challenge is the gap between the procedures of scientific evidence and its intended users (Pati, 2011a). Like Lang (1987) stated, there have been considerable concerns about the gap between the information generated by environmental design research and the ability of designers to use it. If a positive theory for the design profession is not helpful in making design decisions leading to predictable outcomes, then it is irrelevant (Lang, 1987).

That is why this research focuses on understanding how designers interact with research evidence; how the architects interpret and implement research evidence and whether the design process that integrates evidence-based design has been modified. The assumption is that the theory (research evidence) based on scientific research and empirical data should provide descriptions and explanations of the causal relationship between the physical environment and medical outcomes and it can be used by architects and designers to help their decision-making. Like Fisher (1989) stated, the theory is something that practitioners consult if they wish to perform correctly and not from their preconceptions, biases, or personal preferences (Fish, 1989). Clearly, understanding how designers interact with research evidence and bridging the gap between theory and practice is extremely important.

\section{Procedural Theory, Design Process, and Substantive Theory}

Lang (1987) positioned and described the status of procedural theory development. He noted that the procedural theory in environmental design is weak. The statement of concern about the lack of an explicit and rigorous body of positive procedural theory in architecture can be tracked back at least a hundred years ago. One of 
the difficulties in building a procedural theory is simply that environmental design praxis is not easy to study systematically (Lang, 1987). The behavioral sciences can make contributions to the development of procedural theory at two levels. One consists of research findings on the nature of the process as a whole, its overall structure; the other one provides an understanding of the sub-processes of analysis, synthesis, evaluation, and decision (Lang, 1987, p. 34).

The design process can be described in a number of ways and at a number of levels of generalization (Maver, 1975). However, it does consist of a number of basic intellectual activities that are combined in a variety of ways into a number of phases, each of which has distinct character and output. These basic intellectual activities are analysis, synthesis, prediction, evaluation, and decision. In all praxis, some of these are carried out very self-consciously, some intuitively, and some by default (Lang, 1987, p. 45).

The major phases of the environmental design process are presented in the following diagram (Figure 3.2). This General Model of Design Praxis is adopted from Lang (187, p.45). It consists of Intelligence, Design, Choice, Implementation, and Postimplementation Evaluation even though people involved in professional practice may refer them as Programming, Design, Evaluation and Decision, Construction, and Post Occupancy Evaluation (Pena \& Parshall, 2012; Zeisel, 1981). There is a general linearity to the process of architectural design, but it should be recognized that each step is not carried out exhaustively and completely before the next step is begun (Lang, 1987). Also, the process does involve a considerable amount of backtracking when more information is needed or when the designer cannot solve a set of design requirements simultaneously (Zeisel, 1981). 


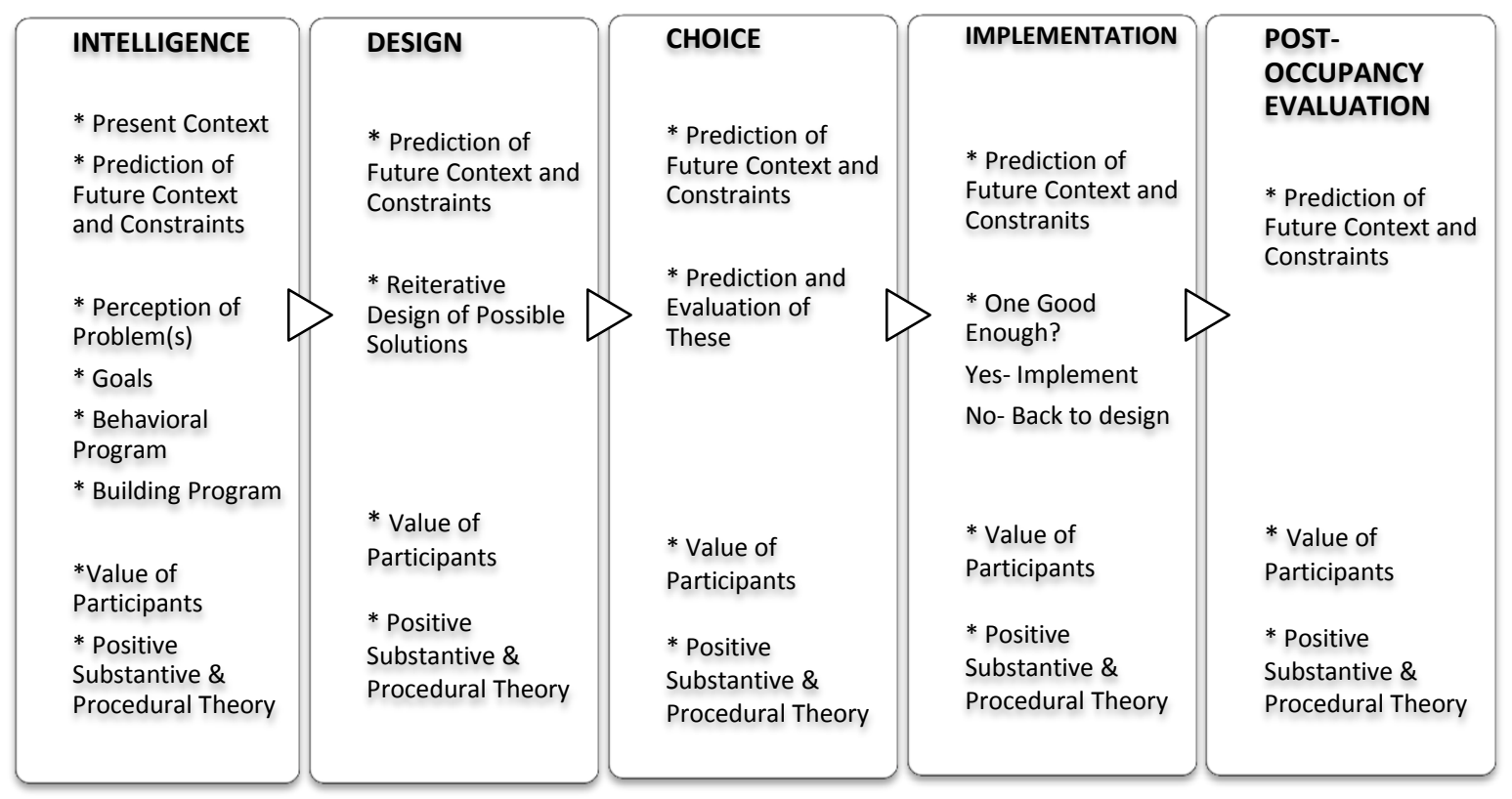

Figure 3.2: A General Model of Design Praxis Adopted from Lang (1987, p.45)

These axioms have not been subject to rigorous testing, although there have been many reviews of them (Lang, 1987). Whether it is desirable process or not is a debatable question (Rowe, 1991). However, this model provides the basis for the development of theory, but theory involves more than model-building; it involves the development of a coordinated set of descriptions and explanations. Since procedural theory, particularly positive procedural theory is very limited, as architectural research progresses, the field of design methodology needs to be enhanced. Models of the process represent an initial step in the development of procedural theory in architectural design (Lang, 1987, p. 46).

Lang (1987) indicated the issues that need to be addressed in developing procedural theory: the nature of the design process as a whole; the nature of human creativity; and the natures of analytical, synthesizing, and evaluative processes. Much of 
our present understanding of these processes is drawn from research in other decisionmaking fields and the behavioral sciences in general (Lang, 1987, p. 19).

On the other hand, substantive theory in architecture is concerned with descriptions and explanations of the physical nature of the built environment, its materials, and structure (Lang, 1987). Substantive theory can be divided into two principles and interrelated components: natural environmental theory and personenvironmental theory. In architectural research, the main concern is with the personenvironment and person-to-person relationship within the environment. It is a strong statement regarding the relationship between procedural theory and substantive theory as Lang (1987) positioned:

It will be clear from the presentation of procedural theory that thoughtfully and sensitively the design process is carried out, a whole series of activities cannot be done well without good substantive theory... Good substantive theory - powerful and externally valid theory - is central to the development of the objectives required for solving a design problem and for designing the principles with which to meet those objectives. (p. 35)

Thus, when developing the procedural theory, substantive theory has to be incorporated into the theory building. They cannot be separated.

In environment-behavior research, developing procedural theory does not mean that the design process can be scientific by definition; the design cannot be scientific. It means, rather, that the process can be described and explained using the methods of scientific or quasi-scientific research (Lang, 1987, p. 19).

Although procedural theory that studies design process and design methodology is limited (Lang, 1987), replacing the intuitive design process that is dominated by imagination by using reason-based procedure is not a new initiative (Tofle et al., 2004). Since the 1960s, scholars (Alexander, 1964; Alexander et al., 1977; Archer, 1970; 
Bazjanac, 1974; Zeisel, 1981) have attempted to develop models for understanding the design process. Their assumption has been that the principles of scientific methods can be applied to the design process. On the whole, these representations are based on models of decision-making in other fields (Simon, 1969). The premise has been that to better predict design outcomes, designers should draw on ever expanding theoretical knowledge instead of using solely aesthetic expressions as Jon Lang (1987) noted: "Good predictions depend on good theory about the phenomenon that is under concern" (p. 45). The expectations for a "good theory" have been grounded in the idea that science is the only approach to explain and understand the world and the way it works (Tofle et al., 2004).

In evidence-based design, the design process, decision making, and design methodology certainly need to be explored and examined. Given the fact that limited research has been done in this area of design process and design methodology, developing procedural theory and sustentative theory for evidence-based design is significant.

\section{Summary of Important Theories for This Research}

Based on the analytical and critical review of the theories that are relevant to this research, I would like to conclude that positive explanatory is very important to this research. The reason is that evidence-based design is using credible research evidence to inform design decisions. Thus, positive explanatory theory is critical for evidence-based design because it contains scientific explanations and descriptions. Tofle et al. (2004) explained that when we speak of scientific explanation, we generally ask why certain phenomena occur. In many cases, if not always, in order to explain a fact, we need to identify its cause. In other words, our intellectual understanding of the world, which 
derives from the scientific explanation, is always causal (Tofle et al., 2004). For instance, we need to know the causes of infection in hospital environments in order to reduce the infection rate. Or, we want to know the cause for using particular nurse station layout in order to improve the performance of nurses. Therefore, the positive explanatory theory is very important to this research. Normative theory, on the other hand, is less important for this study because of the nature of the particular research questions. However, given the nature of design activity to be creative and intuitive, normative theory will be in the discussion.

The procedural theory is also very important to this study. As defined by Lang (1987), procedural theory is concerned with the design process and design methodology. Since this research focuses on the design process and decision making regarding evidence-based design, procedural theory is extremely important in this study. Lang (1987) also stated that a thoughtful and sensitive design process cannot be done well without good substantive theory. Therefore, both procedural theory and substantive theory are equally important in this research.

\section{Lean-led Design and Lean Six Sigma}

When discussing the design process for hospital architecture, Lean-led design and Lean-Six Sigma have to be part of the discussion. Lean Tool is one of the major themes that emerged from interviews in this research. Several participants talked about Lean Tool and the Lean process during their interviews. Many scholars have advocated Lean Six Sigma for evidence-based design and Lean-led design for hospital architectural design (Grunden \& Hagood, 2012; Novicoff, 2013; Stichler, 2013). Therefore, it is 
important to survey the literature in Lean-led design and Lean Six Sigma to compare traditional design process with Lean-led design process in healthcare design. The following section provides background information for Lean Tool and Lean-led design so that the information regarding Lean-led design can be gleaned for data interpretation later in this research.

What is Lean? Lean is a methodology that focuses on eliminating waste-doing more with less - and has its origins in the Toyota Production System that was introduced in Japan (Novicoff, 2013). Then what is Six Sigma? In very broad terms, Six Sigma is a statistically based approach to process improvement. Lean Six Sigma combines the toolboxes of the separate methodologies of Lean and Six Sigma to provide a hybrid approach to process improvement. This combined approach is common because many of the tools in each methodology are similar or overlap (Novicoff, 2013).

Novicoff (2013) defined the basic goals of Lean Six Sigma as the following:

- Identify and eliminate non-value-added activity; that is, any activity that doesn't contribute directly to producing what customers need and want.

- Identify and reduce variation

- Understand and optimize the parts of the process so that it always yields consistent results that customers expect.

There are two primary approaches in traditional Six Sigma: DMAIC and DMADV (Novicoff, 2013). DMAIC stands for Define, Measure, Analyze, Improve, and Control, and is used to improve existing processes. The other approach is DMADV, which represents the five phases of Design for Six Sigma (DFSS)—Define, Measure, Analyze, Design, and Verify—and is used to design new processes to meet customer 
requirements. Table 3.1 presents DMAIC, which is used to improve existing process and DMADV, which is used to design new processes to meet customer requirements in detail according to Novicoff (2013).

Table 3.1: Two Primary Approaches in Lean Six Sigma (Source: Novicoff, 2013)

Two Primary Approaches in Lean Six Sigma

\begin{tabular}{|c|c|c|c|}
\hline & \multirow{2}{*}{$\begin{array}{l}\text { DMAIC (used to improve existing process) } \\
\text { In this step, the concentration is on getting the } \\
\text { "Voice of the Customer" (identifying customer } \\
\text { needs and requirements) and defining what the } \\
\text { goals of the project will be. }\end{array}$} & \multicolumn{2}{|c|}{$\begin{array}{c}\text { DMADV (used to design new } \\
\text { processes to meet customer } \\
\text { requirements) }\end{array}$} \\
\hline Define & & Define & $\begin{array}{l}\text { Define the project } \\
\text { opportunity and goals; } \\
\text { get customer } \\
\text { requirements to define } \\
\text { specifications. }\end{array}$ \\
\hline Measure & $\begin{array}{l}\text { Defining and measuring the "as-is" state is vitally } \\
\text { important. A group needs to determine which } \\
\text { metrics are most important to measure so that } \\
\text { resources can be best spent collecting meaningful } \\
\text { data that will be useful to the team. }\end{array}$ & Measure & $\begin{array}{l}\text { Assess needs and } \\
\text { specifications. }\end{array}$ \\
\hline Analyze & $\begin{array}{l}\text { This phase allows the team to use the data } \\
\text { collected in the Measure phase to examine trends } \\
\text { or patterns in the current process performance. } \\
\text { Only by taking time to understand-systematically } \\
\text { and conclusively - what drives process behavior, } \\
\text { can the correct root causes for performance be } \\
\text { discovered. }\end{array}$ & Analyze & $\begin{array}{l}\text { Statistically examine } \\
\text { options to meet } \\
\text { specifications. }\end{array}$ \\
\hline Improve & $\begin{array}{l}\text { This is the stage where the team selects solutions to } \\
\text { the root causes identified in the Analyze step. By } \\
\text { taking this step in order, the team has a much } \\
\text { better chance of fixing the problem with the correct } \\
\text { solution that will lead to improved performance. } \\
\text { This is also the time when new solutions can be } \\
\text { piloted before large-scale improvement is } \\
\text { attempted. }\end{array}$ & Design & $\begin{array}{l}\text { Develop the } \\
\text { process/product to } \\
\text { meet specifications. }\end{array}$ \\
\hline Control & $\begin{array}{l}\text { The Control phase helps to finalize project solutions } \\
\text { and cement their continued use. The Control Plan } \\
\text { sets up who will continue to monitor the improved } \\
\text { process, how often it will be monitored, and what } \\
\text { the triggers should be if performance starts to slide. }\end{array}$ & Verify & $\begin{array}{l}\text { Check the design to } \\
\text { ensure specifications } \\
\text { are being met. }\end{array}$ \\
\hline
\end{tabular}

Novicoff (2013) states there are five basic principles in Lean: value, value stream, flow, pull, and perfection. All processes should be evaluated against these principles, and 
any part of a process that does not meet the requirements for being value-added should be improved. Evidence-based design has been rapidly implemented in the design of healthcare architecture over the last decade. Using research evidence from multiple disciplines, such as environmental psychology, environmental-behavior studies, and social sciences, combined with clinical expertise helps to design a healing environment that can truly harmonize the needs of employees, patients, and patient families. Systematic integration of research done on healthcare environments can result in better outcomes in terms of patient and employee safety as well as clinical outcomes.

What is Lean-led design? It is a systematic approach to healthcare architectural design that focuses on defining, developing, and integrating safe, efficient, waste-free operational processes in order to create the most supportive, patient-focuses physical environment possible (Grunden \& Hagood, 2012, p. 18). Reiling (2007) stated that Lean can be more than a way to remove waste from processes inside hospital walls. When a construction opportunity arises, the leadership operating system and rules and tools of Lean can apply directly to the design of a new facility. Applying Lean thinking and Lean Tool in a structured way in hospital design can result in an environment that promotes continuous improvement, efficiency, safety and better flow of information, supplies, and service to patients (Reiling, 2007). Lean-led design can help reinforce a Lean culture within the new building.

Grunden and Hagood (2012) summarized the differences between traditional architectural design versus Lean-led architectural design (Table 3.2). Traditionally, an architect leads the design process, starting out right away to draw up some general options based on the perspectives, preferences, and experiences of a group of hospital 
leaders. With Lean-led architectural design, the emphasis is on processes that add value for the patient. The hospital, not the architect, is in the lead. That is a significant role change in the design process. Through a series of disciplined exercises, multifunctional teams look at how work is done today and how it could be done better in the future, and then they design for that future goal (Grunden \& Hagood, 2012). The connections and pathways are examined thoroughly throughout the facility. Far more planning and process development goes into the first stages of Lean-led design and drawing comes later. With Lean-led design, changes include:

1. The amount of time spent in each phase. This means more time spent in the early phases for programming and planning and less time spent later on.

2. A completely different perspective that attempts to design more value for the patient into each process.

3. The opportunity is available to ask questions about how the hospital can deliver value to the patient.

Table 3.2: Traditional versus Lean-Led Architectural Design Philosophies (Source: Grunden and Hagood, 2012)

Traditional versus Lean-Led Architectural Design Philosophies

\begin{tabular}{ll}
\hline Traditional Architectural Design & Lean-led Design \\
\hline Focus on design & Focus on adding value for customer/patient \\
\hline Starts with a functional and space program & Starts with observation at the point of work \\
\hline $\begin{array}{l}\text { User groups (staff leaders within a department or } \\
\text { service) }\end{array}$ & $\begin{array}{l}\text { Value-stream-focused teams (key stakeholders } \\
\text { involved across the whole process of delivering } \\
\text { the service to the patient) used to analyze }\end{array}$ \\
\hline
\end{tabular}


processes

Each user group provides feedback to designers without benefit of understanding "the bigger picture"; rule $2^{9}$ connections not used
Multidisciplinary consensus-based, future-state processes drive the development of the floor plan
Floor plan diagrams are adjusted to accommodate the way the hospital currently works; anticipated process improvements remain unclear, undefined
Floor plan diagrams are used to validate the value stream, optimize future improvements; rules 2 and $3^{10}$ (connections and pathways) are addressed

\section{Environment-Behavior Studies in Healthcare Environment and EB Attributes}

Environment and behavior (EB) study has an interdisciplinary orientation (Altman, 1975; Rapoport, 2005). Like Altman (1975) wrote, the field of environment and behavior is intrinsically interdisciplinary and the work of environment-behavior studies comes from a variety of social and natural science disciplines, such as psychology, sociology, geography, biology, and anthropology, and from applied or practitioner disciplines, such as architecture, urban planning, interior design, and landscape architecture (Altman, 1975, p. 1). Rapoport (2005) identified nine EB mechanisms that link people and environments: physiology, anatomy, perception, cognition, meaning, affect, evaluations, action and behavior, and supportiveness. Within these mechanisms, issues of environmental stress, territoriality, privacy, personal space, wayfinding, restoration, control, design preference, efficiency and many other issues are included and researched in EB studies. Due to the blooming of the healthcare industry, a vast amount of EB research that relates to healthcare environment has been conducted. In the

\footnotetext{
${ }^{9}$ According to Grunden and Hagood (2012), Rule 2 means the connections between customer and supplier in Lean-led architectural design (Grunden \& Hagood, 2012, p. 11).

${ }^{10}$ According to Grunden and Hagood (2012), Rule 3 means pathways connect activities in the path of care in Lean-led architectural design (Grunden \& Hagood, 2012, p. 12).
} 
following sections, the most important environment-behavior attributes are discussed based on evidence of literature surveyed. They depict specific environment behavior (EB) attributes found in the literature related to healthcare environment.

In order to provide a clearer presentation of the context of EB attributes, a table is compiled based on evidence of literature surveyed (Table 3.3). ${ }^{11}$ Although all the literature listed in the table is important to EB studies concerning healthcare environment, and all has the specific relation to type of specialization, a "*” indicates type of care and type of occupancy emphasized in the literature and is discussed in detail, while the literature with "+" have been mentioned in the discussions of literature with a "*”. The discussions of the most important EB attributes are presented in a narrative format in the following sections. I have divided the discussion into three sections: "typical of specialization," "type of care," and "type of occupancy." In each of the sections, not all of the EB attributes are discussed even though most of these EB attributes can be applied to all three sections. Only those EB attributes having significant links with specific building typologies are discussed in each of sections. This is a result of some unique situations that arose in my search of literature which revealed overlaps among different types of care and different types of specialization. A lot of EB research evidence appears to have a generic application in the design of different types of healthcare facilities.

The purpose of creating this table is to provide systematically organized research evidence based on EB attributes. When I conducted searches for research evidence based

\footnotetext{
${ }^{11}$ The table is organized by the most important EB attributes with the supporting empirical EB studies literature and the indications of types of specialization (pediatrics, cancer hospital, etc.), type of care (intensive, general, etc.), and type of occupancy (single units, double units, etc.). The indications for each type of specialization, type of care, and type of occupancy are judged based on the research setting, research subjects as well as the goal and the result of the research.
} 
on these EB attributes, I searched many sources that mainly included Google Scholars, knowledge repository at Center for Health Design website, ERIC, PubMed, ProQuest, Academic Search Complete, Art Full Text, Avery Index, Art Stor, and Scopus. Whether the research evidence in environment-behavior studies has been implemented in the design of Grand River Hospital has been examined through this case study. Therefore, compiling research evidence based on these EB attributes helped me to investigate whether research evidence was implemented in the design through observations, document reviews, and interviews.

Table 3.3 Environment-Behavior Attributes with Supporting Empirical EB Studies Literature

\section{EB Attributes / Supporting Empirical EB Studies Literature}

\begin{tabular}{ccc}
$\begin{array}{c}\text { Type of } \\
\text { Specialization } \\
\text { (pediatrics, } \\
\text { cancer } \\
\text { hospital, etc.) }\end{array}$ & $\begin{array}{c}\text { Type of Care } \\
\text { (intensive, } \\
\text { general, } \\
\text { etc.) }\end{array}$ & $\begin{array}{c}\text { Type of } \\
\text { Occupancy } \\
\text { (single units, } \\
\text { doubles units, } \\
\text { etc.) }\end{array}$ \\
\hline $\begin{array}{c}\text { Long-term } \\
\text { care }\end{array}$ & General & $\begin{array}{c}\text { Single/double } \\
\text { units }\end{array}$ \\
\end{tabular}

\begin{tabular}{|c|c|c|c|}
\hline Privacy * & & & \\
\hline $\begin{array}{l}\text { Bäck, Eva, \& Wikblad, Karin. (1998). This study } \\
\text { investigates patients and nurses' opinions regarding }\end{array}$ & $\begin{array}{l}\text { Long-term } \\
\text { care }\end{array}$ & General & $\begin{array}{l}\text { Single/double } \\
\text { units }\end{array}$ \\
\hline
\end{tabular}
privacy. Two groups have different opinions. Patients in long-term care had higher privacy preferences than those in acute care.

Alalouch, C., \& Aspinall, P. (2007). This research investigates spatial attributes of hospital multi-bed General General Multi-bed
units wards and preferences for privacy.

\begin{tabular}{|c|c|c|c|}
\hline $\begin{array}{l}\text { Alalouch, C., Aspinall, P., \& Smith, H. (2009). This } \\
\text { study examines presences for privacy in hospital } \\
\text { wards. }\end{array}$ & General & General & $\begin{array}{l}\text { Multi-bed } \\
\text { units }\end{array}$ \\
\hline $\begin{array}{l}\text { Barlas, D., Sama, A. E., Ward, M. F, \& Lesser, M. L. } \\
\text { (2001). This research compares the auditory and } \\
\text { visual privacy of emergency department treatment } \\
\text { areas with curtains versus those with solid walls. }\end{array}$ & General & $\begin{array}{l}\text { Emergency } \\
\text { Department }\end{array}$ & $\begin{array}{l}\text { Multi-bed } \\
\text { units }\end{array}$ \\
\hline $\begin{array}{l}\text { Chapman, N. J, \& Carder, P. C. (2003). This study } \\
\text { investigates privacy needs when visiting a person } \\
\text { with Alzheimer's disease from family and staff } \\
\text { expectations. }\end{array}$ & $\begin{array}{l}\text { Long-term } \\
\text { care }\end{array}$ & General & Single units \\
\hline
\end{tabular}




\begin{tabular}{|c|c|c|c|}
\hline $\begin{array}{l}\text { Hutton, Alison. (2002). This study addresses the } \\
\text { private space issues of the adolescent patient in the } \\
\text { ward environment. Issues that are discussed include } \\
\text { the use of the telephone, the bathroom, and the } \\
\text { bedroom, and additional facilities needed to enhance } \\
\text { privacy in the ward. }\end{array}$ & General & General & Single units \\
\hline $\begin{array}{l}\text { Parrott, R., Burgoon, J. K., Burgoon, M., \& LePoire, B. } \\
\text { A. (1989). This research examines privacy between } \\
\text { physicians and patients. It is more than a matter of } \\
\text { confidentiality. }\end{array}$ & General & General & $\begin{array}{c}\text { Single/double } \\
\text { units }\end{array}$ \\
\hline $\begin{array}{l}\text { Harris, P. B, Werner, C. M, Brown, B. B, \& Ingebritsen, } \\
\text { D. (1995). This study is a cross-cultural analysis of } \\
\text { relocation and privacy regulation. }\end{array}$ & General & General & $\begin{array}{c}\text { Single/double } \\
\text { units }\end{array}$ \\
\hline \multicolumn{4}{|l|}{ Territoriality + } \\
\hline $\begin{array}{l}\text { Curtis, S., Gesler, W., Fabian, K., Francis, S., \& Priebe, } \\
\text { S. (2007). In this study, a number of aspects regarding } \\
\text { beneficial or detrimental to well-being were explored. } \\
\text { One of the aspects is territoriality, privacy, refuge, } \\
\text { and social interactions. }\end{array}$ & General & General & Single units \\
\hline $\begin{array}{l}\text { Blumberg, R., \& Devlin, A. S. (2006). This qualitative } \\
\text { study examined the physical design of patient room } \\
\text { and visiting policies of hospitals. A sense of } \\
\text { territoriality is an important component of patient } \\
\text { rooms. }\end{array}$ & General & General & Single units \\
\hline
\end{tabular}

\begin{tabular}{|c|c|c|c|}
\hline Personal Space + & & & \\
\hline $\begin{array}{l}\text { Mroczek, J., Mikitarian, G., Vieira, E. K., \& Rotarius, T. } \\
\text { (2005). In this study, authors explored physical } \\
\text { attributes that have positive effect on patients, such } \\
\text { as easy access to social support, and an environment } \\
\text { (personal space) that fosters a sense of personal } \\
\text { control. }\end{array}$ & General & General & Single units \\
\hline $\begin{array}{l}\text { Barron, A. (1990). This study explores the right to } \\
\text { personal space. }\end{array}$ & General & General & Single units \\
\hline $\begin{array}{l}\text { Popper, B., Anderson, B., Black, A., Ericson, E., \& Peck, } \\
\text { D. (1987). This study investigated physical preference } \\
\text { for children. Findings suggest to provide space for } \\
\text { children's nonmedical activities because providing } \\
\text { personal space the child can identify as his/hers and } \\
\text { allowing walls and ceilings to be personal play } \\
\text { surfaces. }\end{array}$ & Pediatrics & General & Single units \\
\hline \multicolumn{4}{|l|}{ Environmental Stress * } \\
\hline $\begin{array}{l}\text { Ulrich, R. S., Simons, R. F., Losito, B. D., Fiorito, E., } \\
\text { Miles, M. A., \& Zelson, M. (1991). This study }\end{array}$ & General & General & Single units \\
\hline
\end{tabular}


investigates environmental stress in healthcare

setting by using an experiment.

Hilton, B. (1985). This study explores the noise level in General Acute care Single units acute patient care areas.

Griffin, J. P. (1992). This study explores the impact of noise on critically ill people.

General

Intensive

Single units

Topf, M., \& Thompson, S. (2001). This study assesses

General

care

the relationships between multiple patient stress

variable interactions to sleep or other stress-related

outcomes.

\section{Design Preference +}

Whitehouse, S., Varni, J. W., Seid, M., Cooper-Marcus,

Children's

N/A

$\mathrm{N} / \mathrm{A}$

C., Ensberg, M. J., Jacobs, J. R., \& Mehlenbeck, R. S.

Hospital

(2001). The garden was perceived as a place of restoration and healing, and use was accompanied by increased consumer satisfaction. This study makes recommendations for the future use of garden in children's hospital.

Zimring, C., Joseph, A., \& Choudhary, R. (2004). This study examines the role of the physical environment General General Single/double in the hospital of the 21st century.

units

Ulrich, R. S, Zimring, C., Zhu, X., DuBose, J., Seo, H., Choi, Y., ... Joseph, A. (2008). A review of the General General Single/double research literature on evidence-based healthcare design.

Ulrich, R. S. (2001). This paper presents the effects of healthcare environmental design on medical General General Single/double outcomes.

Coad, J., \& Coad, N. (2008). This study examines the views of children and young people regarding their Children's Hospital

units preference of thematic design and color in a new children's unit.

Pati, D., \& Nanda, U. (2011) This study examines the influence of positive distraction on the behavior and Children's

General $\mathrm{N} / \mathrm{A}$ activity of children in two clinic waiting areas.

units

\section{Control*}

Williams, A. M., Dawson, S., \& Kristjanson, L. J. (2008). This study explores the relationship between General General Single units personal control and the hospital environment. 
Lankford, M. G., Zembower, T. R., Trick, W. E, Hacek, D. M., Noskin, G. A., \& Peterson, L. R. (2003). This study investigates the influence of role models and hospital design on the hand hygiene of health-care workers for infection control.
General

Intensive care

Kramer, M., \& Schmalenberg, C. E. (2003). In this study, staff nurses describe control over nursing General General Single/double units practice (C/NP) as a professional nursing function made up of a variety of activities and outcomes.

\section{Restoration *}

Ulrich, R. (1984). This study examines the window view that may influence recovery.

General

General

Single units

Ulrich, R. S. (1991). The findings of this study suggest

General

General

Single units having sense of control; access to social support; positive distractions and natural elements.

\section{Efficiency +}

Chaudhury, H., Mahmood, A., \& Valente, M. (2009).

In this study, four design-related principles are

General General $\quad \begin{gathered}\text { Single/double } \\ \text { units }\end{gathered}$

recommended: balance between patient accessibility

and reduction of disruptions, automation, minimize

staff fatigue, and promoting a culture of safety.

\begin{tabular}{|c|c|c|c|}
\hline $\begin{array}{l}\text { Bayo, M. V., García, A. M., \& García, A. (1995). The } \\
\text { study examines noise levels in an urban hospital and }\end{array}$ & General & General & $\begin{array}{l}\text { Single/double } \\
\text { units }\end{array}$ \\
\hline
\end{tabular}

Tucker, A. L., Singer, S. J., Hayes, J. E., \& Falwell, A.

(2008). This study suggests an underutilized strategy

General

General

Single/double

for improving patient safety and staff efficiency

\begin{tabular}{|c|c|c|c|}
\hline Wayfinding * & & & \\
\hline $\begin{array}{l}\text { Rollins, J. A. (2004). The study investigates using } \\
\text { evidence-based design to improve health care } \\
\text { outcomes for patients, families, and staff. }\end{array}$ & Pediatric & General & $\mathrm{N} / \mathrm{A}$ \\
\hline $\begin{array}{l}\text { Rousek, J. B., \& Hallbeck, M. S. (2011). This study } \\
\text { examines the use of simulated visual impairment to } \\
\text { identify hospital design elements that contribute to } \\
\text { wayfinding difficulties. }\end{array}$ & General & General & $\mathrm{N} / \mathrm{A}$ \\
\hline $\begin{array}{l}\text { Carpman, J. R., Grant, M. A., \& Simmons, D. A. (1983). } \\
\text { This study explores wayfinding in the hospital } \\
\text { environment and the impact of various floor } \\
\text { numbering alternatives. }\end{array}$ & General & General & N/A \\
\hline $\begin{array}{l}\text { Huelat, B. J. (2007). Wayfinding: Design for } \\
\text { understanding. A Position Paper for the }\end{array}$ & General & General & N/A \\
\hline
\end{tabular}


Environmental Standards Council of The Center for

Health Design.

Marquardt, G. (2011). This study investigates wayfinding for people with dementia. It reviews the role of architectural design.

Assisted Living

Long-term care

O'Neill, M. J. (1991). This study examines effects of signage and floor plan configuration on wayfinding accuracy.
Ortega-Andeane, P., \& Urbina-Soria, J. (1988). A case study of wayfinding and security in a Mexico City hospital.
General

General

N/A

Rooke, C. N., Tzortzopoulos, P., Koskela, L. J., \& Rooke, J. A. (2009). This study is about wayfinding: embedding knowledge in hospital environments.

\section{Environmental Stress}

Environmental stress is an environment-behavior attribute. It is defined as a process that occurs when there is an imbalance between environmental demands and response capabilities (S. Cohen, 1986; Evans, 1984). The growing interest in environmental stress has been accompanied by a rapid accumulation of evidence indicating that environmental stressors (e.g. crowding, community noise, air pollution) can elicit substantial stress in large groups of people (S. Cohen, 1986; Evans, 1984). Stress is the process by which an individual responds psychologically, sociologically, and often with behaviors to a situation challenge or threat to well-being (Baum, Fleming, \& Singer, 1985). According to Ulrich et al. (1991), the second concept central to the theory and research regarding environmental stress is "stress recovery" or "restoration." These two terms are used interchangeably. 
The vast majority of research that relates to healthcare environment has focused on the situation challenges or threat to well-being that accordingly elicit stress (Griffin, 1992; Hilton, 1985; Topf, 2000; R. Ulrich, 1984; R. S. Ulrich, 1991; R. S. Ulrich et al., 1991). When discussing environmental stress, an influential Theory of Supportive Design has to be an important topic in the discussion. Theory of Supportive Design was brought up in the 1990s through Roger Ulrich's discussion and publication on the effects of healthcare design on wellness. He interpreted the implications of multiple studies to suggest a theory that designers could use in the development of supportive design for healthcare settings to reduce stress and promote well-being (D. K. Hamilton \& Watkins, 2008). Ulrich (1991) noted:

By focusing on the concept of stress, a theory of supportive design can be developed that conceptualizes human impacts of design in ways that are related directly to scientifically credible indicators or interpretations of wellness. (p. 99)

The Theory of Supportive Design (R. S. Ulrich, 1991) is based on research findings showing that clinical conditions can be seriously affected by stress. According to Hamilton and Watkins (2008):

Ulrich suggests that the patient experiences stress of the illness, which can be partially relieved by therapy; the stress of the environment, which can only be relieved in part by good design. He cites control and choice, noise reduction, positive distraction, social support and access to nature as categories of design interventions that can reduce stress and thus make a positive contribution to the healing process. (p. 80)

In the context of Theory of Supportive Design, healthcare design should do more than produce health facilities that are satisfactory in terms of functional efficiency, project cost, and building codes. Another more important and more critical role for designers is to promote wellness by creating a physical environment that is “psychologically and socially supportive” (Ruga, 1989; R. S. Ulrich, 2000). It is expected 
that the effects of supportive design not only are complementary to the healing effects of drugs and other medical technology and foster the recovery process, but also have patient-centered or supportive characteristics that help patients cope with the stress that accompanies illness (R. S. Ulrich, 1991, 2000, 2001).

The design of healthcare facilities traditionally has emphasized the functional delivery of healthcare without consideration of any psychological or social aspects that would be supportive for patients' recovery. A consequence of this approach has been that psychological and social needs of patients have been largely disregarded in the design of healthcare facilities - and often marginalized in creating visitor and staff spaces (R. S. Ulrich, 2000). In contrast, there is increasing scientific evidence in the past decades that poor design works against the well-being and well-designed physical environment that promotes patients' medical outcomes (R. Ulrich, 1984; R. S. Ulrich, 1999b; R. S. Ulrich et al., 2008).

Furthermore, there is a growing awareness internationally among healthcare administrators and medical professionals of the need to create functional environments that also have patient-centered or supportive characteristics that help patients cope with the stress that accompanies illness (R. S. Ulrich, 1991). Research and theory in the behavioral sciences and health-related fields suggest that healthcare environments will likely support dealing with stress and thereby promote wellness if they are designed to foster: 1) a sense of control and access to privacy; 2) access to social support; and 3) access to positive distractions in physical surroundings (R. S. Ulrich, 1991, 2000, 2001). One of the important aspects in the context of theory of supportive design is providing social support for patients. Many studies in the fields of behavioral medicine 
and clinical psychology have found that individuals with high social support, compared to those with low support, experience less stress and have higher levels of wellness $(\mathrm{S}$. E. Cohen \& Syme, 1985; Sarason, 2013). Social support has been found consistently to be an important factor in stress and wellness studies. Findings suggest that social support should be included in a contemporary theory of stress-reducing design (R. S. Ulrich, 1991). A few examples of design strategies that should foster social support include: providing convenient overnight accommodations for families of patients in private patient rooms; comfortable visitor waiting areas with movable seating that allow family or friends to support patients; and outdoor gardens or sitting areas that foster patient/visitor social interaction.

Another important aspect in the context of the theory of supportive design is providing positive distractions in physical environments. Ulrich (1981) defines that a "positive distraction" is "an environmental feature or element that elicits positive feelings, holds attention and interest without stressing the individual, and therefore may block or reduce worrisome thoughts" (R. S. Ulrich, 1981). The most effective positive distractions are mainly elements that provide connections to humanity. In recent studies, many forms of positive distractions are identified, such as water features, landscape, and artworks (Hathorn \& Nanda, 2008; R. Kaplan \& Kaplan, 1989; Marcus, 2007; Marcus \& Barnes, 1999; Nanda, Eisen, Zadeh, \& Owen, 2011; R. S. Ulrich \& Parsons, 1992). In addition to these important aspects in the context of theory of supportive design, nature as a positive distraction and as an effective stress-reducing factor has been addressed and confirmed by many authors (Marcus, 2007; Sternberg, 2009; R. Ulrich, 1984; R. S. Ulrich, 1981). In fact, integrating nature setting in a hospital dates back to 
ancient Greece. Historically, a theme running through these beliefs is the notion that if individuals are stressed, views of most natural settings will tend to reduce stress (R. S. Ulrich, 1991). There is a rapidly expanding body of research that has tested the old belief that visual contacts with nature have restorative or stress-reducing effects (R. S. Ulrich \& Parsons, 1992).

In 2010, Ulrich et al. proposed a conceptual framework for the domain of evidence-based design which is based on the theory of supportive design (R. S. Ulrich et al., 2010). Although lots of work needs to be done in EBD, such as theory building and evaluation, the theory of supportive design still remains an influential theory and the core context in evidence-based design today (Cama, 2009; D. K. Hamilton \& Shepley, 2010; D. K. Hamilton \& Watkins, 2008; Malkin, 2008). The studies related to environmental stress provide valuable rationale for the design of many different types of healthcare facilities, such as children's hospitals, cancer hospitals, women's healthcare centers, and many other types of specializations.

\section{Wayfinding}

Wayfinding is another EB attribute and can be defined as spatial orientation. It is knowing where you are in a building or an environment, knowing where your desired location is, and knowing how to get there from your present location. Spatial orientation has been defined as a person's ability to determine his position within a representation of the environment made possible by cognitive maps (Passini, 1992). Cognitive mapping is the process whereby people acquire, code, store, recall, and decode information about the relative location and attributes of the physical environment (Moore \& Golledge, 1976; 
Tolman, 1951). It is a fact that a great amount of empirical EB studies have been conducted regarding wayfinding in the healthcare environment (Arthur \& Passini, 1992; Carpman, Grant, \& Simmons, 1983; Haq, Hill, \& Pramanik, 2005; Haq \& Zimring, 2003; B. J. Huelat, 2008; O'Neill, 1991; Ortega-Andeane \& Urbina-Soria, 1988; Rollins, 2004; Rooke, Tzortzopoulos, Koskela, \& Rooke, 2009; J. Rousek \& Hallbeck, 2011; J. B. Rousek, Koneczny, \& Hallbeck, 2009; Tzeng \& Huang, 2009; C. Zimring, 1994). This research evidence provides design strategies for designing different types of specialized hospitals, such as children's hospitals, women's health centers, and many other types of hospitals and medical centers because all these facilities have complex configurations.

The first challenge for visitors to successfully navigate the overwhelming medical environment is being able to find their way around the facility easily. Unfortunately, most hospitals and medical centers are complex mazes with long and confusing corridors and turns as well as confusing signs. Research findings indicate that good wayfinding design promotes healing because being able to understand the environment provides visitors with a sense of control and empowerment (Arthur \& Passini, 1992). Therefore, it is important to design a good wayfinding system that can help reduce stress, anxiety, and fear because those feelings undermine a patient's ability to heal.

Previous EB research indicated that older adults tend to have trouble correctly remembering large-scale, real environments and are less likely to remember the location of landmarks (Caplan \& Lipman, 1995). Previous research also revealed that visual stimuli influence information recall and older adults have more difficulty recalling information and color memory than young people (Pérez-Carpinell, Camps, Trottini, \& Pérez-Baylach, 2006). 
Findings from EB studies have resulted in several recommendations regarding wayfinding design in the hospital environment. One recommendation is that wayfinding design should be an integrated system that includes coordinated elements, such as clear and easily understood signs and numbers, clear and consistent verbal directions (information desks), electronic information displays, and a legible physical setting (Carpman, Grant, \& Simmons, 1993). A recent study also concluded that it is possible to embed physical forms that make it easier for people to find their way intuitively with little need of signage (Rooke et al., 2009). This can be achieved by floor configurations and visual cues that could provide wayfinding behavioral guidance. Arthur and Passini's (1992) study revealed that good wayfinding promotes healing by reducing stress and frustration for visitors. They also indicated that good wayfinding design also promotes functional efficiency and improves visitors' safety and empowerment as well as improves cognitive skills in spatial understanding (Arthur \& Passini, 1992). In addition to these EB studies in wayfinding, Huelat stated in a position paper published by The Center of Health Design that wayfinding was not an afterthought, but carefully designed into the project. By doing so, it allows elements such as curved bulkheads and lighting to be builtin, allowing wayfinding to lead intuitively to the source of information (B. Huelat, 2007). More evidence from EB studies shows that finding one's way around a large, complex building like a hospital is a difficult task, especially adding in the stress that most hospital patients and visitors experience (Arthur \& Passini, 1992). Good design that provides intuitive layout will enhance wayfinding performance. Research findings from Marquardt's study (2011) suggest environmental interventions to promote orientation and wayfinding. The study suggested that wayfinding systems can be designed and 
implemented by two different approaches. One approach is to create the floor plan that can intuitively guide wayfinding performance with environmental cues (Marquardt, 2011). Another approach is to increase architectural legibility by creating distinctive places or forms that can be memorialized through size, proportion, materials and furnishings to enhance wayfinding systems (Marquardt, 2011). Therefore, based on empirical EB study evidence, creating a wayfinding system that integrates visual cues, such as color, landmarks, lighting and providing an intuitive floor configuration is important to achieve a good wayfinding performance in complex healthcare facilities.

\section{Control}

The concept of sense of control is familiar to many designers. A great deal of research has shown that a sense of control is an important factor influencing stress levels and wellness (Steptoe \& Appels, 1989) for diverse groups and situations, such as hospital patients and employees in workplaces. In healthcare contexts, lack of control is a pervasive problem that increases stress and adversely affects wellness. A large body of scientific evidence indicates that humans have strong needs for control with respect to environments and situations. Many studies have found that lack of control is associated with such negative consequences as depression, passivity, elevated blood pressure, and reduced immune system functioning (Bayo, García, \& García, 1995; Topf \& Thompson, 2001; R. S. Ulrich \& Parsons, 1992; R. S. Ulrich et al., 1991; Valente, Potts, Valente, French-St George, \& Goebel, 1992).

Patients are exposed to two general sources of stressors: illnesses and physical/social environments (R. S. Ulrich, 1991). Therefore, providing a good sense of 
control for patients in the physical environment is an important aspect in the theory of supportive design. A few examples of design approaches that should increase control and thereby reduce stress include 1) controllable television in patient rooms and visitor areas, gardens or grounds that are accessible to patients; 2) control of room temperature by patients who typically feel cold; and 3) staff work areas designed and located so as to be accessible to patients yet not produce noise that invades patient rooms (R. S. Ulrich et al., 1991). These design approaches can be used in the design of acute care, intensive care units (ICU) and other types of care.

Another important issue in an ICU is infection control. The number and accessibility of hand-washing sinks also influence compliance of infection control and infection rate. In particular, research evidence suggests that installing alcohol-based hand rub dispensers at the bedside usually improves adherence (R. S. Ulrich et al., 2008). Several studies examined the effects of bedside alcohol-based hand-rub dispensers, and all demonstrated significant improvements in hand-washing compliance (Bischoff, Reynolds, Sessler, Edmond, \& Wenzel, 2000; Creedon, 2005; Lankford et al., 2003; Pittet et al., 2000; Randle, Clarke, \& Storr, 2006).

In addition to patients, nurses and other healthcare staff experience stress and often burnout because their work is characterized by low control and high responsibility (Chaudhury, Mahmood, \& Valente, 2009; Shumaker \& Pequegnat, 1989).This problem can be aggravated by poorly designed work environments; for instance, the lack of lounge or break areas reduces the sense of control by making it difficult to escape briefly from work demands (R. S. Ulrich, 1991; Williams, Dawson, \& Kristjanson, 2008). On the other hand, control and supervision over patients is recognized as one of the 
important aspects of nursing (Kramer \& Schmalenberg, 2003). The notion of having control and supervision over patients has a long history that can be dated back to the Nightingale period. It still remains a vital approach in today's nursing practice even though Nightingale's open ward has been eliminated in modern hospital design.

The nurse station is an important area where nurses can provide control and supervision to patients easily and perform their responsibilities productively. The debate between a central nurse station and a decentralized nurse working station is ongoing. The central nurse station serves as an information hub for the unit. Typically, the central nurse station is arranged in the geographic center of the unit. It is a noisy environment because of the activities of doctors and nurses for retrieving patients' information or processing medical orders. A better way to manage patient information is by using a decentralized nurse station concept which has demonstrated significant improvement to the problems of a central station (McCullough, 2009). In a decentralized nursing environment, a caregiver's workspace (nurse alcove) is spread throughout the patient unit. These workspaces are placed immediately outside the patient rooms. This workspace contains a window that allows the nurse to observe the patient and provide supervision and control over the patients (McCullough, 2009).

A study conducted by Zborowsky et al. (2010) investigated how nursing station design, such as centralized and decentralized nursing station layouts, affected nurses' use of space, patient visibility (control and supervision), noise levels, and perceptions of the work environment. Findings indicate there is decreased interaction and socialization among nurses in decentralized nurse stations. The recommendation from the study is to have a "hybrid" nursing design model in which nurse alcoves are located between every 
two patient rooms, and centralized nursing stations are still provided (Zborowsky, Bunker-Hellmich, Morelli, \& O'Neill, 2010).

In summary, control is an important EB attribute in the healthcare environment. It covers a broad range of context that is not only for patients to have a sense of control, but also for caregivers to have control and supervision over the patients. EB studies have generated a large body of evidence for this attribute. The implications of research related to this EB attribute can be valuable for the design of different types of care units, such as ICU, acute care, and long-term care.

\section{Privacy}

Among all the EB attributes, privacy certainly is one of the most important attributes. Privacy is commonly described as the ability of an individual or group to seclude themselves or information about themselves and thereby express themselves selectively. Privacy may be best defined by Altman (1975) as "selective control of access to the self or to one's group." However, there is no universal definition of privacy (LeinoKilpia et al., 2001; Newell, 1995, 1998).

The concept of privacy has been described through its various dimensions. Burgoon and Parrott identified different dimensions in privacy: physical, psychological, social, and informational privacy (Burgoon, 1982; Parrott, Burgoon, Burgoon, \& LePoire, 1989). Physical privacy is the degree to which one is physically accessible to others. Physical privacy has to do with the concept of personal space and territoriality. Physical privacy is either closely related to these concepts, or it is described to have a personal 
space as a precondition. There are not many studies that address these concepts in the context of healthcare (Lane, 1990).

In the healthcare environment, medical staff and patients have different perceptions of privacy. Findings from Back and Wikblad's study (1998) indicates that patients and nurses agree on the major components of privacy in general, but privacy in a hospital was valued more highly by the nurses than by the patients themselves. Patients in long-term care had higher privacy preferences than those in acute care (Bäck \& Wikblad, 1998). Findings also indicate that physical privacy in a healthcare facility has a positive impact on medical outcomes (R. S. Ulrich, 1991, 2001; R. S. Ulrich et al., 2008).

Empirical research into privacy in health care and nursing is rare. Most studies deal with privacy about physical places (Leino-Kilpia et al., 2001). For example, sound control is one of the aspects of privacy control. Studies into sound levels in hospitals (Bayo et al., 1995; Griffin, 1992; Hilton, 1985) suggest that noise is a major source of stress for patients, and that should be reduced. There are some studies that focus on physical privacy in patient rooms (Bobrow \& Thomas, 2000; Burden, 1998; Clipson, 1973; Morgan, 1999; Solovy, 2002). Studies showed that patients in private rooms were more satisfied with their hospital stay, including their communication with staff members, than those patients staying in multiple-occupancy rooms. Patients who had roommates were less satisfied with the noise, cleanliness, and temperature of the room. When roommates are incompatible, hospitals are likely to incur increased transfer costs. Roommates can also be a source of stress for patients. Specifically, roommates who are unfriendly, have too many visitors, and are seriously ill can have negative effects on other patients (Chaudhury et al., 2005). 
Regarding speech privacy, research has shown that inadequate privacy may lower patient satisfaction and can worsen healthcare outcomes if patients withhold personal information or refuse to be examined because of privacy concerns (Barlas, Sama, Ward, \& Lesser, 2001).

No rigorous study was identified that directly observed the occurrence of speech privacy violations within patient rooms in general wards or ICUs. However, extensive survey data have shown that single-bed rooms, compared to multi-occupancy rooms, provide better protection for patient speech privacy (R. S. Ulrich et al., 2008). When single rooms are not available, as in many emergency departments, installing hard-wall partitions to provide speech privacy is preferable to curtains (Barlas et al., 2001; Karro, Dent, \& Farish, 2005; Mlinek \& Pierce, 1997). To prevent sound leakage and privacy breaches through the ceiling, hard-wall partitions should extend to the supporting ceiling or deck instead of stopping at the ceiling plane. Installing high-performance soundabsorbing ceiling tiles can shorten reverberation times and improve speech intelligibility (Hagerman, Rasmanis, Blomkvist, Ulrich, Eriksen, et al., 2005; Philbin \& Gray, 2002). Furthermore, providing private discussion rooms near waiting, admission, and reception areas may help prevent breaches of speech privacy (Joseph \& Ulrich, 2007).

According to Ulrich et al. (2008), the design intervention that positively affects the largest number of outcomes in a hospital setting is the provision of single-bed patient rooms. The value of single-bed rooms has been acknowledged by the AIA after extensive research and has been included in the 2006 Guidelines for Design and Construction of Health Care Facilities (AIA, 2006). Strong evidence indicates that single-bed rooms improve the following outcomes: hospital-acquired infection, patient sleep, patient 
privacy, communication with patients and families, social support, staff stress, and patient satisfaction (Alalouch \& Aspinall, 2007; Alalouch, Aspinall, \& Smith, 2009; R. S. Ulrich et al., 2008).

\section{Restoration}

According to Ulrich et al. (1991), the second concept central to the theory and research regarding environmental stress is "stress recovery" or "restoration." These two terms are used interchangeably. Restoration can be constructed as a broader concept that is not limited to a stress recovery situation. In contrast to a stress response, restoration from stress involves numerous positive changes in psychological states (R. S. Ulrich, 1991). Central to the psychological component of restoration are positive changes in emotional states, such as reduced levels of negatively toned feeling like fear or anger, and increases in positive-toned affects (R. S. Ulrich, 1979; Zuckerman, 1977).

Lots of EB studies relating to restoration and stress recovery in the healthcare environment have been conducted (R. Ulrich, 1984; R. S. Ulrich, 1991; R. S. Ulrich et al., 1991). One of the factors that relates to stress recovery is the quality of sleep. A number of factors contribute to poor sleep in healthcare settings, including environmental factors like noise, light, and staff-patient interactions; physiological factors, such as the underlying disease and impact of medication; and the psychological characteristics of patients (BaHammam, 2006; Doğan, Ertekin, \& Doğan, 2005; Reid, 2001). Based on research findings, various interventions have been employed to improve patient sleep.

Environmental interventions have been developed to reduce environmental noise and disruptive staff-patient interactions at night, or to maintain the normal light-dark 
cycle of a day, and they have shown favorable results. One intervention is improving the acoustic environment by installing high-performance absorbing materials for environmental surfaces, such as ceilings and walls that can reduce reverberation time, sound propagation, and noise intensity level (Hagerman, Rasmanis, Blomkvist, Ulrich, Anne Eriksen, et al., 2005; Philbin \& Gray, 2002). The other intervention is providing single occupancy rooms and avoiding lighting pollution (R. S. Ulrich, 1991).

Investigators have consistently reported that stress-reducing or restorative benefits of viewing nature are evidenced as a strategy of causing positive emotional, psychological, and physiological changes. Positive feelings such as pleasantness and calm increase, while anxiety, anger, or other negative emotions diminish (Hartig, Evans, Jamner, Davis, \& Gärling, 2003; R. S. Ulrich, 1979, 1991; Van den Berg, Koole, \& van der Wulp, 2003). Based on scientific evidence, a lot of hospital designs have integrated gardens. Several studies suggest that gardens can be effective restorative settings for stressed patients, families, and staff (Marcus, 1999; Marcus \& Barnes, 1999; Sherman, Varni, Ulrich, \& Malcarne, 2005; R. S. Ulrich, 1999a). Well-designed gardens not only can provide restorative nature views, but they also reduce stress and improve outcomes through other mechanisms, such as fostering access to social support, restorative escape, and control with respect to stressful clinical environments (R. S. Ulrich, 1999a; R. S. Ulrich et al., 2008). In addition to connecting with the natural environment, providing positive distractions, such as artwork and paintings is another way to have the restorative effect in the healthcare environment (Pati \& Nanda, 2011). A study conducted by Pati and Nanda (2011) confirmed that the introduction of distraction conditions can result in more calm behavior. Their research data also suggested that positive distraction 
conditions are significant attention grabbers and could be an important contributor to improving the waiting experience for children in hospitals by improving environmental attractiveness (Pati \& Nanda, 2011).

In conclusion, there are vast amount of studies in environment-behavior research that concerns the healthcare environment. The ultimate goal of EB studies is to serve as scientific data-driven evidence that can be the rationale for design process and decision making to achieve the best possible outcomes. Many scholars urge that the only way the EB field can make progress is by developing explanatory theories (Rapoport, 1982, 2000; Tofle et al., 2004) because of the significance and value of explanatory theories. Even though there exists a great amount of research evidence in environment-behavior studies in the healthcare environment, there is still a lot work need in evidence-based design, particularly in the development of positive exploratory theory and theory evaluation (Pati, 2011a; Stankos \& Schwarz, 2007; Tofle et al., 2004). Nevertheless, evidence-based design does present important implications for healthcare design.

\section{Conceptual Framework for the Study}

The conceptual framework for this study is derived from the conceptual framework for the domain of evidence-based design proposed by Ulrich et. al. (2010). The conceptual framework for this study also includes traditional architectural design process and major components in evidence-based design process outlined by Cama and Joseph et al. (Cama, 2009; Joseph \& Kirk Hamilton, 2008). Available research evidence summarized by Joseph et al. (2008) and Ulrich et al. (2004) are also included in the conceptual framework. Built environment variables (R. S. Ulrich et al., 2010) and 
possible best outcomes (R. S. Ulrich et al., 2010) are part of the conceptual framework as well. In addition, different stakeholders as well as project cost and time are also included in the conceptual framework for this study. Maxwell (2012) suggests that a conceptual map of a theory is a visual display of that theory - a picture of what the theory says is going on with the phenomenon you're studying. These maps do not depict the study itself, nor are they a specific part of either a research design or a proposal. However, conceptual maps can be used to visually present the design or operation of a study (Maxwell, 2012). Therefore, I developed the following conceptual map to present the conceptual framework for my research design (Figure 3.3). The lines and arrows between each block indicate the relationships among variables. And like a theory, a conceptual map consists of two things: concepts and the relationships among these (Maxwell, 2012).

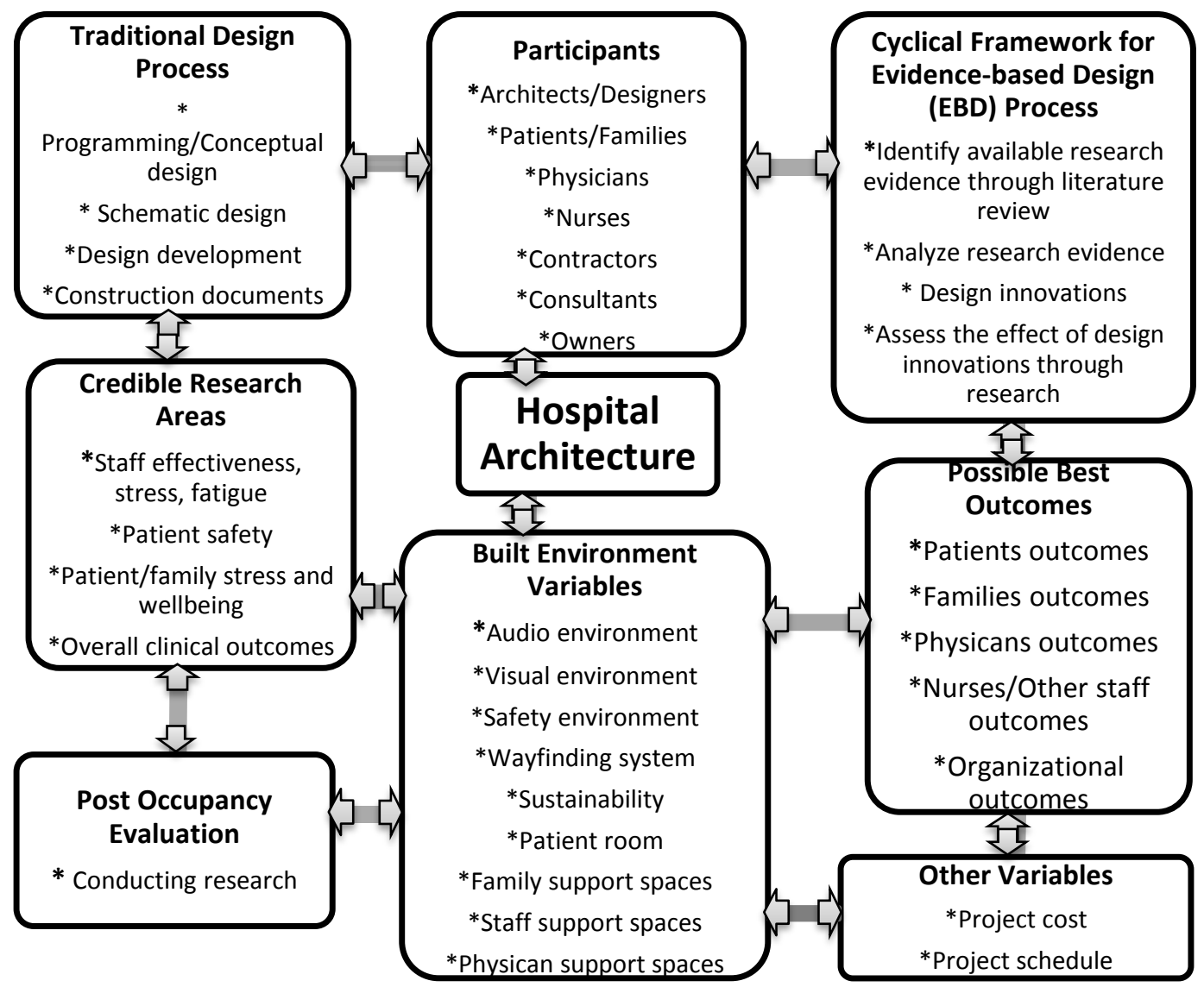

Figure 3.3: Conceptual Map 
In this conceptual map, the built environment is represented by nine design variable categories according to the conceptual framework for the domain of evidencebased design proposed by Ulrich (R. S. Ulrich et al., 2010). These nine design variable categories are: audio environment, visual environment, safety enhancement, wayfinding system, sustainability, patient room, family support spaces, staff support spaces, and physician support spaces.

A study for The Center for Health Design identified more than 700 articles which were published in top peer-reviewed journals by 2004 illustrating a strong relationship between the design of the physical environment and patient and staff outcomes (Urlich et al., 2004). The research report identified four main outcome areas that are affected by the design of the hospital environment: 1) staff effectiveness, stress, fatigue; 2) patient safety; 3) patient, family stress and well-being; and 4) overall clinical outcomes. These four credible research areas are included in the conceptual map.

The four major components in the evidence-based design process that is outlined by Joseph et al. (2008) as a cyclical framework are included in the conceptual map as well. Evidence-based design involves using the best available evidence to inform design decisions. It is more a process than a product (D. K. Hamilton, 2003). Rather than simply following prescriptive advice, design practitioners are required to analyze the evidence critically, interpret and innovate based on the unique context, hypothesize the expected outcomes associated with design interventions, measure the impact of innovations, and report on findings (Cama, 2009; D. Hamilton, 2004).

Possible best outcomes outlined by Ulrich et al. (2010) are also presented and featured on the right side of the conceptual map. It includes participant outcome variables 
and organizational outcome variables. These possible best outcomes contain a series of research evidence concerning the relationship between specific healthcare facility design variable categories and participant and organizational outcomes, such as sleep quality, medical errors, job satisfaction, staff retention, etc.

The conceptual map guided this case study to examine how evidence-based design was integrated in the design process for Grand River Hospital as well as how credible research evidence were interpreted and implemented in the design process of Grand River Hospital. Particularly, the contexts in this conceptual map addressed two research questions for this study. The first one is how the credible research evidence in these four areas was implemented in the built environment to achieve the best possible outcomes in Grand River Hospital. The second one is how the cyclical framework of evidence-based design was integrated in the traditional design process as presented in this conceptual map. The context in this conceptual map also guided the development of interview questions and observation protocols. The project cost and schedule are also major influential factors in design process that were addressed in interview questions. Post-occupancy evaluation is another important component for conducting research that has also been addressed in this study. All these concepts and categories presented in the conceptual map are inter-related and generate impacts among each other. 


\section{CHAPTER FOUR: RESEARCH METHODS}

\section{Philosophical Assumptions}

Philosophical frameworks that guide the work of social scientists can be classified into four paradigmatic families: postempiricism, interpretivism, critical theory, and poststructuralism (Glesne, 2011). Social constructivism is often combined with interpretivism (Mertens, 1998). Epistemology is the word used to refer to the philosophical beliefs about the nature of knowledge (Glesne, 2011). Every research study, therefore, is informed by philosophical and theoretical assumptions. The underlying epistemology of this study is interpretivism and social constructivism.

According to Creswell (2009), the plan to conduct research involves the intersection of the philosophical worldview, strategies of inquiry, and specific methods. In this study, the philosophical worldview is from a social constructivist perspective and it is typically seen as an approach to qualitative research. According to Strauss and Corbin (1998), there are three major components in qualitative research. The first one is the data, which can come from various sources. Interviews and observations are the most common sources. The second component of qualitative research consists of the different analytic or interpretive procedures that are used to arrive at findings or theories (Strauss $\&$ Corbin, 1998). These procedures include the techniques for conceptualizing data which are called "coding." Other procedures are also part of the analytical process, including writing memos and diagramming conceptual relationships (Strauss \& Corbin, 1990). Written and verbal reports are the third component of qualitative research (Strauss \& Corbin, 1998). 
Social constructivists hold assumptions that individuals seek understanding of the world in which they live and work. Instead of asking "What is going on?" with and within social reality, constructionists ask questions about how social realities are produced, assembled, and maintained (Holstein \& Gubrium, 2008; Silverman, 2013).

The goal of social constructivists' research is to rely as much as possible on the participants' views of the situation being studied (Creswell, 2009). Rather than starting with a theory (as in Postpositivism), social constructivist researchers generate or inductively develop a theory or the pattern of meaning. This study took a qualitative approach and attempted to understand how evidence-based design was integrated in the design process of Grand River Hospital and how decisions were made during the design process. In order to create a holistic picture of evidence-based design in the healthcare architecture design process, I looked at the situation from multiple points of view and understood the experience of the participants from their own perspectives.

\section{Social Constructivism and Interpretivism}

When conducting research, social constructivist researchers often ask questions that are broad and general so that the participants can construct the meaning of a situation, typically forged in discussion or interactions with other persons (Creswell, 2009). In this study, the interview questions were open-ended questions which allowed

the participants to tell more about their opinions and experience as well as what they did in the design process for Grand River Hospital.

Glesne (2011, p. 9) stated that it is very important to know how people interpret and make meaning of objects, events, actions, perceptions and so on. Accessing the 
perspectives of several members of the same social group about some phenomena can suggest some cultural patterns of thoughts and actions for that group as a whole (Glesne, 2011). Thus, interviews with a number of architects/designers helped me to find patterns of meaning and thoughts regarding evidence-based design and design process from the designers' perspective. Similarly, interviews with a number of owners, nurses, and facility planning personnel helped me to get some patterns of thought regarding EBD and design process from users and owners' perspectives. Further, interviews with a number of contractors and project managers helped me to find some patterns of meaning and thought regarding the design process because they were involved in the process from the very beginning. In this research, three different interview protocols were generated for three different types of participants - architects and designers, owners and users, and contractors.

Social constructivist researchers often address the process of interaction among individuals. Social constructivist researchers recognize that their own background shapes their interpretation. With the research goal of interpreting the social world from the perspective of those who are actors in that world, it follows that the research methods include interacting with people in their social contexts and talking with them about their perceptions (Glesne, 2011). With the philosophical framework of interpretivism and social constructivism for this study, the research design for this study focused on in-depth interactions with relevant people who participated in the Grand River Hospital design. I observed the physical environment, asked questions, and interacted with participants through the research process. 


\section{Grounded Theory}

This research is a qualitative study that examines the linkage between evidencebased design and hospital architectural design practice using grounded theory methodology. Grounded theory is a methodology created by Barney Glaser and Anselm Strauss in the mid-twentieth century in order to provide qualitative research a process by which theory can be generated (Charmaz, 2006; Glaser \& Strauss, 1967; Patton, 2002). Grounded theory, as envisioned by Glaser and Strauss, is not a theory itself, but a methodology for developing a theory or pattern of meaning that is "grounded" in rich data (Charmaz, 2006; Glesne, 2011).

Strauss and Corbin defined grounded theory as "theory that was derived from data, systematically gathered, and analyzed through the research process" (Strauss \& Corbin, 1990). Grounded theory is a strategy of inquiry in which the researcher derives a general, abstract theory of a process, action, or interaction grounded in the views of participants (Creswell, 2009). In the process of research using grounded theory, researchers develop inductive theoretical analyses from their collected data and subsequently gather further data to check these analyses. In qualitative research, interviews and observations are the most common sources of data (Strauss \& Corbin, 1998). The purpose of grounded theory is theory construction, rather than description or application of existing theories (Charmaz, 2006).

Key features of grounded theory include continual data sampling, simultaneous data collection and analysis, coding and categorizing, memo-writing and comparing in order to generate theory about social phenomena (Charmaz, 2006; Glesne, 2011; Groat \& Wang, 2002; Strauss \& Corbin, 1998). Early data analysis allows the researcher to adjust 
research questions based on the data received and to potentially direct the researcher to other groups of participants, previously unknown, who could contribute to the research. Therefore, data collection and data analysis happen simultaneously instead of waiting to the end of the research to analyze the data (Charmaz, 2006).

In this study, observational data, document review data, and interview data were analyzed and noted all along the way and compared to each other during the study. Since interviews were open-ended and interactive, it allowed richer data to come from the interviews and provided me the flexibility to follow a particular thread of the conversation. Codes and common themes began to emerge from the early data analysis (Charmaz, 2006). Continuous analysis and comparison of the data and the codes which was a true hallmark of grounded theory allowed me to consider the information at hand and to make appropriate adjustments during the research process (Charmaz, 2006). Memos were written at all stages to tie data together and to organize the coding into categories. This process allowed theories and patterns of meaning to be developed and emerge from the data (Charmaz, 2006; Groat \& Wang, 2002).

Strauss and Corbin (1990) stated that grounded theory is a scientific method. If grounded theory is carefully carried out as its procedures are designed, the method meets the criteria for doing "good" science: significance, theory-observation compatibility, generalizability, reproducibility, precision, rigor, and verification (Strauss \& Corbin, 1990, p. 27). Therefore, its systematic techniques and procedures of analysis enable the research to develop a substantive theory that meets the criteria for doing "good" science. For this study, the research design was based on the grounded theory method. I followed the grounded theory method for research design, data collection, and data analysis. 
In summary, the grounded theory approach is a qualitative research method that uses a systematic set of procedures to develop an inductively-derived grounded theory about a phenomenon. The research findings constitute a theoretical formulation of the reality under investigation (Strauss \& Corbin, 1990). Through this grounded theory methodology, the concepts and relationships among them are not only generated but they are also provisionally tested. For this research, concepts and categories from interviews, observations, and document reviews were tested and data triangulation was performed through multiple sources of data. Findings from multiple sources answered two research questions and generated a redefined model for the design process by integrating evidence-based design.

\section{Research Setting}

Grand River Hospital in the United States has been a successful project that was designed by implementing research evidence to achieve the best possible outcomes. It is a 446-bed, 1.1 million-square-foot facility that opened in 2012. This healthcare facility is a destination where wellness, safety, and family-centered care are promoted. Grand River Hospital's design goals focused on quality care, patient and staff safety, and operational efficiency in a healing environment. To increase flexibility and efficiency, core hospital services are shared, including emergency, radiology, surgery, and non-specialty beds as well as logistical services such as environmental services, laboratory, and pharmacy and materials management. The Grand River Hospital facility is situated at a location where visitors can see its logo from the highway. It is a modern healthcare facility that embraces the community. 
Walking inside the facility, visitors are transitioned into a family-centered healthcare environment designed by implementing credible research evidence. Daylighting is maximized for views through floor-to-ceiling glass curtain walls. Wayfinding is improved through the use of a single-loaded daylight concourse that connects the entire facility - existing and new buildings. The interior wayfinding is enhanced by signage, a touch screen map, and an information desk. Back-stage circulation, such as support services, is located on the lower level.

Family members can be an integral part of the healing process. Dedicated space is designed for family members in patient rooms. Both patients and families are provided views to nature in treatment rooms and waiting areas. Dining areas are open to patients, families, and the community. A medical resource center and wireless capability are provided in the facility. Decentralized nursing care brings families closer to the caregivers and allows interactions between family members and caregivers.

The spacious Grand River Hospital campus is home to a variety of inpatient and outpatient healthcare services related to treatment and wellness. Some services are located in the specialty centers or medical offices on the campus, such as the Heart Institute. The center of the medical complex is the seven-story tower. Emergency, acute, and critical care services are focused in this seven-story tower, along with other services such as imaging, laboratory, pharmacy, and others. In the tower, the first floor includes emergency, registration, gift shop, cafeteria, conference rooms, etc. Inpatient oncology patient rooms, intensive care units (ICUs), surgical trauma STICU patient rooms, and pediatric ICU (PICU) patient rooms are located on the second floor. In addition, surgical registration, the surgical family lobby, and the chapel are located on the second floor. On 
the third floor, there are medical ICU patient rooms and ICU/cardiac services. ICUs and other areas related to cardiac care are located at the Heart Institute which is connected to Grand River Hospital. On the fourth floor, there are ortho/neuro trauma patient rooms. Patients in this area require skilled nursing care in their recovery from specific types of injury or surgeries. Additional orthopedic patient rooms and services are located in the Ortho Hospital on the Grand River Hospital campus. On the fifth floor, there are surgical patient rooms. After surgery, a patient who has been in recovery and is ready to be transferred to a patient room is taken to this area. The sixth floor and seventh floor include medical patient rooms. Patients who have medical needs for which surgery is not involved are placed in these areas. The site plan for Grand River Hospital medical campus is shown in Figure 4.1. The main lobby, tower of nursing units, cafeteria, chapel, second floor surgical lounge, emergency department, emergency department lounge, and heart institute lobby were the major areas in this study.

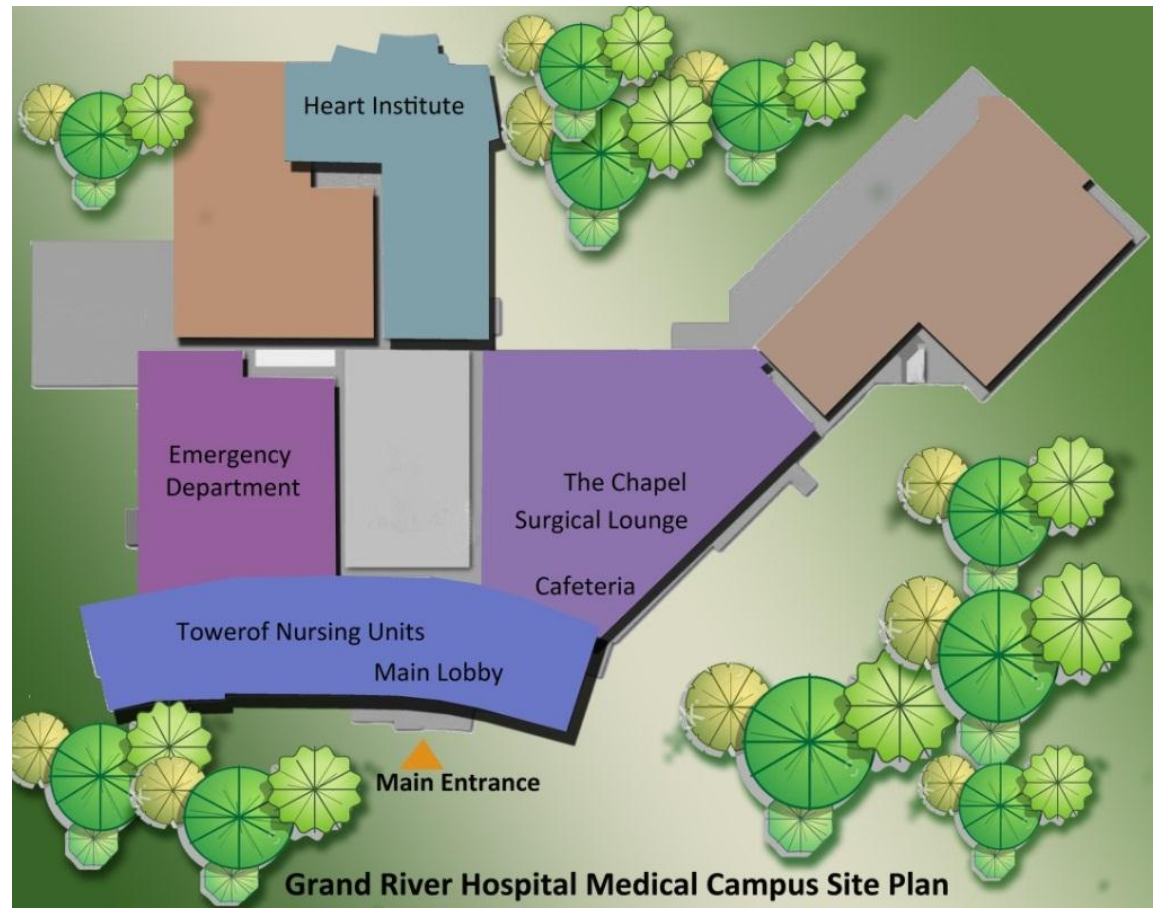

Figure 4.1: Grand River Hospital Medical Campus Site Plan 


\section{Research Design}

In order to answer research questions, this research was designed to collect data from multiple sources. As stated earlier, this research took a Grounded Theory approach that used a systematic set of procedures for data collection, coding, and interpretation so that a theory or patterns of meaning could be derived from abundant data. For this case study research, document reviews, direct observations of physical features of the Grand River Hospital, and interviews were conducted in order to collect rich data.

\section{Participants}

The participants in interviews included architects, designers, contractors, consultants, and hospital management personnel and users who were involved in the design process for Grand River Hospital. A total of 26 participants were interviewed for this research. Each was given an informed consent form, which had been approved by the university's Institutional Review Board (IRB) and Grand River Hospital Institutional Review Board (IRB). The form presented the information, including (1) the study concerned how evidence-based design was implemented in the hospital design process, (2) the participants were not required to participate in the study, the study was completely voluntary, and (3) if they did participate, they could withdraw from the study at any time without penalty.

Snowball sampling is a sampling method where the participant recommends individuals for the researcher to contact next (Sommer \& Sommer, 2002). In this study, snowball sampling was used to access populations that might be difficult to identify, such as consultants who worked on the Grand River Hospital project and users/owners at 
Grand River Hospital. During the interview process, some participants recommended individuals for me to contact for an interview. The Grand River Hospital Research and Innovation Center assisted me with recruiting participants who were involved in their facility design process.

\section{Ethical Considerations}

The following safeguards were employed in this study in order to protect the participant's rights: 1) IRB approval was obtained before interviewing any participants, 2) the research objectives were articulated verbally and in writing so that they were clearly understood by the participants (including a description of how data would be used), 3) permission to proceed with the study as articulated was received from the participant, 4) the participant was informed of all data collection devices and activities, 5) verbatim transcriptions and written interpretations and reports were made available to the participants, and 6) pseudonyms for participants and the hospital facility were used to protect confidentiality.

A spreadsheet titled Interview Schedule and Contacts was created (Appendix I). It lists the pseudonyms of the participants, phone number, date/time, and duration of the recorded interview. It was approved by the Grand River Hospital IRB. I also created a code key to be kept in a separate location from the data. I used the interview protocols which were developed based on document reviews and observations for conducting interviews. The Interview Protocols (Appendix II) and Observation Protocol (Appendix III) were approved by the Grand River Hospital IRB as well. The Interview Protocols consisted of three different interview protocols for different participants: one for 
architects and designers, a second one for the contractors, and a third one for owners and users.

The benefits of conducting this research and potential risks, as well as possible inconvenience to participants, were communicated with the participants in the consent form. In addition, how to protect participants' confidentiality was also communicated with the participants. There are potential benefits for all stakeholders who are working in the healthcare industry, including owners of healthcare facilities, architects and designers, contractors, patients and family members, as well as medical staff. This study helps to provide practical recommendations for the EBD design process in order to increase the rigor of design practice and benefit the healthcare industry. The potential risks might include inconvenience of schedule - time involved to answer interview questions - and might include the possibility of losing confidentiality. To minimize the potential risks, the precautions included scheduling interview times at the convenience of the participants, limiting the interview time to 30-45 minutes, and using pseudonyms for participants and the hospital facility to protect confidentiality. The participants had the alternative to not participating in this study or to skip any questions or stop at any point during the study.

\section{Permission to Conduct the Case Study}

This study was approved by both Grand River Hospital management and the Grand River Hospital Institutional Review Board (IRB). Permission from Grand River Hospital for the expanded research was obtained to study the entire medical center. This included the examination of project-related documents such as drawings, design goals, and design guiding principles. In addition, data collection included interviews with Grand 
River Hospital employees who participated in the facility design process. Permission was also obtained to photograph patient rooms, nurses' stations, procedure rooms, and other necessary areas for conducting direct observations. With the help and support from Grand River Hospital, I was able to identify potential participants for this study. The participants include architects/designers, consultants, contractors as well as Grand River Hospital staff members who were involved in the design process and construction process. These staff members included nurses, Grand River Hospital leadership personnel, and facility planning personnel.

\section{Document Reviews}

Because of their overall value, documents play an explicit role in any data collection in doing case studies. Systematic searches for relevant documents are important in any data collection plan (Yin, 2009). In order to have a comprehensive understanding of Grand River Hospital organization and its design, document reviews was conducted first. Since Grand River Hospital was designed by using evidence-based design led by a set of design guiding principles, including a focus on patient safety and quality care, the document for the set of guiding principles was obtained and reviewed first. For this study, the document reviews included Design Guiding Principles, Patient Room Design Goals, Patient and Staff Safety Related Design Elements, Key Block Plan Drivers as well as floor plans of construction documents. In addition, public documents that related to Grand River Hospital design were also reviewed through published healthcare design magazines and internet resources, such as all stakeholders' websites. The document reviews provided me with a thorough combination of primary and 
secondary sources of data. These documents were coded as part of the open coding process as they were reviewed and analyzed to search for clues and voids within the data.

\section{Direct Observations}

Direct observations can serve as another source of evidence in a case study (Yin, 2009). I also conducted observations simultaneously with document reviews. I photographed and documented environmental features and characteristics that were designed based on credible research. I also observed how these physical environmental designs impacted the users' behavior. This allowed me to have some clues regarding the linkage between evidence-based design and possible best outcomes. An observation protocol was created before observations (Appendix III) and it was also approved by Grand River Hospital IRB. The following areas were observed for this study: cafeteria, chapel, Emergency Department, Emergency Department patient waiting area/family lunge, hospital lobbies, intensive care units (ICU) on the second floor, ICUs on the third floor, hospital main lobby, operating room and preparation/recovery rooms on the second floor, patient rooms and nurses' stations on the $7^{\text {th }}$ floor, and surgical lounge on the second floor. The observations provided me with another source of data that thoroughly combined primary and secondary sources of data. Like document reviews, these observations were coded as part of the open coding process as they were reviewed and analyzed to search for clues and voids within the data.

\section{Interviews}


The participants in interviews for this study included project managers, architects/designers, general contractors and consultants, nurses, Grand River Hospital leadership, and facility planning personnel as owners. A total of 26 participants were interviewed for this case study. All the interviews were audio recorded and transcribed into interview transcripts. Each interview lasted at least 45 minutes, and most of interviews lasted more than 60 minutes.

The intentions and potential benefits of the study were clarified when the participants were recruited. It was explained to the participants how the results of this study may benefit all stakeholders who were working in the healthcare industry, including the owners of healthcare facilities, architects and designers, contractors, patients and family members as well as medical staff. By sharing participants' experience or expertise with using the evidence-based design approach, it was hoped that practical recommendations for the EBD design process could be provided in order to increase the rigor of design practice and benefit the healthcare industry. Complete confidentiality was honored and respected for each of the interviewees. Each participant reviewed and retained a copy of the informed consent form that was approved by the IRB (Appendix IV). The consent form explained what the study was about and that the participant could skip any questions or withdraw at any time without repercussions.

Through initial document reviews and direct observations, interview protocols were developed. Three different interview protocols for three different types of participants (architects/designers, contractors, and owners/users) are located in Appendix II. These interview protocols were approved by both University of Missouri IRB and Grand River Hospital IRB. Additional questions stemmed from the interviews that 
revealed more information and concepts used to answer the research questions. In addition to these questions, knowledge-based questions were included in the interview protocols so participants could demonstrate their experience and knowledge about Grand River Hospital design. I followed interview protocols during the interview process. The interviews were conducted face-to-face, by telephone, or via Skype. Face-to-face interviews were held in participants' offices, in a local restaurant or café, or in the Grand River Hospital lobby. Phone interviews were conducted for participants who were not local. All interviews were audio recorded and transcribed after each interview. Charmaz indicates that when the categories are "saturated," you can stop gathering data (Charmaz, 2006). The word "saturated" here means gathering fresh data no longer sparks new theoretical insight nor reveals new properties of theoretical categories. In this study, it was clear that the categories were saturated with 26 participants. The following table (Table 4.1) presents a list of interviewees and their occupations. Among the interviewees, ten of them are architects/designers, four are contractors/project managers, six are owners/users, and six are consultants.

I interviewed all participants individually except for two interviews. I had two interviews that included two people each and one of those participants participated in both groups. I also had an individual interview with this participant. I have found the group interviews were very informative and I was able to collect a huge amount of information. I also had two pre-interview meetings with two participants. These preinterview meetings provided me tremendous information at the starting point even though I didn't use the interview guide. Lastly, I realized that I needed to clarify some information from the interviews, so I brought the information back to the following 
interviews to verify the information with other participants. All participants were very collaborative and willing to provide further information and clarifications.

Table 4.1 List of Interviewees and Their Occupations

\begin{tabular}{|c|c|c|}
\hline $\begin{array}{c}\text { Interviewees' } \\
\text { Numbers }\end{array}$ & Interviewees & Occupation \\
\hline 1 & Angie & Architect/Designer \\
\hline 2 & Bill & Contractor \\
\hline 3 & Bob & Architect/Designer \\
\hline 4 & Carol & Owner/User \\
\hline 5 & Dan & Consultant/Engineer \\
\hline 6 & David & Contractor \\
\hline 7 & Don & Architect/Designer \\
\hline 8 & Emily & Owner/User \\
\hline 9 & Eric & Consultant/Engineer \\
\hline 10 & George & Project Manager/Contractor \\
\hline 11 & Joe & Owner/User \\
\hline 12 & Julie & Architect/Designer \\
\hline 13 & Karen & Architect/Designer \\
\hline 14 & Ken & Owner/User \\
\hline 15 & Larry & Project Manager / Contractor \\
\hline 16 & Linda & Owner/User \\
\hline 17 & Mike & Architect/Designer \\
\hline 18 & Pam & Consultant/ Engineer \\
\hline 19 & Rick & Programming Consultant \\
\hline 20 & Roy \& Karen & Architect / Designer \\
\hline 21 & Sam & Architect/Designer/Consultant \\
\hline 22 & Steve & Architect/Designer \\
\hline 23 & Susan \& Karen & Research Director, Architect/Designer \\
\hline 24 & Tim & Project Manager / Architect \\
\hline 25 & Tina & Owner/User \\
\hline 26 & Ted & Designer/Consultant \\
\hline
\end{tabular}

\section{Data Analysis Strategy}


As part of the grounded theory methodology and due to the extensive amount of information that was obtained for this study, a three-stage coding paradigm was used to organize and analyze the data. Grounded theory has systematic steps (Strauss \& Corbin, 1998; Strauss \& Corbin, 1990). These steps involve generating categories of information (open coding), selecting one of the categories and positioning it within a theoretical model (axial coding), and then explicating a story from the interconnection of these categories (selective coding) (Creswell, 2009).

Grounded theory coding generates the bones of analysis for this study. Theoretical integration assembles these bones into a working skeleton (Charmaz, 2006). Thus, coding is more than a beginning, it shapes an analytic frame from which you build the analysis (Charmaz, 2006). In this study, initial coding (open coding) was conducted first. I remained open to exploring other theoretical possibilities that could emerge from the data. Initial open coding stuck closely to the original data. Therefore, it provided a clear picture for conceptual categories. Through comparing data with data, coding also helped me to know what participants viewed as problematic. The final step in data analysis involved making an interpretation of the data. Creswell (2009) wrote that the interpretation can take many forms. The interpretation could be the researcher's personal interpretation that is brought from her or his own culture, history, and experience. It could also be a meaning derived from a comparison of the findings with information gleaned from the literature or theories (Creswell, 2009). For this study, the interpretation was a meaning derived from a comparison of the findings with information obtained from the literature and theories in addition to my experience in practicing architecture and interior design for healthcare projects. 
Qualitative data analysis searches the description of general statements about relationships and themes presented in the data. The term "analysis" is a generic term that embraces the three basic categories when analyzing data: description, analysis, and interpretation (Wolcott, 2001). Wolcott (2001) suggested these categories are not exclusive; neither visibly separated by a line, yet identifying and distinguishing each one may be useful to organize and present the data. In qualitative data, especially content analysis, the data collection and gathering simultaneously receive some kind of interpretation. The reading of the data to follow the criteria for inclusion in the database leads to initial interpretation and understanding of the concepts, and for some researchers, the analysis can begin while collecting data (Marshall \& Rossman, 2006). Thus, I started data analysis and interpretation while I was still conducting interviews. This also gave me the opportunity to check the accuracy of information by verifying the major themes that emerged in earlier interviews while I conducted latter interviews.

Furthermore, theoretical sensitivity is paramount in qualitative research using grounded theory methodology. Theoretical sensitivity refers to the researcher's ability to recognize what is important in data and to give it meaning (Strauss \& Corbin, 1990). Theoretical sensitivity comes from a number of sources. One is literature, which includes reading on theory, published research, and documents. The other source is from professional and personal experience. During the process of this research, I brought comprehensive professional knowledge into the research situation. I conducted an extensive literature review regarding theories and relevant research in evidence-based design before I started collecting data. My extensive professional practice experience in healthcare architecture enabled me to move into the situation and gain insight quickly. 
Theoretical sensitivity is also acquired during the research process through continual interactions with the data through data collection and analysis. Strauss \& Corbin (1990) suggested three strategies to produce good theory. These strategies include (1) asking, "What is really going on here?"; (2) maintaining an attitude of skepticism toward any categories emerged or arising early in the research, and validating them repeatedly with the data themselves; and (3) by following the data collection and analytic procedures. I used these strategies throughout my data collection and data analysis process. In the following section, I will discuss initial open coding and memo-writing, which served as data analysis strategies for this study.

\section{Initial Open Coding}

The first phase in data analysis is open coding. Open coding is a process of breaking down, examining, comparing, conceptualizing, and categorizing data (Strauss \& Corbin, 1990). After conducting interviews and transcribing the interviews from audio recording, the initial open coding analysis was completed according to interview transcripts. Strauss and Corbin (1990) explain the procedures of open coding in grounded theory contain two analytic procedures. The first pertains to the making of comparisons, the other to the asking of questions (Strauss \& Corbin, 1990, p. 62). These two procedures help to give the concepts in grounded theory their precision and specificity (Strauss \& Corbin, 1990). Therefore, the first step in my data analysis was conceptualizing data by "labeling phenomena," "discovering categories," "naming a category," and "developing categories in terms of their properties and dimensions." In addition to these techniques, there were several different ways of approaching the process 
of open coding for this study. One was by analyzing the interview transcripts with a lineby-line analysis. Generating categories early through line-by-line analysis is important because categories also become the basis of the theoretical sampling (Strauss \& Corbin, 1990). For some cases, I also used the technique of coding by sentence or paragraph by identifying the major idea brought out in this sentence or paragraph in the interview transcripts. Then I gave it a name and went back to do a more detailed analysis on that concept.

Strauss and Corbin (1990) summarize the open coding process. They explain:

Concepts are the basic building blocks of theory. Open coding in grounded theory method is the analytic process by which concepts are identified and developed in terms of their properties and dimensions. The basic analytic procedures by which this is accomplished are the asking of questions about data; and the making comparisons for similarities and differences between each incident, event, and other instances of phenomena. Similar events and incidents are labeled and grouped to form categories. (p.74)

According to the open coding procedures and techniques that Strauss and Corbin (1990)

described, a spreadsheet was created that contained all the interview questions and categories/concepts. The following table (Table 4.2) presents two sample interview questions with their open coding. Similarly, open coding was conducted for both observations and document reviews. Detailed information regarding open coding for observations (Table 5.5) and open coding for document reviews (Table 5.7) will be discussed in Chapter 5. 
Table 4.2: Sample of Open Coding for Interviews

Open Coding for Interview Questions

1. Describe for me your roles and responsibilities for Grand River Hospital design. What do you like about these?
Categories/Concepts

visioning sessions, collaboration sessions, wellness, community, guiding principles, and design goals; cohesive campus; research; meeting client; supportive and homing

published credible research evidence; window views, private patient room, daylight, patient safety, staff safety, mock-ups, efficiency, patient lift in patient room, infection control, patient experience, flexibility and sustainability, and evidence-based decision; lobby connected to concourse; outdoor space; daylight; public space; positive distractions; art work; garden and nature

\section{Memo-Writing}

Memo writing constitutes a crucial method in grounded theory because it prompts the researcher to analyze the data and codes early in the research process (Charmaz, 2006). As a code was used for the same category over and over, it seemed important to me that I should stop, organize my thoughts, and write these thoughts and ideas down in a memo (see sample memo in Table 4.3). Memos caught my thoughts, captured the comparisons and connections I made, and crystalized questions and directions for me to pursue.

Through writing memos, I constructed analytical notes. It allowed me to consider and analyze the codes into categories. Memos gave me a space and place for further consideration of the implications of the codes. This process helped to move the research into a more theoretical perspective and start developing axial coding.

Memos needed to be done in a manner that could be rearranged, sorted, and grouped, and they are meant to be analytical and conceptual rather than descriptive (Charmaz, 2006; Strauss \& Corbin, 1998). Strauss and Corbin (1998) suggested that diagrams were visual rather than written memos. Both memos and diagrams are devices that depict the relationships among concepts (Strauss \& Corbin, 1998). Thus, the visual diagram method, 
again, helped me to narrow down the categories and gain analytical insights from data to refine theoretical concepts.

Table 4.3: Memo about Design Charrette/Workshop

\section{Design Charrette/Workshop}

I think the charrette was a very interesting process. The charrette on one day really crystalized what we want. Then you started to see the plan as them today.

There were a lot of key players for the design charrette at that point because it was a more integrated project delivery team. We had many representatives from that aspect as well as contractors participated in all of design charrette.

As contractor, we listen. We listened quite a bit at the design charrette. We absorbed information. When you hear something coming up a year later, two years later, you tried to reconnect the dots.

The design charrette was really helpful. Be able to ask a number of questions and then try to sketch out what the project would look like was also an important piece of it. It reflected on whether it met the principles we set. It's a great way to get everyone involved seeing what this building would look like.

I would say there were design workshops throughout the design process. When the design went on, the format for design charrette was one meeting in a large room that had four concurrent user group meetings. Users from different departments were at the meetings for a couple of days with architects when they were in town.

At the design charrette, the conclusion of the user group meetings typically was one overall design presentation about the design of the building and aesthetics of the building.

The design charrette/workshop would wrap up with a summary session and the design with the things that we might change. These were presented to the owner before the architects went to make a lot of changes.

My Thoughts: It is obvious that design charrette/workshop is an important component in the design process for Grand River Hospital. Participants all talked about the design charrette/workshop and made very positive comments about it. Design charrette is an effective strategy that involves all stakeholders early on in the design process. Contractors were brought on board from the beginning during schematic design, which normally is not the case. Having several different concurrent user group meetings at the design charrette/workshop was really beneficial for the design team. Expertise on different subject matters could be easily sought during design charrette. For example, when design team was working on surgery room, they might need some expert's insights regarding infection control. The team could go to a different table and had infection control people to join the design team for surgery room design. 
A set of Design Guiding Principles were created before the actual schematic design started. The interpretations of Design Guiding Principles require the linkage between research evidence and the best possible outcomes. For example, one of the Design Guiding Principles states, "Safety and quality throughout planning and design work." The owner would want to make sure that the design solutions met the requirements of Design Guiding Principles at the design charrette/workshop. It is architects' responsibility to identify and implement research evidence regarding patient safety and quality care into the design. Therefore, linking performance metrics and design metrics is extremely important. Design charrette/workshop is a strategy to facilitate the design work that should integrate research evidence to achieve the best possible outcomes.

Memo writing is the intermediate step between data collection and writing drafts of the research. This process continued until there was theoretical sufficiency of the data.

\section{Strategies for Validating Findings}

Validity is based on whether the findings are accurate from the standpoint of the researcher, the participant, or the readers of an account (Creswell \& Miller, 2000). Creswell (2009) suggested several validity strategies. One of the strategies is to triangulate different data sources of information by examining evidence from the sources and using it to build a coherent justification for themes. For my study, the use of multiple sources of evidence included document reviews, observations, and interviews, which is the "triangulation" strategy to add to the validity of the study. Another strategy for my study was to use "rich and thick description" to convey the findings. This description may transport readers to the setting and give the discussion an element of shared experience (Creswell, 2009). As Creswell (2009) wrote, when qualitative researchers provide detailed descriptions of the setting, the results become more realistic and richer. This procedure can add to the validity of the findings (Creswell, 2009). The internal 
validity of my study was enhanced in several ways. First, the collection and organization of data was systematic. Fundamental to this research is the triangulation of methods and the use of multiple sources of data. According to Creswell (2009), another strategy for validating the data in this study was using "Member Checking" to determine the accuracy of the qualitative findings through taking the specific description or themes back to participants and determining whether these participants felt that they were accurate. This procedure involved conducting follow-up interviews with the participants in the study and providing an opportunity for them to comment on the findings. 


\section{CHAPTER FIVE: FINDINGS}

In this chapter, findings from interviews, observations, and document reviews are articulated. This includes 1) findings from interviews which answered two research questions in this study; 2) findings from observations that revealed research evidence implemented in the design of Grand River Hospital; 3) findings from document reviews that include research in practice in Sackerber Architects, Functional Performance Evaluation (FPE) in Sackerber Architects, and Parametric Modeling Tool and Institute of Design Research and Evaluation (IDRE); and 4) implications - redefined model of design process by integrating evidence-based design. It is important to note that findings did not just come from one single source of data; instead, they were intertwined from multiple sources of data. Therefore, the data was triangulated during the course of data collection.

\section{Findings from Interviews}

In this section, findings from interviews will be described. Two core categories that correspond to two research questions emerged from axial coding. The first core category is regarding research evidence interpretation and implementation in evidencebased design, which corresponds to research question \#1. The second core category is regarding the design process and the decision-making process, which corresponds to research question \#2. Under each of these core categories, primary categories and subcategories were also revealed through axial coding. Therefore, axial coding for two research questions will be discussed first. Then findings from selective coding will be discussed because it is the final step for integration of concepts around a core category and filling in of categories that need further development. I also used diagrams and 
storyline memos for selective coding. The following sections present the detailed findings from axial coding and selective coding.

\section{Axial Coding}

The second stage in the coding process is axial coding. Axial coding specifies the properties and dimensions of a category. The purposes of axial coding are to sort, synthesize, and organize large amounts of data and reassemble them in new ways after open coding (Creswell, 2009). Axial coding puts those data back together in new ways by making connections between a primary category and its sub-categories (Strauss \& Corbin, 1990). In axial coding, subcategories are related to their primary categories through what is called a paradigm model, defined by Strauss and Corbin (1990). In grounded theory we link subcategories to a primary category in a set of relationships denoting causal conditions, phenomenon, context, intervening conditions, action/interactional strategies, and consequences (Strauss \& Corbin, 1990, p. 99). Strauss and Corbin (1990) present a paradigm model for axial coding as the following:
(A) CAUSAL CONDITIONS $\rightarrow$ (B) PHENOMENON $\rightarrow$
(C) CONTEXT $\longrightarrow$ (D) INTERVENING CONDITIONS
(E) ACTION / INTERACTION STRATEGIES $\rightarrow$
(F) CONSEQUENCES

According this paradigm model, the axial coding stage of the data was arranged in new ways to identify the causal relationships between the primary categories and the subcategories for this study. The goal was to make explicit connections between the primary categories and the subcategories with an explanation and understanding of the relationships. During the axial coding process, research evidence interpretation and identification in evidence-based design appeared to be a core category that corresponded 
to research question \#1. Another core category also emerged through axial coding-it is regarding the programming process, the design process, and the decision-making process. The second core category appeared to be corresponding to research question \#2. I wrote analytic memos for each category to develop subcategories relevant to the research questions. The axial coding process was completed for two research questions in this research.

Through the development of a core category, the goal is to sort, synthesize, and organize a large amount of data for the next stage of selective coding (Charmaz, 2006, p. 60). Through data analysis for the first core category of research evidence interpretation and implementation in evidence-based design, it became evident that new strategies and technologies were required to help with interpretation and implementation of research evidence in order to achieve the best possible outcomes. Table 5.1 shows the axial coding for the first core category that includes primary categories and the tentative subcategories. The primary categories are Environment-Behavior Attributes/Credible Research Evidence, Strategies, In-house Research, Technology, and Best Possible Outcomes (Table 5.1). Corresponding subcategories are listed under each primary category.

Table 5.1: Axial Coding for Research Question \#1 Regarding Research Evidence interpretation and Implementation in Evidence-based Design

Primary Categories and Sub-Categories for Interview Axial Coding - Regarding Research Question \#1: Research Evidence Interpretation and Implementation for Evidence-based Design

\begin{tabular}{|c|c|c|c|c|}
\hline $\begin{array}{c}\text { Environment- } \\
\text { Behavior } \\
\begin{array}{c}\text { Attributes/Credible } \\
\text { Research Evidence }\end{array}\end{array}$ & Strategies & In-House Research & Technology & $\begin{array}{c}\text { Best Possible } \\
\text { Outcomes }\end{array}$ \\
\hline Privacy & $\begin{array}{c}\text { Design Guiding } \\
\text { Principles }\end{array}$ & IRDE & Patient Ceiling Lift & Patient Safety \\
\hline
\end{tabular}




\begin{tabular}{|c|c|c|c|c|}
\hline Territoriality & Visioning Sessions & Research in Practice & $\begin{array}{c}\text { Patient Bed-Escape } \\
\text { Alert }\end{array}$ & Fall Prevention \\
\hline Personal Space & Mock-ups & Design Diagnostic & BIM & Infection Control \\
\hline Environment Stress & $\begin{array}{l}\text { Site visit/Pre- } \\
\text { Occupancy } \\
\text { Evaluation }\end{array}$ & $\begin{array}{l}\text { Functional } \\
\text { Framework }\end{array}$ & Cell Phone for Nurses & Quality Care \\
\hline Design Preference & Design Charrettes & $\begin{array}{l}\text { Functional } \\
\text { Performance } \\
\text { Evaluation }\end{array}$ & $\begin{array}{l}\text { Scheduling Software } \\
\text { for Construction }\end{array}$ & $\begin{array}{c}\text { Patient-Centered } \\
\text { Care }\end{array}$ \\
\hline Control & $\begin{array}{l}\text { Integrated Project } \\
\text { Delivery (IPD) }\end{array}$ & Multi-method Tool & $\begin{array}{l}\text { Nurse Tracking } \\
\text { System }\end{array}$ & $\begin{array}{c}\text { Family } \\
\text { Involvement }\end{array}$ \\
\hline Restoration & Literature Reviews & FPE Site Audits & $\begin{array}{l}\text { Medication Supply } \\
\text { Tracking System }\end{array}$ & $\begin{array}{c}\text { Healing } \\
\text { Environment }\end{array}$ \\
\hline Efficiency & $\begin{array}{c}\text { Database for } \\
\text { Research Evidence }\end{array}$ & User Feedback & Robots & $\begin{array}{l}\text { Organizational } \\
\text { Efficiency }\end{array}$ \\
\hline Wayfinding & Collaborations & $\begin{array}{l}\text { Environmental } \\
\text { Analysis }\end{array}$ & $\begin{array}{c}\text { Separate TVs for } \\
\text { Patient and Family } \\
\text { Members in Patient } \\
\text { Room }\end{array}$ & $\begin{array}{l}\text { Employee Injury } \\
\text { Rate Down }\end{array}$ \\
\hline Ceiling Lifts & $\begin{array}{c}\text { Post-Occupancy } \\
\text { Evaluation }\end{array}$ & $\begin{array}{l}\text { Organizational } \\
\text { Success Metrics }\end{array}$ & & $\begin{array}{c}\text { Physician } \\
\text { Effectiveness and } \\
\text { Satisfaction }\end{array}$ \\
\hline $\begin{array}{l}\text { Decentralized Nurse } \\
\text { Stations }\end{array}$ & $\begin{array}{c}\text { In-house Research } \\
\text { Efforts }\end{array}$ & $\begin{array}{c}\text { Triangulation of Data } \\
\text { Collection }\end{array}$ & & $\begin{array}{c}\text { Patient } \\
\text { Satisfaction }\end{array}$ \\
\hline $\begin{array}{l}\text { Nurse Alcoves Outside } \\
\text { Patient Rooms }\end{array}$ & $\begin{array}{l}\text { Lessons Learned } \\
\text { Session }\end{array}$ & $\begin{array}{l}\text { Lessons Learned } \\
\text { Feedback Session }\end{array}$ & & $\begin{array}{c}\text { Reduced Medical } \\
\text { Error }\end{array}$ \\
\hline $\begin{array}{l}\text { Dedicated Medication } \\
\text { Rooms }\end{array}$ & LEAN Tool & $\begin{array}{c}\text { Survey / } \\
\text { Questionnaire }\end{array}$ & & $\begin{array}{c}\text { Reduced Walking } \\
\text { Distances }\end{array}$ \\
\hline $\begin{array}{l}\text { Family Zone in Patient } \\
\text { Room }\end{array}$ & A3 Thinking & Parametric Modeling & & HCAHPS \\
\hline
\end{tabular}

Through the data analysis for the second core category of the design process and the decision-making process, it became evident that each design phase included additional steps and new approaches. Table 5.2 shows the axial coding for research question \#2 regarding the design process and the decision-making process. The axial coding in Table 5.2 includes primary categories of Visioning Sessions, Programming Process; Schematic Design Process; Research Evidence Interpretation and Implementation; Decision-Making Process, Construction Process, and Post-Occupancy Evaluation and Publication. Corresponding subcategories are listed under each primary category. 
Table 5.2: Axial Coding for Research Question \#2 Regarding Design Process and Decision-Making Process in Evidence-based Design

\begin{tabular}{|c|c|c|c|c|c|c|}
\hline \multicolumn{7}{|c|}{$\begin{array}{l}\text { Primary Categories and Sub-Categories for Interview Axial Coding Regarding } \\
\text { Research Question \#2: Design Process and Decision-Making Process }\end{array}$} \\
\hline $\begin{array}{l}\text { Visioning } \\
\text { Session }\end{array}$ & $\begin{array}{l}\text { Programming } \\
\text { Process }\end{array}$ & $\begin{array}{l}\text { Schematic } \\
\text { Design } \\
\text { Process }\end{array}$ & $\begin{array}{c}\text { Research } \\
\text { Evidence } \\
\text { Interpretation } \\
\text { and } \\
\text { Implementation }\end{array}$ & $\begin{array}{l}\text { Decision- } \\
\text { Making } \\
\text { Process }\end{array}$ & $\begin{array}{l}\text { Construction } \\
\text { Process }\end{array}$ & $\begin{array}{c}\text { Post- } \\
\text { Occupancy } \\
\text { Evaluation and } \\
\text { Publication }\end{array}$ \\
\hline $\begin{array}{l}\text { Collaborative } \\
\text { Approach }\end{array}$ & $\begin{array}{l}\text { Collaborative } \\
\text { Approach }\end{array}$ & $\begin{array}{l}\text { Literature } \\
\text { Reviews }\end{array}$ & Intuitive Design & $\begin{array}{c}\text { Site } \\
\text { Visit/Pre- } \\
\text { Occupancy } \\
\text { Evaluation }\end{array}$ & $\begin{array}{l}\text { Contractor } \\
\text { Onboard from } \\
\text { the Beginning }\end{array}$ & $\begin{array}{l}\text { Functional } \\
\text { Performance } \\
\text { Evaluation } \\
\text { (FPE) Site } \\
\text { Audits }\end{array}$ \\
\hline $\begin{array}{l}\text { Hospital } \\
\text { Leadership } \\
\text { Team }\end{array}$ & $\begin{array}{l}\text { Working with } \\
\text { Programming } \\
\text { Consultant } \\
\text { and Architect }\end{array}$ & $\begin{array}{l}\text { Research } \\
\text { Database }\end{array}$ & $\begin{array}{l}\text { Based on Past } \\
\text { Best Practice } \\
\text { Experience }\end{array}$ & Mock-ups & $\begin{array}{l}\text { Contractor } \\
\text { Participate in } \\
\text { Design } \\
\text { Charrette }\end{array}$ & $\begin{array}{l}\text { Multi-method } \\
\text { Tool }\end{array}$ \\
\hline $\begin{array}{l}\text { Collaboration } \\
\text { with Architect }\end{array}$ & $\begin{array}{l}\text { Working with } \\
\text { User Groups }\end{array}$ & $\begin{array}{c}\text { Site } \\
\text { Visit/Pre- } \\
\text { Occupancy } \\
\text { Evaluation }\end{array}$ & $\begin{array}{l}\text { Frustrations } \\
\text { about Research } \\
\text { Evidence }\end{array}$ & $\begin{array}{l}\text { Feedback } \\
\text { from All } \\
\text { Users }\end{array}$ & $\begin{array}{l}\text { Build Mock- } \\
\text { ups }\end{array}$ & User Feedback \\
\hline Site Visits & $\begin{array}{c}\text { Design } \\
\text { Guiding } \\
\text { Principles }\end{array}$ & $\begin{array}{l}\text { Design } \\
\text { Charrette }\end{array}$ & $\begin{array}{c}\text { In-house } \\
\text { Research Team }\end{array}$ & $\begin{array}{c}\text { Design } \\
\text { Charrettes }\end{array}$ & $\begin{array}{c}\text { Manage } \\
\text { Project } \\
\text { Schedule and } \\
\text { Cost }\end{array}$ & $\begin{array}{c}\text { Environmental } \\
\text { Analysis }\end{array}$ \\
\hline $\begin{array}{c}\text { Design } \\
\text { Guiding } \\
\text { Principles } \\
\end{array}$ & $\begin{array}{l}\text { Involving all } \\
\text { Stakeholders }\end{array}$ & Mock-ups & $\begin{array}{l}\text { Research } \\
\text { Database }\end{array}$ & $\begin{array}{c}\text { Field } \\
\text { Research } \\
\text { Manual }\end{array}$ & Using BIM & $\begin{array}{c}\text { Organizational } \\
\text { Success } \\
\text { Metrics } \\
\end{array}$ \\
\hline \multirow[t]{4}{*}{$\begin{array}{c}\text { Past } \\
\text { Experience } \\
\text { and Best } \\
\text { Practice } \\
\end{array}$} & & $\begin{array}{l}\text { Involving all } \\
\text { Stakeholders }\end{array}$ & Publications & $\begin{array}{l}\text { Functional } \\
\text { Performance } \\
\text { Evaluation } \\
\text { (FPE) }\end{array}$ & $\begin{array}{l}\text { Architect on } \\
\text { Construction } \\
\text { Site }\end{array}$ & $\begin{array}{c}\text { Triangulation } \\
\text { of Data } \\
\text { Collection }\end{array}$ \\
\hline & & & $\begin{array}{c}\text { Design } \\
\text { Diagnostic }\end{array}$ & $\begin{array}{c}\text { Performance } \\
\text { Hypothesis }\end{array}$ & & $\begin{array}{l}\text { Non-profit } \\
\text { Unbiased } \\
\text { Research } \\
\text { Group (IDRE) }\end{array}$ \\
\hline & & & LEAN Tool & $\begin{array}{c}\text { Parametric } \\
\text { Modeling } \\
\text { Tool }\end{array}$ & & $\begin{array}{c}\text { Field Research } \\
\text { Manual }\end{array}$ \\
\hline & & & A3 Thinking & & & $\begin{array}{c}\text { Publication } \\
\text { and Research } \\
\text { Dissemination }\end{array}$ \\
\hline
\end{tabular}

\section{Selective Coding}

The third stage in the coding process was selective coding for this research.

According to Strauss and Corbin (1990), selective coding is a process of selecting the core category, systematically relating it to other primary categories and sub-categories, 
validating those relationships, and filling in categories that need further refinement and development (p. 116). Selective coding denotes the final step in analysis: the integration of concepts around a core category and the filling in of categories that need further development (Strauss \& Corbin, 1990). Since storyline memos and diagrams show depth and complexity of thought that serve as mirrors of the evolving theory as Strauss and Corbin (1998) note, I used storyline memos and diagrams for selective coding for this study.

Through the selective coding process, I systematically related core categories which correspond to two research questions to primary categories and sub-categories. More importantly, I validated these relationships and filled in categories that needed further refinement and development.

In the following section, diagrams of selective coding for interviews regarding each of research questions are presented. Following each selective coding diagram for each research question, the storyline memos were written. The contents of subtitles in storyline memos correspond to the sub-categories displayed in selective coding diagrams.

\section{Diagram of Selective Coding for Interviews Regarding Research Question \#1}

Figure 5.1 presents a selective coding diagram for the core category of research evidence interpretation and implementation in evidence-based design as well as other related primary categories and sub-categories. According to interviews and observations, credible research evidence in environment-behavior studies was implemented into the design of Grand River Hospital. The credible research evidence included privacy, wayfinding, infection control, efficiency, supervision and control, connecting with nature, decentralized nurse station, travel distance, patient and staff safety, family involvement, 
healing environment, nurse alcoves outside each patient room, and reduced medical errors. These research evidences were reflected in the design of the physical environment and were confirmed by observations. Other categories are: Design Research, Collaborations, Design Innovation, Best Possible Outcomes and Post-Occupancy Evaluation.

Figure 5.1 shows a cyclical process of evidence-based design which is aligned with the Cyclical Framework of Evidence-based Design process that is proposed by (Joseph \& Kirk Hamilton, 2008) in the Conceptual Map. However, Figure 5.1 presents a new cyclical process with the addition of collaboration activities that include visioning sessions, site visits, IPD approach, design charrettes, mock-ups as well as creating design guiding principles. More importantly, in this new cyclical process, in-house research unit plays a crucial role in research evidence identification and interpretation. Susan, as the director of research for their in-house research unit at Sackerber Architects, talked about their in-house research during her interview. She said:

The in-house research unit provides huge help to architects and designs for research evidence implementation throughout the design process. In addition, inhouse research unit not only conducts post occupancy evaluation, but also conducts research only project that includes environmental analysis, organizational success measurement through triangulated data collections. 


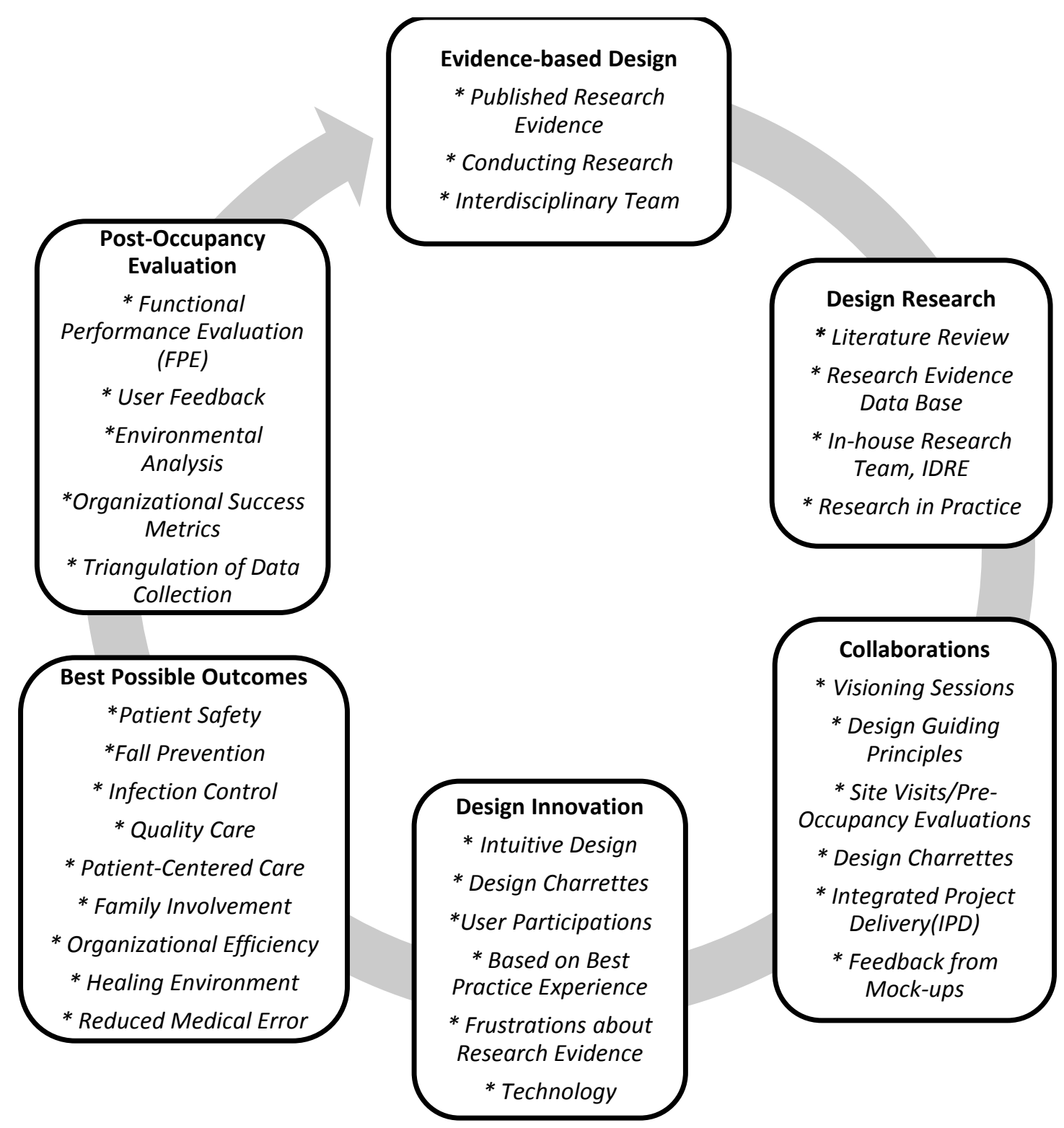

Figure 5.1: Selective Coding Diagram for Research Question \#1 Regarding Research Evidence Interpretation and Implementation in Evidence-based Design

\section{Storyline Memos for Interviews Regarding Research Question \#1}

The following are the storyline memos from interviews regarding research question \#1 - Research evidence interpretation and implementation in Evidence-based Design. The storyline memos serve as explanations for the selective coding diagram in 
Figure 5.1. The following six subtitles correspond to the six categories in selective coding diagram in Figure 5.1.

\section{Evidence-based Design}

Evidence-based design is one of the categories that emerged during the interview process and document review process. All participants spoke highly of the benefits of integrating evidence-based design in healthcare architecture. Participants also emphasized the importance of having an interdisciplinary team at the initial inception of the project. For the Grand River Hospital project, the interdisciplinary team was a group of experts from multiple disciplines both within and outside of Grand River Hospital. Many experienced consultants were hired for the project, such as a programming consultant, wayfinding consultant, and project manager as the owner's representative. Forming the project team at the beginning ensures that all the stakeholders participate in the creation of and collectively understand the project visions and goals. This interdisciplinary team organized and monitored the implementation of the Design Guiding Principles, which was created by Grand River Hospital leadership to ensure that Grand River Hospital achieved the best possible outcomes. Tina, as chief operating officer, talked about creating the design team during her interview:

We had several multi-disciplinary teams that worked together to determine the patient flow, their own workflow within their departments. My role was to make sure that we did have multi-disciplinary individuals. The teams met together on a routine basis. I led many larger steering teams that have representatives from each team and would report on their work.

Another major theme that emerged from interviews was published research evidence and conducting research for evidence-based design (EBD). The core of EBD is 
linking research and design. What differentiates EBD from typical design is its emphasis on using evidence to inform design decision-making and to conduct research to evaluate design strategies. Therefore, two major components in evidence-based design are research evidence and conducting research. All participants expressed their opinions about research evidence and conducting research in EBD. Angie, as lead designer, said:

EBD is a great tool. It has great function. EBD is a lot better now because we have more published research evidence. We used to have only a couple of studies and the findings were not really conclusive. Now we have more of published research. It really helps regarding what is true and what is not.

Don, as medical planner, talked about his opinion regarding research evidence and conducting research during his interview:

Definitely there is a lot of research evidence out there. Some of them have been contradictory. I think there should be a standardized way to collect data. We don't want to have to pick and choose and have some data to reflect your preconceived ideas. That's something that Sackerber Architects is very actively doing.

Clearly, research evidence and conducting research in EBD have been considered very important by the architects and designers. The following are more quotes regarding evidence-based design and conducting research from architects and designers from the interviews. Angie, as lead designer, said during her interview, "We always come up with a clinical trial model, a scientific model that can be tested that it can be replicated." Don, as medical planner talked about research in his interview:

The other thing that we start doing more and more, which I think is a good thing, is the computer simulation. We can observe under the nursing unit how many times a day and who is going to that room. Then we would model that with computer modeling software.

Karen, as the lead architect in Sackerber Architects and EDAC (Evidence-based Design Accreditation and Certification) holder, talked about evidence-based design during her interview: 
Obviously, we had resources to go back to help our client to make the right decision. EBD is helpful to the client to have concrete evidence that says this particular thing will improve your organizational outcomes if you invest on this aspect. So that gives them the confidence to know that they are making the right decision.

\section{Design Research}

Design research was one of the categories that emerged in the data analysis process. Design research was also a repeated common theme during the interviews. All the participants have emphasized the importance of design research in healthcare design. Karen said during her interview, "There are many examples of design innovations that never would have occurred if the designers had not been informed by research and performance thinking." Grand River Hospital is one example that has turned out to be influential. Both architect and hospital leadership emphasized that EBD had its undeniable value. Tina said during her interview, "We definitely need research evidence to support our decisions. With credible research evidence available, we would be able to tell the users, such as nurses and physicians that our decisions were made based on the research evidence." Given the nature of design activity that is creative and intuitive, architects and designers have expressed their needs and expectations regarding the research evidence. Karen provided her insight regarding research evidence in the design process. She said:

Our design probably is more based on past experience because historically it has been such a focus. But, I think you can't diminish the value of having read research articles through the years. When there were multiple ways to go, then pulling the research would help to make the decisions.

Through my conversations with the architects and designers, perhaps the most difficult aspect of the evidence-based design process for architects and designers is to identify the 
evidence and understand it, critically interpret it, and then interpret its relevance for the unique context of the project. EBD is not about rigid rules. The same evidence can help designers create quite different approaches and solutions for addressing similar issues or objectives. Susan talked about their in-house research. She said, "We have a pretty robust research database that holds lots of research articles. We have 3000 plus articles in the database. That database of articles is the genres of the documents that we refer to illustrated evidence-based design guide." Susan's primary responsibility is conducting literature reviews and building the research database as well as conducting postoccupancy evaluations and conducting research-only projects. She helps architects to identify credible research evidence during the programming phase. She also works with the architects to conduct post-occupancy evaluations and Functional Performance Evaluation (FPE), which will be discussed in detail late in this chapter. During my interview with her, Susan stated:

The importance of integrating EBD is being able to articulate the rationale and the intentionality for design. What we do and how we find that should be. When talking about design being intuitive process, which is part of making design "DESIGN." It is not saying when you are evidence-based you are no longer relying on these design skills. It is just more informed intuition.

Clearly, design research is important to both architect and healthcare provider in the decision-making process. Theories in evidence-based design have to be explanatory and descriptive so that designers can use the theories in creative and intuitive design activities. Thus, generating credible research evidence in a form of explanatory theory is a crucial component in evidence-based design.

In addition, I found another important thread during interviews, a non-profit research unit associated with Sackerber Architects. This non-profit and unbiased research 
unit is called Institute of Design Research and Evaluation (IDRE). IDRE will be discussed in detail in findings from document reviews as well as part of the findings that were triangulated from multiple sources of data. Susan talked about IDRE extensively during her interview. She said, "IDRE research team conducts and disseminates evidence-informed research that allows our design teams to create operationally efficient and effective healthcare architecture. IDRE also facilitates and supports their in-house research efforts." The architectural firm Sackerber Architects also has a very strong focus on "research in practice" that includes constantly exploring, learning, experimenting, and testing from concept through occupancy. The goal of research in practice at Sackerber Architects is to comprehensively target and achieve better outcomes through design. Susan added in her interview, "Sackerber Architects focus on meaningful metrics that can be measured, such as design metrics and performance metrics." They also strive to address wellbeing for the users and the organization and the built environment.

Sackerber Architects also become deeper divers into design research. During my interview with Susan, she said:

There are two levels of work for our research unit. First level of work is the research integration into the practice. The second level of work is to dig deeper. Our research is more than just Post Occupancy Evaluation (POE) because POE is just the evaluation. Sackerber Architect is moving towards working on research only project that can generate more research evidence and develop more theories in evidence-based design.

Susan talked more about their in-house research unit. She said, "We do understand that sometimes if we do deeper dive, we would need different set of resources. That is what our research unit stands now." Sackerber Architects' in-house research unit is set up as an independent non-profit entity. It has done robust research that has yielded many publications. Sackerber Architects is a leading architectural design firm in the nation that 
has advanced healthcare design research in many areas and they have an outstanding design portfolio for healthcare architecture. All participants advocated and emphasized the importance of research in design during their interviews. Here are more interview quotes regarding design research from the interviews. Angie said: "We have a very concrete internal research group. So we have that on our own team. Research has been very important for us." Don also added more information regarding design research in his interview: "Yes, we pretty much implemented all of this research evidence. Designing a lot of things same handedness. It reduces error rates and improves efficiency." Julie as a designer also talked about design research extensively during her interview. She said:

Certainly, we advocate for Evidence-based Design. The challenge for it is to guide the medical staff in the process and get the users away from their experience and their intuitive feeling about how things should be. Definitely, it needs knowledge.

\section{Collaborations}

Another common theme that emerged during the coding process was collaborations with all stakeholders. Collaborations for Grand River Hospital design happened in many different ways compared to the traditional design process. The collaborations included visioning sessions, creating design-guiding principles, site visit/pre-occupancy evaluations, design charrettes, Integrated Project Delivery (IPD) approach, and building mock-ups and getting feedback from users for mock-ups as well as Post-Occupancy Evaluation feedback session.

The visioning session was an important collaboration effort in the design process. Many strategic and leadership people from Grand River Hospital participated in the visioning session where they developed key goals for the design. Then it was the 
architect's assignment to interpret what that meant from a design standpoint. According to my interview with Karen, the lead architect on the project, she said, "Most of these goals were not contradictory, but there were some conflicting priorities that the architect couldn't accomplish one without being detrimental to the others." Don talked about design goals in his interview:

There were some very good planning goals that were set up during the visioning session. For example, every patient room has a ceiling lift. The bariatric room was set up on every floor. The nurse alcove between every two rooms makes nurses closer to the patients and provides better visibility and supervision.

Creating Design Guiding Principle was another effort of collaboration. The leadership of Grand River Hospital worked with a programming consultant as well as the architects to create design-guiding principles, which was the main focus of the design intent. Key elements in the design guiding principles included the following: patient and staff safety, noise reduction in the working environment, eliminating distractions, reducing travel distances, and fall prevention; infection control; room standardization; and access to technology and efficiency process as well as creating a healing environment. Chief nursing officer Emily talked about creating Design Guiding Principles during her interview:

We really had a true partnership among our senior leadership to develop the plan for the hospital. The steering committee started out with design guiding principles and tried to maintain the project throughout the course of projects as their true north. The steering committee at Grand River Hospital had a lot of transparency across the groups when they worked on creating design-guiding principles. That was one of the important aspects that made this project so successful.

Site visits were also important in the design process. Grand River Hospital values the experience from the best practice. The design teams, including the client, architect, and designers, visited many existing hospitals across the country. They got to know what 
worked and what didn't work from existing hospital designs and received feedback from users of existing hospitals. Site visits/pre-occupancy evaluation really provided lots of evidence regarding the key elements defined in the design guiding principles. Tim, who is the project manager from LGJ Global, said to me during his interview:

Site visits really helped the design team to get things right at one shot. Hospital leadership and design team spent a lot of time travelling to other facilities to see what worked and what didn't work. Through site visits they worked with design teams to really set the design parameters for safety, the configuration of the patient room, location of nurse stations and many other design aspects. The site visit certainly helped team to know what others were doing and it allowed the team to make evaluations of certain models for critical and aesthetical aspects, and therefore, to make the correct decisions. Seeing picture even video doesn't give the justices of the site visits. The site visits also helped them to evaluate the mock-ups later in the design process.

Design charrette was another common theme that appeared in both document reviews and interviews. There were several design charrettes/workshops during the design process. All stakeholders including leadership of Grand River Hospital, architects, designers, consultants, the project manager, the contractor, and the Grand River Hospital facility planning personnel were involved in multiple design charrettes. Karen said during her interview, "Grand River Hospital as the client was very supportive for having the design charrettes and they really did as much as they could to make the design charrette a very fluid and beneficial process." Karen talked about design charrette in detail:

During the design charrette, all decision makers were in the same room and went through the process of locating each key element. One of the design charrettes was extremely beneficial and getting the design back on track and really focusing on what were the key priorities and what took the secondary priorities. The design charrette was documented in forms of photography because they have done model pieces.

Grand River Hospital design took an Integrated Project Delivery (IPD) approach even though it was not a truly contractual IPD. The contractor was on board from the 
beginning and they were part of many discussions. The benefit of having an IPD-like approach was that the decisions would be shared with all team members. It avoided the possibility that part of the design was unaffordable or didn't meet the budgetary requirements. David, as the contractor, said during his interview:

We helped the decision making to make sure that the design was going the direction that was the most economical and made the most sense. We were involved in a lot of key discussions and informed the client from the other aspects rather than design.

The contractor also helped the client to make the right choice and right decision for structure and construction. All the participants said during their interviews, "Grand River Hospital was highly successful. It was really a true collaborative team even though contractually it was not IPD.”

Mock-up was another common theme that emerged from both document reviews and interviews. All participants talked about mock-ups during their interviews because building mock-ups has been an important component in the design process. The contractor built about eight to ten mock-up rooms including patient room, operating room, Intensive Care Unit, nurse stations, medication room, exam room, and emergency department. Pam, as nursing staff, said during her interview:

After mock-up rooms were built, end users were invited to look at it and run simulations in the mock-up rooms and provided feedback. The end users included nurses; physicians; patients and community people. The mock-up rooms were open to everyone all the time. Users could go to the mock-up rooms and look at it and leave comments in writing.

The mock-up rooms were built based on the plan provided by the architect. The Grand River Hospital facility planning office installed all the equipment. Linda said during her interview, "Some of the spaces were pretty close right off its initial built and some of 
them were re-built at least three times before the client felt it would function as they

required."

Furthermore, the mock-up rooms were all built on-site during the design process.

Angie talked about mock-ups during her interview:

Some of the design charrette meetings happened in the mock-up rooms. It was part of IPD approach as well. Mock-up was a very valuable tool used in Grand River Hospital design process. Architects, designers and user groups were able to test all these mock-up rooms. The contractor started with the cardboard and foam core boards to build the mock-up rooms. But it turned out to be a quality mock-up at end. The mock-ups were built with all the finishes and equipment.

More importantly, quality control was done for mock-up rooms for Grand River Hospital.

Eric, as a design consultant, said:

When mock-ups were built, the team did the quality control and brought in building inspectors at different stages of building mock-up rooms. So that when doing construction in the field, the team knew exactly what needed to be done for the construction to ensure having good quality control for the project.

The following are two more quotes from interviews that illustrate the collaborations during the design process for Grand River Hospital. Angie spoke in detail regarding the design charrette. She said:

We had meetings from 8 a.m. to 5 p.m. every day with the users. Each design team had a lead planner and a support person. All the engineers and consultants also attended meetings. We were all meeting in a large room at five different planning tables.

She also added more information regarding design charrettes/workshops:

We had three schematic design meetings with the users from all departments; we had users from leadership level and front line staff. We also had three meetings for design development. Once we were in design development, we started meetings in the actual mock-up spaces. It helped the medical staff to visualize the space. It was a great approach.

\section{Design Innovation}


Regarding how research evidence was interpreted and implemented in the design of Grand River Hospital, several common themes were discussed by the participants during their interviews. These common themes included intuitive design, design charrettes, user participations, best practice experience, and frustrations about research evidence as well as technology. These were the sub-categories that have been identified during axial coding process. During selective coding, according to Strauss and Corbin (1990), the researcher can begin systematically to group categories. The categories are grouped along the dimensional ranges of their properties in accordance with discovered patterns. This grouping, again, is done by asking questions and making comparisons (Strauss \& Corbin, 1990, p. 135). Therefore, these sub-categories are grouped for category of design innovation, which is identified by comparing the data.

Architects and designers talked about their opinions about implementing research evidence in the design process during their interviews. They believed that the design was more intuitive even though they learned research evidence along the way. Karen said, "The design probably is more based on past experience and best-practice. However, having research evidence available is really helpful to back up our design decisions." According to interviews, everyone agreed that evidence-based design was hugely helpful to the design industry and helped the client to make their right decisions. Karen talked about her opinions about EBD: "In fact, architects and designers still have to rely a lot on intuition because not everything is measurable, not every project has the ability to measure outcomes based on how it used to be and how it is now." Karen also said:

There were occasions that you really could not directly compare things. It gets a little frustrating sometimes when you read some research, but there is no conclusive outcome. I understand it obviously. But just wished that maybe the 
research (standards) could be loosening a little bit and draw conclusion a little more easily after measure the outcomes.

Participants with occupations as architects and designers suggested that

implementing evidence-based design needed to start early, the earlier the better. Karen

said:

Having a research director on staff is hugely beneficial. When it is the time to start a particular project, architect would tell the research director about the project goals and ask the research director to find some research that has been done in articles and what is the current research and current practice. The research director would go through all the research and provide architect exactly things that are most meaningful to the project goals and needs.

Susan reiterated how research evidence was interpreted and implemented in design during her interview. She said:

The in-house design team is an important component for implementing Evidencebased Design. Sackerber Architects has a very robust research team that collaborates with a non-profit organization Institute of Design Research and Evaluation (IDRE). IDRE conducts post-occupancy evaluation, develops field research tools and conducts research only project. Within IDRE unit, researchers do deeper dive studies and become better able to share the research information with healthcare industry.

As indicated earlier, there are two levels of research within this non-profit research unit. The first level is the research integration into the practice that happens at Sackerber Architects in many ways. The second level is to dig deeper, which is more than just Post Occupancy Evaluation. The deeper dive research can develop and generate theories for environment-behavior studies in healthcare environment. In Sackerber Architects, they conduct Functional Performance Evaluation (FPE) which is using metrics to evaluate functional performance. FPE employs different evaluation tools developed by IDRE research staff. FPE will be discussed in detail in an individual section later in this chapter. Susan said, "FPE has made Sackerber Architects so successful because having IDRE as a 
research unit make Sackerber Architects distinguished form other competitors." IDRE is set up as an independent non-profit entity that conducts research and disseminates research findings.

As discussed earlier, design charrette was important in the Grand River Hospital design process. It was really a collaboration effort that brought all stakeholders into one room; even the contractor was brought on board early on. User participation was another important design strategy. Nurses and physicians participated in the design process for patient room, operating room, emergency room, and nurses' stations. They also provided feedback after the mock-ups were built.

Technology was another common theme that emerged in document reviews and interviews. In the Design Guiding Principles, one of the guiding principles is to design a state-of-the-art facility that promotes patient and staff safety and provide quality care for the patients in the healing environment. In Grand River Hospital, ceiling lifts were installed in patient rooms, which have significantly reduced the staff injury rate. Grand River Hospital gave each nurse a cell phone instead of using a paging system. The new communication system was used in the entire hospital, which has made the environment quieter. Emily said during her interview, "We have achieved healing environment by using the technology. It is quiet and much quieter than lots of hospitals you would go." Other technologies included a nurse location tracking system, a medication supply tracking system, and separate TVs for patient and family members in the patient rooms. Tina talked about technology during her interview:

For the nurse tracking system, radio frequency identification devices were carried by staff members. It is very easy to know who is in the room and be able to locate what room the nurses are in just in case they are needed. Another unique feature 
of using technology is using robots for delivery. The robots mainly are used to bring lining cards up and trash that helps to prevent staff injuries.

In addition, many participants with occupations as architects/designers and

contractors talked about Building Information Modeling (BIM) and indicated the benefits

of using BIM during their interviews. Don talked about using BIM during his interview.

He said:

BIM was used in the entire design process for Grand River Hospital. It was the first project that was drawn and documented in BIM at Sackerber Architects. Everything was completed in a full three-dimensional model so that it actually saved a lot of time and a lot of effort especially in construction documents. It also provides a very quick tour for designers and users because everything has been generated in three dimensions.

Don added more information regarding BIM:

The architects and designers could take a camera shots from the model to show clients at the user group meetings. Even during the schematic design, designers could show users how the design looked like at different areas, such as nurse station and the lobby entrance. Incorporating these images early on was very valuable because it helped the client understand and visualize the space.

BIM was also used during construction for clash detection. David, as contractor, said during his interview, "With the BIM technology, it helped to coordinate multi-systems, such as mechanical system, electrical system and fire protection system early on before they were built." BIM definitely provided significant benefit and it significantly increased productivity and reduced errors in design and construction for Grand River Hospital.

\section{Best Possible Outcomes}

The goal of the Grand River Hospital design was to design a state-of-the-art facility that promotes patient safety, fall prevention, infection control, reduced error, quality care, patient-centered care, family involvement, and efficiency. These are defined 
as the best possible outcomes in evidence-based design. These design goals, or best possible outcomes, were articulated in the "Design Guiding Principles," which served as the big focuses of the design aspects for Grand River Hospital. Through document reviews and interviews, physical features that were designed by implementing research evidence to achieve the best possible outcomes were identified. In addition, observations at Grand River Hospital confirmed that a lot of physical features were designed based on research evidence. For example, decentralized nurse stations with nurse alcoves and coupled with supply storage spaces reduces medical staff's walking distance and increased efficiency. Figure 5.2 is a typical nursing unit floor plan in the tower of Grand River Hospital. The orange color presents decentralized nurse stations and nurse alcoves. There are three decentralized nurse stations on each floor. The nurse alcoves are located

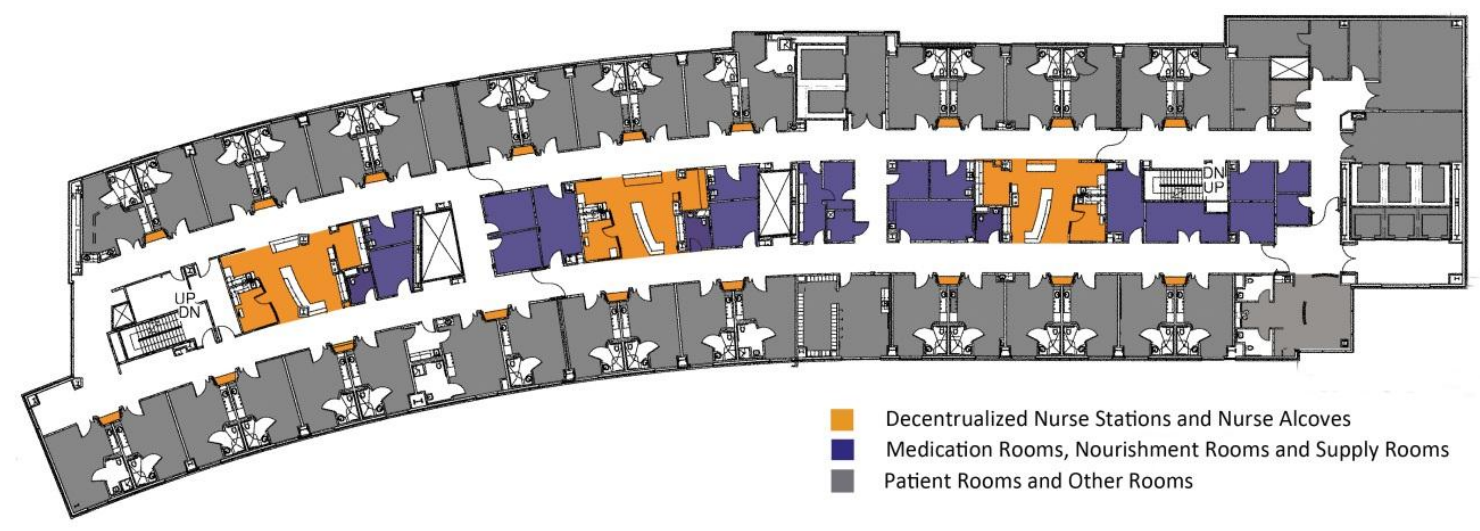

Figure 5.2: Typical Floor Plan of Nursing Unit in the Tower

between two patient rooms so that nurses can supervise patients through the windows. The blue color shows medication rooms, nourishment rooms, and supply rooms. These rooms were provided to each decentralized nurse station. Therefore, nurses' walking distances were reduced. Other examples are designing all private patient rooms and 
providing hand-washing sinks in each patient room to promote infection control; family zone in each private patient room enables family members to be involved in patient care effectively; ceiling lift in each patient room reduces injury rate and promotes patient and staff safety.

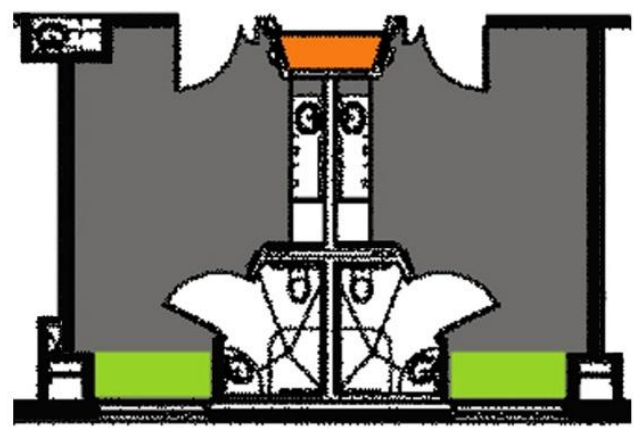

Nurse Alcove Between Two Patient Rooms Family Zone in Patient Room

Figure 5.3 is a typical patient room floor plan. The orange color represents a nurse alcove between two patient rooms. The green color represents a family zone that typically is a convertible sofa to bed for a family member's overnight stay. A hand-washing sink is located

Figure 5.3: Typical Patient Room Layout with a Nurse Alcove, a Family Zone and a Hand-washing Sink evidence implemented in the design of the

physical environment during her interview. She said:

One of the design features that is based on research evidence is nurse alcoves outside each patient room. The nurse assigned to these patients is right there in their rooms verses at the end of the hallway where the nurse can't see the patients. The nurse alcoves provide good visibility and supervision over patients. However, it should be with caution when locate the patient bed in patient room because it is critical for the nurse to see the patient from outside nurse alcove's window and yet to maintain the privacy for patient.

The visibility from nurse alcoves was tested in mock-up patient rooms to ensure that the best outcomes would be achieved.

During my interview with Tina, she also emphasized medication room design, which is one of the safety perspectives in design. She said:

The medication room was designed that was not in the interruptions of the nurse of assembling the medications. Typically, in hospital you find a nurse preparing medications right in the middle of the hallway while multiple people can talk and interrupt. Research has shown that interruptions create medical errors. Therefore, 
having a private medication room where nurses cannot be interrupted is evidencebased and it is based on the safety.

Figure 5.4 presents a typical

decentralized nurse station layout. The blue

area is the medication room. The medication

room is enclosed by the glass so people can

see who is in that medication room.

Additionally, the strategy of reducing

error rates was to design all same-handed

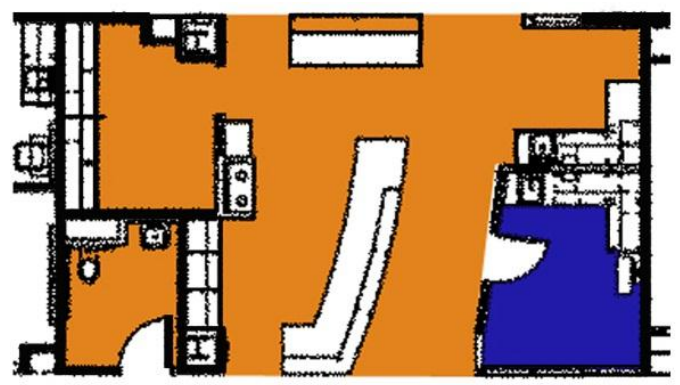

Decentrualized Nurse Station Area

Medication Room

Figure 5.4: Typical Decentralized Nurse Station and Medication Room

rooms, such as all Emergency Department exam rooms, the trauma rooms, and surgery

rooms. Don talked about same-handed rooms more specifically during his interview. He

said:

All surgery rooms were set up the exactly same way, the door, hand washing sink, exam tables, medical gas, gloves and hand sanitizers were all at the same places. The circulation, equipment, supplies and functionalities in the room were exactly same. The standardization of the room can make the procedure more efficient rather than setting up different procedures in different surgery rooms. Research evidence shows that same-handed layout does reduce error rate so that patient safety can be ensured as the best possible outcome.

Don also added more information regarding patient safety and quality care during his interview: "We tried to standardize rooms as much as possible. Not just surgery rooms, but supply rooms, medication rooms, nourishment rooms. The more standardized the room is, the less they are going to grab a wrong thing in patient care." Therefore, the design team strived to standardize design elements. Don also talked about other design features that can help to achieve the best outcomes during his interview. He said:

At the environmental level, the design team tried to less the noise and less the fatigue for caregivers. There is an in-room charting and documentation area in 
every single patient room. It encourages the nursing staff being in the room and communicating with the patients while they are doing the documentation.

Another design goal is to reduce nurses' walking distances. Angie talked about

how the design features can help reducing walking distance in her interview. She said:

Decentralized nurse stations with nurse alcoves outside each patient room and coupled with decentralized supplies storage rooms were designed to reduce walking distances and increase efficiency in Grand River Hospital. Published research evidence has confirmed the linkage between these physical elements and the best outcomes. These physical elements were designed in response to research evidence.

\section{Post-Occupancy Evaluation}

A full Post-Occupancy Evaluation was not carried out for Grand River Hospital.

But, a post-occupancy feedback session as lessons learned and users' survey were conducted. During the interviews, I learned that the post-occupancy feedback session involved all the stakeholders including the architect, programming consultant, hospital end users, and leadership. During the feedback session, the design teams talked about what the design intents were, how they were implemented, and what the final environment looked like. Susan talked about the feedback session extensively during her interview. She said:

Staff feedback, satisfaction and dis-satisfaction were collected in the survey. Grand River Hospital's performance indicators such as employee injury rate went down significantly because we installed ceiling lift in patient rooms. For the questionnaire, pretty much everything was on the positive side. The scores for comfortable and uplifting and supporting of the diverse needs of patients and families are really high. Scores for safety and quality experience; cutting edge technology; LEAN workspace and workflow are very high. Scores for other measures, such as responsive to care delivery process (process architecture); embrace the community and environment (green); physician effectiveness and satisfaction are on high side as well. 
All this information regarding the post-occupancy evaluation session from interviews was also confirmed by document reviews.

The following table (Table 5.3) shows the summary of the post-occupancy

feedback session. Susan told me about it during her interview:

The survey (small sample) was sent out by the architect one week prior to the feedback session. The results were the combination of data from Grand River Hospital's internal metrics survey data, Hospital Consumer Assessment of Healthcare Providers and Services (HCAHPS) survey data and the survey conducted by the research team in Sackerber architects. Architect's survey was designed based on the Design Guiding Principles.

Table 5.3 presents improved outcomes, priorities and successes corresponding to physical features/solutions and implementations as well as environment-behavior attributes and research evidence. It also outlines future research opportunities. The participants at the post occupancy feedback session included architects and designers, Grand River Hospital leadership, nurses, and physicians. The feedback session was facilitated by the architect.

Table 5.3: Summary of Post-Occupancy Feedback Session for Grand River Hospital Post Occupancy Feedback Session (Data from Grand River Hospital and Survey Conducted by the Architect)

\begin{tabular}{|c|c|c|c|}
\hline $\begin{array}{l}\text { Environment-Behavior } \\
\text { Attributes/Credible } \\
\text { Research Evidence }\end{array}$ & $\begin{array}{l}\text { Physical } \\
\text { Features/Solutions and } \\
\text { Implementations }\end{array}$ & $\begin{array}{l}\text { Improved } \\
\text { Outcomes, } \\
\text { Priorities and } \\
\text { Successes }\end{array}$ & $\begin{array}{l}\text { Future Research } \\
\text { Opportunities }\end{array}$ \\
\hline $\begin{array}{l}\text { Research on hospital } \\
\text { employee safety }\end{array}$ & Patient room ceiling lift & $\begin{array}{l}\text { Reduction in } \\
\text { employee injuries }\end{array}$ & \multirow{4}{*}{$\begin{array}{l}\text { 1. Patient and } \\
\text { Family Experience: } \\
\text { How integration of } \\
\text { technology has } \\
\text { impacted } \\
\text { patient/family } \\
\text { experience and } \\
\text { reported satisfaction } \\
\text { (HCAHPS). Conduct } \\
\text { field research. }\end{array}$} \\
\hline $\begin{array}{l}\text { Research on reducing } \\
\text { medical errors in hospital } \\
\text { settings }\end{array}$ & $\begin{array}{l}\text { Dedicated private } \\
\text { medication rooms; } \\
\text { appropriate lighting } \\
\text { levels }\end{array}$ & $\begin{array}{l}\text { Overall reduced } \\
\text { errors }\end{array}$ & \\
\hline $\begin{array}{l}\text { Research on patient fall } \\
\text { prevention }\end{array}$ & $\begin{array}{l}\text { Patient bed-escape alert, } \\
\text { slippery resistant floor } \\
\text { materials; nurse alcoves } \\
\text { outside patient room }\end{array}$ & Reduced fall rates & \\
\hline $\begin{array}{l}\text { Research on impact of } \\
\text { physical environment on }\end{array}$ & $\begin{array}{l}\text { Private patient rooms; } \\
\text { family zones; }\end{array}$ & Patient experience & \\
\hline
\end{tabular}




\begin{tabular}{|c|c|c|c|}
\hline $\begin{array}{l}\text { patient experience; privacy; } \\
\text { territoriality; personal } \\
\text { space; restoration; } \\
\text { efficiency; control; } \\
\text { wayfinding }\end{array}$ & $\begin{array}{l}\text { decentralized nurse } \\
\text { stations and nurse } \\
\text { alcoves; indoor garden; } \\
\text { water feature; daylight }\end{array}$ & & \\
\hline $\begin{array}{l}\text { Research on patient safety; } \\
\text { fall prevention; medical } \\
\text { errors }\end{array}$ & $\begin{array}{l}\text { Dedicated private } \\
\text { medication rooms; nurse } \\
\text { alcoves outside the } \\
\text { patient room; } \\
\text { appropriate lighting } \\
\text { levels }\end{array}$ & Patient safety & \multirow{4}{*}{$\begin{array}{l}\text { 2. Safety: How has } \\
\text { the design/ } \\
\text { integration of } \\
\text { technology, new } \\
\text { processes and } \\
\text { policies affected } \\
\text { handwashing } \\
\text { compliance, } \\
\text { infection rates, fall } \\
\text { rates, medication } \\
\text { error rates, and staff } \\
\text { injury rates? } \\
\text { Conduct field } \\
\text { research. }\end{array}$} \\
\hline $\begin{array}{l}\text { Research on staff safety; } \\
\text { employee back injury }\end{array}$ & $\begin{array}{l}\text { Ceiling lift in patient } \\
\text { room }\end{array}$ & Staff safety & \\
\hline $\begin{array}{l}\text { Research on family } \\
\text { involvement in patient care }\end{array}$ & $\begin{array}{l}\text { Family zone in patient } \\
\text { room; meeting room for } \\
\text { family members and } \\
\text { physicians; separate TVs } \\
\text { for family members and } \\
\text { patient in patient room }\end{array}$ & Family experience & \\
\hline $\begin{array}{l}\text { Research on travel } \\
\text { distance, wayfinding; } \\
\text { decentralized nurse } \\
\text { stations }\end{array}$ & $\begin{array}{l}\text { Decentralized nurse } \\
\text { stations; nurse alcoves } \\
\text { outside patient room; } \\
\text { decentralized supply } \\
\text { rooms }\end{array}$ & Efficiency & \\
\hline $\begin{array}{l}\text { Research on impact of } \\
\text { physical environment on } \\
\text { efficiency and employee } \\
\text { satisfaction }\end{array}$ & $\begin{array}{l}\text { Decentralized nurse } \\
\text { stations; nurse alcoves } \\
\text { outside patient room; } \\
\text { decentralized supply } \\
\text { rooms; sitting area by } \\
\text { the indoor garden; } \\
\text { ceiling lift; meeting room } \\
\text { for family members and } \\
\text { physicians }\end{array}$ & $\begin{array}{l}\text { Physician and staff } \\
\text { experience }\end{array}$ & \multirow{4}{*}{$\begin{array}{l}\text { 3. Efficiency: How } \\
\text { has integration of } \\
\text { technology impacted } \\
\text { all response times; } \\
\text { How has } \\
\text { decentralization of } \\
\text { supplies impacted } \\
\text { time on task and } \\
\text { walking distances? } \\
\text { How has curved } \\
\text { layout impacted } \\
\text { visibility and patient } \\
\text { monitoring }\end{array}$} \\
\hline $\begin{array}{l}\text { Research on restoration; } \\
\text { healing garden; healing art } \\
\text { in healthcare setting }\end{array}$ & $\begin{array}{l}\text { Indoor garden; water } \\
\text { feature; daylight; slightly } \\
\text { curved corridor in } \\
\text { nursing units; soothing } \\
\text { color; art work } \\
\text { throughout the facility }\end{array}$ & Aesthetics & \\
\hline $\begin{array}{l}\text { Research on impact of } \\
\text { technology in healthcare } \\
\text { setting }\end{array}$ & $\begin{array}{l}\text { Ceiling lift; bed-escape } \\
\text { system; nurse tracking } \\
\text { system; medication } \\
\text { supply tracking system }\end{array}$ & $\begin{array}{l}\text { Cutting-edge } \\
\text { technology }\end{array}$ & \\
\hline $\begin{array}{l}\text { Research on efficiency; } \\
\text { workspace adjacency and }\end{array}$ & $\begin{array}{l}\text { Proximity of Cath lab } \\
\text { and other service to }\end{array}$ & $\begin{array}{l}\text { LEAN workspace } \\
\text { and workflow }\end{array}$ & \\
\hline
\end{tabular}




\begin{tabular}{ll}
\hline LEAN design & surgery; proximity of \\
& Imaging to Emergency \\
& Department; proximity \\
& of surgery to ER and \\
& main entrance
\end{tabular}

During the feedback session, the design process and design goals were evaluated by the key stakeholders. Both Susan and Karen emphasized the importance of the feedback session during their interview: "Although it was not a full POE, it served as lessons learned. We can improve our design in the future. We also can conduct future research based on the information from feedback session." Obviously, the postoccupancy feedback session as lessons learned closes the loop of evidence-based design since the EBD process is cyclical. This finding confirms that the EBD process is a cyclical process as described in the conceptual framework and EBD was implemented in the design process for Grand River Hospital project.

\section{Diagram of Selective Coding for Interviews Regarding Research Question \#2}

Figure 5.5 presents a selective coding diagram for the core category of programming process, design process, and decision-making process, which corresponds to research question \#2. There are seven primary categories under this core category. They are visioning sessions, programming process, schematic design, research evidence interpretation and implementation, decision-making process, contractors' roles in design process, and post-occupancy evaluation and publication. In each of these primary categories, there are different sub-categories.

According to interviews, Grand River Hospital was designed through a traditional design process with the modifications. The design process has been modified by adding 
additional phases and utilizing new strategies. For the first primary category visioning sessions, the sub-categories include collaboration with architects to create design guiding principles, site visits, best practice, and past experience as well as a collaborative approach. The second primary category is programming process. The sub-categories include a collaborative approach, working with user group, working with programming consultants and architects, following design guiding principles, and involving all stakeholders. The third primary category is schematic design process, which includes sub-categories of literature review, research evidence database, site visits and preoccupancy evaluation, design charrettes, mock-ups, and involving all stakeholders. The fourth primary category is research evidence interpretation and implementation that includes the following sub-categories: intuitive design, mock-ups, based on the best practice and past experience, frustration about research evidence, in-house research team, and research database. The fifth primary category is the decision-making process that includes sub-categories of site visits, mock-ups, technology, feedback from all users, LEAN tool, and collaborative sessions. The sixth primary category is contractors' roles in the design process, which includes the following sub-categories: contractors onboard at the beginning, contractors participating in design charrettes, building mock-ups, manage project schedule and cost, and using BIM technology. The seventh primary category is post-occupancy evaluation and publication that includes sub-categories of Functional Performance Evaluation (FPE) site audits, user feedback, environmental analysis, organizational success metrics, triangulation of data collection, non-profit unbiased research group, and publication. 


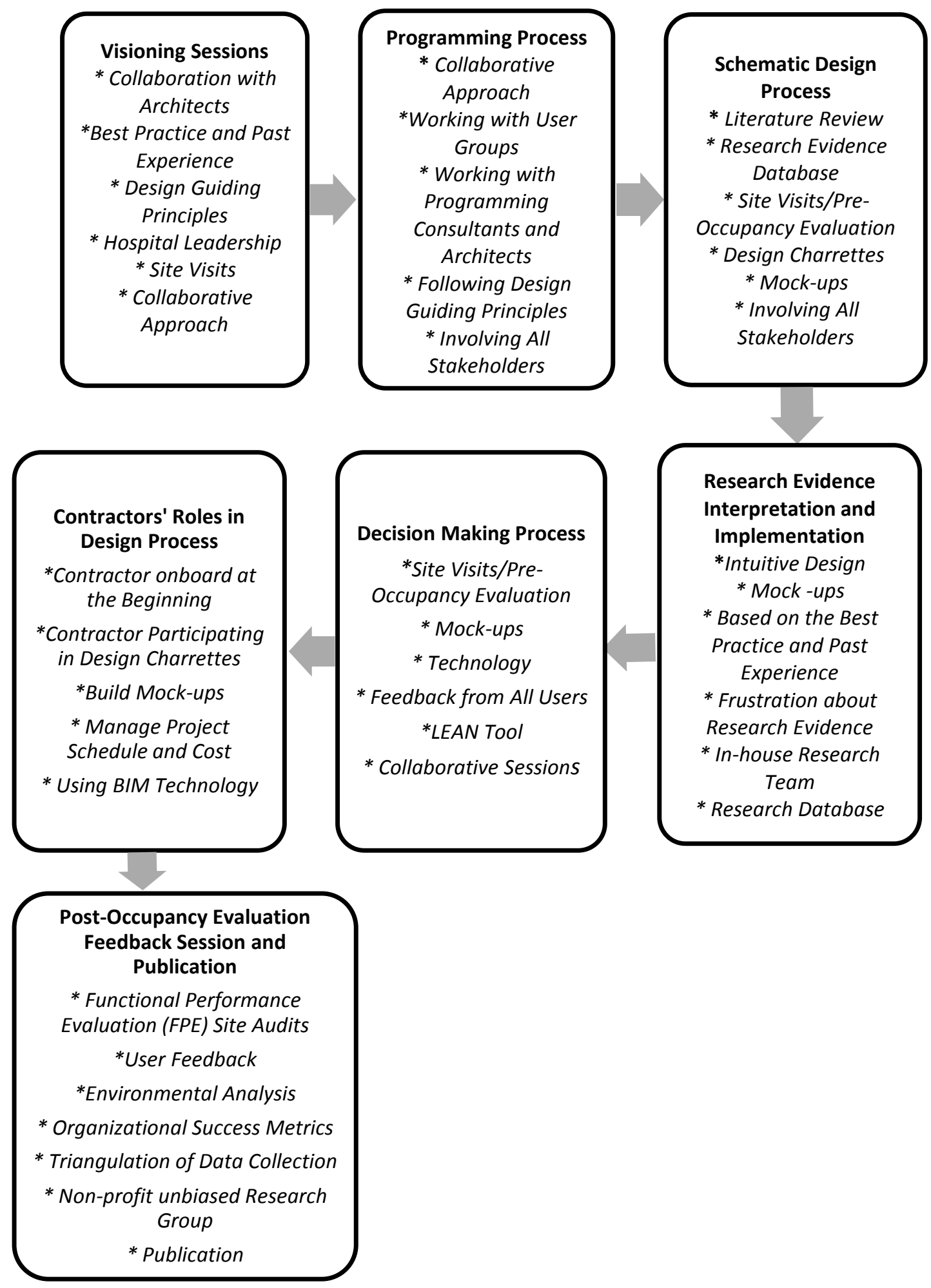

Figure 5.5: Selective Coding Diagram for Research Question \#2 Regarding Programming Process, Design Process and Decision-Making Process in Evidence-based Design 


\section{Storyline Memos for Interviews Regarding Research Question \#2}

The following are the storyline memos for the core categories regarding research question \#2 - programing process, design process, and decision-making process.

The storyline memos serve as explanations for the selective coding diagram for research question \#2 regarding programming process, design process, and decision-making process in Figure 5.5.

\section{Visioning Sessions and Design Guiding Principles}

The very first session in the design process for Grand River Hospital was the visioning session. The goal of the visioning session was to generate a set of design guiding principles that could be the true north for the design team. The visioning session took a collaborative approach that involved both hospital leadership and the architect. Tina talked about how the design guiding principles were created during her interview. She said:

There were different teams of individuals who worked on creating the design guiding principles. Senior leadership team really developed those design guiding principles. But, we did a lot of brainstorming with the architect and the contractor on what would be the principles.

Tina also said:

Some of them were with the experience within the healthcare organization we were trying to build. So, the design guiding principles were created based on the best practice and past experience. But equally what our co-workers would say to us was also important.

Since "Visioning is a planning process through which a community creates a shared vision for its future and begins to make it a reality" (American Planning Association, 2006), Grand River Hospital's design guiding principles were created with shared 
visions. Tina confirmed this during her interview. She said, "A lot of input was from coworkers and patients and families." As the outcomes of the visioning session, priority areas, and organizational objects were identified, there were different teams of individuals who were involved in creating design guiding principles. Senior leadership at Grand River Hospital developed those design guiding principles based on a lot of brainstorming with the architect and the contractor. The architect facilitated the meetings during the visioning sessions. The design guiding principles were also created based on experience within the healthcare organization and the visions of senior leadership. Emily said during her interview:

A lot of input was gathered from co-workers, patients, and families, also. The design team routinely would pull out design guiding principles as they had discussions and reminded everyone what they were going to achieve. The design guiding principles really worked well as a guide rail to keep the team on track.

Grand River Hospital is very committed and focused on patient and employee safety and visitor safety. The design team discussed safety-related things extensively. Angie gave an example of achieving safety outcome during her interview:

For example, the architect informed Grand River Hospital that most healthcare organizations started out with patient lift in every patient room. As the result, Grand River Hospital was one of the few organizations who started using patient lift. In fact, it is the main thing that Grand River Hospital is committed doing based on their goal of promoting safety for both patient and staff.

In their design guiding principles, obviously the safety and efficiency aspects are the main focus. Tina emphasized safety in her interview:

The design really focuses on safe medication delivery, controlling noise to make the work environment as stress free as possible; eliminating distractions, reducing travel distances, putting things in the right place for efficient process as well as providing proper lighting. All these aspects were intentional.

Don indicated another effort for the safety aspect in his interview: 
Another effort was to make sure the working environment for staff supported the right activities and right process. Therefore, special attention was paid to work flow and lean work process in working environment. From efficiency stand point, every design of patient room, corridors, materials selections were focused on achieving that goal.

According to interviews with the participants and document reviews, it is evident that creating a healing environment is the goal for Grand River Hospital. The hospital leadership wants to have a healing environment where patients and family feel less stress and are more comfortable so that the healing can take place. Using a highly integrated approach, even though it was not a formal Integrated Project Delivery (IPD) contract, the collaborations among all team members made this project successful. The team includes leadership at Grand River Hospital; LDJ Global Project and Development Services team, which served as project manager; Sackerber Architects Inc.; various consultants including a programming consultant, wayfinding design consultant, ecological engineering consultant, mechanical, electrical and plumbing consultants, and general contractors Zbranden Construction and McLaughlin Construction. Zbranden Construction is a local construction company.

Design guiding principles were created in collaboration with the architects, contractors, hospital staff, patients, and families. Tina told me that it became more and more inclusive as the process went on. Table 5.4 presents a set of 10 design guiding principles. The first one is patient safety and quality. Grand River Hospital wanted to provide state-of-the-art technology; they wanted to provide a healing environment for patients and their families; they also wanted to have a building that could be expanded in the future. Emily said:

We started out with design guiding principles that maintained the project throughout the course of project as their true north. The team had a lot of 
transparency across the group. The steering committee had a lot of accountability and committee members took responsibilities very seriously.

The design guiding principles were also used for the post-occupancy feedback session when the team evaluated the design goals for the best possible outcomes.

Table 5.4: Design Guiding Principles for Grand River Hospital

\section{Design Guiding Principles}

\begin{tabular}{ll}
\hline $\begin{array}{l}\text { 1. Safety and quality throughout planning and } \\
\text { design work }\end{array}$ & $\begin{array}{l}\text { 6. Lean workspace and workflow; support for } \\
\text { teamwork and communication }\end{array}$ \\
\hline 2. Service excellence & $\begin{array}{l}\text { 7. Cutting-edge technology to improve patient } \\
\text { care, throughput and staff efficiency }\end{array}$ \\
\hline 3. Physician effectiveness and satisfaction & 8. Growth, adaptability and flexibility \\
\hline $\begin{array}{l}\text { 4. Affordable for our community by creating } \\
\text { greater cost efficiency as volume grows }\end{array}$ & $\begin{array}{l}\text { 9. Comfortable, uplifting and supporting of the } \\
\text { diverse needs of our patient and families; support } \\
\text { the Trusted Care brand }\end{array}$ \\
\hline $\begin{array}{l}\text { 5. Responsive to care delivery processes (process } \\
\text { architecture) }\end{array}$ & $\begin{array}{l}\text { 10. Demonstrate stewardship in our design; } \\
\text { embrace the community and the environment } \\
\text { (green) }\end{array}$ \\
\hline
\end{tabular}

Since the design guiding principles stated that the project should achieve the best possible outcomes for safety and quality, some things were extremely prevalent. Emily talked about safety and efficiency in her interview:

One was how to reduce medication errors or medical errors in general. Everything we do need to help prevent errors. Another one was efficiency. What is the best flow for the nurse that would prevent from fatigue and reduce walking distance? Noise is another important issue that was addressed by innovative design. When visitors walk in the hospital, every room is full. But you do not hear any noise in the facility. The design team used different type of materials as well as design elements and strategies to reduce the noise.

Another aspect was really understanding the needs of patient populations. That is why the bariatric room was very important in the design of Grand River Hospital. Tina talked about bariatric room design during her interview. She said, "On each floor, we would 
have a bariatric room to accommodate patient's special needs." The design of Grand River Hospital not only strives to respect different patient populations but also patients' behavioral health. The design has to accommodate various patient populations and make sure to respect their differences.

All participants spoke highly about the benefits of having design guiding principles throughout the process. The design guiding principles was a living document that the design team always looked back upon for the key principles. Karen said, "The design guiding principles were useful because the design team always referenced them as they made key decisions." The design guiding principles ensured that every decision brought the design solutions closer and closer to meeting design goals. Karen added in her interview: "If there were not any living document, if there were not something every team member was aware of and relied on, the design team would not have a clear direction." The design guiding principles were the design teams' common goal and common language. Clearly, the benefit of having design guiding principles is huge. The following are a few quotes from participants who spoke highly about the design guiding principles. Karen said: "I think the client (Grand River Hospital) rely heavily on that (design guiding principles) to help guide their decisions so that was not only based on budget or schedule but also based on some of these key drivers." Emily also added more regarding the design guiding principles. She said:

I was primarily involved in the steering team at that time. We really have a true partnership to help to develop the plan for the building. We had an excellent team that everybody liked about it. We started out with design guiding principles and tried to maintain them throughout the course of the project as our true north.

\section{Programing Process}


Grand River Hospital hired a programing consultant to work on project programming. The programming took a collaborative approach. The programming consultant worked closely with Grand River Hospital leadership, the end users, and the architect. In order to understand the workflow and process among all the departments and within the department, the programming constant met with all the departments multiple times. Rick, as a consultant from a planning firm doing strategical and operational planning, talked about the programming process during his interview:

There were several multi-disciplinary teams that worked together to determine the patient flow, workflow in each department. The teams met on a routine basis. The Design Guiding Principles were integrated into the programming phase. During the programing process, the architect was heavily involved. Then the architect laid out the schematic floor plan based on the project program.

The programming phase was a collaborative process involving all the stakeholders. There were a number of things that were embedded in the design of the facility within the master planning and programming. Rick added more information regarding the programming process during his interview:

For the programming, we focused on function and operational flow, high level department adjacencies and operating models. The operating models were discussed early on in the programming process. They talked about things like $100 \%$ private patient room model. They looked at more functionalized nursing model so that the caregivers are closer to the patients. They talked about how to utilize technology, smart bed, tracking staff, ceiling lift, patient and staff safety. There is lots of this kind of discussions very early on in the process. The discussed topics come out as the important aspects of the design.

During the programming phase, there were lots of sessions focused on the goals in each department. Karen talked about the programming phase during her interview:

There were goals that are not contradictory, but there were some conflicting priorities that design can't accomplish one without being detrimental to the others especially it comes to adjacency issue. But the architect tried to design a facility to accommodate all these priorities. 
Throughout the programming of the facility, the programming consultant along with the architect really referenced a lot of articles and research and brought these elements into the program itself. The architects and designers followed the programming during the design process. Angie said during the interview:

We looked back on the program and see what they try to accomplish in each of departments and how the departments always tie back to these key goals and elements that they want to accomplish. Thus, just coming out of the program, there were a lots of established. But as we designed and moved forward, we had to make design decisions. Often you have to rely on the research to bring the design solutions to the client.

\section{Schematic Design Process}

Schematic design process was featured with design charrettes. It was truly a collaborative process. The schematic design started with the project program that was generated by the programming consultant with the collaboration of nurses, physicians, and architects. During the schematic design phase, multiple design charrettes were conducted that involved architects, designers, project managers, contractors, nurses, and physicians. Don talked about design charrette during his interview:

Each design charrette had slightly different focuses because each charrette was looking at different design aspect. For instance, designers and medical planners were much concerned about how patients flow and how departments flow within the hospital. Very early on, the architects and designers engaged users in design charrettes and understood what they were thinking. So the users felt that they were part of the process and their opinions mattered. Therefore, the users start taking the ownership of the project and keep that ownership as the project moves forward. Thus, the design charrette is also a team-building event at the beginning.

All interviewees who participated in the design charrettes expressed their appreciation of the design charrettes and workshops. All stakeholders have benefited from the design charrette because it really moved the project forward and helped to achieve the design goals. Tim, as project manager, talked about design charrette during his interview. He 
pointed out, "There was one design charrette that has brought the design back on track. That design charrette was particularly helpful and beneficial for the design. The design was developed over the course of many workshops and meetings."

Literature review and research evidence were obtained in the schematic design. Sackerber Architects pulled together completed projects that were designed using evidence-based design as well as research articles. Karen talked about the schematic design process in detail during her interview. She said:

We brought all these types of elements to the hospital leadership. These are the design solutions that we see out there. These design solutions are evidence-based and can make difference in terms of medical outcomes and organizational performance. For example, enclosed private medication rooms, where a caregiver has a focused area to work and not been distracted by other caregivers going there to do the same task.

Karen added more information:

The hospital leadership really wanted to focus on those types of things. The architect provided the initial list of the potential areas that the design could support quality care, patient and staff safety during the schematic design phases. Then the hospital leadership selected the ones that really made sense to them.

The architect helped them go through the list to see which ones exactly applied to the situation. This process is really a collaborative education process for both the owners and architects regarding the research evidence that might lead to the best possible outcomes. It was also clear that Lean-led architectural design was utilized in the design, which emphasized the process and added value for patients. More importantly, the hospital, not the architect, was in the lead in the process. The Lean design and Lean process were also confirmed by interviews with Susan and Don. Both participants talked about the Lean process and Lean tool during their interviews. 


\section{Research Evidence Interpretation and Implementation}

Gathering research evidence was a very important step for the Grand River Hospital project. Based on the client's design goals of creating a healing environment that promotes safety and quality care, the architect conducted a literature review to gather published credible research evidence as the first step during the design process. Then the research evidence was interpreted and implemented in the design through various strategies including design charrettes, building mock-ups as well as site visits by visiting existing successful hospitals that have proven they achieve the best possible outcomes. Susan talked about research evidence interpretation and implementation in her interview. She said, "Although the design activity is intuitive and creative, research evidence provides the rationale in the design that can lead to the best possible outcomes." Karen also talked about her opinion about research evidence interpretation. She said, "I just wish that the research evidence can provide clear research conclusions when we try to decide whether this is applicable." All the participants have spoken of the need for research in healthcare design. It is the consensus that evidence-based design certainly has contributed tremendously in healthcare design that leads to the best possible outcomes for all stakeholders and it will continue to make a huge impact on hospital design.

During the design process, the architects put research evidence and design attributes together from many evidence-based design articles. This was the research evidence that the architects wanted to implement in the design for Grand River Hospital. Angie gave an example during her interview:

For example, in patient room design, when there is great privacy, then the visibility and supervision over patient would be compromised. Thus, the design team had to weigh what was more important than the other and how to provide these design attributes. The design team had these discussions with the owners 
and user groups and went from there almost immediately into mock-up phase. The mock-up was where the design team started getting key clinician and nursing managers input.

Angie explained how the architects work with user groups by using mock-up rooms. She said:

The end users literally come into a bare bone room and all the way through every bit of detail including ceiling and floor materials in order to make sure the design had addressed everything the end users needed. The clinical staffs also run the simulation in the mock-up rooms. We implemented the design features in mockups based on research evidence. Every stage of design had documentations that captured these design features were saved. Therefore, it was easy to communicate with the consultants.

The consultants were with the architects and designers at most of these meetings.

Karen talked about the design tool that has been used in their design process during her interview. She said, "We used a lot of Lean Tools throughout the process. Nowadays, we capture a lot of decisions on A3s, which is something similar in nature as Lean Tool. Then we evolve from there." According to Grunden and Hagood (2012), Lean Tools consist of three major tools: observation, A3 thinking, and rapid improvement events. A3 thinking is a method that helps frontline teams quickly analyze problems to their root causes, envision a better way to work, and devise countermeasures and experiments to get there (Grunden \& Hagood, 2012). A3 is named for the $11 \mathrm{x} 17$ inch sized paper on which it is drawn. It is a one-page, hand-drawn document that relies on observation and teamwork to devise experiments and make improvements (Grunden \& Hagood, 2012).

Susan also talked about Lean Tool during her interview. She said, "A shift in the design process is to make sure that we have documentation that is very thorough. One 
thing that helps the LEAN approach is the idea of using A3." Karen explained A3 during the interview:

A3 is a documentation tool that is coming out of the LEAN concept. It is about 11 $\mathrm{x} 17$ size of paper. On that piece of paper, you describe the problem from the background through the process of evaluating the problem and solving the problem. So it is documentation of problem solving. It is referred to A3 just because of the paper size.

Susan explained A3 further during my interview with her. She said:

Within that A3, you would have research; cost analysis; why we should be using this research; how much we will be saving, how much we actually will be paying as well as any implications of the design. It is a great tool where you put all the pieces together on one sheet of paper. Then you would have the conclusion from it.

Susan also talked about the relationship between LEAN and evidence-based design. She

said:

Again, I think A3 is the example that EBD is very aligned with what we are doing with LEAN. I would say it's important that we think about EBD and we make EBD a little more dynamic. We think about the tools that can be used by designers during the design process rather than just feeding information to designers. The other suggestion for EBD would be focusing more on process integration for EBD whether it is LEAN or it is IPD. Try to see what evidencebased design means to these new delivery strategies is important.

Angie talked about implementing research evidence during her interview. She

said:

Research evidence has been implemented in Grand River Hospital design, for example, decentralized nurse stations. There is a nurse alcove between every two rooms. It brings nurses to the bedside and makes nurses closer to patients. The other research evidence in the design is to decentralize the support spaces.

In Grand River Hospital, there are 36 beds on each floor. They were divided into three sets of twelve. There are three rooms for supplies and three spaces for nurses to get together on each floor. For every twelve rooms, there is a clean room, a medication room, a nourishment room, and a nurse station. That set of twelve patient rooms has its own 
support spaces. Figure 5.2 presents a typical nursing units floor plan in the tower at Grand River Hospital. It provides clear visualization of the design for decentralized nurse stations and decentralized supply spaces. Angie said during her interview, "So the nurses never go too far to get medical supplies or medications. It reduces the walking distances for nurses. It turns into more time for nurses at the bedside instead of spending time searching for medical supplies." Furthermore, visibility to the medication room is taken into consideration. Angie said, "Medication room is an all-glass room. Besides visibility, nurses also have disruption free when they prepare medications. The enclosed glass provides the sound privacy and it allows the nurses to keep an eye out in the nursing unit."

\section{Decision-Making Process}

Since Grand River Hospital's design took a collaborative approach, the decisionmaking process certainly reflected that nature. The decisions were made based on the outcomes of design charrettes and feedback from mock-up rooms. Therefore, the design decisions were data driven and evidence driven. In addition, contractors had an important role in decision making regarding project schedule and cost.

David, as the contractor, said: "We were brought on board very early. We attended design charrettes and we listened and we asked questions." The contractor played a critical role in schedule management, cost management, setting up the budget, and making sure that the design and budget were coordinated with all disciplines.

The design charrette really played a crucial role for decision making. Karen talked about the design charrette in detail during her interview. She said: 
There was one major design charrette that brought all the decision makers in one room at the time. All team members literally went through the process of locating each of the key elements and making the decisions as they replaced design elements that were more important than the others.

Karen also talked about adjacency studies during the design charrette. She said:

There were some adjacencies that took some kind secondary priority over the really strong key adjacency. Through this major design charrette, the adjacency issues were resolved. That one charrette was extremely beneficial and got the design back on track. That design charrette really focused on what the key priorities were and what took the secondary priorities.

For the Grand River Hospital project, design decision making was a collaborative

effort. Karen expressed her gratitude for Grand River Hospital's effort of facilitating the design process. She said:

The client really did as much as they could to make the process extremely fluid and beneficial for the design team. One of the luxuries the design team had was taking over an auditorium space on client's existing medical campus. The design team took over that space for a week when architects, designers and consultants came in town and had different phases of design process. Throughout that week, the design team had key meetings on interiors, departmental adjacency studies, exterior design and many other design areas. Having that dedicated auditorium space made it possible to bring everybody into the room together and had workshops to address design issues.

Tim also talked about the design charrette in detail. He said:

The architects met with the hospital leadership at the beginning of the week to present what the key decisions were. The architects also had the departmental meetings separately. There were four concurrent meetings at the time. It allowed the design team members to join different meetings when they needed. For example, while the architect was conducting a surgery room design meeting and someone else is conducting the meeting for the design of ICU. They were all in one room together so they could easily get someone from other meetings.

Karen added more information about the design charrette and design workshop

during her interview. She said:

If I had a key decision in surgery as I was working on the design, and we were working through the flows to ICU, we could quickly grab the ICU team and say let's talk about this design how it flowed in a certain way. 
Having everybody in the same room was very beneficial. In the same space, engineers, medical equipment planners, and many other design teams were there. All team members could go from team to team and participate in all the designs. Karen also said:

At the end of the week, the architect reported to Grand River Hospital leadership team. The decisions made by the user groups would be reported to the leadership team in order to ensure that the project was moving to the right direction. The entire process was really beneficial because the architects/designers were able to get input from everybody at the same time. It really moved forward the design and we did not have to wait getting users' input.

The collaboration really made the design process more efficient.

Don talked about using mock-ups for their decision making in the design process during his interview. He said, "Every time we make decisions, we would take user groups into mock-up rooms and they could see the full scale room. The users could change the layout of the room and move things around and move things to different heights." Don added more information regarding mock-ups. He said:

The families and patients were also brought in the mock-up room. Users could provide feedback regarding the furniture arrangement and medical equipment location and installation height. The designers would fine tuning the design in a full scale and three-dimensional room. Eventually the designers would have exact colors, materials and equipment in the rooms for commentary and approval before they are going to build more of these rooms.

\section{Contractors' Roles in the Design Process}

Two contractors were involved in the construction of the Grand River Hospital project. One contractor is a local construction company, Zbranden Construction, and the other contractor is not a local construction company, McLaughlin Construction. Both contractors have extensive experience with building healthcare facilities and they had a joint venture for the Grand River Hospital project. The construction process was really a 
team effort and took a collaborative approach. For instance, the project manager who was the consultant stayed in town during the construction period; the architect visited the job site every week. The participants told me that they all had a very good experience working on the Grand River Hospital project. Many participants said that the Grand River Hospital project was one of the best projects they had worked on in their career. They truly believed it was a team effort that made the project successful.

Mike was the project manager who was responsible for the construction of the Grand River Hospital project. He said during his interview:

I am responsible for architectural staff involvement and managing various consultants, engineers and structural engineers, mechanical, electrical, civil engineers and landscape designers. The integrated project delivery approach was very important. You brought everybody to the table all the way in the process. That applied to the construction side as well.

Although IPD was not contractual for the Grand River Hospital project, IPD was very important not only because it brought the general contractor on board early on, but also it allowed critical sub-contractors to be on board early.

Tim was the consulting project manager who worked on behalf of the owner and managed the project. Tim really spoke highly of Grand River Hospital. He said to me during his interview, "I think this project is better than most of projects that I have experienced. In Grand River Hospital, programming decisions were made based on a lot of data-driven information." Tim added more information about the design process during his interview:

The program is a very effective program. When the design team moved to the schematic design (SD), the team was focused on pretty well made decisions to get overall configurations for all the rooms. Then the team looked at the adjacency and size of the rooms to make sure that hospital flowed well and the rooms had the right size as needed. During design development (DD) phase, the team focused on the rooms and really moved a whole lot after schematic design. So, the 
team was able to pay attention to details. For instance, the designers needed to get the power outlets and data outlets at the right location. Users were able to get involved and provided feedback so that the details could be implemented into construction documents (CD). There were still some changes during construction documents phase. The changes during CDs were not typically very significant. A lot of decisions were made as improvements or fix things that didn't work very well. Once getting in the construction, there was a good amount of construction oversight from Sackerber Architects.

Tim emphasized that his team was on site all the time. The responsibility of his team was to make sure when the changes and decisions were made, they were within the budget, they didn't impact the schedule, and they were the right changes. Tim also said, "It is important to document the changes with good reasons. It has to demonstrate the needs of making changes during the construction phase."

One of the major themes that emerged from interviews was great team effort. Every participant spoke highly of Grand River Hospital as the client and the team effort. The entire team worked very well together, making sure they made the right decisions at the right time and controlled cost effectively. The LDJ Global Project and Development Services team did an excellent job managing the project. They worked with the owner and design team to ensure the right decisions were made for the right situations.

The contractors were brought on board from the beginning. They participated in all the design charrettes and workshops where the contractors offered their input. In the meantime, the contractors had the opportunity to listen and ask questions. They gained insight about the project through design charrettes. The contractor was responsible for building mock-up rooms. They built mock-ups for many key rooms so everyone could come in and physically move things around and provide different options for the design. The mock-ups were built during the schematic design phase. Additionally, the contractors were responsible for managing the project schedule and cost. BIM technology was also 
used during construction phases. The construction manager used BIM for modeling the construction and to detect possible collisions. The following are some sample quotes from my interview with George who is the project manager for all aspects of design and construction. He talked about the contractor' roles in detail during his interview. He said:

We were brought on board early on so we can provide constructability, and cost information to the team so that they can make proper business decisions. Then we stepped further and we brought in mechanical and electrical sub-contractors so we could have a sound expertise to make sound business decisions regarding the pricing.

George also added more information regarding the management of construction budget and schedule. He said:

Yes, we reported on the budget every time when we got together. Periodically, we will hit the milestone of the design. We will do a full estimate in detail. As the design become more complete, we will periodically do construction schedule and cost evaluation to make sure the design not only meets the construction schedule, but also the cost.

\section{Post-Occupancy Evaluation Feedback Session and Publication}

Post-occupancy evaluation was an important step in the evidence-based design. Although there was no full POE for Grand River Hospital, there were feedback/lessons learned sessions that served as part of POE. Susan talked about post-occupancy evaluation and Functional Performance Evaluation (FPE) at Sackerber Architects in great detail during her interview. She said, "Typically, if it is a full POE, Functional Performance Evaluation (FPE) would be conducted at the client site with client's agreement." FPE is a multi-method tool developed by the design and research teams at Sackerber Architects based on their fundamental premise that "every design decision is a performance hypothesis." Susan explained, “The FPE includes site audits, user feedback, 
environmental analysis and organizational success metrics. The data was collected by triangulation methods. The conclusion would be developed after collecting meaningful data and using key metrics as well as multiple measures." The FPE can provide facility owners insight into ways to improve and optimize operations through facility design, and assist design teams in understanding the consequences of their decisions and engage in continuous improvement.

Both Susan and Karen not only talked about FPE but also talked about Institute of Design and Research Evaluation (IDRE) during their interviews. Susan said:

At Sackerber Architects and IDRE, one of the things that we have been trying to do is trying to develop more actionable tools for designers to use. For example, within different healthcare system, we are developing a parametric modeling tool which can quickly calculating walking distances translated into heat map between key rooms. So, in 20-30 minutes you can see snap shots showing what the distances between patient rooms and supporting spaces. This can be used to compare different floor configurations.

Susan also added:

In addition to what we have already, we did field work and did the observations on site and got these frequencies of usage of different rooms and sequence of movement. Then we developed the simulation tool based on their field work and observations. The goal is trying the tools that we are developing over times so that the designers will be able to do research in house by themselves and it doesn't require a separate researcher.

Susan talked about their current research goal during her interview. She said:

The focus at Sackerber Architects now is integrating research into practice. So we develop the tools and try to get information and feedback. Eventually the designers will be the one who own the tool. So they don't have the separation between research and design.

In evidence-based design, publication and dissemination of research findings is an important step that closes the loop of the cyclical design process. Post occupancy evaluation, along with functional performance evaluation, can generate publishable 
results. According to my interviews with Susan, Angie, and Karen at Sackerber Architects and IRDE, they have published numerous articles in a knowledge repository on the Center of Health Design website, Healthcare Design Magazine, as well as the IRDE website. The published research evidence can be utilized for future healthcare projects. The following is a sample quote from my interview with Angie. Angie said:

We have members in IRDE in different offices. We have many ways that we share information with companies. People are looking at what is the latest and greatest research findings out there. We have the information for people published on IRDE website. We actually have quickly applicable research that has been done on site as part of the design process.

\section{Findings from Observations: Research Evidence Implemented in the Design of Grand River Hospital}

I conducted observations inside the Grand River Hospital facility. I followed observation protocols and photographed the physical environment while I conducted observations. Table 5.5 presents open coding for my observations, which were based on the information I filled in the Observational Protocols while I conducted observations (see Appendix III for a sample of filled Observational Protocol). The open coding table for observations (Table 5.5) presents the physical features and environment-behavior attributes/research evidence. The environment-behavior attributes or research evidence is directly linked to these physical features. 
Table 5.5: Open Coding for Observations

Open Coding for Observations

\begin{tabular}{|c|c|c|}
\hline $\begin{array}{l}\text { Observational } \\
\text { Settings }\end{array}$ & Physical Features & $\begin{array}{c}\text { Environment-Behavior } \\
\text { Attributes / Research } \\
\text { Evidence }\end{array}$ \\
\hline $\begin{array}{l}\text { Emergency } \\
\text { Department, first } \\
\text { floor }\end{array}$ & $\begin{array}{l}\text { The ED is designed with both private patient } \\
\text { rooms and semi-private patient rooms. The } \\
\text { semi-private patient room allows two } \\
\text { patients occupancy. There is a medical staff } \\
\text { working area in both private and semi- } \\
\text { private patient rooms. Central nurse stations } \\
\text { coupled with decentralized work stations; } \\
\text { caregiver working space in both private and } \\
\text { semi-private rooms; hand sinks are provided } \\
\text { in each patient room; big class window in } \\
\text { patient room with curtains }\end{array}$ & $\begin{array}{l}\text { privacy, infection control; } \\
\text { supervision over patient; staff } \\
\text { efficiency; technology }\end{array}$ \\
\hline $\begin{array}{c}\text { Emergency } \\
\text { Department Patient } \\
\text { Waiting Area/Family } \\
\text { Lounge }\end{array}$ & $\begin{array}{l}\text { The patient waiting arear/family lounge is } \\
\text { divided into three areas by partial partitions. } \\
\text { A big mural is installed in one of the waiting } \\
\text { area/family lounges. Several sofas and } \\
\text { lounge chairs and coffee tables are arranged } \\
\text { freely in these waiting areas. There is a } \\
\text { touch screen machine that allows children } \\
\text { to find questions and answers in the first } \\
\text { waiting area. A coffee counter is arranged by } \\
\text { this waiting area as well. There are a couple } \\
\text { of planters in this area. There are two triage } \\
\text { rooms on the opposite of this waiting area; } \\
\text { children's play area; several planters; height } \\
\text { glass windows; outdoor patios; daylight }\end{array}$ & $\begin{array}{l}\text { restoration; patient-centered } \\
\text { care; family involvement in } \\
\text { healing process; positive } \\
\text { distractions; nature; healing } \\
\text { art }\end{array}$ \\
\hline $\begin{array}{l}\text { 7th floor patient } \\
\text { rooms and nurses' } \\
\text { stations }\end{array}$ & $\begin{array}{l}\text { Private patient rooms; decentralized nurse } \\
\text { stations; centralized nurse stations; family } \\
\text { zone in each patient room; window views } \\
\text { for patients and caregivers; daylight; hand } \\
\text { sink; patient lift; bed escape alert; } \\
\text { medication room; medical supplies room; } \\
\text { meeting area for staff and family members; } \\
\text { slight curve in corridor }\end{array}$ & $\begin{array}{l}\text { privacy; infection control; staff } \\
\text { efficiency; restoration; staff } \\
\text { supervision over patient; } \\
\text { patient-centered care; family } \\
\text { involvement; daylight; window } \\
\text { views; reduce medical errors; } \\
\text { patient and staff safety; } \\
\text { quality care; patient room } \\
\text { standardization/same handed; } \\
\text { technology }\end{array}$ \\
\hline $\begin{array}{l}\text { 2nd floor ICU in the } \\
\text { tower }\end{array}$ & $\begin{array}{l}\text { three central nurse stations; twenty-four } \\
\text { surgical and trauma ICUs; six pediatric ICU; } \\
\text { all private patient rooms; one surgical } \\
\text { lounge; surgical registration; family zone in } \\
\text { each patient room; working space for } \\
\text { caregivers in patient rooms; centralized } \\
\text { nurse stations and decentralized nurse } \\
\text { stations; hand sinks; meeting room for } \\
\text { family members and staff; window views for }\end{array}$ & $\begin{array}{l}\text { staff efficiency; privacy for } \\
\text { patient; family involvement } \\
\text { and patient-centered care; } \\
\text { supervision over patient; } \\
\text { infection control; restoration; } \\
\text { daylight; window views; } \\
\text { reduce medical errors; patient } \\
\text { and staff safety; patient room } \\
\text { standardizations }\end{array}$ \\
\hline
\end{tabular}


patients and staff; daylight; big glass curved

wall in corridor; patient lift and bed escape

alert

\begin{tabular}{|c|c|c|}
\hline $\begin{array}{l}\text { 3rd floor ICU in the } \\
\text { tower }\end{array}$ & $\begin{array}{l}\text { three central nurse stations; twenty-four } \\
\text { surgical and trauma ICUs; a family lounge } \\
\text { outside nursing units; all private patient } \\
\text { rooms; one surgical lounge; surgical } \\
\text { registration; family zone in each patient } \\
\text { room; working space for caregivers in } \\
\text { patient rooms; centralized nurse stations } \\
\text { and decentralized nurse stations; hand } \\
\text { sinks; meeting room for family members and } \\
\text { staff; window views for patients and staff; } \\
\text { daylight; big glass curved wall in corridor; } \\
\text { patient lift and bed escape alert; food } \\
\text { preparation room for nutrition staff; toilet } \\
\text { room is located at the foot wall; coffee areas }\end{array}$ & $\begin{array}{l}\text { staff efficiency; privacy for } \\
\text { patient; family involvement } \\
\text { and patient-centered care; } \\
\text { supervision over patient; } \\
\text { infection control; restoration; } \\
\text { daylight; window views; } \\
\text { reduce medical errors; patient } \\
\text { and staff safety; patient room } \\
\text { standardizations; technology }\end{array}$ \\
\hline $\begin{array}{l}\text { Heart Institute Lobby, } \\
\text { first floor }\end{array}$ & $\begin{array}{l}\text { one information desk; touch screen map; } \\
\text { one waiting area; art work/paintings; big } \\
\text { stained glass wall facing entrance; two story } \\
\text { open entrance; elevators facing information } \\
\text { desk }\end{array}$ & $\begin{array}{l}\text { wayfinding; restoration; } \\
\text { positive distractions }\end{array}$ \\
\hline Main Lobby & $\begin{array}{l}\text { indoor garden; water feature; huge stained } \\
\text { glass mural; reception desk; two-story open } \\
\text { space; white piano; art works; wayfinding } \\
\text { signage; touch screen map; sitting area; } \\
\text { open loft; big glass curtain wall }\end{array}$ & $\begin{array}{l}\text { wayfinding; restoration; } \\
\text { daylight; nature; healing } \\
\text { environment; quality care; } \\
\text { patient-centered care; positive } \\
\text { distractions, healing art works }\end{array}$ \\
\hline $\begin{array}{l}\text { 2nd floor Operating } \\
\text { Room and } \\
\text { Preparation/Recovery } \\
\text { rooms in the tower }\end{array}$ & $\begin{array}{l}14 \text { operating rooms; locker rooms for staff; a } \\
\text { preparation/recovery area; total } 24 \text { patient } \\
\text { rooms; bathroom is shared by two adjacent } \\
\text { patient rooms (Jack and Jill); a sink and toilet } \\
\text { in the bathroom with ADA accessibility; a } \\
\text { working station for medical staff in patient } \\
\text { room; a hand sink in patient room; nurse } \\
\text { alcoves outside the patient rooms }\end{array}$ & $\begin{array}{l}\text { infection control; privacy; } \\
\text { supervision over patient }\end{array}$ \\
\hline $\begin{array}{l}\text { Surgical Lounge, } \\
\text { second floor }\end{array}$ & $\begin{array}{l}\text { It is a loft looking lounge that overlooks the } \\
\text { main lobby area and the water feature in } \\
\text { the indoor garden; a reception desk on west } \\
\text { side of the surgical lounge; three televisions } \\
\text { on the wall or on the column; free standing } \\
\text { sitting area; several planters are in the } \\
\text { surgical lounge area; partial walls to divide } \\
\text { waiting areas; there is a children's waiting } \\
\text { area }\end{array}$ & $\begin{array}{l}\text { restoration; patient-centered } \\
\text { care; family involvement in } \\
\text { healing process; positive } \\
\text { distractions }\end{array}$ \\
\hline Cafeteria, first floor & $\begin{array}{l}\text { open space; three divided dining areas; art } \\
\text { works; plants in dining area; partial walls }\end{array}$ & $\begin{array}{l}\text { patient and staff safety; } \\
\text { community engagement; }\end{array}$ \\
\hline
\end{tabular}


divide the space; slip-resistant floor

nature; healing environment

materials; curved hall leads to cafeteria;

community people

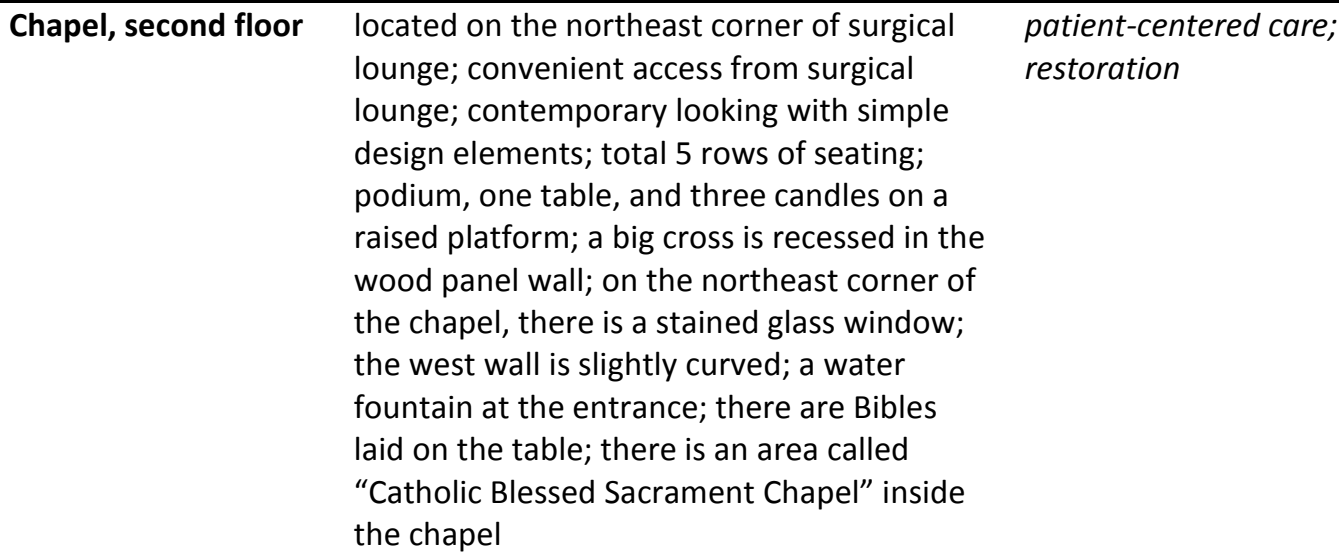

According to open coding for observations, it was obvious that lots of credible research evidence related to the healthcare environment was implemented in the design of Grand River Hospital. The implementation of research evidence was also confirmed by the triangulation methods, especially interviews. Based on open coding of observations, core categories of implemented research evidence, corresponding design strategies, and design attributes are presented in Table 5.6. The following section describes the findings from my observations regarding the research evidence that has been implemented in the design of the physical environment in Grand River Hospital. Since findings from observations and interviews are intertwined, interview quotes are used to confirm the findings from observations regarding research evidence implementation in the design of Grand River Hospital. 
Table 5.6: Findings from Observations (Confirmed by Interviews)

\begin{tabular}{|c|c|c|c|c|c|c|c|c|c|c|c|c|c|c|c|c|}
\hline & & earc & Evid & nce & mple & ented $\mathrm{i}$ & in the $\mathrm{L}$ & Desig & $n$ of & Granc & Rive & Hos & ital & & & \\
\hline Research & & & & & Desig & Strateg & ies and & d Env & ironr & nenta & Attr & bute & & & & \\
\hline $\begin{array}{l}\text { Related to } \\
\text { the Best } \\
\text { Possible } \\
\text { Outcomes } \\
\text { (Safety, } \\
\text { Efficiency, } \\
\text { etc.) }\end{array}$ & 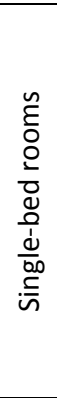 & 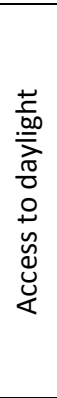 & 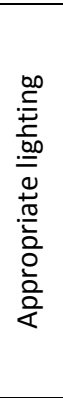 & 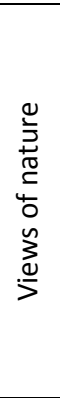 & 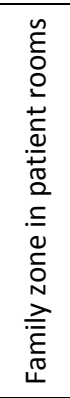 & 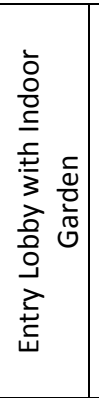 & 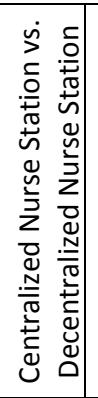 & 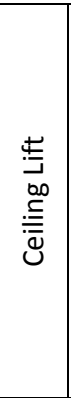 & 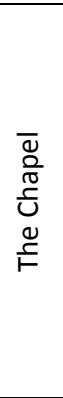 & 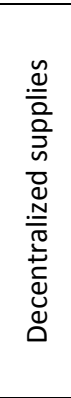 & 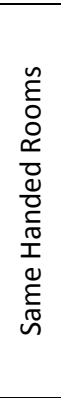 & 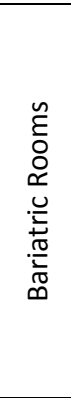 & 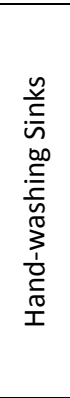 & 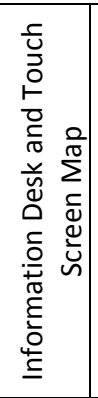 & 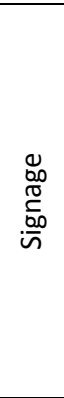 & 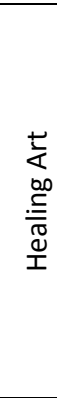 \\
\hline $\begin{array}{l}\text { Healing } \\
\text { Environment, } \\
\text { Positive } \\
\text { Distractions }\end{array}$ & & * & & * & & * & & & * & & & & & & & $*$ \\
\hline Privacy & $*$ & & & & & & & & & & & & & & & \\
\hline $\begin{array}{l}\text { Supervision } \\
\text { and Control }\end{array}$ & & & & & & & $*$ & & & & & & & & & \\
\hline $\begin{array}{l}\text { Infection } \\
\text { Control }\end{array}$ & * & & & & & & & & & & & & * & & & \\
\hline $\begin{array}{l}\text { Safety for } \\
\text { Caregivers }\end{array}$ & & & & & & & & * & & & & & & & & \\
\hline $\begin{array}{l}\text { Safety for } \\
\text { Patients - } \\
\text { Errors, } \\
\text { Lighting Level }\end{array}$ & & & $*$ & & & & & $*$ & & & $*$ & & & & & \\
\hline $\begin{array}{l}\text { Patient } \\
\text { Centered } \\
\text { Care- } \\
\text { Restoration }\end{array}$ & * & & & * & $*$ & & & & $*$ & & & $*$ & & & & $*$ \\
\hline $\begin{array}{l}\text { Connecting } \\
\text { with Nature - } \\
\text { Daylight and } \\
\text { Window Views }\end{array}$ & & & & & & * & & & & & & & & & & \\
\hline $\begin{array}{l}\text { Walking } \\
\text { Distance/ } \\
\text { Efficiency }\end{array}$ & & & & & & & * & & & * & & & & & & \\
\hline Wayfinding & & & & & & & & & & & & & & $*$ & $*$ & \\
\hline
\end{tabular}




\section{Healing Environment and Positive Distractions}

During my observations, the first impression I got is that the Grand River Hospital facility was designed in a way that makes visitors feel welcoming. The space is calming

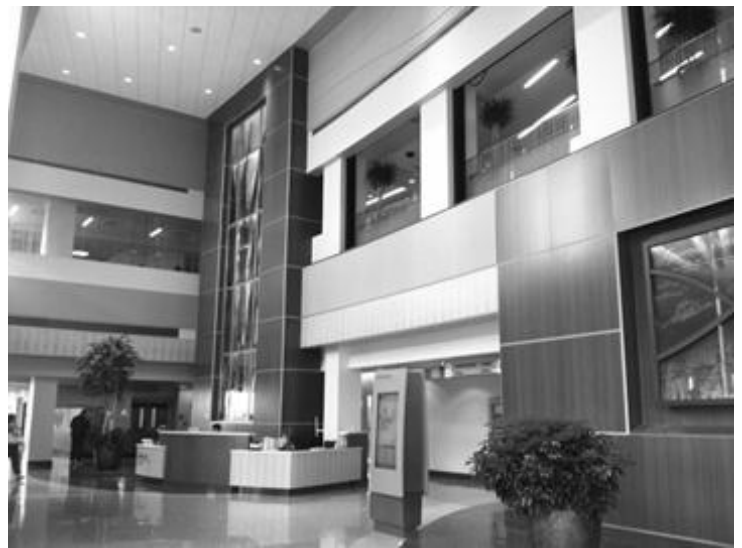

Figure 5.6: Main Entry Lobby and appealing by a well-designed entry

lobby (Figure 5.6). The lobby is a two-story open space that can be viewed from the second floor surgical lounge. There is a big stained glass mural facing the entrance. There is an information desk and a touch screen map in the lobby. An indoor garden with water feature adjacent to main lobby is

provided at the northeast corner of the building (Figure 5.7). The corner is formed by two perpendicular glass curtain walls. The huge glass curtain wall allows a great amount of daylight to shed into the interior space. There are three small fountains that create small waterfalls in the garden. The curved pathway leads visitors to the cafeteria. Across the pathway is a sitting area. There are armchairs, sofas and coffee tables in the sitting area. The walk pathway is finished with terrazzo with sparkles. The indoor garden is situated in a two-story open space as well. Visitors can hear

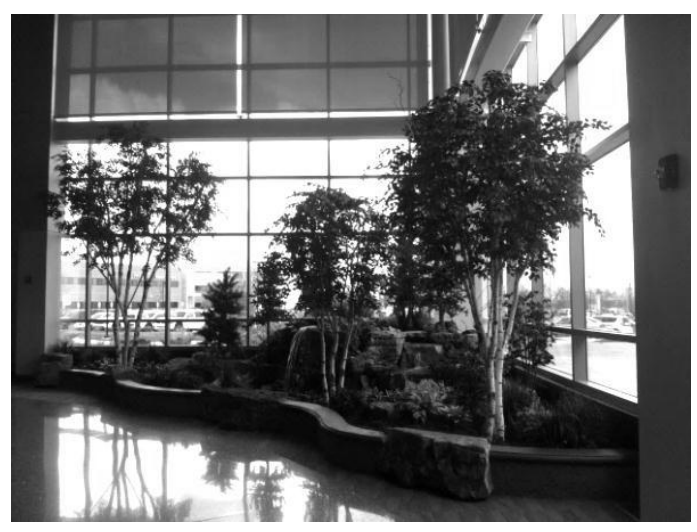

Figure 5.7: Indoor Garden the water sound and see sunlight passing through the glass curtain walls that provide a soothing effect. In addition, many sitting areas are designed inside and outside the 
facility. Figure 5.8 shows an example of a sitting area in the lobby viewed from the second floor surgical lounge. Not only can visitors rest there but also medical staff can have a break during their busy work. Tina said during her interview:

In the lobby area, we had a water feature. The reason for that is because the water is very soothing. Some of the patients can benefit from that. The actual benefit is for families and our caregivers. So, you will see families sitting at the water fall for relaxation, prayer, meditation, and also our physicians. They came to tell me how many times they would come before the big case, sat there and just kind of relax. So they could go in with a better state of mind, very clear state mind and also helped them think through maybe some of the issues they had.

Emily talked about the lobby design during her interview: "Overall we want to have a healing environment that will make patients and families feel destressed and comfortable. So the healing could take place for patients. Therefore, a lot of what we did is to promote that kind of environment." Figure 5.9 is a conceptual floor

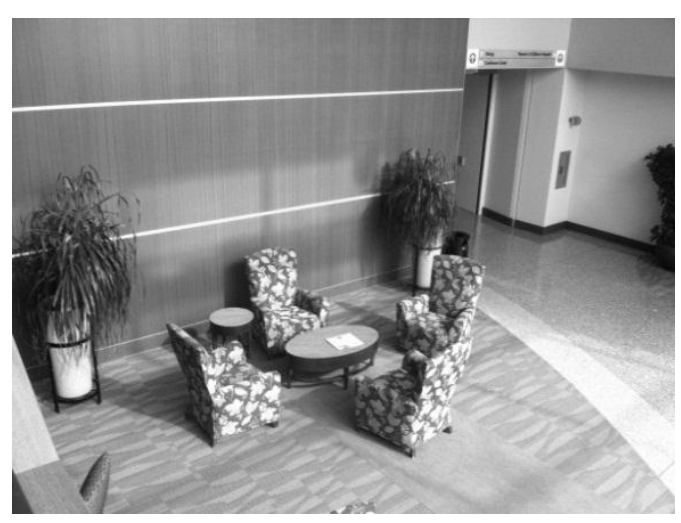

Figure 5.8: Sitting Area in Main Lobby plan for the lobby area. It is clear that there are a couple of seating areas next to the indoor garden. People like to sit there for relaxation. In addition, during my observations, I saw various innovative seating arrangements throughout the facility. These are meant to

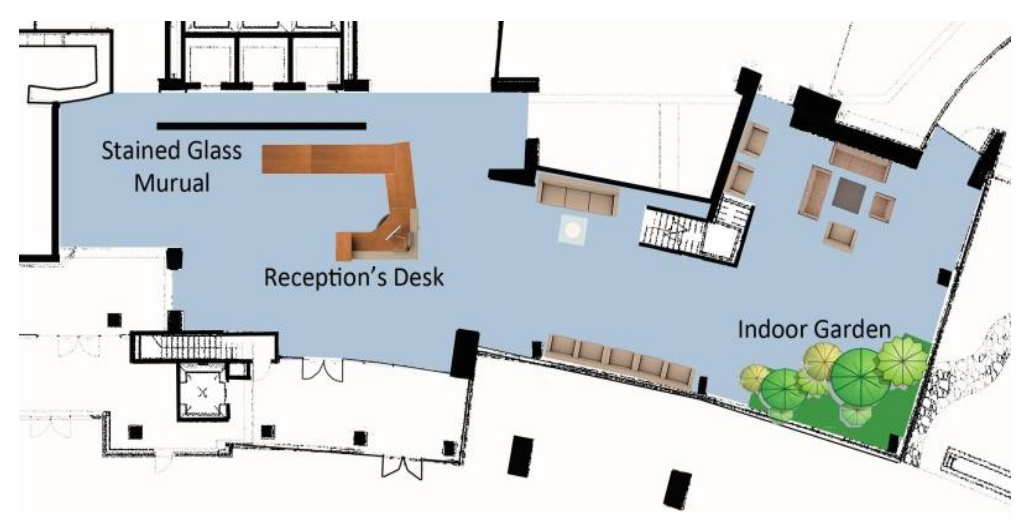

Figure 5.9: Main Lobby at Grand River Hospital 
encourage patients and visitors to socialize.

The notion that the physical environment plays an important role in patient healing and the therapeutic process has been confirmed by previous studies. Based on my observations and interviews, it is clear that Grand River Hospital's physical attributes are in response to research evidence about creating a healing environment in order to benefit patients, families, and caregivers.

\section{Privacy}

Another main category from open coding for observations is privacy. The research evidence regarding privacy was implemented in the design of Grand River

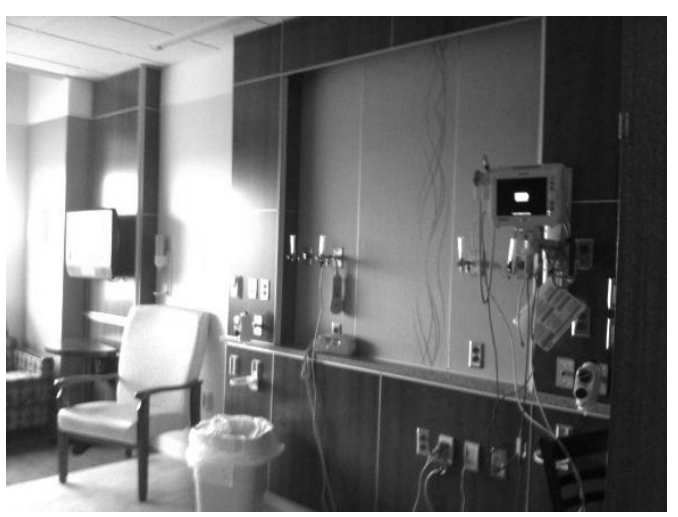

Figure 5.10: Private Patient Room Showing Head Wall
Hospital through all private patient rooms. This is also confirmed by interviews with the owners, architects, and consultants. All patient rooms were designed as single-bed patient rooms with dedicated space for families. Figure 5.10 shows a typical patient room head wall. This patient room was occupied by a patient but the patient was taken out for exam when I had the observation and took the photo; that is why the patient bed is not in the photo. An important aspect in patient room design is providing window views to bring daylight in. Karen talked about patient room design during her interview. She said, "So the design of patient rooms and nursing units was all about trying to get natural light." Julie said:

We have all the private rooms. It has been the standard for a quiet while. There are views to the exterior, glass and a lot of connection to nature. We try to do that as much as possible whether in the patient room or in family and staff areas. 
In each patient room, there is a family space where family members can spend the night (Figure 5.11). Storage space is also provided for family members in the patient room. A

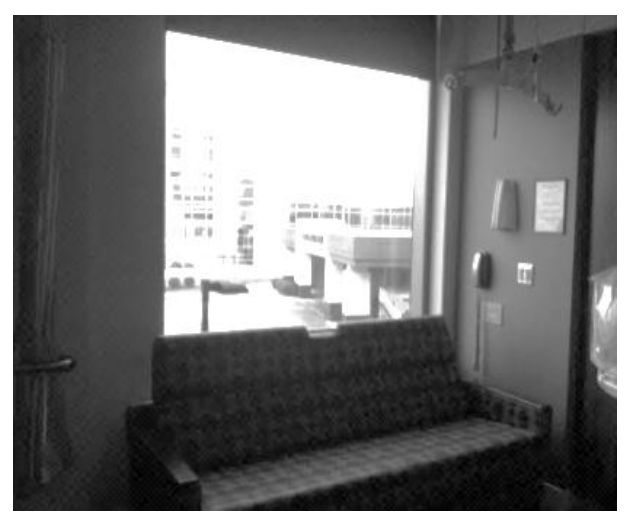

Figure 5.11: Family Space in Private Patient Room separate TV is provided for family members. Each

patient room has daylight and a window view to

the outside.

During my interview with Don, he said,

"Yes, we pretty much implemented all of this

research evidence by designing all private patient rooms with family zone to provide privacy to

patient and families." Karen talked about designing patient rooms during her interview:

"Obviously private patient room was in the early discussion because it is in the design

guiding principles and it is fully supported by research evidence from infection control

standpoint and from patient experience standpoint." Emily talked about designing private

patient rooms:

I think several things are clearly evidence-based, whether it should be private rooms vs. semi-private rooms. That was the decision that we had to make. Based on infection prevention, cost of transferring patients, putting male and female together in the same room, all these considerations went away when we decided to have private rooms.

Emily continued in her interview:

The patient room was set up in terms of clear pathways to the bathrooms. Having access to the computer for the nurses in patient room allows nurses to have more bedside time with patients instead of to be outside at the centralized nurse station. So, we not only moved the computers into the room, but also have sub-nurse alcoves that allow the nurses to be closer to patients. So that reduces patient falls and patient injuries. 
Many other participants also talked about how to achieve privacy for patients and families when they were involved in the patient room design. The following are some quotes regarding patient room design from my interview with Julie. She said: "There were a number of things in the patient room that were developed for all patient rooms. That was the requirement for privacy. The room was equipped with large window that increases the views to exterior." Julie also added more details regarding the design of private patient room:

We made sure there was a comfortable and adequate family zone in patient room for each of families. We also included bathroom and TV and storage space. They also had audio jack so the family can watch TV without distracting the patient sleeping. We did provide family zone in critical care rooms which was not always the case.

In summary, based on observations, the design attributes in private patient rooms in Grand River Hospital correspond to research evidence related to privacy. According to the literature surveyed earlier regarding privacy research evidence, it is obvious that designing private patient rooms can lead to better infection control and better patient experience. Equally important, nurses should have supervision and control over patients in private patient rooms, which will be discussed in detail in the next section. In addition, since patient-centered care has been an integral component in nursing, designing private patient rooms with space for families is important because it allows family members to participate in patient care and the healing process. Therefore, all these design attributes revealed from my observations and interviews are in response to research evidence related to privacy.

\section{Supervision and Control}


Grand River Hospital is designed in a race track floor configuration. The floor plan is designed in a slightly curved shape (See Figure 5.12). It breaks down long

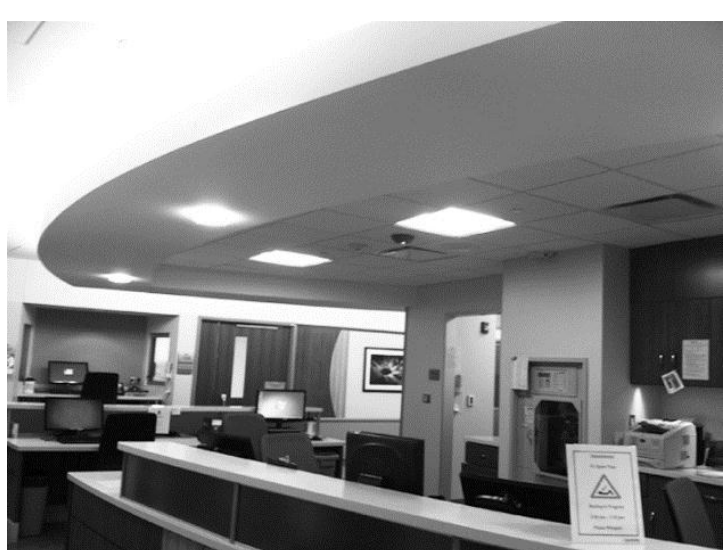

Figure 5.12: One of three decentralized Nurse Stations institutional looking corridors and adds

interests to the space while good visibility is

still ensured. There are three decentralized

nurse stations on each nursing unit floor.

Figure 5.12 is one of three decentralized

nurse stations. Each nurse station supervises

twelve patient rooms. There are a total of 36

patient rooms and 18 decentralized nurse alcoves between each two patient rooms on each floor. Figure 5.13 shows the decentralized nurse alcove outside patient rooms. On each floor, nurses' alcoves were spread throughout the nursing unit. These nurse alcoves were placed immediately outside the patient rooms. The nurse alcove contains windows that allow the nurse to observe the patient and provide supervision over the patients. This not only can improve visibility of the patient, but also can reduce walking time for nurses. Previous studies concluded that

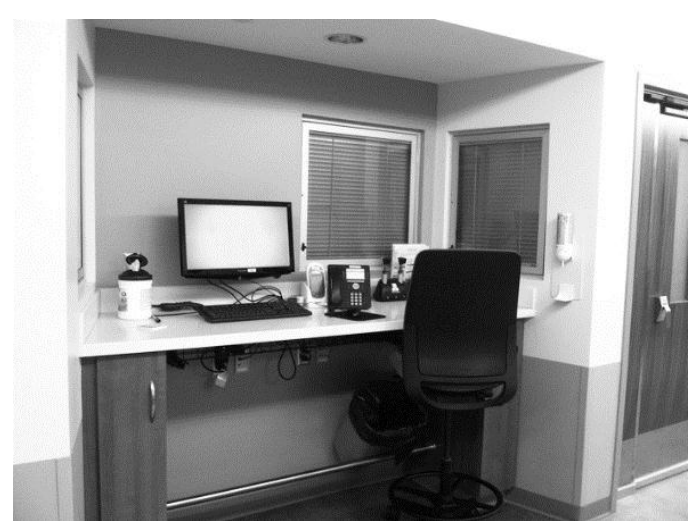

Figure 5.13: Decentralized Nurse Alcove Outside Patient Room decentralized nursing stations allow nurses to interact more closely with patients and increase bedside time for nurses.

During my interview with Tina, she said:

Research evidence implemented on nursing units is the design of the alcoves. That way the nurses assigned to these patients are right there at these rooms verse 
at the end of the hallway where they couldn't see the patients. So it provided a good visibility for that patient. We spent a lot of time on where you place the bed so you can see from the window outside and give the patient privacy. But, yet, you can be monitoring at the duty. So, the placement of the patient in that bad was very critical to your eyesight from that alcove location.

Angie said during her interview:

Some of the research evidence that has been implemented in Grand River Hospital is trying to decentralize the nurse station. For example, between every two patient rooms, there is a nurse alcove. It brings nurses to the bedside and brings them closer to patients.

In nursing practice, control and supervision over patients is recognized as one of the important aspects of nursing (Thomson \& Goldin, 1975; Verderber \& Fine, 2000). The notion of having control and supervision over patients has a long history that can be dated back to the Nightingale period (Nightingale, 1863; Thomson \& Goldin, 1975). It remains a vital approach in today's nursing practice even though Nightingale's open ward has been eliminated in modern hospital design. Since the value of single-bed rooms has been acknowledged by the American Institute of Architects (AIA) after extensive research and has been included in the Guidelines for Design and Construction of Health Care Facilities (AIA, 2006), all patient rooms have been designed for single occupancy in modern healthcare facilities. As a consequence, it is not easy for nurses to have direct supervision and control over patients compared with the open ward.

Apparently, the hybrid model of having decentralized nurse stations and nurse alcoves between two patient rooms is the design attribute in Grand River Hospital. This can improve visibility of the patient and reduce walking time for nurses. Previous studies show that decentralized nursing stations allow nurses to interact more closely with patients. These design attributes certainly correspond to research evidence regarding hybrid nursing unit design that allows both privacy and better supervision and control. 


\section{Infection Control}

Infection control is one of the important design goals for Grand River Hospital. In order to achieve this design goal, the first design strategy is having all private patient

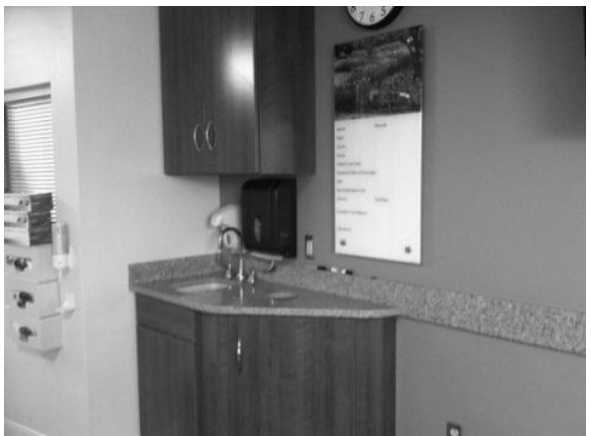

Figure 5.14: Hand-washing Sink in Patient Room rooms. The second strategy is having hand-washing

sinks in every patient room. According to research

evidence, the placement of handwashing sinks in

patient rooms and treatment areas can provide better

infection control. When I conducted my observation,

immediately inside the room where it was visible to all who

entered the room and also where the patient could observe the staff washing their hands (Figure 5.14). Grand River Hospital also makes waterless, antibacterial hand sanitizers available in patient rooms as well, and even provides their medical professionals with antimicrobial scrubs as another way to

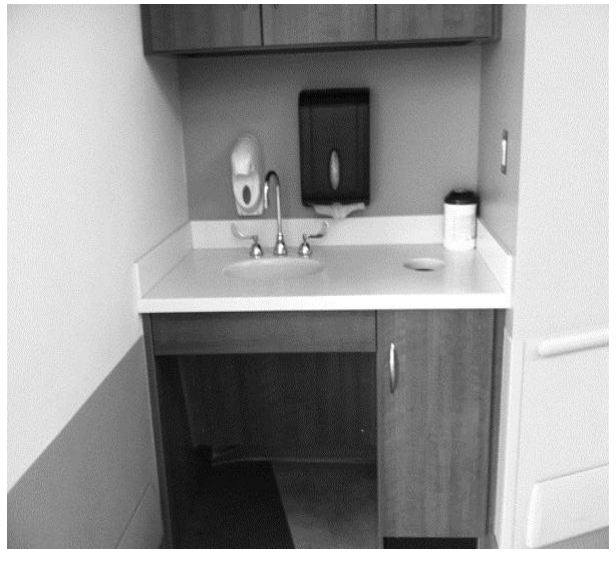

Figure 5.16: Handwashing Sink in Corridor prevent germ growth

(Figure 5.15).

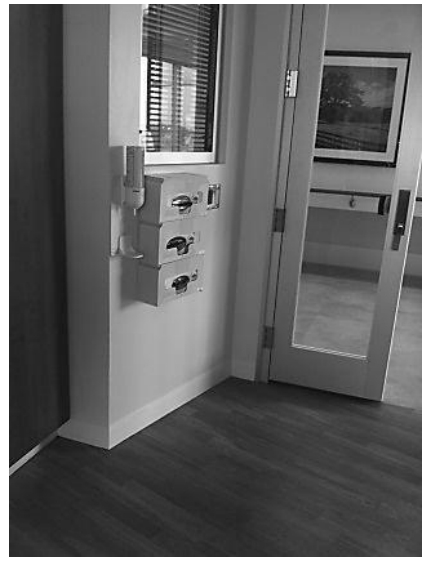

Figure 5.15: Antibacterial Hand Sanitizers in Patient Room

The location and quantity of handwashing

sinks are two major aspects that can improve compliance and reduce infections. In addition to providing a handwashing sink in each patient room, there are also several handwashing sinks in the hallway of the nursing unit (Figure 5.16). 
These design attributes and strategies in Grand River Hospital certainly correspond to research evidence regarding infection control. Research findings state that implementing a hand washing policy is important for infection control. Locating a number of handwashing sinks in different locations provides convenience to caregivers and makes implementing the hand washing policy more effective.

Another important design aspect for infection control is specifying appropriate materials. Don talked about materials for infection control during his interview: "Every material we choose whether was floor covering, wall covering, curtain, counter top material, etc., we worked with hospital infection control officers to make sure it was not only disease resistant, easy to clean, but also it was easy to maintain.” Don continued:

We designed hand-washing sinks in every patient room, we selected solid surface counter top that prevents bacteria growth. We designed integral back splashes for the counter top so that it is easy to clean. Flooring materials were seamless welded. No seams, no cracks and low maintenance in patient toilet rooms and public toilet rooms. If we would chose ceramic tiles, we chose over-sized ceramic tiles to less the grout joints. We specified epoxy grout that can prevent bacteria grow. We made sure that the ceiling tiles in the room are cleanable and washable.

All architects and designers, as well as owners, talked about how they selected materials from an infection control standpoint. Here are more quotes from my interviews with the owner and design consultant. Linda talked about infection control during her interview. She said: "Our infection control team looked at any way that patients or staff could be at risk of the infection and try to improve upon." Eric as design consultant said: "Obviously we were extremely involved in infection control. We were dealing with infection control in design, like negative pressure in the patient room. One of the things we worked with the team is the isolation room." 


\section{Safety for Caregivers}

In their design guiding principles, one of the important design goals was to promote safety and quality care for both patient and staff in Grand River Hospital. During

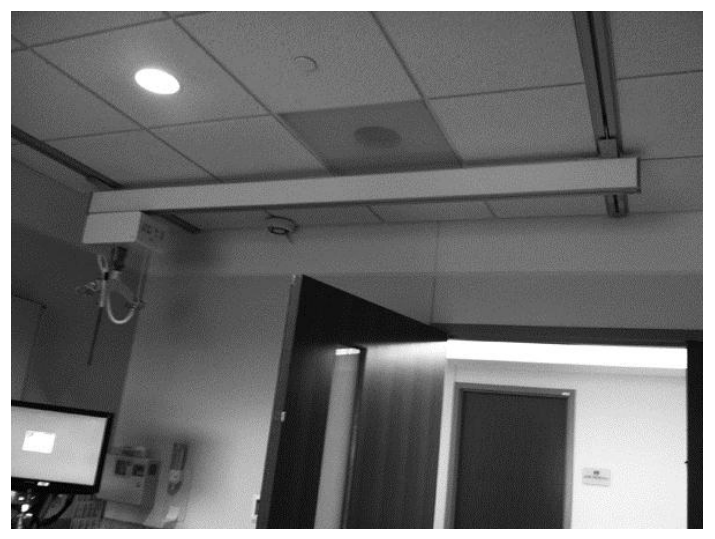

Figure 5.17: Ceiling Lift in Patient Room

my observations, I saw a ceiling lift system that was installed in each patient room on every floor (Figure 5.17). According to research evidence, the ceiling lift is an effective way to reduce risk of injury not only for patients but also for nurses. The ceiling lift is a system that is mounted on the ceiling and can be operated electronically. For patients who require additional and specialized equipment for transferring, showering, toileting, as well as other routine and specialized medical examinations and care, the ceiling lift can help move the patient to another bed or wheelchair. Previous studies show that a lot of staff injuries happened during the process of moving patients. Therefore, installing ceiling lifts in patient rooms can reduce staff back injuries. This design strategy is also confirmed by my interviews with the participants. Emily talked about research evidence implemented in the design of Grand River Hospital. She said, "From the employee safety perspective, we put all the ceiling lifts in all patient rooms. That was a very expensive decision because employee safety was very important to us. Ceiling lifts reduced lifting injuries and it was also comfortable for patients." Obviously, this design attribute corresponds to research evidence regarding employees' safety. The research director at Sackerber Architects told me during her interview that Grand River Hospital's survey data show that their injury rate was reduced 
significantly after the ceiling lifts were installed in their facility. Clearly, the best possible outcomes were achieved by implementing this piece of research evidence through design innovations.

\section{Safety for Patients}

As mentioned in the previous section, safety for patients is another important design goal in Grand River Hospital's design principles. Many physical attributes were designed for promoting patient safety. Based on my observations, these design attributes are: dedicated medication rooms, standardized rooms (surgery rooms, emergency department exam rooms), nurse alcoves, slip-resistant floor materials, and hand railings in the hallway. These findings were revealed from both observations and interviews.

Previous research evidence shows that most medical errors occur due to healthcare system or healthcare facility design. Environmental factors contributing to medical errors include low light levels, inadequate private space for work, frequent distractions and interruptions, and noisy, chaotic environments. These identified root causes of medical errors can help in developing design solutions to maximize patient safety.

In addition, appropriate lighting design and space planning at the nurse station ${ }^{12}$ are important so that medication errors can be reduced and the efficiency can be increased.

During my observations in nursing units at Grand River Hospital, I saw dedicated medication rooms on each floor. Each decentralized nurse station has a dedicated

\footnotetext{
${ }^{12}$ Space planning and nurse station design have a huge impact on efficiency and walking distance.(Zborowsky et al., 2010; C. Zimring et al., 2004). Thus, it is important to consider the impact of these two factors on nurses' job performance.
} 
medication room. Providing appropriate lighting is one important aspect. Reducing interruption and noise is another strategy to prevent medication error. Therefore, Grand River Hospital's medication room was designed to eliminate or minimize interruptions while the nurse assembles the medication. Tina talked about medication room design during her interview. She said:

Typically, in the hospital you find a nurse preparing medications right in the middle of the hallway while multiple people talking and interrupting. Interruptions create medical errors. Therefore, in Grand River Hospital, medication room is designed as a private room where nurses can't get these interruptions. The other part of the medication room is the glass so you can see who is in the medication room.

During my interview with Emily, she said:

Another research piece we did utilize was the research on medication safety, interruption to dispensing of medications and administering medications from nurses. We spent a lot of time on research at previous campus. We had nurses deliver meds without people interrupting them. In old setting, the Pyxis machine was in the hallway. It is very open. It was easy to be interrupted. We were very intentional. We built medication rooms that are enclosed. We also set up the culture. If you were in there, you would not be interrupted. If you are preparing medications, you need that undivided attention. I think this is one of the pieces that we got feedback from nurses. The nurses clearly understand that and appreciate that. The medication room is a place quiet.

Participants talked about medication room design during their interviews. For example, Tina said: "Interruptions create medical errors. So having a room that was a private room where you couldn't get these interruptions. That was evidence-based and it was based on the safety." Additionally, Don also emphasized on lighting level and safety during his interview. He said: “Appropriate lighting in working areas can reduce errors. We made sure to have good lighting levels."

The second design attribute for patient safety is for all rooms to be same-handed. I observed several different patient rooms in the Emergency Department. They are all 
same-handed patient rooms. In these same-handed rooms, furniture placement and location of supplies and equipment are identical. The purpose of these design features is

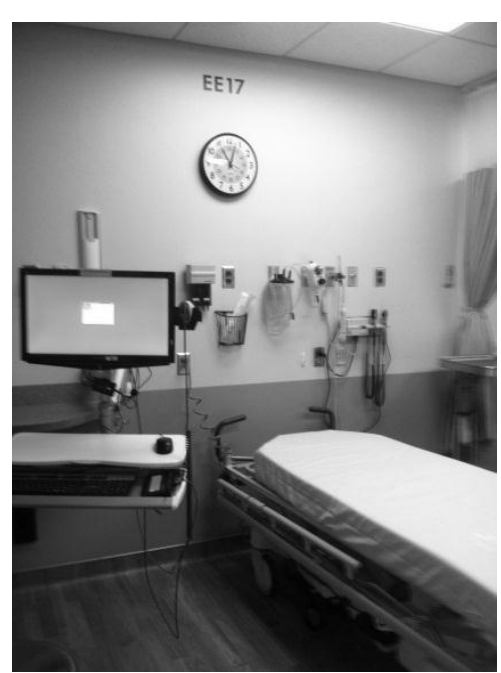

Figure 5.18: Standardized Exam Room in Emergency Department to reduce the cognitive burden on the staff, which is dealing with variations from room to room. I also observed the exam rooms in the Emergency Department. Figure 5.18 is an example of an exam room in the Emergency Department. All the exam rooms are samehanded as well. Same-handed means that everything in the room is in the identical location. That includes the following design attributes: circulation, supplies and functionalities, equipment, the door and hand-washing

sink, the exam tables, medical gas and optical, and all of the supplies. The standardization was utilized for more efficiency and accuracy rather than having different procedures in difference rooms because of different setup in each room. More importantly, research evidence shows that same-handed room layout does reduce error rate. Tim talked about research implementation for designing Grand River Hospital during his interview:

For safety reason, I am pretty sure that all rooms are same-handed rooms. They are the same direction. The rooms are the same configuration. This adds to patient safety. This allows nurses not to think right side or left side of patient. They always go to the same place for materials.

During my interview with Don, he said, "Yes, we pretty much implemented all of this research evidence. Designing a lot of things same-handed is to reduce errors and improve efficiency." Apparently, findings from my observations revealed that research evidence about patient safety is implemented in the design of Grand River Hospital through 
designing same-handed rooms. This is also confirmed by the interviews with the participants.

The third design attribute for patient safety is designing nurse alcoves between two patient rooms (Figure 5.13). This has been discussed in the supervision and control section. In Grand River Hospital, nurse alcoves are spread throughout the nursing unit on every floor. These nurse alcoves allow the nurse to observe the patient and provide direct supervision over patients, which can prevent patient falls. Emily talked about designing nurse alcoves during her interview: "Sub-nurse alcoves allow the nurses to be closer to patients, which reduces patient falls and patient injury."

The other important design feature for patient safety is the bed-escape system. Grand River Hospital installed a bed-escape system on each patient bed, which is a new technology that can prevent patient falls. Ken, as VP for facility planning, talked about the bed-escape system during his interview:

From patient safety perspective, we do have the beds that the patient has fall precautions. If the bed is not set in the prescribed way, according to these precautions, it notifies nurses. Patients get out of the bed, the bed notices different weight, then it would notify the nurse. If the patient is back in bed, it would notify the nurse too. We learned that most patient falls occurred when patient was brought back from imaging or treatment at a different location within the hospital. Patients try to get out of the bed without any assistance and they fall. There is high occurrence for that. Therefore, very large percentage of patient falls is through this kind of situation. Once they were brought back to the bed, the changing of the weight notifies the nurse that the patient is back. Then nurses can attend to that patient and make sure what they need.

Tim talked about the bed-escape alarm during his interview: "Yes, that actually is built in the Hil-Ron bed. That is a bed escape alarm. The nurse will get a call when the patient gets out of the bed. That's part of the safety precautions." 
Obviously, with the nurse alcoves near the bedside and the bed-escape alert, nurses can provide instant help and attention to patients to prevent patient falls. Studies show that the combination of nurses being closer to the patient at decentralized nurse alcoves and family members spending the night in patient rooms contributes to fall prevention. The design attributes I observed correspond to research evidence regarding patient fall preventions. Furthermore, according to this project's post occupancy feedback session and Grand River Hospital survey data, the patient fall rate has been significantly reduced after implementing these design features.

The last couple design attributes for patient

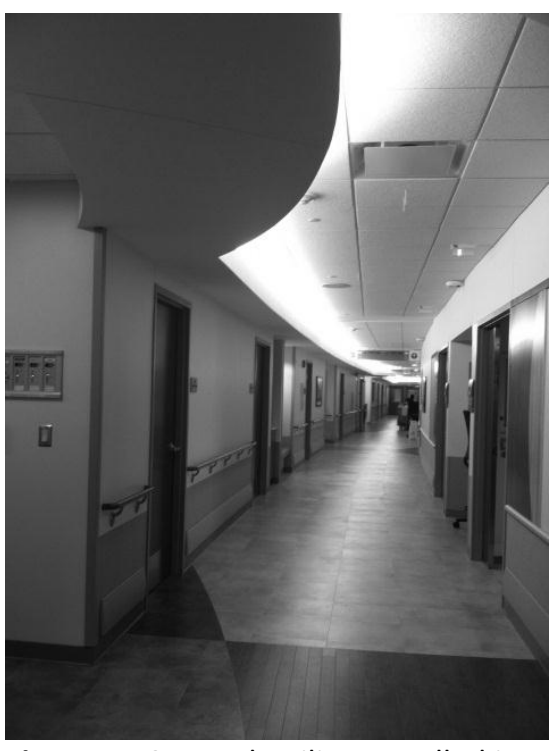

Figure 5.19: Hand Railing Installed in a Slightly Curved Corridor safety are using slip-resistant flooring materials and installing hand railing in hallways. I observed these design features during my observations. Figure 5.19 presents hand railing installed in a slightly curved hallway. Studies show that slip-resistant materials and hand railings can prevent patient falls. The design attributes I observed are in response to research evidence regarding patient fall prevention. The implementation of this evidence was also confirmed

by my interviews with the participants. The following are sample quotes regarding patient fall prevention from the interviews. Tina said:

The tile is slip-resistant. So, the patients won't fall. In the hallway, you want the patient to be mobile and be able to walk. So, we had those hand railings along the sides so they can use those as well as seats.

Tina also added more information regarding patient fall prevention: 
We tried different types of flooring materials. We actually installed some in renovated areas in our old facility. We want to see if it is slippery or too many patterns, which would create fall risk for our patients.

\section{Patient-centered Care and Restoration}

During my observations at Grand River Hospital, I observed an indoor garden

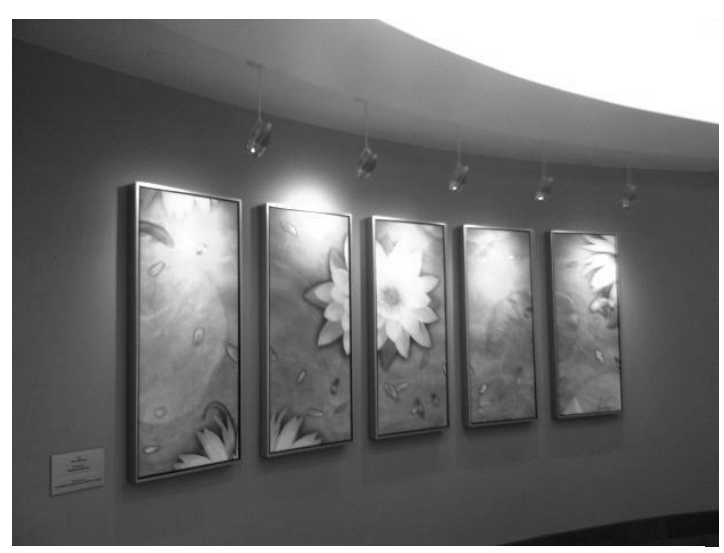

Figure 5.20: Art Works in Hallway which is designed with a water feature and is situated in a corner of the two-story open lobby. I also observed many art works and wayfinding signage that were displayed throughout the facility. Figure 5.20 is an example of artwork hanging in the hallway.

During my interview with Tim, he said:

The artwork selection was almost local source of art. Grand River Hospital invited local artists to bring their art works and present examples of their style. The selection committee looked at all the pieces of art works and decides which style would be most suitable for the facility. Some of the art works are commissioned, some of them are produced already and some of them are replicated. Therefore, it is an appropriate balance. Using art works from local artists really help the organization to have closer connection with the community.

I also saw a white piano (Figure

5.21) situated at the corner of the lobby

during my observation. It is used by the

healing arts program. During my

observation, I saw a lady playing the

piano while a lady was dancing there. A patient in a wheelchair accompanied by

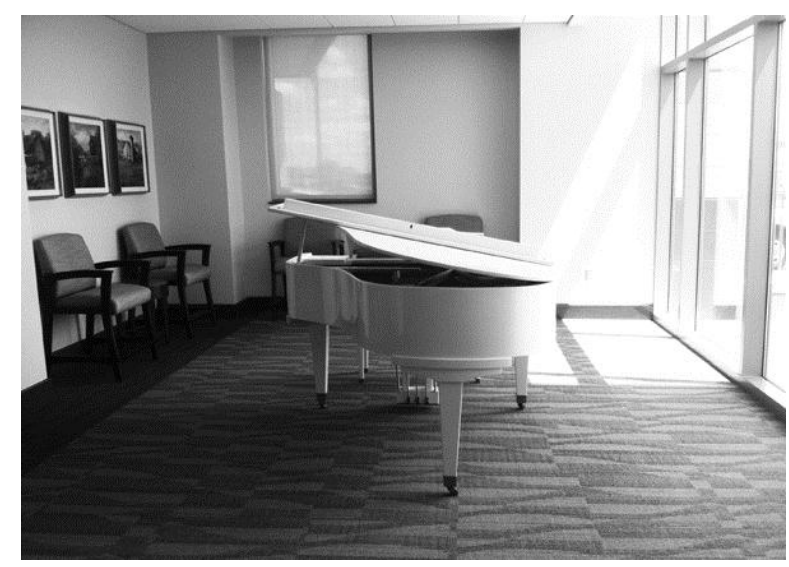

Figure 5.21: Piano at the Corner of Lobby for Healing Art Program 
his family was watching the performance. Later during my interviews with the participants, I brought this back to the interview. The participants confirmed that was the healing art program Grand River Hospital had.

Another design feature in Grand River Hospital is a chapel located on the northeast corner of the surgical lounge on the second floor (Figure 5.22). It is not a very big chapel, but it provides a place for patients and families to pray. Prayer is an important

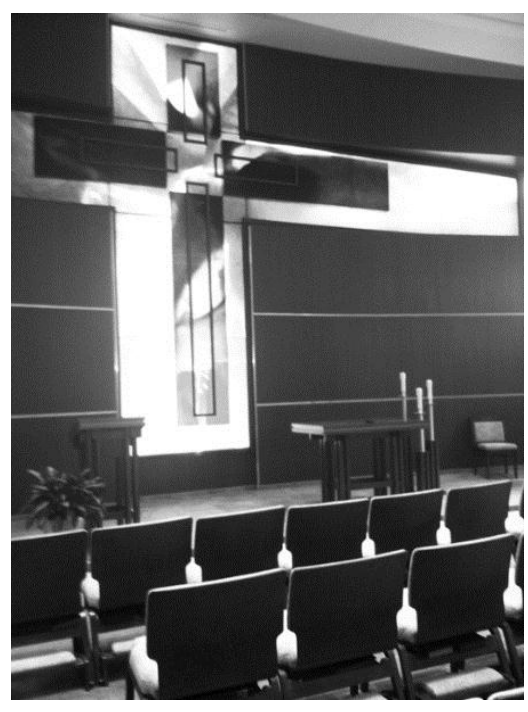

Figure 5.22: The Chapel in Grand River Hospital activity in hospitals, which can be traced back to the Middle Ages. The literature review shows that the relationship of ward to chapel can be seen from many open ward and chapel arrangements all over the hospitals during the Middle Ages. Patients needed to hear mass each day because faith remained the main healthcare offering during that time (Thomson \& Goldin, 1975). Even today, the religious feelings would be even more intense among patients. Designing a chapel to meet the spiritual needs of patients is important in patient-centered care practice. The chapel in Grand River Hospital is a contemporary design with simple design elements. There is a podium, one table, and candles on a raised platform. A big cross is recessed in the wood panel wall. On the northeast corner of the Chapel, there is a stained glass window; the west wall is slightly curved. There is a water fountain at the entrance. 
Another design attribute in the nursing unit at Grand River Hospital is to provide a meeting room for families and medical staff. I observed the meeting room during my observations (Figure 5.23). By providing a meeting space for patients and families, family members can be effectively involved in the diagnostic and treatment process. This space can be used for meetings between physicians and patient family members when the conversations cannot take place in patient rooms. Patientcentered care has emerged as the norm in acute care settings. The American College of Critical Care Medicine

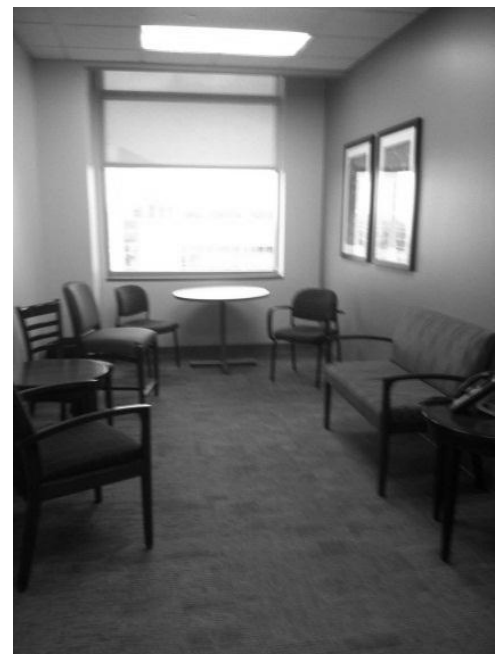

Figure 5.23: Meeting Room for Families and Medical Staff and the Society of Critical Medicine have published recommendations to support family involvement in the care of their critically ill loved ones. With the effectiveness of patient-centered care, the following changes have been made in hospitals: open visitation but determined collaboratively between caregivers and family; single-bed rooms with space for family members; and opportunity for family members to participate in patient care consultation and decision making with clinical

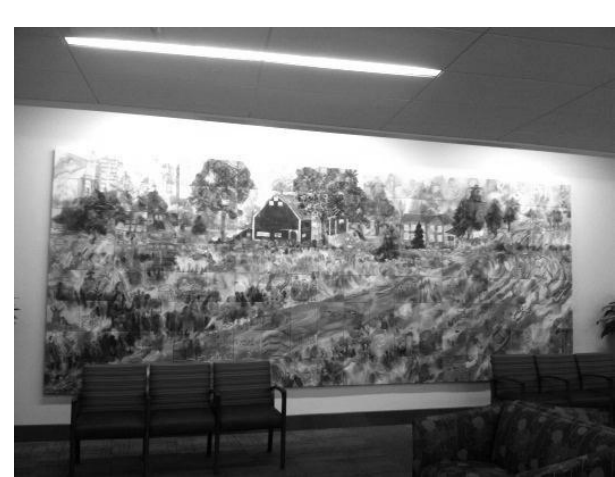

Figure 5.24: A Big Mural Installed in the Waiting Area/Family Lounge in Emergency Department personnel.

\section{In addition, I observed a waiting} area/family lounge in the Emergency Department. The patient waiting arear/family lounge is divided into three sub-areas by partial partitions. A big mural is installed in one of the sub-waiting areas/family areas (Figure 5.24). Several sofas and 
lounge chairs and coffee tables are arranged freely in these waiting areas. There is a touch screen machine that allows children to find questions and answers in the first sub-waiting area (Figure 5.25). A coffee counter is arranged nearby to this waiting area as well. There are two triage rooms on the opposite of this waiting area. There is a children's play area in the center of the waiting area/family lounge. The floor-to-ceiling glass curtain walls allow daylight to shed in. Patients can see outdoor patios and flowers through the big

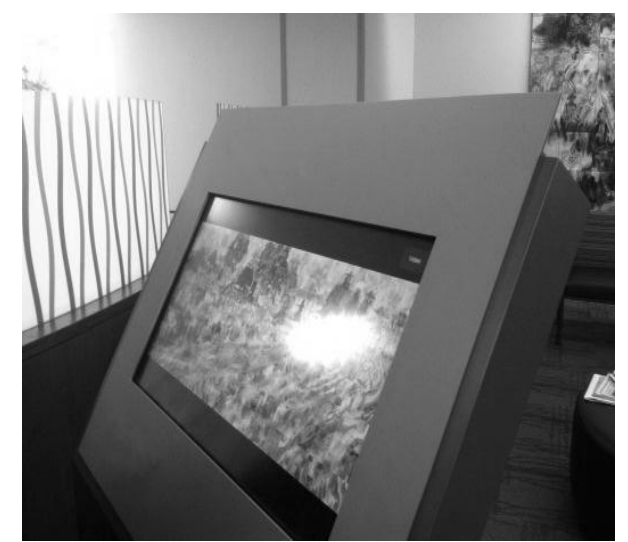

Figure 5.25: Touch Screen Machine for Children in the Waiting Area/Family Lounge in Emergency Department glass windows.

Based on my observations, it appears that these design attributes correspond to research evidence regarding patient-centered care and restorations. Many studies have been conducted in the areas of restoration and stress recovery in the health care environment (R. Ulrich, 1984a; R. S. Ulrich, 1991). Environmental interventions have

been developed to reduce environmental stress, such as healing gardens and art works as positive distractions. Many studies suggest that gardens can be restorative settings for stressed patients, families, and staff members (Marcus \& Barnes, 1999; Sherman et al., 2005; R. S. Ulrich, 1999a). Several studies also suggest to provide positive distraction conditions such as art works in the healthcare environment in order to result in more calm behavior so that improved waiting experience can be achieved (Pati \& Nanda, 2011). Therefore, it is clear that all this research evidence was implemented in the design of Grand River Hospital through the design attributes mentioned above. 


\section{Connecting with Natural Daylight and Window Views}

Another core category emerged from open coding for observations-connecting with nature and providing daylight and window views. Through my observations, I saw big glass curtain walls in the main lobby. I also observed that there was a nice scenic view connecting to nature at the end of the hallway in the nursing unit on each floor

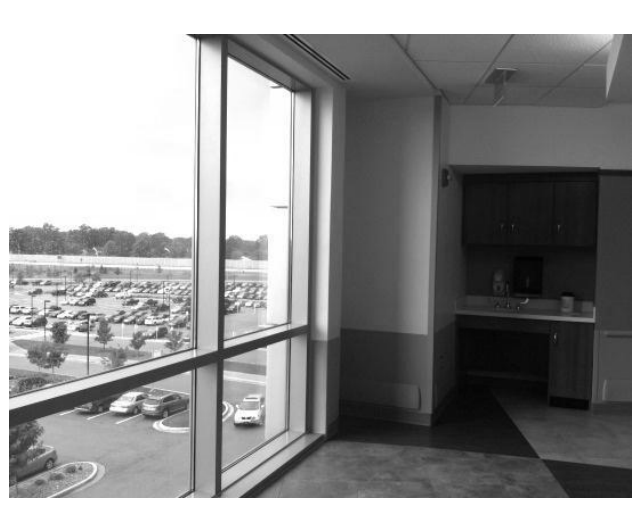

Figure 5.26: Big Window View at the End of Hallway in Nursing Unit
(Figure 5.26). Thus, medical staff can have window views when they are working in the nursing unit. In addition, as mentioned earlier, windows are designed in every patient room in Grand River Hospital. There are several outdoor patios and gardens adjacent to Grand River Hospital. Patients and visitors can rest there.

These patios can be seen from the inside through big glass windows as well. When I conducted observations, I saw visitors and patients sitting at the patios and having conversations.

A great deal of research has shown that connecting with nature in the healthcare environment can reduce stress levels. Therefore, maximizing access to windows with views of nature and daylight is an easy way to improve wellness and job performance of medical staff. The design attributes of maximizing window views in Grand River Hospital correspond to this research evidence. The design feature of connecting with nature is also confirmed by interviews. Sam talked about how the facility was designed to connect with nature during his interview:

I think evidence-based design has become more important in hospital design, especially for healing. Not only for the patients to be eased a little, but also for the 
loved ones. Offering spaces and places that are more soothing is important. Since the water has a very soothing aspect, water has been placed inside Grand River Hospital as well as several outside areas. Setting a soothing theme that welcomes visitors is important because a soothing setting can make patients feel calm.

Sam added in his interview:

There is something to supplement that which is outdoor dining. We created an outdoor dining area that was designed with water elements. Patients and families can go there when weather permits to have outside eating. These outside areas also allow nurses to get away from busy work. Staff can really get away from the hospital by walking there.

Linda talked about how a healing environment was created in her interview:

We looked at the things that affect patients' abilities to heal. Some of these were to make the space less institutional, less clinical and more feeling like hospitality and home like, bringing the outside into the building; the ability to have sunlight and views of outdoor spaces; and definitely the approach of the family and having the family with the patient so that it increases your ability to heal quicker. So, it's important to let family to be part of patients' healing process.

\section{Walking Distance - Efficiency}

As discussed earlier, there are three decentralized nurse stations on each nursing unit floor. Each nurse station supervises twelve patient rooms. There are eighteen decentralized nurse alcoves between each two patient rooms.

Figure 5.2 on page 123 shows

decentralized nurse stations couple with

decentralized supply spaces as well as decentralized nurse alcove outside patient rooms. When I conducted observations in the nursing unit, I saw that there were benches in the hallway for patients and families to rest.

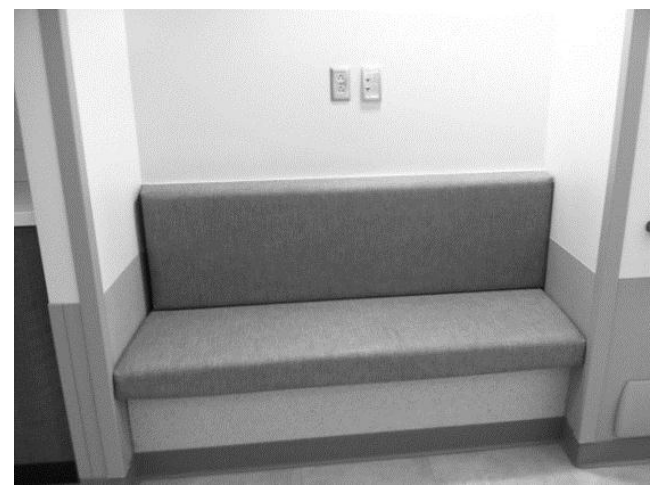

Figure 5.27: Built-in Bench in Hallway in Nursing Unit

Figure 5.27 presents the built-in bench in the hallway. The built-in benches allow patients 


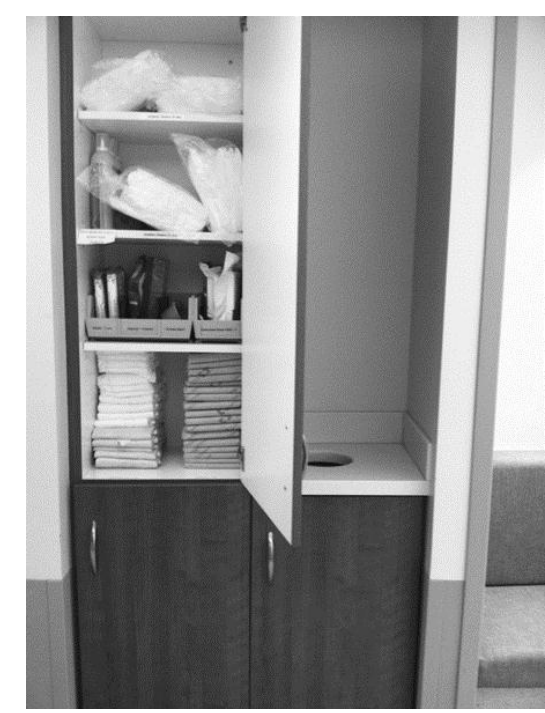

Figure 5.28: Decentralized Supply Space and families to rest in the hallway when they need.

Next to the bench, there is a storage space for medical supplies. There are multiple decentralized supply spaces provided in the hallway of the nursing unit. Figure 5.28 is an example of decentralized supply space that provides convenience for nurses to get the medical supplies so that the walking distances are reduced. Since the location and quantity of handwashing sinks are two major aspects that can

improve compliance and reduce infections, several handwashing sinks are provided in the hallway of the nursing unit (Figure 5.19) in addition to providing a handwashing sink in each patient room. Based on research findings that implementing a handwashing policy is important for infection control, locating a number of handwashing sinks in different locations provides convenience to caregivers in order to reduce walking distance and increase efficiency.

Nurses spend a lot of time walking in their working environment. Many studies have been conducted regarding the walking distance in different types of unit layouts, such as radial, single corridor, double corridor $^{13}$ (M. Shepley \& Davies, 2003; M. M. Shepley, 2002; Sturdavant, 1960; Trites, Galbraith, Sturdavant, \& Leckwart, 1970). A study carried out by Zborowsky et al. (2010) confirmed that decentralized linen and supply storage and decentralized nursing stations with a nursing work area between every

\footnotetext{
${ }^{13}$ Different types of unit layouts are also called hospital typologies. James and Tatton-Brown (1986) defined three elements for a nursing unit: patient space (bed, toilet, and day space); nursing space (nurse station, utility rooms, offices), and corridor. The different ways in which these elements are arranged can be classified into a number of different hospital typologies (James \& Tatton-Brown, 1986).
} 
two rooms or with a cluster design of four to eight rooms around a nursing work area diminished walking distances for nurses (Zborowsky et al., 2010).

Based on findings from observations that were confirmed by interviews, it is clear that these design attributes correspond to research evidence related to walking distance and efficiency. The efficient configuration of nurse station is decentralized nurse stations coupled with decentralized supply rooms because it can reduce walking distance significantly. This research evidence was implemented in the design of Grand River Hospital through design interventions as observed.

\section{Wayfinding}

During my observations, wayfinding design certainly was an important aspect that has drawn my attention. In the lobby area, the wayfinding system was designed by providing an information desk, a touch screen map, and signage throughout the facility. I observed the lobby area to see how visitors were led to their destinations. Did they rely on the information desk? Or, did they follow the signage or simply use the touch screen map? The result of my observations is that almost every visitor would stop at the information desk either to get directions for their destinations or get other questions answered.

There is clear signage in the lobby that leads visitors to elevator lobby, gift shop, imaging, and Heart Institute right next to the information desk. There is additional signage near the indoor garden that leads visitors to the cafeteria and conference rooms. The curved pathway through the indoor garden intuitively leads visitors to enter the cafeteria, which is open to the community. 
Designing a wayfinding system by providing multiple wayfinding designs for Grand River Hospital was confirmed by my interviews with participants. Tim talked about wayfinding design during his interview. He said:

From a wayfinding standing point, there were a lot of time and effort to look at wayfinding. The wayfinding consultant was incredible. They looked at the entire project and wayfinding was coordinated with our work. So, the art work was provided not only as positive distraction, but also the art work itself is part of wayfinding system as well. They are located at certain point that can get people to the destinations. Not just rely on signage. The artwork will lead you to the facility as land mark.

I interviewed Ted, who is the wayfinding design consultant. He provided his insight and opinions about wayfinding design. He said, "My company does three things.

We are place makers, we are environmental graphic designers. We add jewelry or final layers of visual components on large scale projects." Ted added, "Before we do anything in place making, environmental graphics, and wayfinding, we must understand our audience." Ted also talked about how they conducted research for wayfinding design for Grand River Hospital project. He said:

Now everything is based on evidence-based design. It is really based on experience. To work on the experience, we have to understand the factors that affect someone's behavior. We engage to the project not just in office looking at the architectural and interior floor plans. We need to observe our client. So we took a team of people to Grand River Hospital. We interviewed people. We have photographed people and followed people. Basically, we observed what happened to people. We sat in cars and we watched them. See if they followed people or they followed the sign. We made observations. We took notes and pictures and watched. Same thing happen to the interiors.

Ted talked about how they observed people in the lobby during his interview:

What happened to the lobby door? Where do visitors go first? Some people know where they go. But some people have to go to front desk and must have visual confirmation and they must talk to someone. There are some people who are very technical. They expect to have something to download to their smart phone. Then you may have someone rely on maps or diagrams and always looking for orientation maps. 
Because of the diverse audience and users, it is extremely important to study these audiences. Ted said:

We study our audience regarding their age group and their educational levels. We followed people, took notes and we took hundreds of pictures of daytime and nighttime, weather conditions, exterior and interior. We interviewed people at the front desk. We interviewed security people and volunteers. We interviewed everybody who had the badge. We conducted interviews with nursing people, hospital administrators, leadership, architects, landscape architects, civil engineers for Grand River Hospital. We try to understand the core challenge. That's our evidence-based design.

Clearly, conducting research is an integral component in wayfinding design for Grand River Hospital. The design decisions certainly were informed by the wayfinding consultant's research. When I conducted interviews with other participants, they all talked about the wayfinding design that does not solely rely on signage; instead, it is a wayfinding system that uses one design intervention to compliment other design interventions in order to achieve the best wayfinding performance. The following are additional quotes regarding wayfinding design from my interview with Ted. He said: "Artwork is used in wayfinding. You use a point as a reference to get directions. It is called a landmark. We have different landmarks in the hospital and lobbies." Ted also added: "Information giving is very important in the hospital. When you go to patient rooms in other hospitals, you see flags, papers on the doors." Ted explained how the information was given in the design of Grand River Hospital. He said:

At Grand River Hospital, we designed some kind of insert plank with color codes so that precaution can be given on the door. Patient room planks - electronic planks meaning the room number is electronic and ties back to the nurse station and ties to an in-room message board in each patient room. We have to be very careful regarding how we display these messages. We have to understand different levels of given cautions. 
Spatial configuration is considered the most important aspect of good wayfinding design because it makes the space easier to understand and navigate. ${ }^{14}$ In addition, a good wayfinding design can be achieved through a variety of visual cues, including signage, landmarks, maps, information desks, directories, shape, color, textures, light, and sound. Therefore, creating a wayfinding system that integrates visual cues and providing an intuitive floor configuration is important to achieve a good wayfinding performance in complex healthcare facilities.

Apparently, findings from my observations and interviews show that the wayfinding design for Grand River Hospital is research informed. Research evidence regarding designing a wayfinding system using multiple design interventions is implemented for this project.

\section{Summary of Research Evidence Implemented in the Design of Grand River Hospital}

Based on my observations and interviews, it is clear that a lot of research evidence was implemented through design innovations. The design attributes I observed correspond to published research evidence. To summarize the research evidence that was implemented in the design of Grand River Hospital, I would like to use quotes from interviews. One participant said:

Yes, we pretty much implemented all of research evidence. Designing lots of things same-handed rooms; everything is at the same place and the nurses don't need to go look for stuff. It reduces error rates and improves efficiency. Every

\footnotetext{
${ }^{14}$ A previous study suggested that wayfinding systems can be designed and implemented by two different approaches. One approach is to create floor plan that can intuitively guide wayfinding performance with environmental cues. Another approach is to increase architectural legibility by creating distinctive places or forms that can be memorialized through size, proportion, materials and furnishings in order to enhance wayfinding systems (Marquardt, 2011).
} 
place we could, we would put views and natural lights; positive distractions and even it is just artwork. Every patient room has a very large family area that encourages family to room in and stay with the patients. Study shows if you can engage patient family into the process, patients heal faster and go home sooner and have less readmit than those who do not have family involved in the care. Regarding Wayfindings, we try to keep things very simple and have very straightforward circulation. So we don't have to rely on excessive amount of signage. Signage we did use was clean, very precise and arranged in very critical area. Again, simple process and logical progression through orienting factors. When you are going through elevator area, you see a fountain or a view to outside, a light at the end of corridor which help patients and family orient where they are in the space. We do see the need for traditional signage as well.

In addition to the design attributes mentioned above that was designed in response

to research evidence, another design feature that deserves a special mention is their

bariatric room design. Tina spoke about the design process for bariatric rooms in detail:

Regarding our bariatric rooms, we never have had bariatric rooms, unfortunately patients weigh more, like a 500 pounds patient is not at normal. A typical hospital patient room was built at max maybe for 300 pounds patient. So we had to do lots of investigation on bariatric beds, furniture to make sure it was respecting for dignity and also that would maintain their weight. Big piece of that would be the lifting equipment. It is the best practice that you don't see hospital doing this to have a patient lift in every room. So we had lot of different vendors to determine which one is the easiest one to use. It needs to be safe to our patients and safe to our workers. The bariatric lift is different from the lift we use for average weight patients, creating that size of room would allow having that type of device as well as larger pieces of furniture. We spent a lot of time creating these bariatric rooms, which is positive for each of these individuals.

In summary, research evidence was interpreted and implemented in the design of

Grand River Hospital in order to achieve the best possible outcomes. These findings came out of a triangulation method by using multiple sources of data.

\section{Findings from Document Reviews (Data Triangulated by Interviews)}

I conducted document reviews for this case study at Grand River Hospital. Table 5.7 is the open coding for document reviews. Table 5.7 presents data sources that include 
architect design documents, websites for all stakeholders, and published articles. The table also presents the titles of the documents as well as the main categories/concepts that emerged from the document reviews. Some of these main categories/concepts are used for axial coding and selective coding for research question \#1 and research question \#2, which have been discussed in previous sections (findings from interviews in this chapter). However, some of these categories/concepts really pertain to the theme regarding how research is conducted at Sackerber Architects. In this section, four important findings from document reviews will be discussed. These findings include research in practice at Sackerber Architects, Functional Performance Evaluation (FPE) in Sackerber Architects, Parametric Modeling Tool, and Institute of Design Research and Evaluation (IDRE). The implication of findings will be discussed as well.

Table 5.7: Open Coding for Document Reviews

\section{Open Coding for Document Reviews}

Data Sources Titles Categories/Concepts

\begin{tabular}{lll}
\hline $\begin{array}{l}\text { Architect Design } \\
\text { Document }\end{array}$ & $\begin{array}{l}\text { Guiding Principles and Key } \\
\text { Block Plan Drivers }\end{array}$ & $\begin{array}{l}\text { Guiding principles; safety and quality; service } \\
\text { excellence; physician effectiveness; } \\
\text { affordable; efficiency; grows; lean and } \\
\text { teamwork; communication; technology; } \\
\text { adaptability and flexibility; diverse needs; } \\
\text { trusted care; community and environment }\end{array}$ \\
& & \\
& Patient and Staff Safety & Lighting; noise reduction; visibility; hand \\
Architect Design & washing accessibility and air quality; acuity \\
Document & adaptable features; supplies/equipment \\
& accessibility; travel distance minimization; \\
& room standardization; access to information \\
& technology/communications; prevent patient \\
& falls; healthy environments; compliance with \\
& ADA; ergonomic considerations in work \\
& spaces
\end{tabular}


privacy; window view; daylight; patient storage; infection control; hand wash sink; multiple hand sanitizer dispenser; family amenities

\begin{tabular}{lll}
\hline Healthcare Design & Keys to Collaboration and & Integrated approach; without formal \\
Magazine & Process & integrated project delivery (IPD) contract; \\
& collaboration for success; guiding principles; \\
& state-of-the-art technology; healing \\
& environment for patients and their families; \\
& design charrette/workshop; budget and \\
& schedule; benefit the community; integration \\
& of all team members early on
\end{tabular}

\begin{tabular}{|c|c|c|}
\hline Architect Website & Grand River Hospital Project & $\begin{array}{l}\text { Minimize travel distances; visually cohesive } \\
\text { campus; increase flexibility and efficiency; } \\
\text { family-centered environment; natural } \\
\text { materials; soothing colors; daylighting is } \\
\text { maximized; wayfinding; concourse; } \\
\text { decentralized nurse station }\end{array}$ \\
\hline Architect Website & $\begin{array}{l}\text { Grand River Hospital } \\
\text { Project's Vision and Design }\end{array}$ & $\begin{array}{l}\text { Community spirit; promoting health; wellness } \\
\text { and family centered care; healing } \\
\text { environment; quality care; patient and staff } \\
\text { safety; reducing medical errors; reducing } \\
\text { patient falls and injuries; efficiency; travel } \\
\text { distance; voices of doctors and nurses for } \\
\text { operating rooms; exam rooms and patient } \\
\text { rooms; intuitive wayfinding; cues of } \\
\text { pathway, landmark form; lighting; pattern, } \\
\text { art and signage; sustainability; team } \\
\text { collaboration; an integrated delivery model } \\
\text { with standard contract }\end{array}$ \\
\hline
\end{tabular}

\begin{tabular}{|c|c|c|}
\hline $\begin{array}{l}\text { Project Manager - } \\
\text { LDJ Global Project } \\
\text { and Development } \\
\text { Service Company } \\
\text { (Consultant) } \\
\text { Website }\end{array}$ & $\begin{array}{l}\text { Healthcare construction and } \\
\text { design }\end{array}$ & $\begin{array}{l}\text { Collaborative healthcare best practices } \\
\text { techniques and project management; smart } \\
\text { rooms; smart beds and materials handing } \\
\text { robots; over-bed lift systems in each patient } \\
\text { room; minimize back strain for caregivers; } \\
\text { energy efficient windows; window views; } \\
\text { nature }\end{array}$ \\
\hline $\begin{array}{l}\text { Project Manager - } \\
\text { LDJ Global Project } \\
\text { and Development } \\
\text { Service Company } \\
\text { (Consultant) } \\
\text { Website }\end{array}$ & Innovative execution & $\begin{array}{l}\text { Collaborative process; three-stage design } \\
\text { process; soliciting separate bid package; } \\
\text { strategically re-sequenced construction; lime } \\
\text { stabilization that mixes lime with excavated } \\
\text { soil to chemically heat to enable backfill work } \\
\text { in freezing cold weather }\end{array}$ \\
\hline
\end{tabular}




\begin{tabular}{|c|c|c|}
\hline $\begin{array}{l}\text { Grand River } \\
\text { Hospital Website }\end{array}$ & $\begin{array}{l}\text { NICU (Newborn Intensive } \\
\text { Care Unit) }\end{array}$ & $\begin{array}{l}\text { Family-centered care; all private patient } \\
\text { room; family space in patient room; family } \\
\text { participate in the care of newborns }\end{array}$ \\
\hline Contractor Website & $\begin{array}{l}\text { Grand River Hospital } \\
\text { Construction }\end{array}$ & $\begin{array}{l}\text { Joined venture; patient-centered care; } \\
\text { blending the latest technology; safety }\end{array}$ \\
\hline $\begin{array}{l}\text { Architect's Design } \\
\text { Document }\end{array}$ & $\begin{array}{l}\text { Grand River Hospital Post } \\
\text { Occupancy Debrief Report / } \\
\text { Lessons Learned }\end{array}$ & $\begin{array}{l}\text { Design guiding principles; safety and quality } \\
\text { throughout planning and design work; } \\
\text { physician effectiveness and satisfaction; } \\
\text { responsive to care delivery process; lean } \\
\text { workspace and workflow; cutting-edge } \\
\text { technology to improve patient care, } \\
\text { throughput and staff efficiency; growth; } \\
\text { adaptability and flexibility; embrace the } \\
\text { community and the environment (green); } \\
\text { reduced fall rates; increased market share; } \\
\text { reduction in employee injuries; errors are } \\
\text { lower overall; patient experience; aesthetics; } \\
\text { wayfinding; spacious family friendly smart } \\
\text { room; ceiling lifts; interdepartmental } \\
\text { adjacency; technology; opportunity for } \\
\text { study/publication; research opportunity }\end{array}$ \\
\hline $\begin{array}{l}\text { Architect's Design } \\
\text { Document }\end{array}$ & Post CD work plan schedule & $\begin{array}{l}\text { Architectural design; interior design; mock- } \\
\text { up room changes; MEPF coordination; } \\
\text { exterior architectural standards; key dates; } \\
\text { coordination meetings; project management }\end{array}$ \\
\hline $\begin{array}{l}\text { Architect's Design } \\
\text { Document }\end{array}$ & $\begin{array}{l}\text { Grand River Hospital project } \\
\text { action items }\end{array}$ & $\begin{array}{l}\text { Construction documents; } \\
\text { milestones/schedule; responsible party; } \\
\text { architectural; partition; roof plan; casework; } \\
\text { reflected ceiling plan; details; misc. items } \\
\text { from Grand River Hospital design standards; } \\
\text { site work coordination }\end{array}$ \\
\hline Architect Website & $\begin{array}{l}\text { Research in practice/ } \\
\text { featured research }\end{array}$ & $\begin{array}{l}\text { Constantly exploring, learning, } \\
\text { experimenting and testing - all the way from } \\
\text { concept through occupancy; } \\
\text { comprehensively target and achieve better } \\
\text { outcomes through design; research in } \\
\text { practice; inform through design process and } \\
\text { confirm at the end of process; target; } \\
\text { explore; define; measure; monitor; test; } \\
\text { functional framework; wayfinding; workflow; } \\
\text { relationship; flexibility; technology; } \\
\text { patient/family; stress; key rooms; operations; } \\
\text { support; safety; sustainability; research is } \\
\text { everything below the surface; functional } \\
\text { performance evaluation; every design } \\
\text { decision is a performance hypothesis; multi- } \\
\text { method tool; FPE site audits; user feedback; }\end{array}$ \\
\hline
\end{tabular}


environmental analysis; organizational

success metrics; triangulation of data collection; continuous improvement; research is not prescriptions for design; research is the ingredients for design; CADRE; non-profit unbiased research group; develop and implement relevant original research

\begin{tabular}{lc}
\hline Institute of Design & Healthcare Workplace: \\
Research and & Design Diagnostic of the \\
Evaluation & Surgical ICU \\
(IDRE)Website &
\end{tabular}

A systematic current state analysis that studies the relationship between facility design; human experience and organizational efficiency in order to inform future state design' study design; user experience \& workflow; space utilization analysis; patient room configuration; nurse station; walking analysis; sound analysis; patient monitoring; metrics that matter

\begin{tabular}{lcl}
\hline $\begin{array}{l}\text { Institute of Design } \\
\text { Research and } \\
\text { Evaluation (IDRE) }\end{array}$ & $\begin{array}{c}\text { Clinic 20XX: Designing for an } \\
\text { Website }\end{array}$ & $\begin{array}{l}\text { Drivers for healthcare paradigm shift; } \\
\text { system; patient; provider; field, technology; } \\
\text { more access and more accountability for } \\
\text { patients; drivers that lead to several trends: } \\
\text { mHealth; Telehealth; coordination health; } \\
\text { population health; retail health } \\
\text { understanding physicians and patients; } \\
\text { guiding principles for a change }\end{array}$ \\
& & \\
\hline $\begin{array}{l}\text { Institute of Design } \\
\text { Research and } \\
\text { Evaluation (IDRE) } \\
\text { Website }\end{array}$ & Field Research Manual & $\begin{array}{l}\text { Field research framework; reported data; } \\
\text { observed data; spatial data; kick off call; } \\
\text { online survey development; interview and } \\
\text { observation guide; parametric analysis; data } \\
\text { analysis and report }\end{array}$ \\
\hline
\end{tabular}

According to open coding for document reviews, one major finding that emerged was how research was conducted at Sackerber Architects. Findings were summarized in Table 5.8. These research activities and strategies at Sackerber Architects were also confirmed by the participants during their interviews since this study took an approach that used a triangulation method with multiple sources of data. The following section describes the findings from document reviews regarding research activities and research strategies at Sackerber Architects. In the meantime, interview quotes are used to confirm 
the findings from document reviews. At the end of the findings from document reviews, the implications of findings are discussed. The implication from this research is a redefined model of design process by integrating evidence-based design. A description and explanation of redefined design process is also articulated.

Table 5.8: Findings from Document Reviews (Confirmed by Interviews)

\begin{tabular}{ccccc}
\hline \multicolumn{2}{c}{ Findings: How Research is Conducted at Sackerber Architects and Their Research Strategies } \\
\hline $\begin{array}{c}\text { Research in Practice } \\
\text { in Sackerber } \\
\text { Architect }\end{array}$ & $\begin{array}{c}\text { Functional } \\
\text { Performance } \\
\text { Evaluation (FPE) in } \\
\text { Sackerber Architects }\end{array}$ & $\begin{array}{c}\text { Parametric } \\
\text { Modeling Tool }\end{array}$ & $\begin{array}{c}\text { Institute of Design } \\
\text { Research and } \\
\text { Evaluation (IDRE) }\end{array}$ & Implications \\
\hline $\begin{array}{c}\text { Design process: } \\
\text { Research informs } \\
\text { design and research } \\
\text { confirms design }\end{array}$ & $\begin{array}{c}\text { Process of Functional } \\
\text { Performance } \\
\text { Evaluation (FPE) }\end{array}$ & Spatial analysis & $\begin{array}{c}\text { Publications, tools } \\
\text { and resources at } \\
\text { IDRE }\end{array}$ & $\begin{array}{c}\text { Redefined model of } \\
\text { design process by } \\
\text { integrating } \\
\text { Evidence-based } \\
\text { Design }\end{array}$ \\
\hline $\begin{array}{c}\text { Process of research in } \\
\text { practice at Sackerber } \\
\text { Architects }\end{array}$ & Field research \\
framework & Proximity studies & $\begin{array}{c}\text { Research evidence } \\
\text { compiled by IDRE }\end{array}$ & \\
\hline $\begin{array}{c}\text { Design metrics and } \\
\text { performance metrics } \\
\text { for research in } \\
\text { practice }\end{array}$ & & & & \\
\hline
\end{tabular}

\section{Research in Practice at Sackerber Architects}

One of the important findings from document reviews is how Sackerber Architects conduct research and how they integrate research in practice. This important finding was also confirmed by interviews. Sackerber Architects is an architectural design firm, well-known nationally and internationally, that devotes a lot of effort and energy to research in architectural practice. Sackerber Architects is an Evidence-based Design Accreditation and Certification (EDAC) firm based on how many people have passed 
EDAC exams. Sackerber Architects was also the Pebble project partner in 2014. They worked with different healthcare systems on the Pebble project.

According to document reviews, research in practice at Sackerber Architects is about constantly exploring, experimenting, and testing - all the way from design inception through user occupancy. Sackerber Architects strive to focus on meaningful metrics including design metrics and performance metrics as well as technology, and they address wellbeing for the individual, the healthcare organization, and the builtenvironment. They believe that research in practice is to comprehensively target and achieve the best possible outcomes through design innovations. In my document reviews, I found a quote by Susan regarding research in practice at Sackerber Architects. Susan wrote:

Research is not just about writing reports, peer-reviewed papers, or books. Nor is research about creating prescriptions for design. Rather, the purpose of research is to create the ingredients for design; to discover what works, and why it works, allowing architects to create the most amazing environments based on the best possible information and insight.

Susan also told me during her interview: "We have a very active research team in house. We conduct our own research in addition to post occupancy evaluation. We developed a very robust post-occupancy evaluation tool, which is called functional performance evaluation (FPE)." FPE will be discussed in detail in the following section. Based on document reviews and interviews, I created the following diagram (Figure 5.29) to represent the design process that is used at Sackerber Architects. The design process is informed by research at the beginning of the design process and the process is ended by research in order to confirm that the best possible outcomes have been achieved as planned. 


\section{Design Process}

Programming Schematic Design

\section{Research}

Research and Confirm

Figure 5.29: Research-Informed Design and Research-Confirmed Design Diagram

During my interview with Angie, she also talked about how they implement research evidence in practice. She said:

As I always worked with the idea of evidence-based design, I don't know any other way. To me, you bring to the table the best practice. Evidence-based design now allows us to have more research evidence to look at. It's how we have been doing things for a long time at least at Sackerber Architects. We always look what is out there and what is the best practice. We are very involved in what is out there in terms of research evidence. We have a very concrete internal research group. So we have research on our own team. Research has been very important for us.

During my interview with Susan and Karen, they talked about how research was conducted at Sackerber Architects. Susan said, "It is critical to realize that design solutions are performance hypothesis. They cannot be tested without metrics. Therefore, design solutions need to be linked with potential outcomes. In addition, design metrics have to be linked with performance metrics." Based on document reviews and interviews, I created the following chart that illustrates the research process at Sackerber Architects (Figure 5.30). During this research process, whether the design is constructed as planned and whether the hypothesis is true will be examined and evaluated. At Sackerber 
Architects, the research findings for a specific project are compared to baseline and industry benchmarks. The following chart provides a framework for all healthcare research projects at Sackerber Architects. The research in practice process starts with "Target" and then goes through "Explore," "Define," "Measure," "Monitor," and "Test."

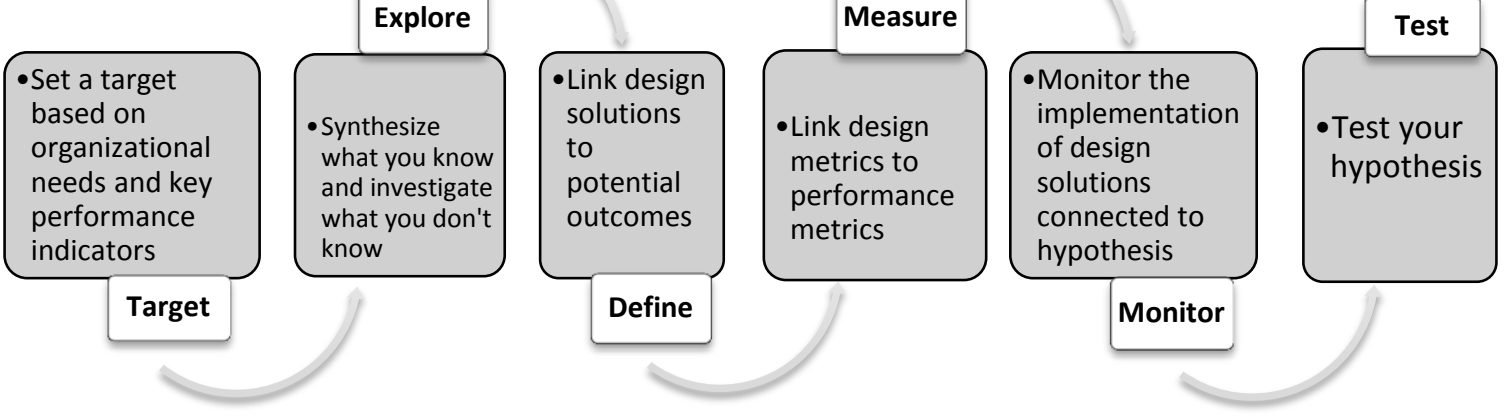

Figure 5.30: Process Model of Research in Practice at Sackerber Architects

Since the impact of design solutions cannot be tested without metrics, linking design metrics with performance metrics becomes critical in research. Based on document reviews and interviews, I also created the following table (Table 5.14) to present the design metrics and performance metrics that are used in research and performance evaluation at Sackerber Architects. The Design metrics include travel distance, adjacencies, lines of sight, acoustic properties, configurations, material performance, flexibility, and adaptability. The performance metrics include satisfaction, employee turnover, employee injury, energy consumption/building performance, fatigue, efficiency/productivity, usability/occupancy metrics, environment/physics health, and environment metrics (lighting, sound, etc.). These design metrics and performance metrics have been used at Sackerber Architects when they conduct research. Both 
Process Model of Research in Practice (Figure 5.32) and Design Metrics and

Performance Metrics for Research in Practice (Table 5.9) are the research frameworks at Sackerber Architects.

Table 5.9: Design Metrics and Performance Metrics for Research in Practice at Sackerber Architects

\begin{tabular}{|c|c|c|}
\hline \multicolumn{3}{|c|}{$\begin{array}{c}\text { RESEARCH in PRACTICE } \\
\text { Design Metrics and Performance Metrics }\end{array}$} \\
\hline Design Metrics (Physical Data) & $\begin{array}{l}\text { Performance Metrics } \\
\text { (Operational Data) }\end{array}$ & \\
\hline Travel Distance & Satisfaction & \multirow{3}{*}{$\begin{array}{l}\text { 1. Design solutions are } \\
\text { performance hypothesis. They } \\
\text { cannot be tested without } \\
\text { metrics. }\end{array}$} \\
\hline Adjacencies & Employee Turnover & \\
\hline Lines of Sight & Employee Injury & \\
\hline Acoustic Properties & $\begin{array}{l}\text { Energy Consumption/Building } \\
\text { Performance }\end{array}$ & \multirow{3}{*}{$\begin{array}{l}\text { 2. Is the design being } \\
\text { implemented as planned? Are } \\
\text { your hypothesis protected? }\end{array}$} \\
\hline Configurations & Fatigue & \\
\hline Material Performance & Efficiency/Productivity & \\
\hline Flexibility/Adaptability & Usability/Occupancy Metrics & \multirow{3}{*}{$\begin{array}{l}\text { 3. Compare to baseline and } \\
\text { industry benchmarks. Did it } \\
\text { succeed? Where did it fail? } \\
\text { Why? }\end{array}$} \\
\hline & Environmental/Physical Health & \\
\hline & $\begin{array}{l}\text { Environment Metrics (Lighting, } \\
\text { Sound, etc.) }\end{array}$ & \\
\hline
\end{tabular}

\section{Functional Performance Evaluation (FPE) at Sackerber Architects}

Functional Performance Evaluation (FPE) is another important finding from this research according to document reviews and interviews. During my interview with Susan, she said, "We actually developed a very robust post-occupancy evaluation tool, which is called functional performance evaluation (FPE)." FPE is a multi-method tool developed by Sackerber Architects' design and research teams based on their fundamental premise that "every design decision is a performance hypothesis." The FPE 
is focused on understanding how the designed facility is supporting the people and processes within the space as originally envisioned. A well-designed facility can improve performance at multiple levels including behavioral, environmental, and organizational levels. The true evaluation of the success of a design project is its functional performance after occupancy. According to document reviews, the FPE includes site audits, user feedback, environmental analysis, and organizational success metrics. The philosophy is using "triangulation" data collections. The researchers collect meaningful data using key metrics and use multiple measures before developing conclusions. The FPE provides facility owners insight into ways to improve and optimize operations through facility design, and assists design teams in understanding the consequences of their decisions and engaging in continuous improvement.

Document reviews also revealed that typically there are four team members on a functional performance evaluation team. They are Sackerber Architects' senior leadership, subject matter expert, project team member, and research assistant. The FPE process takes twelve weeks. One of the key things is the site tour that only takes two days so that the research team will not disturb the client's daily operations. The FPE team tries to collect data which has been collected by the organization, such as patient fall rates and injury rates. On the architecture side, it includes the square footage. For a healthcare project, the FPE team specifically looks at operational statistics, staff survey statistics, and health outcome statistics. Before going to the site, the FPE team sends out a survey to get users' feedback. The survey is sent to the senior leadership of the healthcare organization, physicians and staff, unit directors, and managers. Sometimes the FPE team will conduct focus groups to get their feedback. On the site tour, the FPE team looks at 
the key spaces, such as patient rooms, corridors, and other main spaces. The FPE team focuses on the building scale and the room scale. There are a series of environmental analyses on the site tour. The FPE team looks at the sound level, travel distance, and visibility. The team tries to understand the percentage of visible spaces from different points. After collecting all these data, the team analyzes and triangulates the data.

All the findings about FPE from document reviews were confirmed by interviews. More importantly, more information was yielded from interviews and all information was verified and clarified regarding FPE during interviews. During my interview with Susan, she talked about the process for FPE. She confirmed and clarified:

We would send out a survey to staff members before we go out to the site. It's a full day audit. It usually includes one senior designer, one junior designer, one clinical/operational person, and one person as guest who has expertise in healthcare design. The assumption is always at least one person if not two who are not originally on the design team and at least one person who is originally from the design team. We kind of try to keep it balanced.

Susan also explained what they do for FPE:

Part of what we do for FPE is that before we go to the site, we not only send out the survey, but also ask them to share with us all their metrics, which could be on patient falls, infections, HCAHPS, etc. We do make sure that we triangulate all different kinds of data, such as their key performance indicators, our expert audit, as well as their survey data.

Susan also indicated in her interview:

We would also get light level and sound level on site. The other thing that we start doing just for the most recent FPEs is we use parametric modeling tools that help us measuring walking distances and visibility from key points of the unit.

Parametric modeling is a simulation which will be discussed in detail in the next section.

From both document reviews and my interview with Susan, another very important aspect emerged. Sackerber Architects has a non-profit research unit called Institute for Research Evaluation. IDRE not only conducts FPE, but also conducts 
research-only projects. IDRE does deeper dive studies which has distinguished Sackerber Architects from other design firms in the nation. More detailed information about IDRE will be discussed in the following section.

Based on data from document reviews and interviews, the process for FPE is summarized and illustrated in Figure 5.31. The first step is information gathering; the second step is to do observations, interviews, and questionnaire in the field; the third step is applying simulation modeling, such as parametric modeling; and then interpreting these findings and evaluating and integrating them into the design in the future. The significance of FPE is to engage in deeper dive studies by using triangulated methods.

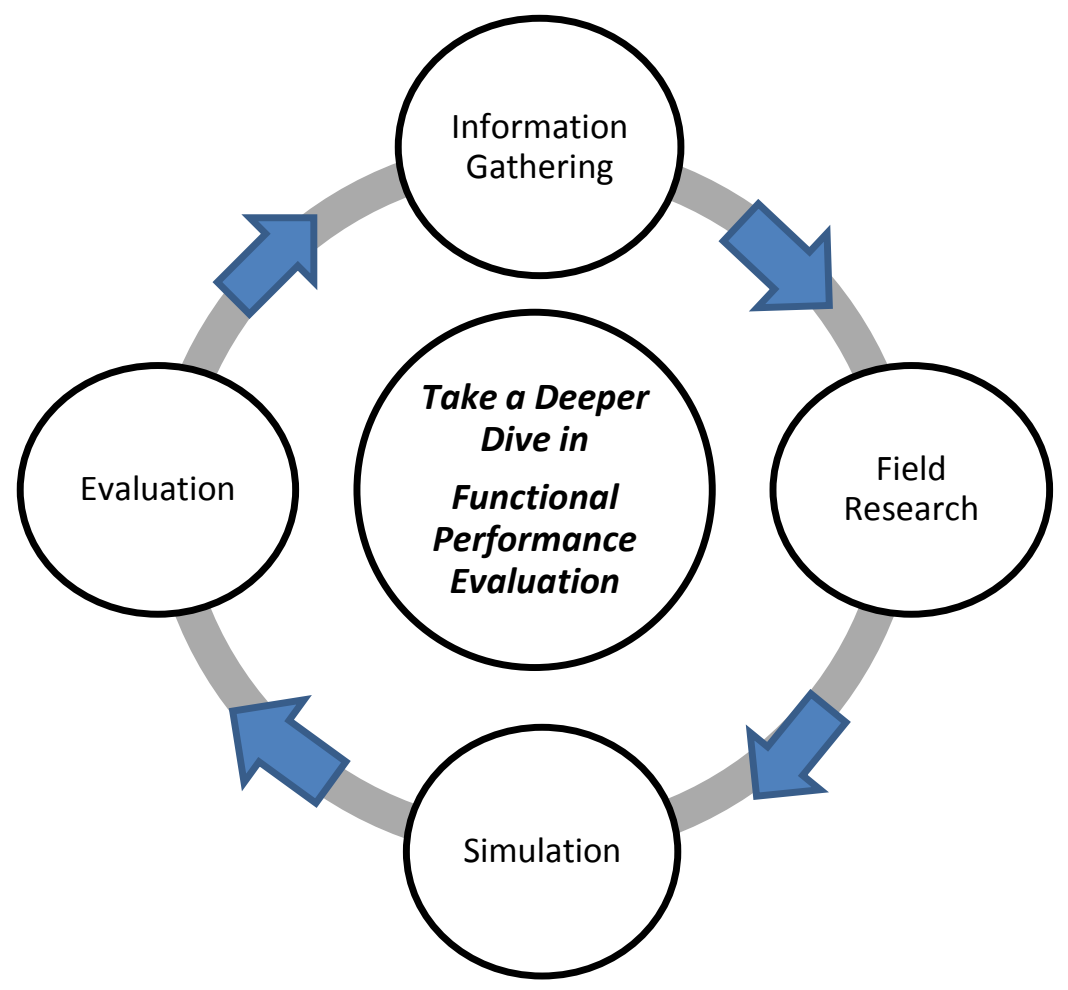

Figure 5.31: Process of Functional Performance Evaluation (FPE)

Furthermore, there are three components in the FPE process that include human experience, operations, and design. Figure 5.32 was created based on document reviews and interviews regarding these three major areas. The first phase is to ask the client what 
their experience is and their design intents are and what they are trying to achieve. The second phase focuses on how their design intent is applied to their operations. The third phase is focused on design. Figure 5.32 presents deeper dive studies in functional performance evaluation that examine human experience, organizational operations, and facility design.

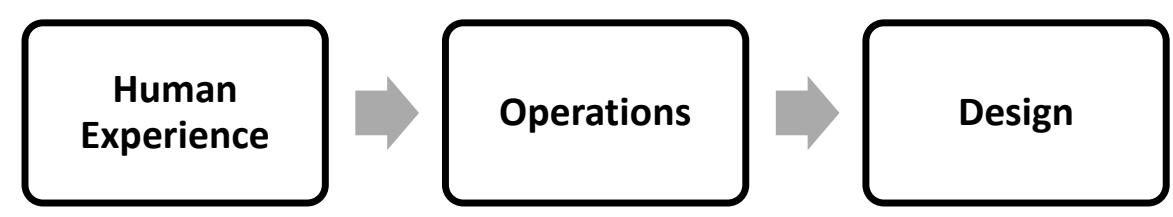

Figure 5.32: Deeper Dive Studies - Functional Performance Evaluation (FPE)

For deeper dive studies in these areas in functional performance evaluation (FPE), twelve key measure categories are identified at Sackerber Architects. Based on document reviews and interviews, a table was created to illustrate twelve key categories used in FPE at Sackerber Architects (Table 5.10). These twelve key categories include wayfinding, workflow, relationship, support, technology, safety, flexibility, operations, patient/family, key rooms, stress, and sustainability. These are the research areas that the FPE team would exam and evaluate.

Table 5.10: 12 Key Categories for Functional Performance Evaluation

12 Key Categories for Functional Performance Evaluation (FPE)

\begin{tabular}{cccc}
\hline Wayfinding & Workflow & Relationship & Support \\
\hline Technology & Safety & Flexibility & Operations \\
\hline Patient/Family & Key Rooms & Stress & Sustainability \\
\hline
\end{tabular}


Susan talked about field research for FPE during her interview. Her explanation made it very clear about field research. She said:

We send the survey out a week in advance. We meet with clinical leaders to understand A to get the survey deployment, B we would get the metrics from them on their key performance indicators. Then four people go on site. How that site visit is divided up is we pair up groups of two and go to different departments. The group of two should include one person who worked on the design and one person who didn't work on the design.

Susan also talked about audit in their field research:

We do audit for all the units. That audit instruction now has the new version by using the Center for Health Design tool for units checklist. Thus we make that tool a little robust and it can be used in audit. Then the team would do a debrief round table with the hospital leadership in order to get some open-ended questions and their comments on what worked and what didn't work. We also would share some audit information with them. We create the report at the end of it.

Both document reviews and interviews revealed that FPE's field research would take two and half days. Based on document reviews and interviews, the following diagram (Figure 5.33) is created that represents the frameworks for the site visit/field research at Sackerber Architects. First the confirmation of conducting FPE should be obtained from the client by making a kick-off call. Before the FPE team goes to the site, the online survey should be sent out. Observation and interview protocols also need to be developed. On the first half day, the research team will conduct a site tour, pilot shadowing, interviews, and sound readings. On the next day, the research team will conduct on-site observations, interviews, behavior maps, shadowing, and sound readings as well as parametric modeling simulations. On the last day, there will be interviews, debrief, and behavior maps. It is a two and half day site visit. 


\section{Protocol Development}

* Interview

* Observation Guide

-Kick off call

- Online Survey

Development
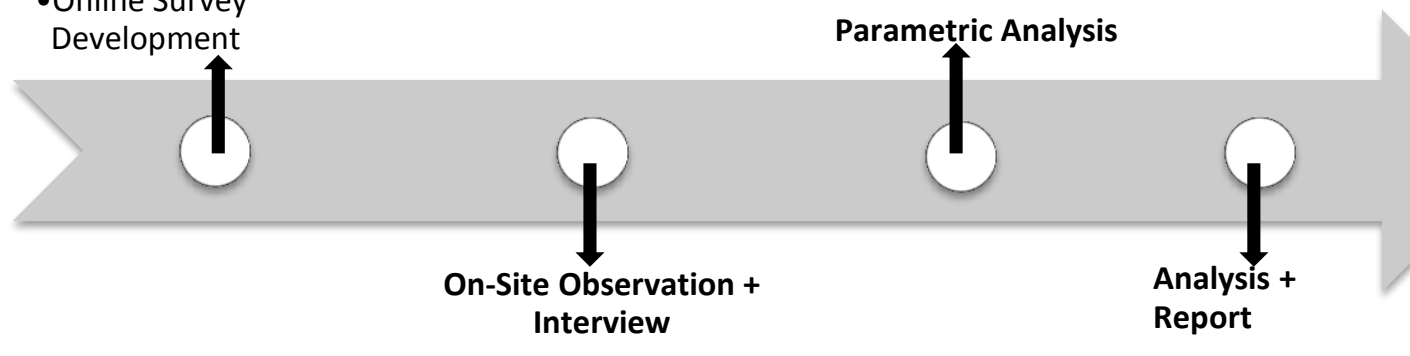

- On-Site Data

- Online

Survey

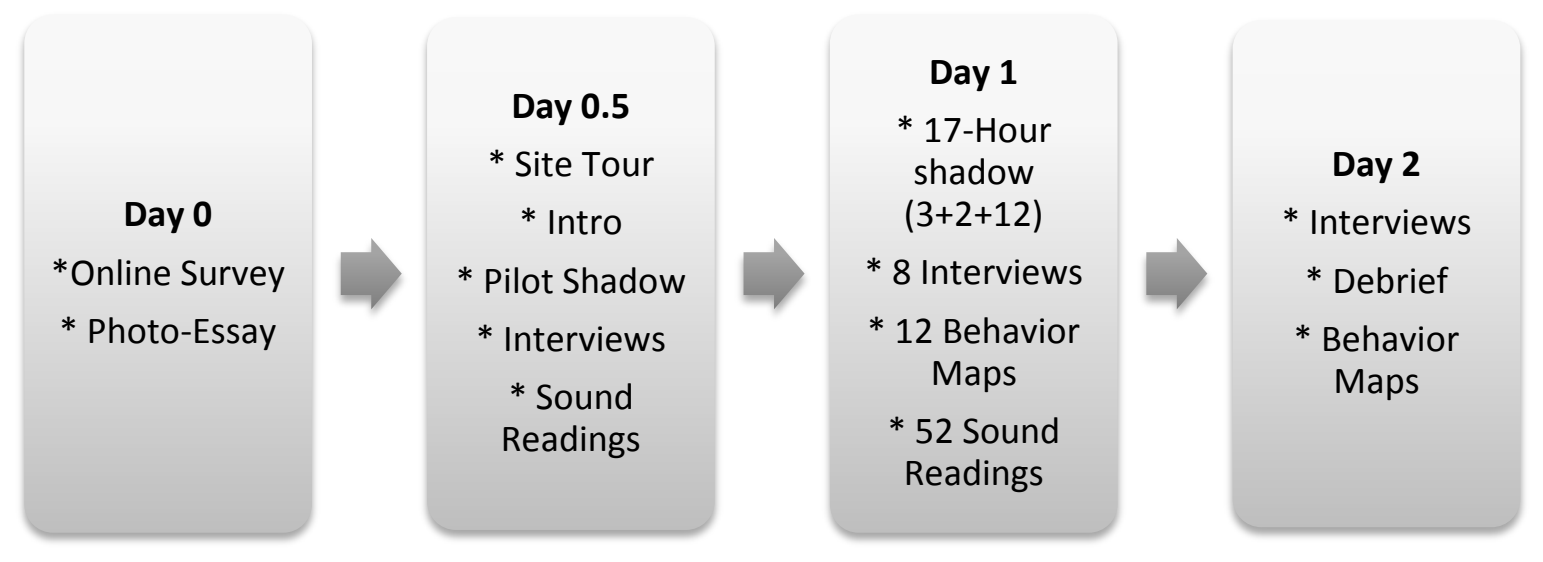

Figure 5.33: Field Research (Site Visit) Framework

Research in practice requires the architects and designers to inform themselves about what has been done and examined before, explore and experiment with new ideas, and subsequently develop an innovative design solution. Research in practice is also about monitoring implementation during construction, and testing outcomes of postoccupancy to determine whether the design has worked as expected, and learn lessons for the next project. Based on document reviews and interviews, it's clear that Sackerber Architects has developed a six-step process aligned with typical project delivery to assist 
the clients and design teams to integrate research in practice. I created a diagram (Figure 5.34) according to findings from document reviews and interviews to illustrate this integrated process at Sackerber Architects.

In this diagram, the design process starts with "Research Inform" design and ends with "Research Confirm" design. With a traditional design process model that goes through concept design, schematic design (SD), design development (DD), and construction documents (CD) and construction administration (CA), six research steps are integrated throughout the entire design process. The first step is at the beginning of the design process even before concept design. It sets the target and creates design aims based on key performance goals of the organization. The second step happens during concept design and schematic design phases. It is an exploration and experiment step. It is to gather knowledge, understand users, simulate scenarios, and test properties by using tools that balance the technology with empathy. The third step happens during the schematic design and design development phases. It defines design and links design solutions to performance hypothesis. The fourth step is in design development phase. It is for measuring and identifying key metrics in design and performance, and to collect baseline data. The fifth step happens during construction documents and construction administration phases. It is a step for monitoring. It confirms that the design is implemented as planned, and towards targeted performance goals. The sixth step happens after the construction administration. It is for testing the success of the design and conducting post-occupancy evaluation to determine whether the target was achieved. 


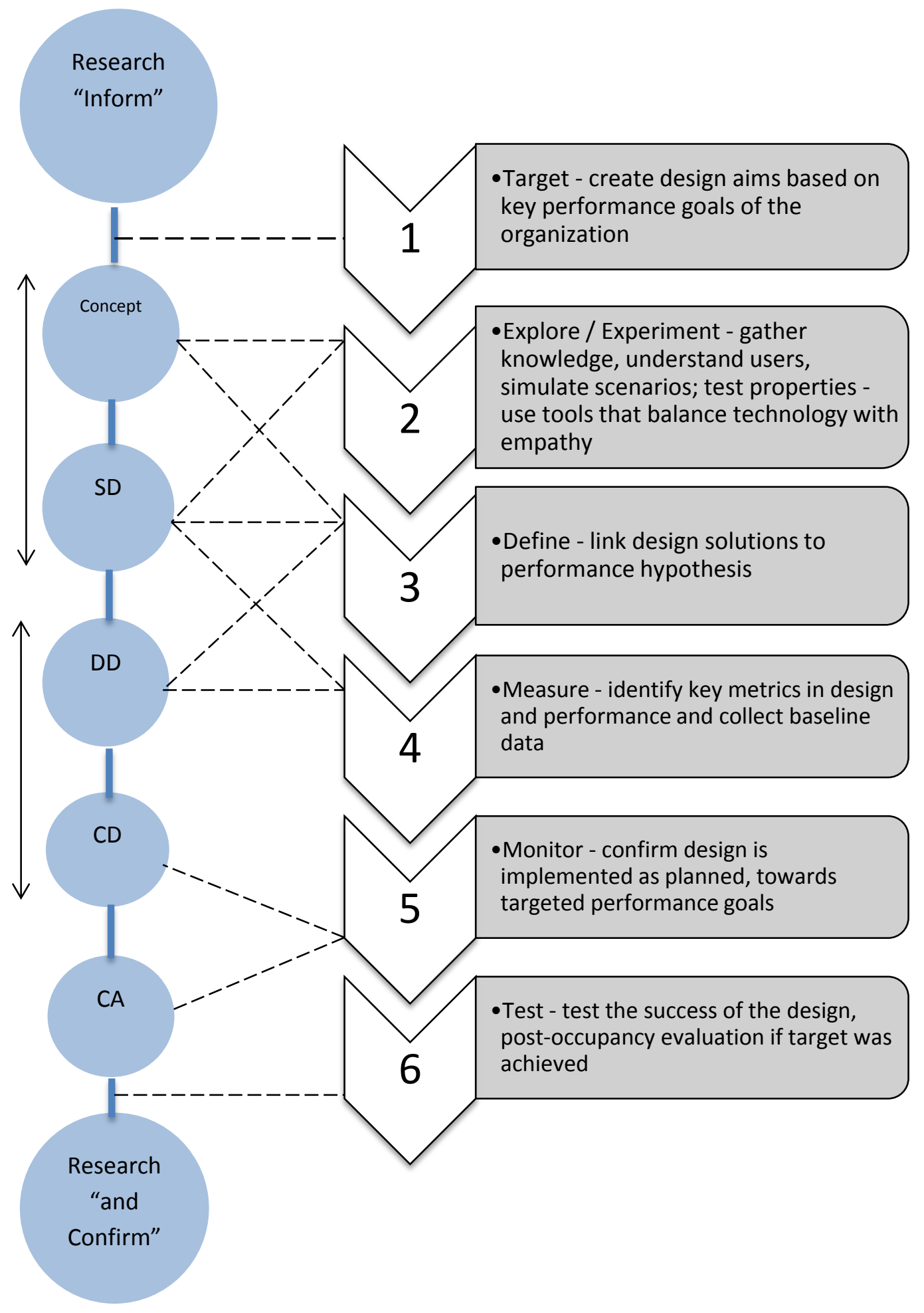

Figure 5.34: Integrating Research in Practice in Design Process Diagram at Sackerber Architects 
It is tangibly clear that the culture of research and a commitment to metrics evaluations is an integral part of this design process at Sackerber Architects. Although it is still challenging to integrate research with design, making it part of the process, this six-step process highlights how research thinking can be incorporated into existing processes at Sackerber Architects. This process certainly enables designers to target and achieve better outcomes through this "research informed" and "research confirmed" process.

\section{Parametric Modeling Tool}

Using the parametric modeling tool in functional performance evaluation (FPE) is another important finding from this research. The parametric modeling tool was developed by the research team at Sackerber Architects. It is a computer-generated tool that allows researchers and designers to conduct spatial analysis regarding visibility, proximity, and walking distance.

Functional performance evaluation (FPE) includes field research and off-site spatial analysis. The field research typically focuses on human behavior and perception, while the off-site spatial analysis includes visibility, proximity, and walking distance analyses which is conducted by using a parametric modeling tool. Obviously, multiple tasks, including online surveys, systematic behavioral observations, semi-structured interviews, sound studies, and advanced spatial analysis through parametric modeling were conducted in FPE at Sackerber Architects. The model (field research + spatial analysis) was developed as a rapidly deployable model that can be replicated during the course of FPE. 
During my interview with Susan, she talked about parametric modeling during the course of FPE. She said:

One of the things we have been trying to do is trying to develop more actionable tools for designers to use. For example, within different healthcare system, we are developing a parametric molding tool which can quickly calculating walking distances translated into a heat map between key rooms. So in 20-30 minutes you can see snap shot what the distances between patient rooms and supporting spaces when comparing different configurations. But what we added to that was we did field work for FPE and did the observations on site and got this frequency of usage of different rooms and sequence of movement. Then we developed the simulation tool based on that.

Susan also talked about the parametric modeling tool for their future usage. She emphasized:

All of these tools we are developing really depend on how the design team would use it differently. It depends on how much time that would be put aside for research on the project. However, our hope is trying the tools that we are developing over time. Designers will be able to do this in house themselves. It doesn't require a separate researcher. Our focus right now is integrating research into practice. So we developed tools and we try to get the information and feedback. Eventually the designers are the one who own it. So we don't have the separation between research and design.

In my opinion, this is a very good statement. There really should not be any separations between research and design. Research and design should be integrated seamlessly in design process.

Another example of using the parametric modeling tool at Sackerber Architects was discovered from document reviews. The example is to develop a path-finding algorithm using Rhino/Grasshopper in order to calculate walking distance between each two spaces and to simulate total walking distances for nurses over their working shifts. The generated parametric model enables the design team to precisely analyze and evaluate design options earlier and faster in the design process. It also allows 
optimization of design configurations using parameters derived from available evidence related to health workplaces in hospitals.

Additionally, the parametric modeling tool has been published by IDRE. A study conducted by their research group employed the same triangulated methods as mentioned in FPE. In their study, in addition to field research, they also included a parametric analysis of the plans using tools developed by Sackerber Architects' computer modeling research group to assess proximity between key spaces (translated into a heat map) and visibility (via isovists). Field research findings added the human layer to spatial analysis regarding user experience, workflow, space utilization, and patient monitoring.

Based on document reviews, it is important to note that the parametric modeling tool needs to be developed based on field research data. Information from the field research was used to develop a "sequence mapper" to simulate walking in the new unit based on observed behavior in field research. Susan said, "The design team can use parametric modeling tools for each design configuration to optimize the floor layout. The design team also can use computer generated three-dimensional mock-ups and parametric modeling tools to interact with users." The design of mock-ups and parametric modeling tools were based on insight gleaned from on-site research and spatial analysis.

In summary, the parametric modeling tool is developed by using Rhino/Grasshopper which is a computer simulation program. It is used for spatial analysis in functional performance evaluation at Sackerber Architects. The parametric modeling tool also can be used to examine visibility, proximity and walking distance in order to optimize floor configurations during the design process for healthcare architecture. 


\section{Institute of Design Research and Evaluation (IDRE)}

Another important finding from this research is Institute of Design Research and Evaluation (IDRE). Both document reviews and interviews revealed that IDRE is a notfor-profit entity associated with Sackerber Architects and it is committed to fostering innovation and excellence in design. The first mission of IDRE is contributing to the growing body of research evidence related to design performance, and impact on users, organizations, and environments. The second mission is disseminating knowledge to the design and user community in credible forums. IDRE envisions making research a catalyst for meaningful innovation for architectural practice. IDRE is under the leadership of its Executive Director. Since IDRE is an entity affiliated with Sackerber Architects, Sackerber's in-house research team members are researchers at IDRE.

Susan talked about IDRE, as IDRE Executive Director, during her interview. She said:

Many years ago, my predecessor started a non-profit research unit called the Center for Research Evaluation. That's the unit for conducting deeper dive studies. We just started a research project for a children's hospital that was an Integrated Project Delivery (IPD) project. It was completed and just occupied this year. But we started a research project founded through grants to try to understand how effective the entire IPD process was. We become a deeper diver. That's something we did through IDRE and will be able to share that information with the industry. That is our deeper dive non-profit research unit.

Obviously, IDRE not only conducts post-occupancy evaluations or FPE, but also conducts deep dive studies by investigating other research topics, such as IPD.

Document reviews also revealed that The Institute of Design Research and Evaluation (IDRE) conducts and disseminates evidence-informed and comparative research worldwide. Their publications allow the design teams to create operationally efficient and effective healthcare architecture. IDRE's work provides deep dives into 
research focused on enhancing human and organizational wellbeing. By developing strategic partnerships with academic institutions and industry partners, IDRE is able to provide a means to pursue funding for independent research that facilitates rigorous immersion into key design issues in the healthcare industry. During my interview with Angie, she confirmed that their research is published and disseminated. She said: "We have the information for people. We have quickly employable research that has been done on site as part of the design process. That's what we presented at the last EDRA conference."

Based on document reviews and interviews, I created a table (Table 5.11) to illustrate the publications by IDRE. These publications include reports, technical papers, research synthesis, journal articles, trade magazines, and presentations. Topics in these publications cover a broad range of spectrums including patient experience, design diagnostics, using the parametric modeling tool, EBD research, integrating research in practice, making metrics meaningful in design, field research, research-based practice, and many other topics. In addition to publications from IDRE, Table 5.11 also illustrates tools and resources developed by IDRE. These tools and resources include a research guide, infographics, and topical literature searches. All of this information is available not only for Sackerber Architects, but also for the entire healthcare industry. 
Table 5.11: Publications, Tools, and Resources at IDRE

\begin{tabular}{|c|c|}
\hline $\begin{array}{l}\text { Publications, Tools, and } \\
\text { Resources by Institute } \\
\text { of Design Research and } \\
\text { Evaluation (IDRE) }\end{array}$ & Topics \\
\hline Report & $\begin{array}{l}\text { * Clinic 20XX -Designing for an Ever-Changing Present; * Patient Experience } \\
\text { Mapping; * Design Diagnostics }\end{array}$ \\
\hline Technical Papers & * Using Parametric Modeling to Optimize Walking Distances and Workflow \\
\hline Research Synthesis & $\begin{array}{l}\text { Toilet Location - Inboard vs. Outboard; Headwall vs. Footwall; Same Handed vs. } \\
\text { Mirror; }{ }^{*} \text { handrails at the bedsides; }{ }^{*} \text { Medical gas booms, columns and headwalls; } \\
\text { * Design for dementia }\end{array}$ \\
\hline Journal Papers & $\begin{array}{l}\text { * Parametric analysis in medical-surgical units; * Design elements contributing to } \\
\text { wayfinding; * Impacts of decentralized nursing units design; * Physical design } \\
\text { correlates of efficiency and safety in Emergency Department; * Using membrane } \\
\text { diffuser in exam room; * Post-Occupancy Evaluation; * Research in professional } \\
\text { practice; * Patient room standardization; * Flexible inpatient unit design; * } \\
\text { Evidence-based Design; *Influence of positive distractions; *Environmental } \\
\text { psychology theories and EBD; * Patient room configurations in acute care; } \\
\text { *Research-design interaction: *Relationship between exterior views and nurse } \\
\text { stress }\end{array}$ \\
\hline Trade magazines & $\begin{array}{l}\text { *EBD research; *Integrating research in practice; *Making metrics meaningful in } \\
\text { design; * Designing for wayfinding; * The impact of the affordable care act on } \\
\text { design; * Design features and patient/staff visibility; * Patient safety; * Promoting } \\
\text { healing; * Positive distractions; * Private patient room; * Caregiver stress; * } \\
\text { Functional flexibility; * Medical gas ceiling booms }\end{array}$ \\
\hline Presentations & $\begin{array}{l}\text { * Field research; * Parametric analysis; * LEAN IPD; * Design diagnostic-research } \\
\text { based practice; * Impact of safe and efficiency in ED; *Decentralization; * } \\
\text { Efficiency; * BIM; * Positive distractions; * Booms vs. Headwalls; * Patient room } \\
\text { configurations; Window view and nurse stress }\end{array}$ \\
\hline Research Guide & How to complete field research -2.5 days \\
\hline Infographics & $\begin{array}{l}\text { *Clinic 20XX roadmap; *Healthcare system performance comparison (2014); *On } \\
\text { demand patient expectations; *The new care team; *Big data's three V's; * } \\
\text { MHEALTH; *Tele-HEALTH; *Coordinated health; *Population health and wellness; } \\
\text { * Retail health; *Facility innovation spread; * Journey through surgery } \\
\text { department; * Patient experience mapping; *Care team configuration; *Design } \\
\text { diagnostic timeline }\end{array}$ \\
\hline $\begin{array}{l}\text { Topical Literature Searches - } \\
\text { Research Evidence }\end{array}$ & $\begin{array}{l}\text { *Emergency department; }{ }^{*} \text { Intensive care units (ICUs); }{ }^{*} \text { Pediatric ICUs; } \\
\text { Decentralized vs. centralized nurse station; * Medication delivery system; } \\
\text { *Simulation centers in nursing schools }\end{array}$ \\
\hline
\end{tabular}

During my interview with Susan, she also talked about how research evidence

was identified at Sackerber Architects. She said:

We have internal resources which is called EBD Illustrate Guide where we took some evidence-based design principles and see how we apply it. It is translating what we have done and what evidence says. We annotate whether the evidence 
exists; whether just no evidence or whether something should be explored. We also annotate what kind of strategies we should use in that EBD Illustrate Guide.

Susan also talked about how they organized their database during her interview:

The database is an Endnote database. We had been collecting articles. Our job from research side is separating the fact from the guess. We only try to look at the critical research articles. We also look at the industry articles and practices and to see what the newer trends are. The evidence-bases are pretty small in many cases for the industry articles. We also do searches online by using PubMed, EESCO, Google scholar, etc. These are places we go for getting articles. Yes, Center for Health Design (CHD) is definitely one of our first place to go. We used knowledge repository on CHD website. We are affiliated member with CHD. We were the Pebble member for the last year. We also are an EDAC accredited firm.

According to document reviews and interviews, I also created a table (Table 5.12)

to present research evidence compiled by IDRE, which can be used during the design process not only by Sackerber Architects, but also by the entire design industry. This research evidence includes evidence for design of emergency department, intensive care units (ICUs), pediatric intensive care units (NICUs), centralized vs. decentralized nurse stations, medication delivery system, and simulation centers in nursing schools.

Table 5.12: Research Evidence Compiled by Institute of Design Research and Evaluation (IDRE)

Research Evidence for Different Types of Buildings and Their Related Design Attributes

\begin{tabular}{|c|c|c|c|c|c|}
\hline $\begin{array}{l}\text { Design of } \\
\text { Emergency } \\
\text { Department }\end{array}$ & $\begin{array}{c}\text { Design of } \\
\text { Intensive Care } \\
\text { Units (ICUs) }\end{array}$ & $\begin{array}{c}\text { Design of } \\
\text { Pediatric } \\
\text { Intensive Care } \\
\text { Units (ICUs) }\end{array}$ & $\begin{array}{c}\text { Design of } \\
\text { Centralized vs. } \\
\text { Decentralized } \\
\text { Station }\end{array}$ & $\begin{array}{l}\text { Medication } \\
\text { Delivery } \\
\text { System }\end{array}$ & $\begin{array}{c}\text { Design } \\
\text { Simulation } \\
\text { Centers in } \\
\text { Nursing } \\
\text { Schools }\end{array}$ \\
\hline Design & $\begin{array}{c}\text { Environmental } \\
\text { Correlates of } \\
\text { Efficiency and Safety }\end{array}$ & Design & $\begin{array}{l}\text { Impacts of } \\
\text { Decentralized } \\
\text { Nursing }\end{array}$ & $\begin{array}{l}\text { Nurse Servers } \\
\text { over Central } \\
\text { Medication } \\
\text { Rooms and } \\
\text { Efficiency }\end{array}$ & Design \\
\hline Efficiency & $\begin{array}{c}\text { Impacts of } \\
\text { Decentralized } \\
\text { Nursing }\end{array}$ & $\begin{array}{c}\text { Family Centered } \\
\text { Care }\end{array}$ & $\begin{array}{l}\text { Walking Distance } \\
\text { and Bed Units }\end{array}$ & At the Bedside & $\begin{array}{l}\text { Nurse Education- } \\
\text { Simulation }\end{array}$ \\
\hline Errors & $\begin{array}{c}\text { Headwall vs. Ceiling } \\
\text { Booms }\end{array}$ & $\begin{array}{l}\text { Headwall vs. } \\
\text { Ceiling Booms }\end{array}$ & $\begin{array}{c}\text { Waste Reduction } \\
\text { and Decentralized } \\
\text { Nursing }\end{array}$ & $\begin{array}{c}\text { Medication } \\
\text { Storage Cabinets }\end{array}$ & $\begin{array}{l}\text { Standardized } \\
\text { Patient Room }\end{array}$ \\
\hline Furniture & $\begin{array}{c}\text { Design } \\
\text { Characteristics }\end{array}$ & Infection Control & $\begin{array}{c}\text { Nurse } \\
\text { Communication } \\
\text { and Nurse Station }\end{array}$ & Controlled Drugs & $\begin{array}{l}\text { Same-handed } \\
\text { Patient Room }\end{array}$ \\
\hline
\end{tabular}




\begin{tabular}{|c|c|c|c|c|}
\hline & \multicolumn{4}{|c|}{ Typology } \\
\hline Infection Control & Efficiency in ICUs & Noise & $\begin{array}{c}\begin{array}{c}\text { Nursing Unit Design } \\
\text { and }\end{array} \\
\text { Communication }\end{array}$ & Configurations \\
\hline LEAN & Communication & $\begin{array}{c}\text { Positive } \\
\text { Distractions }\end{array}$ & $\begin{array}{l}\text { Nurse's Functional } \\
\text { Use of Space and } \\
\text { Work Environment }\end{array}$ & Workflow \\
\hline Noise & Culture Change & Quality of Care & $\begin{array}{l}\text { Nurses' Work } \\
\text { Activity }\end{array}$ & $\begin{array}{c}\text { Reduced Cognitive } \\
\text { Load }\end{array}$ \\
\hline Overcrowding & $\begin{array}{l}\text { Exterior View and } \\
\text { Nurses' Stress }\end{array}$ & Sleep & Technology & Efficiency \\
\hline $\begin{array}{c}\text { Patient } \\
\text { Experience }\end{array}$ & $\begin{array}{c}\text { Indoor Daylight and } \\
\text { Length of Stay }\end{array}$ & $\begin{array}{l}\text { Headwall vs. } \\
\text { Ceiling Booms }\end{array}$ & & Safety \\
\hline Patient Flow & Safe Medication & $\begin{array}{l}\text { Exterior View and } \\
\text { Nurse Stress }\end{array}$ & & \\
\hline Patient Privacy & $\begin{array}{c}\text { Experience of } \\
\text { patient and Family } \\
\text { Visit }\end{array}$ & Miscellaneous & & \\
\hline $\begin{array}{c}\text { Patient } \\
\text { Satisfaction }\end{array}$ & $\begin{array}{l}\text { Private Patient } \\
\text { Room }\end{array}$ & & & \\
\hline $\begin{array}{c}\text { Pediatric } \\
\text { Emergency } \\
\text { Department }\end{array}$ & Infection Control & & & \\
\hline Stress & $\begin{array}{l}\text { Mortality Rates and } \\
\text { Supervision }\end{array}$ & & & \\
\hline $\begin{array}{l}\text { Violence and } \\
\text { Security }\end{array}$ & Evidence-based Art & & & \\
\hline Waiting time & $\begin{array}{c}\text { Type of ICUs and } \\
\text { Productive Work } \\
\text { Environment } \\
\end{array}$ & & & \\
\hline $\begin{array}{l}\text { Workplace } \\
\text { Interruptions }\end{array}$ & $\begin{array}{c}\text { Medication Errors } \\
\text { and Environmental } \\
\text { Design }\end{array}$ & & & \\
\hline Miscellaneous & $\begin{array}{c}\text { Family Participation } \\
\text { and Improved } \\
\text { Outcomes }\end{array}$ & & & \\
\hline
\end{tabular}

In summary, IDRE is a very active and robust research entity. It helps Sackerber

Architects to identify, interpret, and implement research evidence. It also works with

Sackerber Architects to conduct post-occupancy evaluation as well as Functional

Performance Evaluation (FPE). More importantly, IDRE also takes a deeper dive in research by doing research-only projects. IDRE collaborates with universities and healthcare organizations as well as The Center for Health Design for many research initiatives. They publish and disseminate research evidence to the design community and 
healthcare industry. It really benefits all the stakeholders. By affiliating with IDRE, it makes Sackerber Architects stand out from its competitors.

\section{Implications}

The purpose of this study is to have a fuller and deeper understanding of how evidence-based design is implemented in hospital design and how design decisions are made in the design process. Sufficient information and saturated data has been collected to answer research questions.

Through triangulated data collections, the findings reveal that evidence-based design (EBD) was incorporated in the design process of Grand River Hospital in order to achieve the goal of designing a hospital that promotes patient safety and quality care as well as other goals defined in the design guiding principles. This study provided an indepth analysis of data collected from multiple sources to understand how evidence-based design was implemented in the design process. According to the data from interviews and document reviews, it became evident that the traditional design process has been modified and shifted in order to identify, interpret, and implement research evidence for the Grand River Hospital project. In addition, functional performance evaluation (FPE) could be conducted to serve as either post-occupancy evaluation (POE) or as a tool to collect data in order to evaluate and optimize design solutions. Findings showed that implementation of EBD changed the design process from a linear process to a cyclical process. The following section describes the implications from research findings of this study. It also explains the redefined model of design process in detail. 


\section{Redefined Model of Design Process by Integrating Evidence-based Design}

According to Lang (1987), the major phases of a traditional architectural design process are presented in the General Model of Design Praxis (Figure 3.2). It consists of Intelligence, Design, Choice, Implementation, and Post-implementation Evaluation even though people who are involved in professional practice may refer to them as Programming, Design, Evaluation and Decision, Construction, and Post Occupancy Evaluation (Pena \& Parshall, 2012; Zeisel, 1981).

Based on findings from interviews, observations, and document reviews, and comparing them with the General Model of Design Praxis generated by Lang (1987), I created a diagram (Figure 5.35) that depicts the design process that integrates evidencebased design for Grand River hospital. It is clear that the design process has been modified and shifted compared to the general model of design praxis created by John Lang (1987).

Sackerber Architects is an EDAC certified and EDAC Advocate architectural design firm. Evidence-based design (EBD) is the process of basing decisions about the built environment on credible research to design healing and therapeutic environments that help improve patient and staff satisfaction, reduce errors, enhance efficiency, and support the latest technological advancements. Over the years, a number of approaches to the EBD process have emerged as pioneering organizations have taken credible research evidence as knowledge and adopted it to their unique healthcare design projects. However, the common thread in all of the approaches is that EBD needs to be integrated into different phases of the design process (Malone et al., 2008). According to the Center for Health Design website, EDAC certified and advocate firms take an additional step, 
ensuring their healthcare teams actively incorporate EBD into their healthcare projects. The following diagram (Table 5.13) presents eight steps in the evidence-based design process that have been advocated by EDAC certified firms on the Center for Healthcare Design website. Obviously, the projects completed by EDAC certified and advocate firms do not necessarily incorporate all eight steps in the evidence-based design process for their projects. However, findings from multiple sources of data collection in this case study confirmed that the following eight steps were followed in the design process of Grand River Hospital. These eight steps are highlighted in blue in the redefined model of design process in Figure 5.35.

Table 5.13: The Evidence-based Design Process -Eight Steps (Source: EDAC Advocate Brochure, 2016)

\section{The Evidence-based Design Process - Eight Steps}

\begin{tabular}{ll}
\hline 1. Define EBD goals and objectives & 5. Develop a hypothesis \\
\hline 2. Find sources for relevant evidence & 6. Collect baseline performance measures \\
\hline 3. Critically interpret relevant evidence & 7. Monitor design \& construction \\
\hline 4. Create \& Innovate EBD concepts & 8. Measure post occupancy results
\end{tabular}




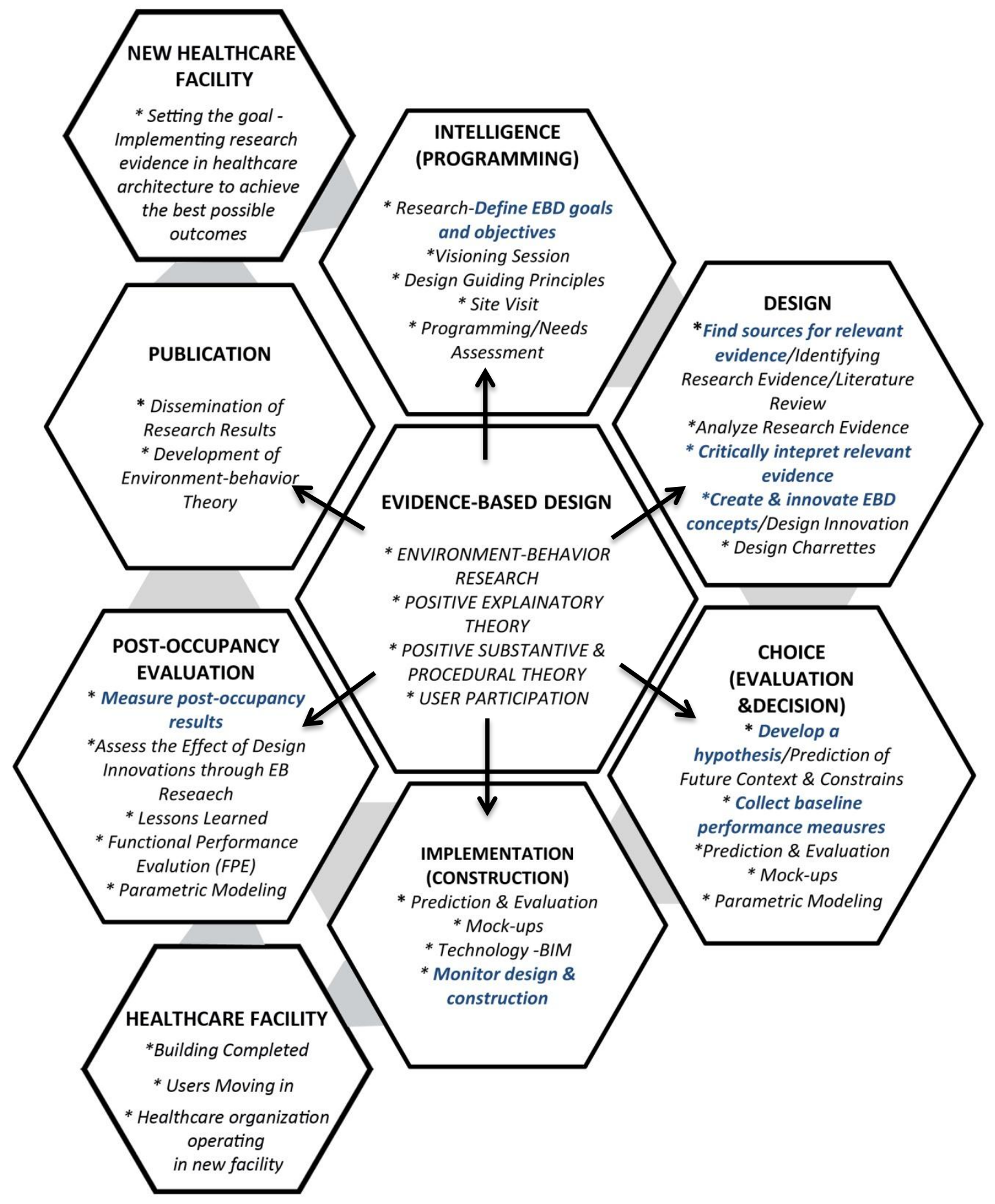

Figure 5.35: The Model of Redefined Design Process by Integrating Evidence-based Design 
In this redefined design process model, several additional sub-phases were added, including developing a research evidence database; conducting design charrettes; building mock-ups and site visit; and having visioning sessions before the programming phases. In this redefined model, the design process not only should start with research at the beginning to inform design decisions, but also the design process should be ended by the research to confirm that the best outcomes are achieved as planned.

Due to integrating evidence-based design into the design process, several strategies surfaced in the design process of Grand River Hospital. One strategy is taking a collaborative approach. Bringing all stakeholders on board early on definitely enhanced the communication and information exchange among all different discipline team members. The second strategy is to let users participate in the design process, especially in the programming process as well as building mock-ups and evaluating mock-ups. The third strategy is having the design charrettes for design innovations, which is another collaborative effort. Another strategy is the site visit at existing successful hospitals by evaluating users' performance and medical outcomes so that it can be the reference for design and the best practice for Grand River Hospital. Generally speaking, four projectrelated activities conducted as part of the Grand River Hospital project delivery offer the possibility of generating quality data that can be used as evidence in the decision-making process. These activities include visioning session, programming and needs assessment, room mock-ups, and functional performance evaluation (FPE). Although there was no full FPE for Grand River Hospital, instead a post-occupancy feedback session was conducted. 
Additionally, the parametric modeling tool can be used in FPE for spatial analysis regarding visibility, proximity, and walking distance in nursing units. The Parametric Modeling Tool also can be used to enhance and optimize the spatial configurations during the design process. The in-house research team for Institute of Design Research and Evaluation (IDRE) plays a central role for identifying and implementing research evidence. The research unit also conducts research to assess functional performance through design metrics and performance metrics. They also publish and disseminate research findings. Angie confirmed this during her interview:

We have twenty-four offices. We have members in IDRE in different offices. We worked on research project that we received grant. We have many ways to share information with the company. People are looking at what is the latest and greatest research evidence out there.

Lang (1987) suggests that the general model only provides the basis for the development of theory, but theory involves more than model-building. Theory involves the development of a coordinated set of descriptions and explanations (Lang, 1987). Therefore, it is absolutely necessary to describe and explain the redefined model of design process based on findings of this research as presented in Figure 5.35.

\section{Description and Explanation of Redefined Design Process}

In the following section, the descriptions and explanations for the redefined design process model are organized in five sub-sections, including design research, prediction and evaluation-building mock-ups, user participations, technology, and cyclical process, not a linear process. These five sub-sections depict the main features and characteristics of this redefined model of design process by integrating evidencebased design. 


\section{Design Research}

There are a great amount of studies in environment-behavior research that are concerned with healthcare environment. The ultimate goal of EB studies is to serve as scientific evidence that can guide the design process and lead to data-driven decisions to achieve the best possible outcomes. Two of the fundamental tenets of evidence-based design are the use of reliable evidence in decision making and generating evidence where it is lacking (Pati, 2011b). Scholars urge that the only way the EB field can make progress is by developing explanatory theories (Rapoport, 1982, 2000; Tofle et al., 2004) because of the significance and value of explanatory theories. As I mentioned earlier, there is still a lot of work to be done in evidence-based design, especially in the development of positive exploratory theory and theory evaluation (Pati, 2011a; Stankos \& Schwarz, 2007; Tofle et al., 2004). Nevertheless, EBD does present important implications for healthcare design. Although a lot of research needs to be done in evidence-based design, EBD certainly can benefit designers and other populations that are influenced by design interventions.

On the other hand, EBD introduces the necessity of a new skill set to architects and designers. In addition to extensive experience and deep domain knowledge in healthcare design, the new EBD design method demands the integration of the best available research evidence into decision making (Haq \& Pati, 2010). This presents a radical transformation in design behavior. It means that designers must be able to interact with scientific evidence, interpret the evidence, assess the applicability of research findings in design decisions, and, finally, implement the evidence. In some instances, it would require designers to engage in empirical research. Sackerber Architects' current 
practice sets an example that architects and designers need a new skill set to be able to conduct research.

\section{Research, Evidence Generation in Practice, and New Skill Set}

In this redefined design process model, the first phase - intelligence (programming) - involves research by defining EBD goals and objectives, a visioning session, creating design guiding principles, a site visit, and programming/needs assessment. In the second phase, design involves finding sources of relevant evidence, identifying research evidence/literature review, analyzing research evidence, critically interpreting relevant evidence, creating design innovation, and conducting design charrettes. It is obvious that research and identifying and analyzing research evidence are important components in these phases. As discussed earlier, designers should have a different design skill set than before. This new skill set has two folds, the ability to interact with research evidence, and the ability to conduct research. This new skill set enables designers to identify, analyze, interpret, and implement research evidence in the design process.

In addition to being able to identify, analyze, and implement research evidence, the designers also should participate in the research process, such as post-occupancy evaluation (POE) or functional performance evaluation (FPE) or using the parametric modeling tool. These activities appear again in the choice (evaluation $\&$ design) phase, post-occupancy evaluation phase, and publication phase.

Therefore, the significant difference in this redefined model is that it requires architects and designers to be involved in conducting research to generate evidence while 
designing the building. The methods and activities for generating evidence can be adopted from the practice in the Grand River Hospital project. These methods and activities include visioning sessions, program/needs assessment, building mock-up rooms, functional performance evaluation (FPE), post-occupancy evaluation or POE feedback session, and the parametric modeling tool. More detailed discussion regarding evidence generation can be found in Chapter 6.

\section{Prediction and Evaluation - Building Mock-ups}

Prediction and evaluation is another important component in evidence-based design. After research evidence is identified and interpreted, the research evidence needs to be implemented and evaluated to predict the best possible outcomes. For Grand River Hospital, building mock-ups was the strategy to implement and evaluate the design as well as to predict the possible outcomes. Building mock-ups have been used as a simulation tool to enhance design decision making in many other hospital designs, such as the University Medical Center at Princeton involving a simple mock-up (Peavey, Zoss, \& Watkins, 2012). There are many different simulation tools for informing decision making. Peavey et al. (2012) articulated two major simulation and mock-up tools that include experience-based simulation and computer-based simulation. Physical mock-ups certainly are experiential in nature and foster a high level of user involvement. Mock-ups are often a physical prototype of an environment or a specific room that is built for the evaluation of design solutions. The decisions can be based on input from highly integrated teams of end users, designers, managers, and researchers. Physical mock-ups can have a high level of fidelity, interaction, and user immersion (Watkins, Myers, \& 
Villasante, 2008). Mock-ups not only allow hospital staff, clinicians, researchers, and designers to evaluate and test design innovations or to improve existing practice, but also provide an opportunity to foster relationships with manufacturers, such as art, furnishing, and equipment companies interested in testing their products in care delivery scenarios.

The mock-ups tend to be of "key rooms" whose layout and configuration guide future design, planning, and construction efforts for an entire unit or department. Another study was conducted in the Department of Veterans Affairs (VA) facility by Watkins et al. (2008) in order to establish evidence-based design (EBD) guidelines for inpatient rooms. This study used mock-ups as a simulation technique during the study to test, evaluate, and modify evidence-based design solutions. The latter part of the study included the location of patient beds and standard headwall position, technology and spaces for nurse charting activities, clearances (e.g., equipment, wheelchair, and bariatric patient), universal rooms, and patient and family amenities (Watkins et al., 2008).

Obviously, the mock-ups allowed researchers and designers to evaluate and confirm EBD solutions and strategies for the development of VA inpatient room standards (Watkins et al., 2008).

At Grand River Hospital, the team built mock-ups for patient rooms, operating rooms, nurse stations, medication rooms, the emergency department, and all other important rooms. Then they ran simulations in each of these rooms to get feedback from the end users. Some of these rooms were built at least three times before the final layout. The full-size mock-ups were used to test, evaluate, and modify evidence-based design solutions for these major rooms and areas for the Grand River Hospital project. 
Therefore, mock-ups and simulations are effective ways to evaluate the design that implements the research evidence and predicts the best possible outcomes.

Angie said in her interview:

In the mock-ups, we would test the visibility to patient room and visibility from the alcove to patient bed. All these designs have to be tested in the mock-up room. We brought staff through the mock-up room and run simulations to see if the outlet should be moved over. We even tested different patient lift. There were three different patient lifts from three different vendors. So we were able to test them in the mock-up room. It was all based on our best practice, our knowledge, and staff's desire how these rooms should be set up.

George, as the lead for the entire team, spoke about the mock-up during his interview:

One of the most important aspects in the process was the experience of building mock-up rooms. It was a significant part of the project and it involved all the stakeholders, such as nurses, physicians, patients, and owners. We probably built 8-10 different rooms, such as ICU, patient room, nurse station, operating room, and medication room, as so on. Mock-ups helped users to understand and visualize design elements and space. Building mock-up also minimized the cost and it is fundamental to minimize the risk and get things right.

Proper utilization of mock-ups means diligently testing and evaluating design solutions and providing a platform for user feedback. Participants should be given a systematic process to share input objectively and interactively. A structured feedback can inform design decision making. For Grand River Hospital, the mock-up rooms were open all the time. Users could go to the mock-up rooms and provide evaluations and feedback. There was a place for everyone to write notes and comments. Then the feedback was taken to the design group for discussion regarding the concerns and comments.

Linda said in her interview:

We mocked rooms, we got furniture showroom to the staff and they can try them. We got lots of feedback from clinical staff and a lot of input from the community and people who have been our past patients. We built a space and knocked it down and built space and knocked it down and continued to clarify exactly how the building would function as the way we wanted them to function. 
In the Grand River Hospital project, all the mock-up rooms were full scale and fully equipped. Carol said in her interview: "All patient care team would be in mock-up rooms, respiratory, lab, etc. Everybody in the hospital was invited to go down to look at the room, including patients.”

Thus, the best practice for prediction and evaluation of design solutions includes providing mock-ups at various stages of development for user groups. Mock-ups provide the ability to analyze users' performance in the simulated work environment. Mock-ups should include not only a patient room, which has been the traditional mock-up scenario, but also other spaces, such as nurse stations, operating rooms, and exam rooms. It is also important to install all the finishes, furnishing, and equipment in mock-up rooms. In the design process of Grand River Hospital, building mock-ups was such an important component for evaluation and prediction. Testing scenarios and running various simulations in the full-scale mock-up rooms resolved many of the uncertain perceptions during the design process. User groups were invited to the mock-up rooms and provided feedback and refinements that enhanced the design of key rooms, such as patient room, nurse station, operating room, medication room, ICU, and so on.

\section{User Participation}

Implementing evidence-based design needs to involve end users in the design process. The programming phase is the chance for users to speak about their needs and their work flows. User participation in programming phases can provide valuable information that is grounded in end users' input. Building and evaluating mock-ups is another opportunity for end users to participate in the design process because users have 
first-hand experience of using the space. When the simulations are conducted in mockups, end users can provide accurate feedback. Multidisciplinary end users who will be involved in the mock-up sessions should include physicians, nurses, hospital administrators, and allied health professionals such as pharmacists, respiratory therapists, and physical therapists.

Therefore, one important way to ensure that the organization and users' requirements are met is to effectively involve them in the design process. Participatory involvement of users has to be a crucial component in the design process. All interview participants in this study believe that having physicians, nurses, support staff, and executive leadership have a meaningful role in the decision-making process results in better design solutions. Therefore, user participation is another strategy to ensure a successful project.

\section{Technology}

Technology is another important aspect in evidence-based design. Several examples can be found in the design of Grand River Hospital. In order to promote patient and staff safety, a patient lift is provided in each private patient room. Patient lifts can effectively reduce the staff back injury rate according to research evidence. Technology is also used in supply rooms to increase the efficiency for medical staff. Robots are used in Grand River Hospital. Tina said:

Robot mainly is used to bring lining and trash carts up that helps to prevent staff injuries. That wasn't really minimizing staffing needs. But having robotics be able to do that minimize the chance of injury for people who are always pushing and pulling different units for waste and lining. 
New building information management (BIM) software fosters collaboration and information sharing by tracking every aspect of the project in real time (Grunden \& Hagood, 2012, p. 247). For example, it can detect potential clashes of the heating and electrical systems and track budget consequences of each change. In the Grand River Hospital design, BIM technology was used from the beginning. Don talked about BIM during his interview. He said:

One more thing that is unique with Grand River Hospital. That was our first project that was drawn and documented in BIM. Everything was done in a full three-dimensional model. At that point, it was 1.1 million sf. That was the only project that fully modeled in BIM. That actually saved a lot of time and a lot of effort, especially in construction documents. It also gave us a very quick tour because everything has been generated in three dimensions. We could take camera shot from the model to show the client at the user group meetings. Even during the schematic design, we were able to show them how the nurse station looked like and how the entrance looked like. Incorporating these images early on was very valuable and it helped the client to understand the spatial relationship. This design tool has almost zero additional work. But it was extremely valuable helping end users to visualize what we tried to do.

Technology is also used in research. The parametric modeling tool is developed by using special software. Researchers and designers can use the parametric modeling tool in FPE for spatial analysis or in the design process for enhancing and optimizing spatial configurations in a faster and more effective way.

\section{Cyclical Process not a Linear Process}

The redefined design process model for integrating EBD is different from the traditional design process model created by Lang (1987). One major difference is that the redefined model is a cyclical process while the traditional process model is linear. The reason is that evidence-based design not only needs post-occupancy evaluation but also requires publication and dissemination of research results that can be implemented by 
future healthcare projects. This redefined design process model starts with research to "inform design" and it ends with research to "confirm design." This cyclical process model is aligned with the cyclical framework in the conceptual map which is derived from the EBD framework defined by Ulrich et al. (2010). The second difference is that the redefined model requires additional steps in the design process that collaboratively identify, interpret, and implement research evidence. These additional steps not only include eight steps (Table 5.17) that were followed by EBD advocate architectural firms, but also include other steps which were found through this case study at Grand River Hospital. For example, visioning sessions, design charrettes, and mock-ups are added within each phase. Several new strategies have to be used in the redefined design process model. These strategies include collaborations with all stakeholders, user participations in all activities, and using technology. These additional steps and new strategies make the redefined design process model significantly different from the traditional design process model. The redefined design process model puts research in an important and repeated position where research evidence is identified, analyzed, implemented, and assessed. Another important aspect in this redefined design process model is conducting research that links design metrics with performance metrics in order to evaluate whether the best possible outcomes are achieved. Functional performance evaluation (FPE) is a new approach for post-occupancy evaluations in this redefined model, which features onsite audit and using the parametric modeling tool to assess the best possible outcomes.

Another significant difference in the redefined model is that it requires a different skill set for architect and designers. This new skill set requires architects and designers to be able to interact with research evidence and be able to conduct research. The redefined 
design process model integrates evidence-based design in an effective way based on this case study at Grand River Hospital.

\section{Conclusions}

Through document reviews, observations, and interviews for the case study at Grand River Hospital, research questions were answered by research findings. Findings from this study confirmed that evidence-based design presents important implications for healthcare design and EBD can benefit designers and other populations, such as patients, patient family members, physicians, nurses, and hospital operations who are impacted by the design interventions in the physical environment.

Regarding research question \#1 - how credible research evidence is identified, interpreted, and implemented in the design process of Grand River Hospital - findings provided a huge amount of information that answered this research question. Findings also revealed clear descriptions and explanations regarding how research evidence is identified, interpreted, and implemented in the design of Grand River Hospital.

At the beginning of the project, the Sackerber Architects design team conducted intensive visioning sessions with key stakeholders to establish design guiding principles. Prior to beginning design work, a literature review was conducted in order to identify sources of data for the investigation. The in-house research team and research database at Sackerber Architects played an important role in identifying research evidence. Based on this case study for Grand River Hospital design, it seems that having a research team inhouse with knowledgeable researchers is a tremendous help to the design team.

Experienced researchers can use their expertise to help identify best available research 
evidence and create a research database for architects and designers. Since architects and designers normally prefer visual images and illustrations, creating diagrams that have visual images to illustrate the relationship between research evidence and design solutions will be a huge help for architects and designers. Sackerber Architects has many visual research diagrams available that can be used by their architects and designers.

Evidence-based design goals for Grand River Hospital were clearly identified in their design guiding principles that served as a true north for the project. These EBD goals are: implementing all private patient room units, providing clear visibility and direct line of sight to all patients, increasing privacy and offering greater support for patients and improving family and nurse/physician communication, and reducing overall noise level in the units. Improving patient safety and quality care are the most important design goals.

To achieve the evidence-based design goals, the architects and designers linked the design metrics with performance metrics when they interpreted the research evidence. The in-house research team and IDRE compiled a lot of research evidence that designers can use during the design process. This compiled research evidence is organized in a way that design metrics and the best of outcomes are linked. It provides a meaningful resource for designers when they interpret the research evidence. Findings of this research revealed that architects and designers referred to the research articles and compiled research evidence in order to interpret their implications for the Grand River Hospital design. In addition, the architects and designers and user groups conducted site visits that served as the best practice experience. They began with process mapping to define future workflows, implemented A3 exercises to study floor configurations and adjacency 
options, and drew diagrams to test different options by comparing different workflows of healthcare delivery. In order to implement the research evidence and evaluate the design solutions, the design team and the contractor built full-scale mockups of different key rooms for testing whether the best possible outcomes could be achieved. Use of full-scale mock-ups provided the nursing staff and physicians with an opportunity to conduct simulations and provide feedback.

Findings from observations revealed that the physical environment and design attributes at Grand River Hospital were designed in response to research evidence in order to achieve the best possible outcomes. These possible best outcomes were set as their design goals in design guiding principles. For example, in order to have better visibility for patients, they designed nurse alcoves between patient rooms. Decentralized nurse stations, coupled with decentralized supply rooms and medication rooms, were designed in order to respond to research evidence of efficiency and walking distance. Enclosed medication rooms were designed in response to research evidence of medical errors. Having a separate family zone in patient rooms, with many homelike amenities, was designed in order to enhance the patient and family experience during a time that can be both exciting and stressful. A ceiling lift was installed in every patient room in response to research evidence on preventing staff injury. All these findings were also confirmed by interviews.

Regarding research question \#2 - How implementation of evidence-based design changes the programming process, design process, and decision-making process of healthcare design - findings from this study also provided huge amount of information to answer this research question. Implementing EBD certainly changed the design process 
and decision-making process. Findings shown that evidence-based design has to be integrated into the design process at the very beginning, the earlier the better. In addition, EBD has to take a collaborative and interdisciplinary team approach that involves all the stakeholders. To identify and interpret research evidence, architects and designers should stay at the cutting edge of the current research. It is really helpful and beneficial for architects to have research staff in house. Visioning sessions and design charrettes that involved all the stakeholders helped to identify and interpret the research evidence by innovative design solutions. To implement research evidence, building mock-ups and running simulations in mock-ups can help to predict whether the design can achieve the best possible outcomes. With the goals clearly determined, the design developed and evolved naturally and smoothly to resolve and address each goal established in the design guiding principles.

Grand River Hospital and Sackerber Architects also conducted a post-occupancy evaluation session to validate the effectiveness of each design strategy and project goals. The results of the feedback session show significantly improved patient and staff injury rates and improved patient satisfaction survey scores. Another important aspect is that the Integrated Project Delivery (IPD) system showed considerable cost savings using a collaborative process.

According to findings from a data triangulation approach that included interviews, observations, and document reviews, the design process was redefined to incorporate evidence-based design. The traditional design process is a linear process while the redefined design process is a cyclical process. The redefined model is consistent with the EBD framework that is generated by Ulrich et. al. (2010). However, additional steps and 
strategies need to be added in the redefined design process by conducting visioning sessions, design charrettes, mock-ups and simulations, and conducting research by using the parametric modeling tool. The decision-making process is also a collaborative approach, which is always after visioning sessions, design charrettes, mock-ups, simulations, and evaluations. In this redefined design process, EBD has to be an integral part of the project from its very inception through initial occupancy and the entire facility’s lifecycle.

Another important finding from this study is how research links with practice at Grand River Hospital. Design research is an important component in the redefined design process model. Linking research and design is the core of evidence-based design in healthcare design. In fact, what differentiates EBD from the traditional design process is the emphasis on using research evidence to inform design decision making and support the evaluation of design innovations. Findings of this study revealed that Sackerber Architects has a very robust research team in house. This research team is also affiliated with IDRE, which is an independent non-profit research entity. IDRE not only conducts post-occupancy evaluation, but they also take deeper dives in research by conducting research-only projects. IDRE disseminates and publishes research findings. The Sackerber Architects research team and IDRE have developed research tools that can help designers conduct research during the design process and post-occupancy evaluation process. FPE is a tool developed by Sackerber Architects that can be used in postoccupancy evaluation. The parametric modeling tool not only can be used in FPE as a data triangulation tool, but it can also be used in the design process to evaluate visibility, proximity, and walking distance. 
Another important implication from this study is the requirement of a new skill set for architects and designers. The new skill set includes the ability to interact with research evidence and the ability to conduct research. In the EBD design process, EBD professionals use research throughout the lifecycle of the project. It is important to critically interpret relevant evidence during the design process. In order to determine if evidence is credible and can be used to inform the design and the hypothesis, architects and designers have to understand the relevance of the research as well as the validity and reliability of the research. It is also necessary for architects and designers to understand the research methods and evaluation tools. Both researchers and architects and designers should work collaboratively in the design research process to evaluate the design interventions by using design metrics and performance metrics. Finally, publication and dissemination research findings need to be done in order to close the loop of the cyclical design process.

Evidence-based design is a new wave in healthcare design and there is no doubt that EBD has beneficial implications for all stakeholders. Like Hamilton (2014) states, if interpretation of credible scientific evidence and carefully measured outcomes from completed projects can help produce better results, possibly including better clinical outcomes, there would be a significant obligation to utilize a rigorous research-informed design process for the project. Currently, there are several advocates for evidence-based design, such as the Center for Health Design and Health Environments Research and Design (HERD) journal. HERD is an international, peer-reviewed journal that features research and methodology papers, theory articles, case studies, and book reviews focused on the effects of heath environments and design on patient and organizational outcomes 
(D. K. Hamilton, 2014). Therefore, developing more explanatory theory in environmentbehavior studies in the healthcare environment certainly can contribute and help architects and designers who refer to the scholarly literature and research findings in order to interpret their implications for achieving the best possible outcomes in a healthcare environment. 


\section{CHAPTER SIX: DISCUSSIONS}

The purpose of this research is to have a deeper and better understanding of how evidence-based design is integrated into the design process for healthcare architecture.

Specifically, this research attempted to learn how research evidence is identified, interpreted, and implemented in the design process. Additionally, this research attempted to learn how EBD has changed the programming process, design process, and decision-making process. In Chapter 5, findings of this research about the participants' experience of being involved in the design of Grand River Hospital and its design process were thoroughly articulated based on interviews, observations, and document reviews. Findings include seven primary categories: "visioning sessions," "design charrette," "building mock-ups," "in-house research and research database," "functional performance evaluation (FPE)," "parametric modeling tool," and "Institute of Design Research and Evaluation (IDRE)." This chapter will provide discussion, insight, and interpretation of these data, and propose a new theoretical framework for future evidence generation in EBD for consideration.

\section{Research-Informed Design and Research-Confirmed Design and Post- Occupancy Evaluation}

Traditional design process is changing in so many ways already. There are changes in the project delivery process due to Integrated Project Delivery (IPD). There are also changes in the design process, because of LEAN, that go all the way through construction. Then there is evidence-based design, which makes design more research informed. Therefore, the entire design paradigm is shifting. Susan said in her interview, "EBD cannot and should not be considered isolation. When research evidence is used to inform design decisions, the better design decisions will be made. Therefore, the overall 
healthcare delivery process is more efficient and better outcomes are achieved." Based on findings of this research, a redefined model of design process by integrating evidencebased design is generated (Figure 5.35). The implications from findings of this case study are that the design process should start with research to inform design and the design process should end with research to confirm design. The design process should be a cyclical process that closes the loop of the process for research, design, and research. The following diagram (Figure 6.1) represents this cyclical process that starts with research and ends with research. In this diagram, it is clear that research plays a critical role throughout the process. One important aspect in this diagram is to analyze research evidence and link it to performance hypothesis. The second important aspect is to link design solutions to performance hypothesis. Then, it requires identifying key design metrics and performance metrics. In order to evaluate whether research evidence has been implemented and whether the best possible outcome could be achieved, mock-ups can be used as tools for evaluation and prediction. Mock-ups include both physical fullsize mock-ups and computer-generated models. Nada et al. (2015) suggested combining field research and spatial parametric analysis tools so that behavior and spatial data can be layered in a thorough analysis of the current work environment before designing a new one. This approach was also found in findings of this case study at Grand River Hospital. The parametric analysis tool is a computer-generated tool that can be used for spatial analysis regarding visibility, proximity, and walking distance. The parametric modeling tool also can be used during the design process to optimize the spatial configurations in a very quick way. 


\section{Research- Informed Design}

*Establish research evidence database *Identify research evidence/Literature reviews

* Analyze research evidence by linking performance

$$
\text { hypothesis }
$$

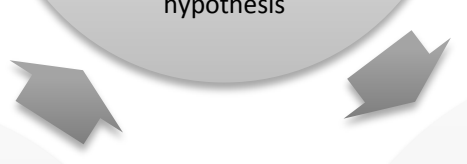

\section{Research-Confirmed Design}

* Functional Performance Evaluation (FPE)

* Post Occupancy Evaluation

* Dissemination of Research Results

* Development of E-B Theory in Healthcare Environment

\section{Design}

* Creating Design Guiding Principles (Programming)

* Design Charrette (SD)

* Link design solutions to performance hypothesis (SD)

* Identify key metrics in design and performance (SD, DD)

* Evaluation and Prediction -Mockups and Parametric Modeling (CD)

* User Participation (Entire process) *Technology

Figure 6.1: Diagram of Cyclical Design Process - Starts with Research and Ends with Research

An important phase in the redefined cyclical design process is post-occupancy evaluation (POE), also called diagnostic POE or functional performance evaluation (FPE), according to document reviews. With its growing desire to integrate evidencebased design into the decision-making process, design firms have demonstrated increased interest in conducting post-occupancy evaluations (POEs), specifically for healthcare design projects. POEs have been conducted since the 1960s, stemming from human environmental research (Guinther, Carll-White, \& Real, 2014). POE has been defined as "the process of evaluating building in a systematic and rigorous manner after they have been built and occupied for some time"(Preiser, Rabinowitz, \& White, 1988, p. 3). 
Current research has shown that conducting post-occupancy evaluation should take a multi-methodological approach and it should be diagnostic and performance based (Brown, Wright, \& Brown, 1997; Guinther et al., 2014; Kotzer, Zacharakis, Raynolds, \& Buenning, 2011; Nanda, Pati, \& Nejati, 2015; M. M. Shepley, Bryant, \& Frohman, 1995). There are three levels of effort that constitute a typical POE. It is a cyclical process for carrying out the research that involves planning, conducting, and applying (Preiser, 2001). Level one is an indicative POE, which is the simplest one, that leads to an "awareness of issues in building performance" (Preiser, 2001, p. 11). The second level is an investigative POE that yields a more thorough understanding of the causes and effects of issues in building performance (Preiser, 2001, p. 11). The third level is diagnostic POE that gathers the most information and can lead to the creation of new knowledge about aspects of building performance (Preiser, 2001, p. 11). It is important to understand that there is no single standardized method or set of tools for conducting a POE. It is also crucial that the process used to conduct a POE be documented to inform future evaluations and studies because the process of POE is cyclical. According to findings of this case study and the practice at Sackerber Architects, when conducting a deeper dive study and evaluating the built environment in a typical POE, the process is called functional performance evaluation (FPE). FPE is more like "diagnostic" POE, which can lead to the creation of new knowledge regarding the relationship between the healthcare environment and users' behavior.

Findings of this case study revealed that FPE was conducted in Sackerber Architects for several healthcare projects. Recently, interest in conducting healthcare FPEs has been on the rise (Pati, 2011b). FPE can be conducted at any time during the life 
of a facility. Typically, they are conducted a few months after the occupancy of a new or newly renovated facility. Thus, FPE is also known as post-occupancy evaluation, but it is at a diagnostic level. When robustly conducted, FPE can provide information to support a wide range of decision making including programming, design, the identification of research questions, the development of research hypotheses, the prediction of the economic life of a facility, and to help rationalize areas for capital expenditure (Pati, 2011b). According to document reviews, architects and researchers at Sackerber Architects conducted FPE by using rapidly developed field research and timely simulation. In addition, online surveys, systematic observations, semi-structured interviews, sound studies, and advanced spatial analysis through a parametric modeling tool were conducted. Methodologically, a 2.5-day field study module combining field research with spatial analysis is indispensable since it allows a triangulation between observed data, interview data, and spatial analysis data. All this data is invaluable for rapidly developed research which can be timely in informing design.

The variations and combinations of methods in functional performance evaluation (FPE) or Diagnostic post-occupancy evaluation (POE) make triangulated data collections. Based on previous studies (Guinther et al., 2014; Nanda et al., 2015) and research findings from this case study at Grand River Hospital, I created the following table (Table 6.1). This table presents multiple methods in both FPE and Diagnostic POE. The methods for FPE include field research that takes a triangulated approach plus off-site spatial analysis using a parametric modeling tool, as well as systematic observations. The typical methods for POE include systematic observations, interviews, and focus groups. The intention of creating this table is to present multiple methods that can be combined in 
different ways in FPE or Diagnostic POE. As discussed earlier, FPE has not been

conducted as often as Diagnostic POE. In future studies, FPE should become more and more popular. Nevertheless, the methods for FPE or Diagnostic POE should be chosen based on specific projects and design objectives. The methods also should be chosen based on a conceptual framework, such as the conceptual framework for evidence-based design proposed by Ulrich et al. (2010).

In Table 6.1, for field research that takes a triangulated approach, the methods include the following: photo-essay, sound recording, interviews/focus groups, on-site observation, and online survey or questionnaire. For off-site spatial analysis that uses the parametric modeling tool, it includes the following aspects: visibility, proximity, and walking distance analysis. For systematic observation, it includes built environment variables, circulation, walking distance measurement, waiting times, interactions between staff, patients and visitors, and occupancy counts.

Table 6.1: Data Collection Methods in FPE and POE

\begin{tabular}{cl}
\hline $\begin{array}{c}\text { Data Collection Methods for Functional Performance Evaluation (FPE) and Diagnostic Post-Occupancy } \\
\text { Evaluation (POE) }\end{array}$ \\
$\begin{array}{c}\text { FIELD RESEARCH - } \\
\text { TRIANGULATED } \\
\text { APPROACH }\end{array}$ & \multicolumn{1}{c}{ DATA COLLECTION PROCESS } \\
\hline Photo-Essay & $\begin{array}{l}\text { Prior to starting data collection, a detailed photo-essay is undertaken-this entails a } \\
\text { tour of the facility with annotations on a to-scale map and systematic photo- } \\
\text { documentation. }\end{array}$ \\
\hline Sound Recording & Collecting sound levels from predetermined locations. \\
\hline Interviews/Focus & $\begin{array}{l}\text { Interview with users including nurses, physicians, patients and visitors to get their } \\
\text { feedback regarding their experience and perception of the facility. }\end{array}$ \\
\hline On-Site Observation & $\begin{array}{l}\text { Extensive shadowing, unit-wide observations, calculating walking distances. During } \\
\text { shadowing sessions, walking steps from one task to another are counted and } \\
\text { recorded. }\end{array}$ \\
\hline Online & $\begin{array}{l}\text { A questionnaire/survey that includes open-ended questions is conducted with the unit } \\
\text { staff. Demographic questions about years of experience, patient load, and current role } \\
\text { are asked. }\end{array}$ \\
\hline Survey/Questionnaire & \\
\hline OFF-SITE SPATIAL & \\
PARAMETRIC &
\end{tabular}




\begin{tabular}{|c|c|}
\hline MODELING TOOL & \\
\hline Visibility & $\begin{array}{l}\text { The rhino/grasshopper model (isovist) is used to analyze the sight lines to evaluate the } \\
\text { visibility of patients or patient rooms from central nursing stations. }\end{array}$ \\
\hline Proximity & $\begin{array}{l}\text { A rhino/grasshopper model was developed to assess the proximity. Proximity } \\
\text { assessment was exported to a heat map. The heat map shows three levels of } \\
\text { proximity: margins for low (under } 60 \text { feet), reasonable ( } 60-120 \text { feet), and extensive } \\
\text { (more than } 120 \text { feet) walking. The proximity is defined by color code. }\end{array}$ \\
\hline $\begin{array}{l}\text { Walking Distance } \\
\text { Analysis }\end{array}$ & $\begin{array}{l}\text { A rhino/grasshopper model was developed to assess the walking distance from every } \\
\text { patient room to the supply closest or support space (proximity calculator). }\end{array}$ \\
\hline \multicolumn{2}{|l|}{ OBSERVATIONS } \\
\hline \multirow[t]{5}{*}{$\begin{array}{l}\text { Built Environment } \\
\text { Variables }\end{array}$} & $\begin{array}{l}\text { Positive Distractions: Researchers document the use of environmental stimulations in } \\
\text { the waiting areas, corridors, and treatment rooms (interactive art, computer stations, } \\
\text { toys, game systems, furnishings, television) }\end{array}$ \\
\hline & $\begin{array}{l}\text { Wayfinding: Researchers document patient response to signage and wayfinding } \\
\text { information. }\end{array}$ \\
\hline & $\begin{array}{l}\text { Acoustical Properties: Researchers record noise levels throughout the facility or } \\
\text { specific area using digital sound level meters. }\end{array}$ \\
\hline & $\begin{array}{l}\text { Lighting: Researchers measure the illumination level of the care area environment } \\
\text { using a digital light meter. }\end{array}$ \\
\hline & $\begin{array}{l}\text { Use of Medical Equipment and Supply Cabinets: Researchers record the frequency of } \\
\text { use of linen supplies and medical equipment. }\end{array}$ \\
\hline Circulation & $\begin{array}{l}\text { Behavioral Mapping: Using a floorplan of the unit, researchers observe and record } \\
\text { paths of travel for the identified study population to determine the efficiency and use } \\
\text { of the designed floorplan. } \\
\text { Through Traffic: Researchers document the frequency of through traffic in specific } \\
\text { areas of the facility }\end{array}$ \\
\hline $\begin{array}{l}\text { Walking Distance } \\
\text { Measurement }\end{array}$ & $\begin{array}{l}\text { Using pedometers, researchers determine physician, nurse, and technician travel } \\
\text { distances within the care area environment. Data documentation correlates to } \\
\text { behavioral mapping. }\end{array}$ \\
\hline Waiting Times & $\begin{array}{l}\text { Utilizing a stopwatch, researchers determine actual waiting times of patients entering } \\
\text { and exiting the primary waiting areas and time spend in specific room. }\end{array}$ \\
\hline $\begin{array}{l}\text { Interactions between } \\
\text { Staff, Patients and } \\
\text { Visitors }\end{array}$ & $\begin{array}{l}\text { Researchers document where the interactions between staff, patients and visitors } \\
\text { occurred and with whom. }\end{array}$ \\
\hline Occupancy Counts & Researchers record the quantity of occupants in various locations of facility. \\
\hline
\end{tabular}

The methodology for conducting FPE or POE should be designed to evaluate the effectiveness of the physical features in response to the client's design guiding principles, design objectives of the architects, and organizational performance outcomes.

Additionally, multi-methodological approaches are critical to validate the research findings. As Zimring and Reizenstein state, specific methodologies need to be designed 
to focus on a single attribute of the setting, as opposed to collecting data from a more holistic point of view (C. M. Zimring \& Reizenstein, 1980). As discussed earlier, data collection methods such as behavioral observations, questionnaires, and focus groups should be designed based on a conceptual framework. Because each hospital is uniquely different, researchers must be cautious about the generalizability of the findings. The literature review confirms that pre- and post-occupancy evaluations provide the richest information to compare and validate the findings (Guinther et al., 2014). Therefore, it would be helpful if both pre- and post-occupancy evaluation can be conducted. Finally, according to the research findings of this study, I suggest that partnerships between architectural design firms and healthcare providers should be formed to assist design practitioners in carrying out FPE or POE. Such partnerships offer greater objectivity in the evaluation and assessment as well as increased research expertise. This kind of partnership can generate more rigorous research evidence and make bigger contributions to the body of knowledge of evidence-based design.

\section{Environment-Behavior Studies and Theory Development}

One of the important categories of findings from this study is design research for the healthcare environment. Environmental design scholars often embrace a sciencebased perspective grounded in confirmation, refutation, and refinement, and from this viewpoint, researchers can contribute to a cumulative knowledge base (Schwarz, 1999). Rapoport (1990), for example, explains that any design becomes a set of hypotheses to be evaluated in terms of whether the objectives have been met. Rational theories derived from hypotheses are commonly used in the post-occupancy evaluation of healthcare 
facilities. Nonetheless, the application of science-based research to improving healthcare facilities is ongoing.

Great progress has been made in evidence-based design, not only in research but also in practice; but, far more progress is still needed. The findings from this case study confirm that evidence-based design certainly is beneficial for all stakeholders. It obviously is a developing paradigm for future healthcare design. More importantly, EBD knowledge helps the design team to be better informed with quality information. Based on this case study, recommendations and implications for theory development and research are discussed in the following.

Based on findings of this research, I echo the call for the development of more explanatory theory like many scholars who have stated the importance of creating positive explanatory theories for the design profession (Hillier, 1996; Johnson, 1994; Lang, 1987; Rapoport, 2000; Stankos \& Schwarz, 2007; Tofle et al., 2004). Evidently, there is much more work need to be done in evidence-based design, both in theory building (positive explanatory theory and procedural theory) as well as practice that integrates scientific evidence in design decision making. Lang (1987) explains the positive theory development and its use:

Theory building involves more than describing the world. It involves explanation. It is a creative process in that it involves the construction of conceptual structures both to order and explain observations. The goal is to be able to use these structures to describe what is happening and to predict what is going to happen. The value of positive theory depends on its explanatory and predictive power. (pp. 13-14)

Hag and Pati (2010) stated in their study report that one noteworthy factor as it relates to the design phases is that evidence without a description of the context and precedence is perhaps less meaningful. One frustration regarding research evidence did 
emerged from the interview during this case study. The architect has wished that the conclusion of research evidence was more explanative and conclusive instead of just saying future research would be needed. Both this case study at Grand River Hospital and Hag and Pati's study (2010) showed that once an environmental factor or characteristic is identified as beneficial or detrimental to the quality of care either by an in-house researcher or by the designer himself/herself through literature review, the architect and designer's focus quickly shifts from the evidence to the design context and precedence. An architect is better served at this point if information regarding context and precedence is available along with the evidence (Haq \& Pati, 2010). This confirms that positive theory has to have description and explanation. Otherwise, the theory would be less meaningful.

Moreover, Tofle et al. (2004) wrote, when we speak of scientific explanation, we generally ask why certain phenomena occur. In many cases, if not always, in order to explain a fact, we need to identify its cause. In other words, our intellectual understanding of the world, which derives from the scientific explanation, is always causal. For instance, we need to know the causes of infection in hospital environments in order to reduce the infection rate. Or, we want to know the cause for using a particular nurse station layout in order to improve the performance of nurses. That is why scholars have urged to develop positive explanatory theory for evidence-based design.

Regarding theory evaluation, a number of studies have addressed its importance (Pati, 2010, 2011a; Stankos \& Schwarz, 2007; Tofle et al., 2004; Viets, 2009). According to Lang (1987), scientists may use empirical techniques to test theories, but fields such as 
history and often architecture have to rely on quasi-scientific methods. ${ }^{15}$ Thus, positive theory in architecture research cannot fulfill the requirements of the philosophy of logical positivism proposed by A. J. Ayer (Ayer, 1936). Pati (2011) proposed a framework regarding evidence evaluation in evidence-based design. One of the methods is quasiexperimental method that has been used on the Pebble Project, a research program within The Center for Health Design (Pati, 2011a). Other methods include Post-Occupancy Evaluation (POE), quantitative meta-analysis, and qualitative interviews and focus groups (Pati, 2011a).

Since evidence-based design is using credible research evidence to inform design decisions, developing positive explanatory theory certainly is critical for evidence-based design. As defined by Lang (1987), procedural theory is concerned with the design process and design methodology. Thus, developing procedural theory is also extremely important for evidence-based design. Lang (1987) also states that a thoughtful and sensitive design process cannot be done well without good substantive theory. Therefore, developing both procedural theory and substantive theory are necessary. This case study attempted to make recommendations for the development of procedural theory by recommending a redefined design process model (Figure 5.35) with descriptions and explanations. However, findings from one single case study cannot be considered to have good generalizability. More case studies can be conducted in the future by using the same protocols for interviews and observations at different hospital settings.

\footnotetext{
${ }^{15}$ A common form of study in the quasi-experimental category is the before-and-after study design. Beforeand-after studies in healthcare design have typically involved collecting baseline data before moving into a new facility and collecting a second set of data on the same measures after moving into the new or renovated facility.
} 
Theories are very important in architectural research. Since pure scientific approaches in environment and behavior studies have limitations (Toulmin, 1992), and all the scientific discoveries were causes of or contributors to paradigm change (Kuhn, 2012), scholars argue that the only way this field can make progress is by developing explanatory theories (Rapoport, 2000) because of their significance and value.

Evidence-based design has come a long way, as some new books attest (Cama, 2009; D. K. Hamilton \& Shepley, 2010; D. K. Hamilton \& Watkins, 2008; Malkin, 2008; McCullough, 2009; Nussbaumer, 2009; Sternberg, 2009). In new medical practice, only so-called hard data could be involved in making clinical decisions. Assumptions, opinions, and beliefs were not allowed to interfere with obtaining a clear picture of the body. Myths and speculations were supposed to be replaced by facts (Tofle et al., 2004). Similarly, in healthcare architectural design practice, only studies that provide causal explanations for the effects of a physical attribute in a healthcare environment can help the decision making in the design process. Pati (2011b) wrote in his article, the most challenges in current environment-behavior studies or evidence-based design research is that examining causation is eliminated and alternative explanations for the phenomenon observed is lacking. Pati (2011b) also stated that two of the fundamental tenets of evidence-based design are the use of reliable evidence in decision making and generating evidence where it is lacking. Based on the findings of this case study, I echo the call and urge to develop more positive explanatory theories with the rigor in environmentbehavior studies that can be used by architects and designers for healthcare design.

Because the design process is creative and intuitive in general, it requires theories of possibility in the sense that they exist in the humanities, especially in art. However, 
because the design process is also predictive, it needs the analytic theories of actuality and possibility (Tofle et al., 2004). Environmental design is based on a cyclical process that involves creative as well as predictive phases. The creative and predictive phases of the design process explain the need to use normative and analytic aspects of theories. The normative aspects of a theory tell the designer where to search for possible solutions in the creative phases, whereas the analytic aspects inform the designer how the solution will work. Here I cite Hillier (1996)'s statement to reinforce the need of both positive and normative theories that have the attributes of explanation and description.

Why should architectural theories take this distinctive form of combining propositions about how the world should be with the propositions about how it is believed to be? The answer is to be found in the nature of what architects do, that is design. Through its nature as an activity, design raises issues to which architectural theories propose solutions in the form of analytic-normative complexes of theoretical ideas. (p. 59)

It is paramount to distinguish positive theory and normative theory because each will help designers become proficient at problem solving, especially through the experience of testing their solutions. Nevertheless, as Lang states, "Theories and models can enhance understanding of design process and the relationships between people and the physical environment" (1987, p. 24). Lang also emphasizes that "empirical facts in themselves do not guide practice, but the theory can. Therefore, research needs to focus on theory building" (Lang, 1987, p. 22). However, Lang (1987) warns of the danger of thinking that positive theory in architectural research is a simple accumulation of facts about the world because these facts do not provide a deep understanding of how the world is. Therefore, the development of positive explanatory theory is necessary. As Rapoport (2000) indicates, the power of theory in design comes from its ability to describe and explain phenomena. Development of design theory is a creative process that 
involves not only construction of conceptual structures, but an explanation of observations. Theories are used to describe what is happening and to predict what will happen. The value of positive theory in design correlates directly to its ability to predict outcomes of design (Stankos \& Schwarz, 2007).

The most common problem with architectural theories is that they have too often been strongly normative and weakly analytic (Hillier, 1996). Hillier (1996) explains and positions the problem of architectural theory:

It has been too easy to use them to generate designs, but they are too weak in predicting what these designs will be like when built. The theories of modernism were, for example, quite easy to follow in generating designs to satisfy normatively stated objectives. The problem was that the architectural means proposed were not the means required to achieve those objectives. The theories were weakly analytic. They did not deal with the world as it actually is. The normative dominated the analytic. (p. 65)

Similarly, Groat and Wang (2002) state the same problem that most precedents in design are weakly analytical and strongly normative and are probably better defined as proactive in addressing a particular design issue, rather than predictive of specific outcomes. Clearly, many scholars have voiced the importance of developing positive theories based on the status of normative theory being strong and positive theory being weak in architectural research (Groat \& Wang, 2002; Hillier, 1996; Lang, 1987; NorbergSchulz, 1968; Proshansky, 1974).

Today, as designers have become increasingly aware of the relationship between research and design, the term "evidence-based design" has become a well-known and commonly used term in healthcare architectural practice. One challenge for EBD is theory development. The nature of the design is its creative activities. Architectural theories should propose solutions in the form of analytic-normative complexes of 
theoretical ideas (Hillier, 1996). Thus, the normative statements in the form of prescriptions for particular environment attributes need to be supported by better understanding and explanation. In other words, "explanatory theory needs to precede normative statements that should be based on such explanatory theory" (Rapoport, 1987, p. 12).

Evidence-based design certainly is a new chapter in healthcare architecture history that has evolved from six waves as defined by Verderber and Fine (2000). Evidence-based design has played a critical role in shifting hospital architectural design process and shaping new images of hospital architecture. The value of a real evidencebased design for healthcare settings is indisputable, and its benefits to patients, staff, and hospital administrators are undeniable (Stankos \& Schwarz, 2007). However, there are still many challenges for researchers to explore not only in the theory building and research aspect but also in the practice aspect. The subject matter of evidence-based design is complex and multifaceted. In the new chapter of healthcare architecture, mastering the knowledge for the application of research findings in healthcare settings requires a new skill set for architects and designers. This new skill set includes the ability to interact with research evidence and the ability to conduct research.

\section{Sustaining the Legacy of Florence Nightingale's Environmental Theory and Further Advancing Environment-Behavior Studies in Healthcare Design}

Findings from both direct observations and interviews revealed that a lot of design attributes were in response to research evidence in order to achieve the best possible outcomes at Grand River Hospital. Although the literature review shows that the Nightingale ward has been eliminated in modern healthcare architecture, Nightingale's 
environmental theory has been sustained in nursing practice and modern hospital design. Florence Nightingale was one of the first nurses to document the impact of the built environment on patients' medical outcomes. She wrote about sanitation, ventilation, and infection control in her book Notes on Hospitals (Nightingale, 1863). She also understood that environmental aspects such as light, color, and noise, along with nurses' supervision, significantly contributed to patients' medical outcomes. Obviously, Nightingale was well aware of the impact the built environment has on patients through her direct observations. Nightingale's environmental theory includes several aspects from the built environment as Nightingale (1863) listed in her book: noise, light, air, ventilation, cleanness, and variety. In fact, all of her believes and notions were from her intuitive observations of patient outcomes and their surrounding environment. In recent years, many environmentbehavior studies in the healthcare environment have given scientific basis to Nightingale's environmental theory. Many scientific studies have investigated how physical attributes in the built environment impact patients' medical outcomes (Rubin et al., 1997). A vast amount of scientific research findings have confirmed Nightingale's notions in her book. In addition, current studies also further advanced Nightingale's environmental theory by revealing more research findings not only the impacts of environmental attributes on patients' medical outcomes, but also on caregivers' job performance and healthcare organization operational efficiency. Recommendations have been made regarding designing a healthcare environment that promotes patient and caregivers' safety, organizational efficiency, and the best possible medical outcomes based on a great amount of credible research evidence. Samples of evidence can be found in the compiled research evidence table in Chapter 3: Literature Review. 
Therefore, the body of knowledge in evidence-based design has become more and more mature and comprehensive. It is paramount to expand evidence-based design research and explore more intellectual culture between science and design. It is important to further advance environment-behavior studies in healthcare environment.

\section{Interdisciplinary Team Approach}

Collaborating with all stakeholders and taking an interdisciplinary teaching approach is a strategy used in many different activities in this redefined design process model. In order to identify and interpret research evidence that meets the client's design goals, collaborations with all stakeholders are essential in the design process. The building program should be created in collaboration with the leadership of the healthcare organization, end users, and architects. Visioning sessions, design charrettes, mock-ups, evaluations, and simulations are all conducted in collaboration with consultants, contractors, engineers, and end users. Therefore, collaboration with all stakeholders is the key to a successful project.

Another aspect of collaboration is to collaborate with an interdisciplinary team with different expertise. Any complex healthcare project needs an evidence-based approach for many key decisions. Although many decisions deserve focused expertise of best practice, major design decisions should be evidence-based. According to the findings of this study, I am convinced that the successful design decisions can comfortably coexist whether it is evidence-based or best practice-based. However, credible research evidence does provide the rationale to back up the decisions that are made based on expertise and best practice. In addition, innovation and creativity should come from 
expertise, especially in areas that impact medical campus planning, non-clinical settings, user experience, public spaces, and the aesthetics of a design solution. Thus, it is extremely important to include different expertise within an interdisciplinary team collaboration. Taking an interdisciplinary team approach and collaborating with all stakeholders occurred in every aspect of the Grand River Hospital project. Expertise, skills, and methods were applied in concert for this project.

\section{Research Meets Design in Practice}

Another important finding from this case study is the parametric modeling tool that was developed by researchers and architects at Sackerber Architects. The implications from this finding are beneficial for integrating research and design in practice. There is a growing body of evidence in the area of how design attributes in the physical environment impact human health and well-being. Incorporating this body of research evidence into healthcare design can result in possible best outcomes. How do

you implement research evidence in design innovations in order to be more efficient and precise, and to predict desired outcomes from the design process? Findings from this research provided a recommendation for this question, which is using the parametric modeling tool in design practice like Sackerber Architects has been doing. The parametric modeling tool enables the design team to quickly and precisely analyze and evaluate different design options early on in the design process. It also allows optimization of floor configurations using design parameters derived from credible research evidence related to healthy and efficient workplaces in the healthcare 
environment. In addition, the parametric modeling tool allows the client and design team to see the consequences of design decisions prior to construction.

Parametric modeling is an act of design in the design process rather than a static three-dimensional model. Parametric modeling is a reusable and configurable process. With clearly defined relationships between inputs, decisions, and actions, an infinite number of variations of design can be generated from one set of rules. With the parametric modeling tool, design solutions can rapidly be optimized. Furthermore, using parametric models allows one to quickly create, evaluate, and compare multiple design options.

There exists an extensive body of literature on how nurses spend their time, the extensive distances they walk, and the need to reduce walking distances for nurses (Hendrich et al., 2009; Pati, Harvey Jr, \& Thurston, 2012; Zadeh, Shepley, \& Waggener, 2012). Thus, efficiency is an important parameter in hospital design. In order to calculate walking distances between two spaces and to simulate total walking distances for nurses, a pathfinding algorithm was developed using Rhino/Grasshopper at Sackerber Architects. The researchers and designers at Sackerber Architects used the parametric modeling tool to create a more efficient working environment for nurses by reducing walking distances and optimizing workflows. In addition, they also used the parametric modeling tool to compare decentralized and centralized nursing units, and demonstrated how plan analytics can serve as a valuable research tool. Within the parametric modeling tool, data is interpreted and visualized in a heat map. The heat map is a diagram that allows designers to quickly see the performance of a design layout. According to the color coding, designers can identify which patients' rooms are too far away from medical 
supply spaces. The heat map provides a quick visualization for the summary of the efficiency for a specific design.

Implementing credible research evidence with the help of analytical tools such as parametric modeling analysis allows architects and designers to evaluate the impact of optimized spatial configurations and organizational effectiveness early on during the design process. A study conducted by Mullins (2001) shows that architects, designers, and healthcare professionals recognize the parametric modeling tool as a meaningful and valuable approach for integrating evidence-based design and optimizing design processes and healthcare facility performance (Mullins, 2011). The benefit of using the parametric modeling tool goes beyond rapid evaluation of the proposed design options in building configurations. Alternative design solutions can be generated to inform the operational planning and space programming that ultimately satisfy the design goals. Using the parametric modeling tool to help research meet design in practice has been confirmed by Sackerber architects' practice in this study.

\section{Recommendations for Evidence Generation in Evidence-based Design}

The methods that should be used and the activities that should be conducted to generate evidence for evidence-based design is another implication from this study. The following section depicts recommendations for generating evidence in evidence-based design. As discussed earlier, developing positive explanatory theory is crucial in evidence-based design research. Architects and designers need theories and research evidence that provide causal explanations for the effects of a physical attribute in a healthcare environment to help their decision making in the design process. Our 
intellectual understanding of the world, which derives from the scientific explanation, is always causal (Tofle et al., 2004). Architects and designers need theories and research evidence that provide a clear description and explanation not only of how the physical environment should be but also what operational and medical outcomes would be if theory and research evidence is implemented. Therefore, understanding and measuring the impact of design on operational processes and medical outcomes is a key area in conducting evidence-based design (EBD) research (Pati, 2010). Pati (2010) states that without this information, any EBD research is of less practical value although possibly still theoretically relevant because it will add limited applicable knowledge to the information support base.

As discussed in the literature review, a randomly controlled study or Randomly Controlled Trial (RCT) is the most robust and rigorous experimental study. Given the complexity of architectural research, sometimes it is very difficult to conduct a randomly controlled study and experiment. Thus, adopting the practices from findings of this case study at Grand River Hospital and literature reviews in previous studies, several research activities and methods for evidence generation are recommended when evidence from scientific research or randomly controlled experiment is not yet available or is in its developing stage. Table 6.2 presents the recommendations for research activities and methods for evidence generation as well as the usage of evidence. 
Table 6.2: Activities and Methods for Evidence Generation

\section{Activities and Methods for Evidence Generation}

\begin{tabular}{|c|c|c|c|}
\hline ACTIVITY/SESSION & ACTIVITY FREQUENCY & METHODS & USAGE OF EVIDENCE \\
\hline Visioning Session & $\begin{array}{l}\text { Typical task conducted early on in } \\
\text { the design process for every } \\
\text { hospital design }\end{array}$ & $\begin{array}{l}\text { Focus group; } \\
\text { collaborative sessions }\end{array}$ & $\begin{array}{l}\text { Data on priority areas; } \\
\text { strategic plan; design guiding } \\
\text { principles }\end{array}$ \\
\hline $\begin{array}{l}\text { Programming/ } \\
\text { Needs } \\
\text { Assessment }\end{array}$ & $\begin{array}{l}\text { Typical task conducted early on in } \\
\text { the design process for every } \\
\text { hospital design }\end{array}$ & $\begin{array}{l}\text { Questionnaire; } \\
\text { interviews; focus } \\
\text { groups }\end{array}$ & $\begin{array}{l}\text { Physical needs; } \\
\text { programming; adjacencies; } \\
\text { performance analysis; } \\
\text { functional requirements }\end{array}$ \\
\hline Room Mock-ups & $\begin{array}{l}\text { Typical task conducted as part of } \\
\text { design process; it can be } \\
\text { conducted at different times in } \\
\text { the process--rough mock-ups or } \\
\text { equipped mock-ups. It is for most } \\
\text { of hospital projects. }\end{array}$ & $\begin{array}{l}\text { Questionnaire; } \\
\text { interviews; comments } \\
\text { from users }\end{array}$ & $\begin{array}{l}\text { Design decision making; } \\
\text { lessons learned; evaluation } \\
\text { of implementing of research } \\
\text { evidence; users' feedback }\end{array}$ \\
\hline $\begin{array}{c}\text { Functional } \\
\text { Performance } \\
\text { Evaluation(FPE) }\end{array}$ & $\begin{array}{l}\text { Conducted at any time after the } \\
\text { building is completed; most } \\
\text { commonly performed as } \\
\text { diagnostic post-occupancy } \\
\text { evaluation; not frequently } \\
\text { conducted; FPE include field } \\
\text { research + parametric modeling }\end{array}$ & $\begin{array}{l}\text { Field research; } \\
\text { systematic } \\
\text { observations; } \\
\text { shadowing session; } \\
\text { interviews; } \\
\text { questionnaire; } \\
\text { parametric modeling }\end{array}$ & $\begin{array}{l}\text { Design decision making; } \\
\text { lessons learned; user's } \\
\text { feedback; programming; } \\
\text { research hypothesis } \\
\text { development; identify } \\
\text { research questions }\end{array}$ \\
\hline $\begin{array}{l}\text { Post Occupancy } \\
\text { Evaluation } \\
\text { Feedback Session } \\
\text { (Lessons Learned) }\end{array}$ & $\begin{array}{l}\text { Not a full post-occupancy } \\
\text { evaluation; data are collected } \\
\text { from hospital's HCAHPS data and } \\
\text { questionnaire with small samples; } \\
\text { a collaborative session with } \\
\text { architects, designers, users, and } \\
\text { hospital leadership }\end{array}$ & $\begin{array}{l}\text { Systematic } \\
\text { observations; } \\
\text { interviews; } \\
\text { questionnaire; focus } \\
\text { groups }\end{array}$ & $\begin{array}{l}\text { Although it is not a full POE, } \\
\text { POE feedback session } \\
\text { provides data regarding } \\
\text { building performance; user } \\
\text { feedback; decision making } \\
\text { and future research } \\
\text { directions }\end{array}$ \\
\hline $\begin{array}{l}\text { Parametric } \\
\text { Modeling }\end{array}$ & $\begin{array}{l}\text { Parametric modeling tool is } \\
\text { developed using Rhino/ } \\
\text { Grasshopper in order to calculate } \\
\text { walking distance between each } \\
\text { two spaces and to simulate total } \\
\text { walking distances. Parametric } \\
\text { modeling also can be used to } \\
\text { examine the proximity of key } \\
\text { rooms and visibility from nurse } \\
\text { station to patient rooms. }\end{array}$ & $\begin{array}{l}\text { The rhino/grasshopper } \\
\text { model (isovist) is used } \\
\text { to analyze the sight } \\
\text { lines to evaluate the } \\
\text { visibility of patients or } \\
\text { patient rooms from } \\
\text { central nursing } \\
\text { stations. Heat map is } \\
\text { used to measure } \\
\text { proximity; walking } \\
\text { distance also can be } \\
\text { measured in rhino/ } \\
\text { grasshopper model. }\end{array}$ & $\begin{array}{l}\text { Examining walking distance; } \\
\text { proximity and visibility in } \\
\text { nursing units; enhancing the } \\
\text { process of floor } \\
\text { configuration design }\end{array}$ \\
\hline
\end{tabular}

Randomly Controlled Study - Generally speaking, the fundamental structure of a randomized controlled study is to have two equivalent groups that are created through randomized assignment from a common pool. One of the groups is used as the experimental or treatment group, and the other is considered the control group. This is regarded as the gold standard of research. It is a very robust and rigorous type research that explains causations.

Before-and-After Design - Studies with pre and post data collection when equivalent or matching groups are unavailable. This "before-and-after" research design includes two options. One is "before-and-after" design with one group. The second option is examining differences between groups. These options are considered less robust than the randomized controlled study. 
Quasi-Experiment - When examining causation is the primary objective in research, conducting a true randomly controlled experiment is not always easy, especially in environmental design research. The researcher should consider using any quasi-experimental opportunities that exist.

In order to provide a narrative for the recommendations, Randomly Controlled Study is discussed first. Then recommended research activities that can generate evidence are discussed based on the findings from this case study. Since Before-and-After Design study, as well as quasi-experiment, were not conducted in Grand River Hospital, it is not necessary to discuss these methods in detail. The brief descriptions can be found in Table 6.2 .

Randomized Controlled Trials (RCT) were advocated by Archie Cochrane in the early 1970s as a source of more reliable evidence than other types of information. RCT generates a considerable body of reliable research that is available to form the foundation of evidence-based medicine (EBM). RCT is regarded as the gold standard of research. If the researcher can properly design and implement a study along these lines, it should eliminate any alternative explanations for observed phenomena when researchers try to draw explanation and description from data and generate evidence and theory (Pati, 2010). This kind of research design is absolutely robust and rigorous as a scientific research.

In evidence-based practice, quality evidence from sources other than traditional scientific research has already been promoted (Stetler et al., 1998). Pati (2011) articulates day-to-day non-research activities that incorporate certain necessary attributes of scientific research can produce quality evidence. The methods in day-to-day non-research activities include visioning, programming/need assessment, and room mock-ups (Pati, 2011b). Three more activities which are not part of a standard architectural project 
delivery process are also suggested by Pati (2011b). These additional activities also contribute considerably to the body of evidence including functional performance evaluation (FPE), quality improvement studies, and pilot projects as part of transition management (Pati, 2011b). Among these six suggested activities, visioning, programming/need assessment, room mock-ups, and functional performance evaluation (FPE) were confirmed by this case study at Grand River Hospital. In addition, a postoccupancy evaluation feedback session is a valuable method to generate evidence and propose future research questions. Through these methods, quality evidence can be generated to inform design decisions.

It is important to clarify that the recommended methods in Table 6.2 are limited to non-experimental methods and, more specifically, activities that by definition fall outside the realm of research. These tasks and activities normally can be conducted by designers and professionals in typical projects to generate high-quality evidence. Some methodological modifications should be incorporated based on fundamental principles of scientific research.

The methods used in a visioning session include focus groups and collaborative sessions. A visioning session is typically conducted early on during the design process for healthcare design. Data are used for generating design guiding principles, strategical planning, and priority areas. A similar activity with the potential for rich data and evidence generation is programming and needs assessment. The methods used for this activity include questionnaires, interviews, and focus groups. Capturing and storing such data in a consistent manner can provide a useful means to analyze and forecast future trends. Many design firms have already conducted this activity. For example, an archival 
analysis of program data from two decades is conducted in a study (Latimer, Gutknecht, \& Hardesty, 2008). The findings demonstrated that hospital departments have been increasing in floor area in a consistent and significant manner. The analysis helps the discussions regarding future needs and the sustainable use of resources. Using building mock-ups is another opportunity for evidence generation, and they are utilized in most projects like Grand River Hospital. Mock-ups provide the opportunity to evaluate the physical environment as a concept or an intervention in a full-scale and fully equipped environment. Different data can be generated from mock-ups including those from questionnaires, interviews, comments, and observations. If all the information from mock-ups can be stored and retrieved in a meaningful manner, the findings from mockups can serve as valuable knowledge during programming and design phases and help to identify potential research questions and develop research hypotheses.

Functional performance evaluation (FPE) is another method that can generate research evidence. It is usually conducted at any time after the building is completed; most commonly performed as diagnostic post-occupancy evaluation even though it is not frequently conducted. FPE includes field research and parametric modeling, which has been discussed earlier in this study and will be discussed in detail in the next paragraph. Field research includes systematic observations, shadowing session, interviews, and questionnaires. When robustly conducted, the information obtained from field research can support a wide range of design decision making including programming and lessons learned. Field research can get user's feedback and help develop the research hypothesis and identify research questions. 
Post-occupancy evaluation (POE) certainly can generate research evidence. But, a POE feedback session also can quickly provide evidence to a certain degree. For the POE feedback session, data are collected from hospital's HCAHPS data and questionnaire with small samples. A collaborative session with architects, designers, users, and hospital leadership were conducted at Grand River Hospital as a successful example. Although it is not a full POE, POE feedback sessions do provide data regarding building performance, user feedback, decision making, and future research directions.

Parametric modeling is another method that can be used not only for helping the design but also to generate research evidence. The parametric modeling tool is developed using Rhino/Grasshopper in order to calculate walking distance between each two spaces and to simulate total walking distances. Parametric modeling also can be used to examine the proximity of key rooms and visibility from nurse stations to patient rooms. In the parametric modeling tool, the rhino/grasshopper model (isovist) is used to analyze the sight lines to evaluate the visibility of patients or patient rooms from central nursing stations. A heat map is used to measure proximity; walking distance also can be measured in the rhino/grasshopper model. Research evidence can be generated regarding nurses' walking distance, proximity and visibility in nursing units, and enhancing the process of floor configuration for hospital design.

However, it is important to enhance data quality from these activities. Otherwise, evidence generated from these activities may be regarded as anecdotal (Pati, 2012). What needs to be done in order to transform these data into valuable evidence? Pati (2012) stated that an important area of consideration is the standardization of instruments across contexts and activities. Based on findings from this case study at Grand River Hospital, 
functional performance evaluation (FPE) and a visioning session can be the areas where standardization can be utilized. For instance, use the same FPE instrument across hospitals that will enable the robust comparison of data. Similarly, using the same protocol across multiple visioning sessions will enable the robust comparison of data and the identification of needs and trends in major areas. Standardization of an FPE instrument across the entire healthcare design industry will ensure that data are comparable and provide a platform to generate quality evidence from everyday activities.

In addition, in order to provide a certain degree of confidence, repeated observation of similar relationships or interventions in multiple studies and larger datasets may achieve a higher level of confidence. The result from this kind of study may not explain the nature of causation, but they may have relevance for the practical application of design concepts in the healthcare environment. Moreover, although with a less robust design, when same findings are repeated from multiple studies, study outcomes attain levels of confidence comparable to those from experimental designs (Pati, 2010).

There are many opportunities to generate quality data through non-research activities in the design process or after the project is completed. Many of these activities are standard steps in the hospital design process. These data will serve as valuable evidence in a wide range of decision-making processes, such as the visioning session, programming phase, and schematic design phases. These activities were conducted in the design process for Grand River Hospital. With increased rigor of ensuring data quality, the results from these activities could be turned into evidence when evidence from scientific research is not yet available or is in its developing stages. 
It is necessary to re-state that robust scientific research is absolutely the one that needs to be conducted for evidence-based design. The activities suggested based on research findings from this case study can be used as a supplement when scientific research is not yet available. Generally speaking, control groups are used when examining the presence and absence of one specific treatment or if intervention is of primary interest (Pati, 2011b). Therefore, the use of control groups in environmental design research has followed the same logic. In evidence-based design practice, however, we may be more interested in comparing different types of physical design attributes. For example, the primary interest may not be in examining the extent to which efficiency is affected if a decentralized nurse station is present versus absent. Rather, the primary interest could be in comparing centralized nurse station vs. decentralized nurse station regarding nurses' walking distances. In such case, there could be two or more equivalent groups, with each group associated with a different design solution (centralized nurse station and decentralized nurse station) (Pati, 2011b). Such studies may have more immediate practical application in evidence-based healthcare design, as opposed to the traditional experiment with a control group. Future research topics could cover a wide spectrum in which some require scientific research with a control group and some may only need comparative studies with multiple groups in different settings with different design attributes.

Findings from this research presented a comprehensive framework for integrating evidence-based design in the hospital architectural design process. Findings also provided a framework for diagnostic post-occupancy evaluation or functional performance evaluation (FPE) in healthcare design. Findings indicated that a systematic, multi- 
methodological approach developed based on a conceptual framework can lead to higher quality FPE. Findings also revealed that research activities can be conducted in a normal design process even though they are non-scientific research with a control group. With standardization of protocol and instrument used in FPE, data quality can be ensured and data can be compared in different hospitals. Therefore, evidence can be generated when scientific research is not yet available or in developing process. Nevertheless, evidencebased design has come a long way. More explanatory theory in environment-behavior studies, particularly in the healthcare environment, need to be developed so the body of knowledge of evidence-based design can become more comprehensive, more robust, and more practical.

Rather than striving for closure, I would like to leave both myself and other scholars pondering the essential issues that I have addressed based on findings from this research. Despite the limitations, the findings are significant as a view into how to integrate evidence-based design into the design process as well as how the design process has been modified. The findings revealed that it is important to develop more descriptive and explanatory theories through environment-behavior studies. The data also revealed that collaborations with all stakeholders, conducting design charrettes, using technology, building mock-up rooms, conducting functional performance evaluations (FPE), and disseminating research findings are essential in evidence-based design practice. It is also interesting to note that certain significant findings suggest some modifications to Jon Lang's General Model of Design Praxis (Lang, 1987). Instead of having a linear design process, a redefined cyclical design process model that integrates evidence-based design has been proposed based on findings of this research. In the context of the redefined 
model, additional components have been added in the design process, such as in-house research unit, mock-ups, design charrettes, field research, parametric modeling, and disseminating research evidence.

It is also recommended to use multiple or mixed methods to conduct environment-behavior research in the healthcare environment. This notion is also supported by many other scholars (Creswell, Klassen, Plano Clark, \& Smith, 2011; Pati, 2011b, 2012). It is important in this early stage of evidence-based design knowledge development to examine cause and effect as well as meaning in research studies of this nature.

A few assertions can be made as a result of this research. First, multiple methods and activities for generating evidence during the design process should continue to be considered as important to evidence-based design. In this process, architects and designers should have a new skill set that includes the ability to interact with research evidence and the ability to conduct research. Second, developing explanatory theory that describes cause and effect in the healthcare environment is paramount. Finally, it is necessary to conduct more case studies in different hospitals in order to validate the redefined design process model that embraces research activities in architectural practice. 


\section{Appendix I}

Interview Schedule and Contact

\begin{tabular}{|c|c|c|c|c|}
\hline & Interview Sch & Jule and Contac & formation & \\
\hline $\begin{array}{c}\text { Interviewee's Name } \\
\text { (Pseudonym) }\end{array}$ & $\begin{array}{c}\text { Contact } \\
\text { Information (Phone } \\
\text { number) }\end{array}$ & $\begin{array}{l}\text { Occupation (Architect, } \\
\text { Designer, Consultant, } \\
\text { Contractor, User, etc.) }\end{array}$ & Interview Date & $\begin{array}{l}\text { Interview } \\
\text { Duration }\end{array}$ \\
\hline & & & & \\
\hline & & & & \\
\hline & & & & \\
\hline & & & & \\
\hline & & & & \\
\hline & & & & \\
\hline & & & & \\
\hline & & & & \\
\hline & & & & \\
\hline & & & & \\
\hline & & & & \\
\hline & & & & \\
\hline & & & & \\
\hline & - & & & \\
\hline & & & & \\
\hline & & & & \\
\hline & & & & \\
\hline & & & & \\
\hline & & & & \\
\hline & & & & \\
\hline
\end{tabular}




\title{
Appendix II: Interview Protocol
}

\author{
for Architects and Designers
}

\section{Interview Guide Part One:}

\section{Focus on Evidence-based Design}

1. Describe for me your roles and responsibilities for Grand River Hospital (GRH) design. What do you like about the project?

2. Evidence-based design has been utilized in healthcare design for the past decades. Can you give me examples of the design (such as patient room, lobby, nurses' station, etc.) that is created based on credible research evidence in Grand River Hospital project?

3. Grand River Hospital (GRH) was designed through Integrated Project Delivery (IPD) approach; describe for me your role and experience in IPD process for this project.

4. Describe for me how the "Design Guiding Principles" that focuses on patient safety and quality care were generated for GRH project.

5. Think back to when you first start GRH project. Tell me how Patient Room Design Goals, Patient, and Staff Safety-Related Design Elements, Key Block Plan Drivers were created. How was the information in these documents found? Are there any other design-related documents that you would like to share with me?

6. Describe for me what credible research evidence are identified for creating GRH that promotes patient safety and quality care. (For example, private patient room, positive distractions, infection control, patient fall prevention, wayfinding, circulation, staff efficiency, etc.)

7. The Design Guiding Principles and design related documents are focused on patient and staff safety and quality care for patients. Usually, the design is created intuitively based on architects/designers' experience and users' needs. Describe for me how this written research evidence is interpreted and implemented in GRH project.

8. Evidence-based design is a new approach comparing with the traditional design approach. I am curious to learn from your perspective what opinions and suggestions you have regarding evidence-based design for healthcare design. 


\section{Interview Guide Part Two:}

\section{Focus on programming process, design process, and decision-making process}

1. There were several "Design Charrettes/Workshops" that involved architects/designers, contractors, owners, and all of the design team with various consultants. Tell me about these design charrettes/workshops. Describe for me your roles and what you did in these "Design Charrettes/Workshops."

2. As mentioned earlier, the evidence-based design has been a new approach for healthcare design in the past decades. Describe for me how evidence-based design has been integrated into the design process for Grand River Hospital? What have the differences EBD made to the entire traditional design process for GRH project?

3. Evidence-based design is using credible research evidence to inform design decisions. For example, artwork provided throughout the facility; water feature and other positive distractions presented in public lobbies. These are the design decisions based on research evidence that these physical features can provide a better healing environment for patients. Tell me at what point it is decided which research evidence is attainable.

4. The traditional Design process includes Programming, Schematic Design, Design Development, Construction Documents and Construction Administration. Describe for me how the decisions were made in each of these phases for GRH project.

5. The design process for GRH project is different from the traditional design process. Describe for me how the project cost and schedule are controlled in the design process for GRH project.

6. Grand River Hospital is a massive project. Patient safety and quality care are the primary design goals. Tell me about the new strategies and methods that have been used in the design process for GRH project.

7. The design process for GRH project is different from the traditional design process. I am curious to learn from your perspective what opinions and suggestions you have regarding the design process and decision-making process for GRH project. 


\title{
Appendix II: Interview Protocol
}

\author{
for Contractors
}

\section{Interview Guide Part One:}

\section{Focus on Evidence-based Design}

1. Grand River Hospital (GRH) was designed through Integrated Project Delivery (IPD) approach; describe for me your role and experience in IPD process for this project.

2. A set of "Design Guiding Principles" that focuses on patient safety and quality care was generated for GRH project. Did you participate in the process of developing that set of "Design Guiding Principles"? If not, why? If yes, how?

3. Evidence-based design is using credible research evidence to inform design decisions. For example, artworks provided throughout the facility; water feature and other positive distractions presented in public lobbies. These are the design decisions based on research evidence that these physical features can provide a better healing environment for patients. Tell me what kind of contributions you have made in implementing research evidence for GRH project.

4. Evidence-based design involves steps of identifying, interpreting and implementing credible research evidence. Tell me about your involvement or contributions in any of these steps for GRH project. For example: implementing access to information technology /communication as one of the patients and staff safety related design element. Perhaps you have been involved in the design of IT/communication system? If not, Why?

5. There were several "Design Charrettes/Workshops" that involved architects/designers, contractors, owners, and all of the design teams with various consultants. Tell me about these design charrettes/workshops. Describe for me your roles and what you did in these "Design Charrettes/Workshops."

6. There were many mock-ups in the construction process, and building mock-ups was an important component in the process. Describe for me about the building mock-ups process for both interior mock-ups and exterior mock-ups.

7. Evidence-based design is a new approach comparing with the traditional design approach. I am curious to learn from your perspective what opinions and suggestions you have regarding evidence-based design for healthcare design. 


\section{Interview Guide Part Two:}

\section{Focus on programming process, design process, and decision-making process}

1. The traditional Design process includes Programming, Schematic Design, Design Development, Construction Documents and Construction Administration. Describe for me at what point you were involved in the design process as a contractor and your experience in GRH project design process.

2. Tell me about your involvement in producing construction documents process by comparing your participation in other design phases, such as programming, schematic design and design development. Describe for me your interactions and experience with architects, engineers, and owners.

3. Describe for me about the contributions you made in the decision-making process. At what point? And for what kind of decisions?

4. The design process for GRH project is different from the traditional design process. Describe for me how the project cost and schedule are controlled in the design process and construction process for GRH project.

5. Describe for me what the differences are in the design process and construction process for Grand River Hospital project comparing with other projects you have worked on. As a contractor, how did you see that evidence-based design been integrated into the design process for Grand River Hospital?

6. Grand River Hospital is a massive project. Patient safety and quality care are the primary design goals. Tell me about the new strategies and methods that have been used in the construction of GRH facility.

7. The design process for GRH project is different from the traditional design process. I am curious to learn from your perspective what opinions and suggestions you have regarding the design process and decision-making process for GRH project. 


\title{
Appendix II: Interview Protocol
}

\author{
for Owners/Users
}

\section{Interview Guide Part One:}

\section{Focus on Evidence-based Design}

1. Describe for me your roles and responsibilities for Grand River Hospital (GRH) design. What do you like about it?

2. Evidence-based design has been utilized in healthcare design for the past decades. GRH is designed based on "Design Guiding Principles," "Patient and Staff SafetyRelated Design Elements," etc. Can you give me examples of the design (such as patient room, lobby, nurses' station, etc.) that is designed based on credible research evidence in Grand River Hospital project?

3. Grand River Hospital (GRH) was designed through Integrated Project Delivery (IPD) approach, describe for me your role and experience in IPD process for this project.

4. Describe for me how the "Design Guiding Principles" that focuses on patient safety and quality care were generated for GRH project. Were you involved in that process? If yes, what kind of role did you play?

5. Think back to when you first start GRH project. Tell me how Patient Room Design Goals, Patients, and Staff Safety-Related Design Elements, Key Block Plan Drivers were created. How was the information in these documents found? Are there any other design-related documents that you would like to share with me?

6. There were several "Design Charrettes/Workshops" that involved architects/designers, contractors, owners, and all of the design team with various consultants. Tell me about these design charrettes/workshops. Describe for me your roles and what you did in these "Design Charrettes/Workshops."

7. Describe for me what strategies you have used to create a facility that promotes patient safety and quality care.

8. Evidence-based design is a new approach comparing with a traditional design approach. I am curious to learn from your perspective what opinions and suggestions you have regarding evidence-based design for healthcare design. 


\section{Interview Guide Part Two:}

\section{Focus on programming process, design process, and decision-making process}

1. As mentioned earlier, evidence-based design has been a new approach for healthcare design in the past decades. Describe for me what the differences EBD has made to the entire traditional design process for GRH project.

2. The traditional Design process includes Programming, Schematic Design, Design Development, Construction Documents and Construction Administration. Describe for me your involvement in each of these phases and how the decisions were made in each of these phases for GRH project.

3. Describe for me your interactions and experience with architects, engineers, consultants and contractors in programming, schematic design, design development, construction document and construction administration phases.

4. There are new approaches in the design process and construction process for GRH project. Describe for me how the project cost and schedule are controlled in the design process and construction process for GRH project.

5. Tell me about the contributions you made in the decision-making process. At what point? And for what kind of decisions?

6. Grand River Hospital is a massive and complex project. Patient safety and quality care are the primary design goals. Tell me about the new strategies and methods that have been used to achieve these design goals for GRH project.

7. The design process for GRH project is different from the traditional design process. I am curious to learn from your perspective what opinions and suggestions you have regarding the design process and decision-making process for GRH project. 
Appendix III

\section{Observation Protocol}

\section{Demographic Information:}

Field Setting for Observation:

Date/Time

\section{Descriptive Notes:}

Description of Physical Setting:

Accounts of Particular Activities or Events:

Researcher's Analytic and Reflective Notes: 


\section{Appendix IV: Sample of Observation Sheet}

\section{Demographic Information:}

Field Setting for Observation:__2nd floor ICUs in Tower_

Date/Time_July $17^{\text {th }}, 2015,9: 00 \mathrm{am}$

\section{Descriptive Notes:}

\section{Description of Physical Setting:}

The $2^{\text {nd }}$ floor is for medical ICUs. The floor plan is designed in a slightly curved shape in the tower. There are three central nurse stations (I couldn't take photos of the central nurse stations at this time because of people were working there). There are total 24 Surgical and Trauma ICUs on this floor (Figure 1 to Figure 21). There are 6 Pediatric ICU on this floor as well (I couldn't take photos in PICU due to more strict privacy constraints). All ICUs are designed as private patient rooms. There is a surgical registration on this floor. A surgical family lounge is on the second floor as well. There is a Chapel on the second floor.

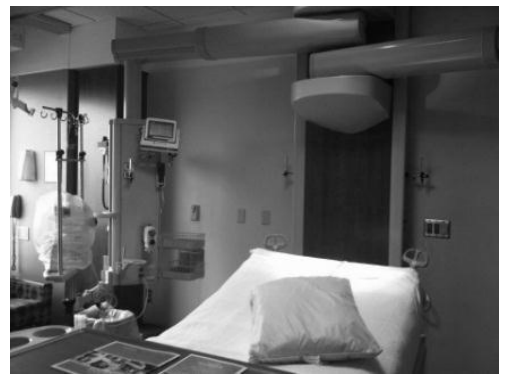

Figure 1

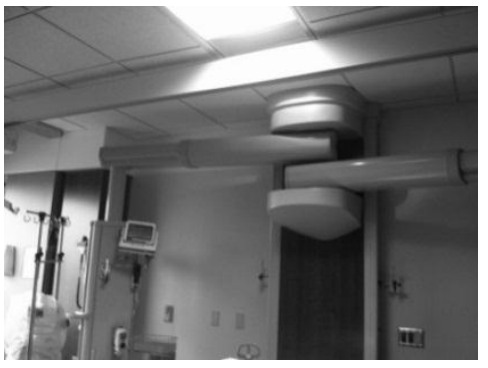

Figure 2

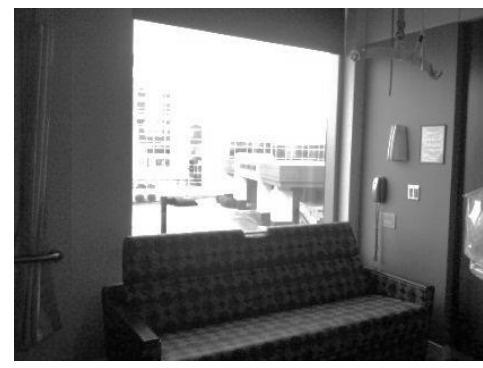

Figure 3

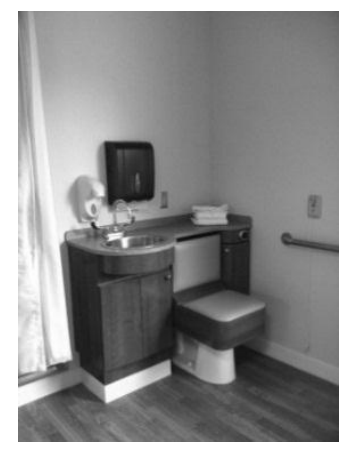

Figure 4

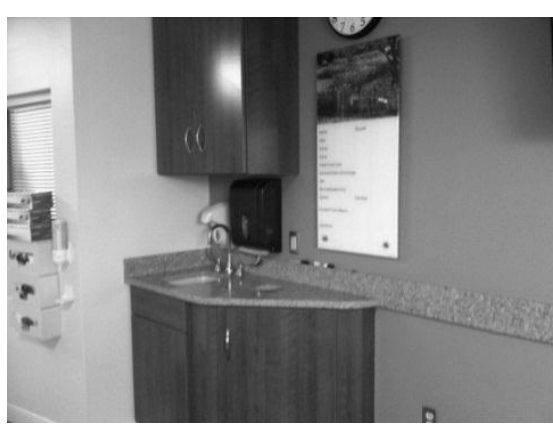

Figure 5

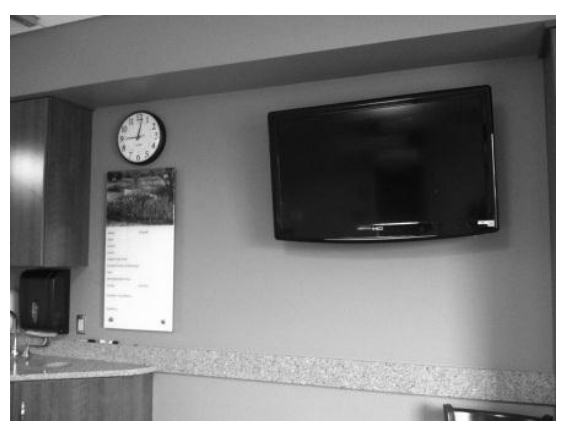

Figure 6 


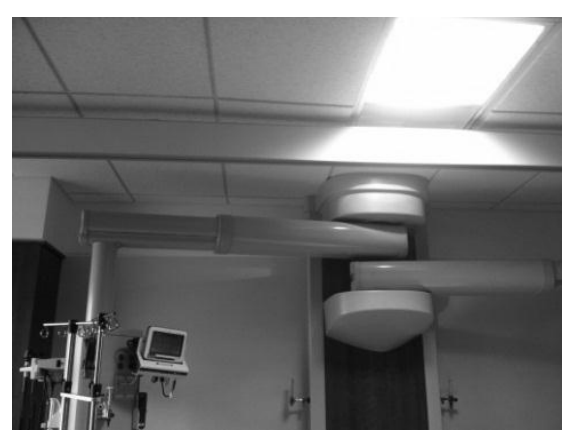

Figure 7

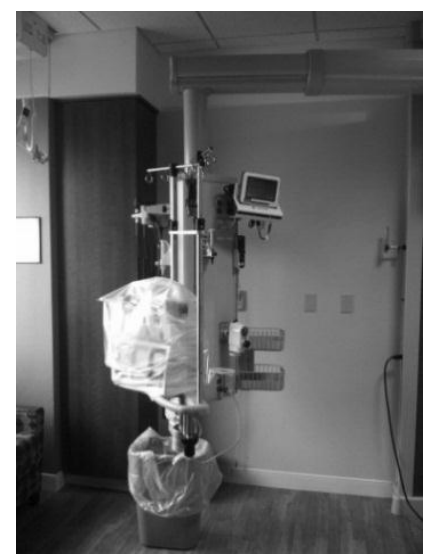

Figure 8

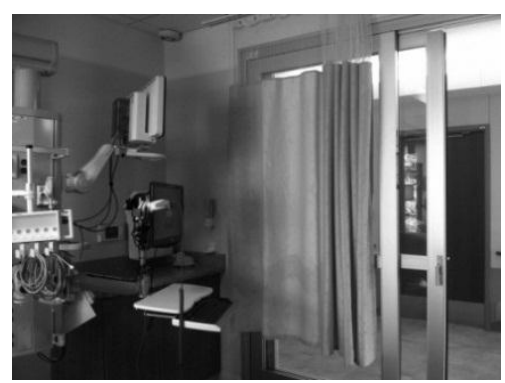

Figure 9

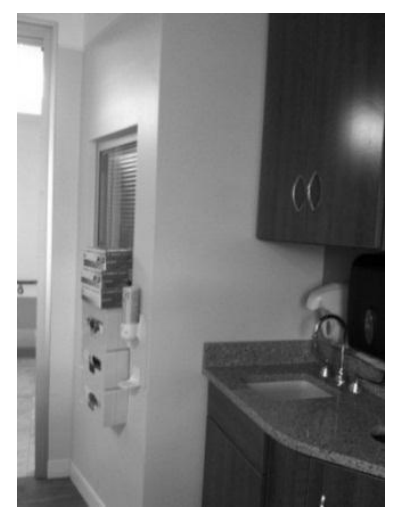

Figure 10

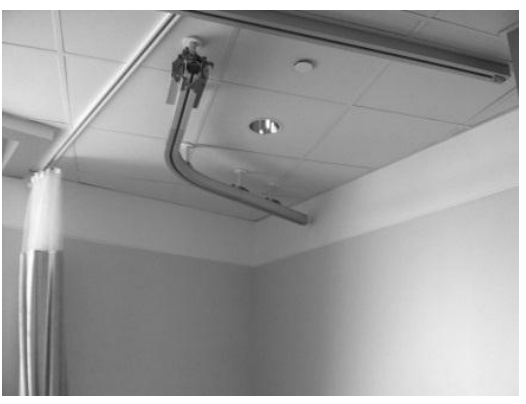

Figure 11

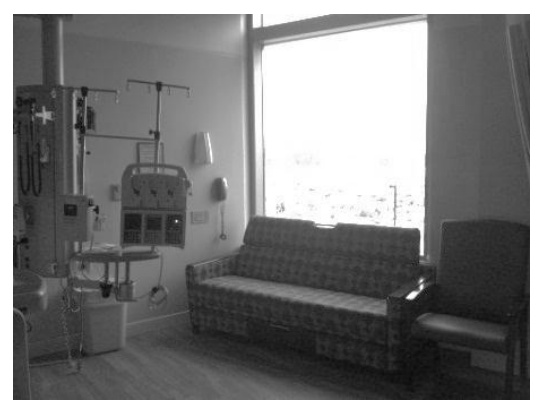

Figure 12

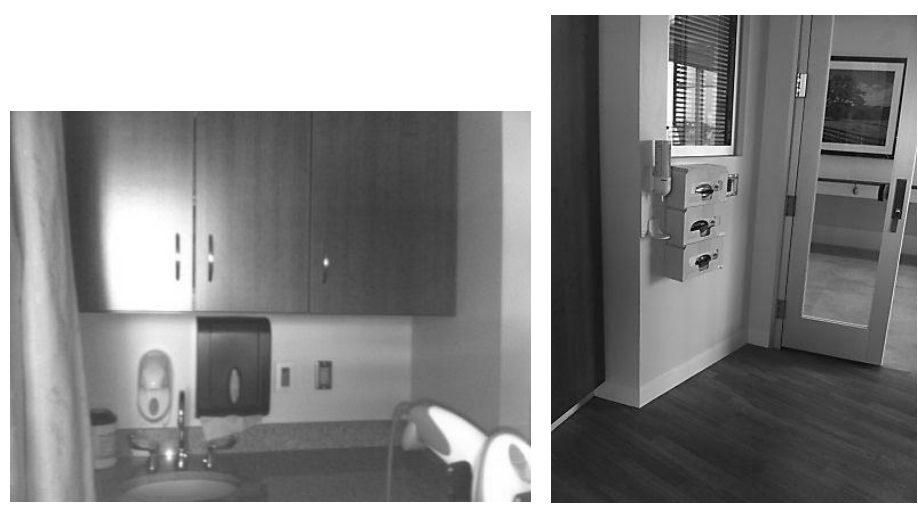

Figure 13

Figure 14

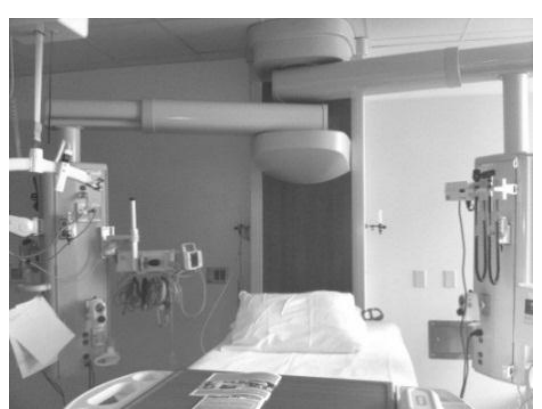

Figure 15

In each ICU, there is a family space for family members (Figure 3 and Figure 12). Family members have their own TV. Patient has their TV as well (Figure 6). The ICU has its own bathroom for the patient (Figure 4). There is a track on the ceiling for patient lift (Figure 11). There is a working zone for medical staff (Figure 5, Figure 10). There is a 
sink for medical staff and there are hand sanitizers on the wall (Figure 5, Figure 10, Figure 13 and Figure 14).

There is a big glass curtain wall at the end of the hallway of each floor (Figure 16). It provides daylight for staff, visitors, and patients. There are decentralized nurse stations outside each patient room so the caregiver can provide direct supervisions for the patient (Figure 17).

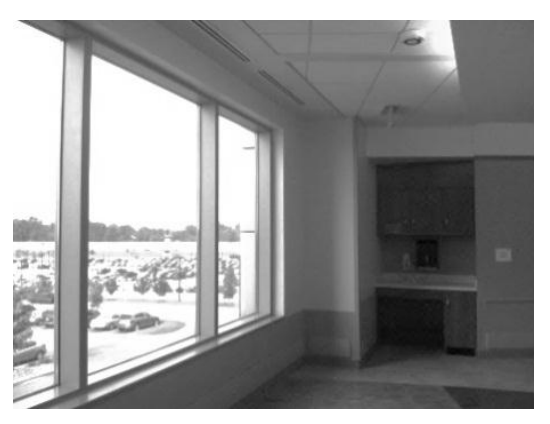

Figure 16

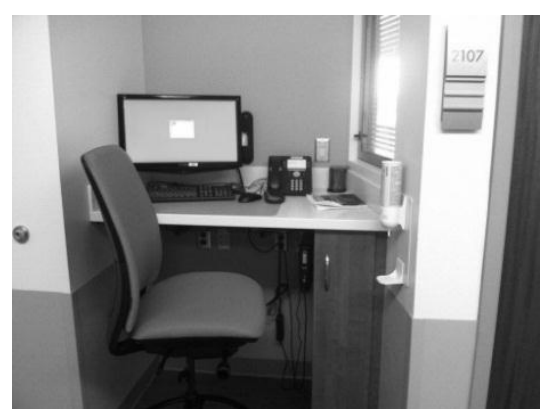

Figure 17

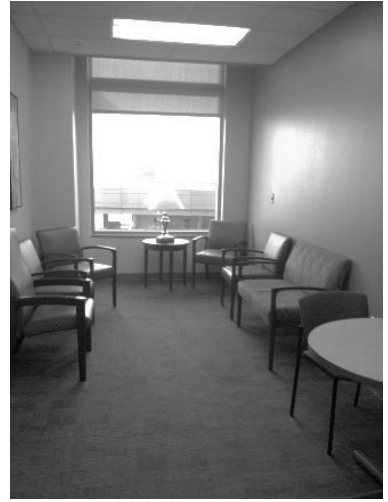

Figure 18

All medical ICUs are private patient rooms on this floor. There are decentralized nurse stations outside each ICU (Figure 17). There is a private meeting room on this floor (Figure 18, Figure 19). There are several alcoves for medical equipment plug- in on the floor. There are also several small coffee areas on this floor (Figure 20 and Figure 21).

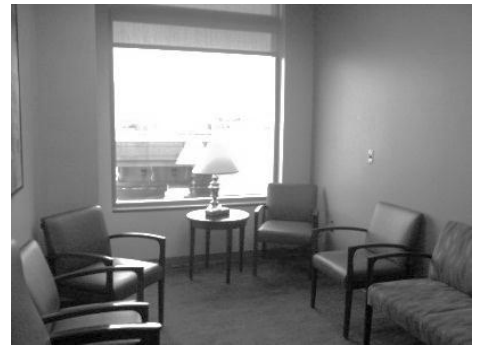

Figure 19

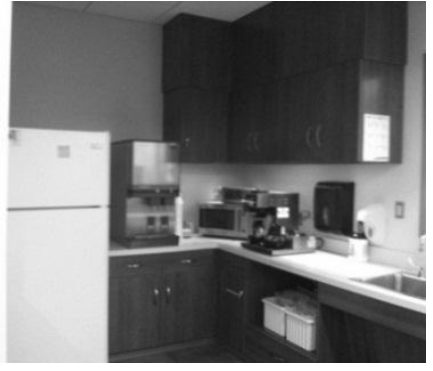

Figure 20

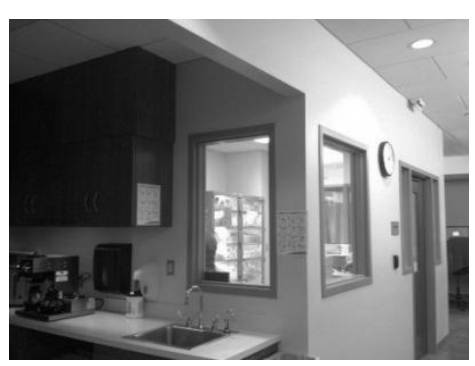

Figure 21

\section{Portraits of the Participants:}

This floor is very busy. I see a lot of medical staff working on the nurse stations. That's why I couldn't take photos at the central nurse stations. Several patients are in the patient rooms. A few family members were in the patient room with the patient. 
I see two empty patient rooms. I had the chance to go into the room and observe the room and its layout. I took many photos in two different ICU rooms.

Accounts of Particular Activities or Events:

I see a lot of medical staff working at the central nurse stations. Several patients are in their beds in ICU. A couple of family members is with the patients.

\section{Researcher's Analytic and Reflective Notes:}

The curved hallway design is an effective solution to break down the institution look in a boring long corridor. Decentralized nurse station with viewing windows provides convenient supervision to patients in private patient room. The multiple central nurse stations instead one central nurse station provides efficiency for physicians and nurses.

Research findings indicate that decentralized nurses' stations provide better efficiency. I think the combination of centralized and decentralized nurse stations is an effective solution to achieve privacy for patients and efficiency for medical staff.

Providing hand sinks in patient rooms and in hallways promotes infection control.

The ceiling lift can reduce the staff injury and promote patient safety. 


\section{Appendix V}

\section{SUBJECT CONSENT FORM FOR}

Implementing Evidence-based Design in Hospital Architecture and Shifting the Design Process: A Case Study

This is an interview type of research study in order to have input from different stakeholders regarding how evidence-based design (EBD) is integrated into hospital architectural design process. Please take your time to make your decision. This consent form may contain words that you do not understand. Please ask the investigator to explain any words or information that you do not clearly understand. You are being asked to take part in this study because you have participated in the design process of Grand River Hospital.

\section{Why is this study being done?}

The purpose of this research is to understand how evidence-based design has been implemented in hospital architectural design and practice by architects/designers, subconsultants, contractors and end users at Grand River Hospital. The goal of this research is to create a deeper and fuller understanding of how evidence-based design process is integrated into the traditional design process and how credible research is interpreted and how the design decisions are made for Grand River Hospital.

\section{How many people will take part in the study?}

About 30 people will take part in this study.

\section{What will happen if I take part in this research study?}

You will be asked to participate in open interviews regarding the project design process, decision-making process and your roles in the design process. Your opinions about evidence-based design will be asked as well. You will be audio recorded so that the researcher will be able to transcribe and analyze the data. It is also a possibility that you share any documents that you feel is relevant to the study. The only audio recording will be used during interviews.

\section{How long will I be in the study?}

This study will take approximately 30-45 minutes of your time to complete. Appointments will be made with each volunteer to meet their schedules.

\section{Can I stop being in the study?}

Your participation in this case study is voluntary. Yes. You can decide to stop at any time. Tell the researcher if you are thinking about stopping or decide to stop. You can stop participating at any time without penalty. 
What side effects or risks can I expect from being in the study?

This is a minimal risk study. The potential risks might include the inconvenience of the schedule; time involved to answer interview questions and might include loss of confidentiality.

\section{Are there benefits to taking part in the study?}

Your participation may benefit all stakeholders who are working in the healthcare industry including the owner of healthcare facility, architects and designers, contractors, patients and family members as well as medical staff. By sharing your experience or expertise of using evidence-based design approach, it is hoped to help to provide practical recommendations for the EBD design process in order to increase the rigor of design practice and benefit the healthcare industry.

\section{What other choices do I have if I do not take part in this study?}

You have the option of not participating in this study, and will not be penalized for your decision.

\section{Will my personal information be kept private?}

Yes. To keep the personal information private, pseudonyms for participants and GRH will be used. Participants' names and GRH's name will not be associated in any publication or presentation with the information collected about or with the research findings from this study.

\section{What are the costs of taking part in this study?}

There is no cost for you to participate in this study. You will not be paid for taking part in this study.

\section{What happens if I am injured because I took part in this study?}

This is a minimal risk study. It is not likely that you will be injured during this study, but if you have been injured in any way, please contact the Principal Investigator immediately at 260-481-6008.

\section{What are my rights as a participant?}

Taking part in this study is voluntary. You may choose not to take part or may leave the study at any time. Leaving the study will not result in any penalty or loss of benefits to which you are entitled. In addition, you can choose to skip any questions that you do not wish to answer or withdraw at any time.

\section{Whom do I call if I have questions or problems?}

For questions about the study or a research-related injury, contact the researcher: Suining Ding, Ph.D. Candidate, NCIDQ, ASID, IDEC, Principal Investigator, Department of Visual Communication and Design, Visual Arts Building, VA213, Indiana University Purdue University Fort Wayne, Fort Wayne, IN 46805, Tel: 260-481-6008 
For questions about your rights as a research participant, contact Grand River Hospital Institutional Review Board (which is a group of people who review the research to protect your rights) at 999-555-1234.

Or University of Missouri Campus Institutional Review Board (which is a group of people who review the research studies to protect participants' rights) at (573) 882-9585 or umcresearchcirb@missouri.edu.

\section{Where can I get more information?}

You may contact:

Suining Ding, Ph.D. Candidate, NCIDQ, ASID, IDEC

Principal Investigator

Prof. Benyamin Schwarz, Ph.D.

Department of Visual Communication and Design

Visual Arts Building, VA213

Faculty Advisor

Department of Architectural Studies

Indiana University Purdue University Fort Wayne

Fort Wayne, IN 46805

Tel: 260-481-6008

137 Stanley Hall

University of Missouri

Columbia, MO 65211

Tel: 573-882- 4904

You will get a copy of this form. You may also request a copy of the protocol (full study plan) by contacting Principal Investigator.

\section{Signature}

I have been given a copy of all three pages of this form. I have read it. I have had the opportunity to ask questions, and have had my questions answered. I understand the information and I willingly agree to take part in this study.

Signature of Study Subject

Date

Printed Name of Study Subject

Study Subject's Address

Signature of Investigator/Designee

Printed Name

Date

Obtaining Informed Consent 


\section{BIBLIOGRAPHY}

Adams, A. (2008). Medicine by design: the architect and the modern hospital, $1893-$ 1943: University of Minnesota Press.

AIA, F. (2006). Guidelines for Design and Construction of Health Care Facilities. Washington DC, American Institute of Architects.

Alalouch, C., \& Aspinall, P. (2007). Spatial attributes of hospital multi-bed wards and preferences for privacy. Facilities, 25(9/10), 345-362.

Alalouch, C., Aspinall, P., \& Smith, H. (2009). On locational preferences for privacy in hospital wards. Facilities, 27(3/4), 88-106.

Alexander, C. (1964). Notes on the Synthesis of Form (Vol. 5): Harvard University Press.

Alexander, C., Ishikawa, S., \& Silverstein, M. (1977). Pattern languages. Center for Environmental Structure, 2.

Altman, I. (1975). The environment and social behavior: Privacy, personal space, territory, crowding: Brooks/Cole Publishing Company Monterey, CA.

American Planning Association. (2006). Planning and urban design standards: John Wiley \& Sons.

Archer, L. B. (1970). An overview of the structure of the design process. Emerging methods in environmental design and planning, 285-307.

Arthur, P., \& Passini, R. (1992). Wayfinding: people, signs, and architecture.

Ayer, A. J. (1936). Language, Truth, Logic. New York: Dover.

Bäck, E., \& Wikblad, K. (1998). Privacy in hospital. Journal of advanced nursing, 27(5), 940-945.

BaHammam, A. (2006). Sleep in acute care units. Sleep and Breathing, 10(1), 6-15. 
Barlas, D., Sama, A. E., Ward, M. F., \& Lesser, M. L. (2001). Comparison of the auditory and visual privacy of emergency department treatment areas with curtains versus those with solid walls. Annals of emergency medicine, 38(2), 135139.

Baum, A., Fleming, R., \& Singer, J. E. (1985). Understanding environmental stress: strategies for conceptual and methodological integration. Advances in environmental psychology, 5, 185-205.

Bayo, M. V., García, A. M., \& García, A. (1995). Noise levels in an urban hospital and workers' subjective responses. Archives of Environmental Health: An International Journal, 50(3), 247-251.

Bazjanac, V. (1974). Architectural design theory: Models of the design process. Basic questions of design theory, 3, 20.

Berry, L. L., Parker, D., Coile, R., Hamilton, D. K., O Neill, D. D., \& Sadler, B. L. (2004). The business case for better buildings. Frontiers of health services management, 21, 3-24.

Bischoff, W. E., Reynolds, T. M., Sessler, C. N., Edmond, M. B., \& Wenzel, R. P. (2000). Handwashing compliance by health care workers: the impact of introducing an accessible, alcohol-based hand antiseptic. Archives of internal medicine, 160(7), 1017-1021.

Bobrow, M., \& Thomas, J. (2000). Multibed verses single-bed rooms. Building type basics for healthcare facilities New York: John Wiley \& Sons, 145-157.

Brown, B., Wright, H., \& Brown, C. (1997). A post-occupancy evaluation of wayfinding in a pediatric hospital: Research findings and implications for instruction. Journal of Architectural and Planning Research, 35-51.

Burden, B. (1998). Privacy or help? The use of curtain positioning strategies within the maternity ward environment as a means of achieving and maintaining privacy, or as a form of signalling to peers and professionals in an attempt to seek information or support. Journal of Advanced Nursing, 27(1), 15-23.

Burgoon, J. K. (1982). Privacy and communication. Communication yearbook, 6, 206249. 
Burpee, H. (2009). History of Healthcare Architecture. Mahlum Architects Healthcare Design Insights.

Cama, R. (2009). Evidence-based healthcare design: Wiley. com.

Caplan, L. J., \& Lipman, P. D. (1995). Age and gender differences in the effectiveness of map-like learning aids in memory for routes. The Journals of Gerontology Series B: Psychological Sciences and Social Sciences, 50(3), P126-P133.

Carpman, J. R., Grant, M. A., \& Simmons, D. A. (1983). Wayfinding in the hospital environment: The impact of various floor numbering alternatives. Journal of Environmental Systems, 13(4), 353-364.

Carpman, J. R., Grant, M. A., \& Simmons, D. A. (1993). Design that cares: Planning health facilities for patients and visitors: Jossey-Bass.

Charmaz, K. (2006). Constructing grounded theory: A practical guide through qualitative analysis: Pine Forge Press.

Chaudhury, H., Mahmood, A., \& Valente, M. (2005). Advantages and Disadvantages of Single-Versus Multiple-Occupancy Rooms in Acute Care Environments A Review and Analysis of the Literature. Environment and Behavior, 37(6), 760786.

Chaudhury, H., Mahmood, A., \& Valente, M. (2009). The effect of environmental design on reducing nursing errors and increasing efficiency in acute care settings: a review and analysis of the literature. Environment and behavior.

Claridge, J. A., \& Fabian, T. C. (2005). History and development of evidence-based medicine. World journal of surgery, 29(5), 547-553.

Clipson, C. W., \& Wehrer, J. I. . (1973). Planning for cardiac care: A guide to the planning and design of cardiac care facilities.

Cohen, S. (1986). Behavior, health, and environmental stress: Springer Science \& Business Media.

Cohen, S. E., \& Syme, S. (1985). Social support and health: Academic Press. 
Creedon, S. A. (2005). Healthcare workers' hand decontamination practices: compliance with recommended guidelines. Journal of Advanced Nursing, 51(3), 208-216.

Creswell, J. W. (2009). Research design: Qualitative, quantitative, and mixed methods approaches: Sage Publications, Incorporated.

Creswell, J. W., Klassen, A. C., Plano Clark, V. L., \& Smith, K. C. (2011). Best practices for mixed methods research in the health sciences. Bethesda (Maryland): National Institutes of Health, 2094-2103.

Creswell, J. W., \& Miller, D. L. (2000). Determining validity in qualitative inquiry. Theory into practice, 39(3), 124-130.

Doğan, O., Ertekin, Ş., \& Doğan, S. (2005). Sleep quality in hospitalized patients. Journal of clinical nursing, 14(1), 107-113.

Evans, G. W. (1984). Environmental stress: CUP Archive.

Fish, S. (1989). Doing What Comes Naturally: Change, Rhetoric, and the Practice of Theory in Literary \& Legal Studies: Duke University Press.

Forty, A. (1980). The modern hospital in England and France: the social and medical uses of architecture. Buildings and Society: Essays on the Social Development of the Built Environment, 61-93.

Glaser, B., \& Strauss, A. (1967). The discovery ofgrounded theory. London: Weidenfeld and Nicholson.

Glesne, C. (2011). Becoming qualitative researchers: An introduction: Person Education Inc.

Griffin, J. P. (1992). The impact of noise on critically ill people. Holistic Nursing Practice, 6(4), 53-56.

Groat, L., \& Wang, D. (2002). Architectural research methods. New York.

Grunden, N., \& Hagood, C. (2012). Lean-led hospital design: creating the efficient hospital of the future: CRC Press. 
Guinther, L., Carll-White, A., \& Real, K. (2014). One size does not fit all: A diagnostic post-occupancy evaluation model for an emergency department. HERD: Health Environments Research \& Design Journal, 7(3), 15-37.

Gutman, R. (1972). Site Planning and Social Behavior. Journal of Social Issues, 22(4), $103-115$.

Hagerman, I., Rasmanis, G., Blomkvist, V., Ulrich, R., Anne Eriksen, C., \& Theorell, T. (2005). Influence of intensive coronary care acoustics on the quality of care and physiological state of patients. International Journal of Cardiology, 98(2), 267270.

Hagerman, I., Rasmanis, G., Blomkvist, V., Ulrich, R., Eriksen, C. A., \& Theorell, T. (2005). Influence of intensive coronary care acoustics on the quality of care and physiological state of patients. International journal of cardiology, 98(2), 267270.

Hamilton, D. (2004). Hypothesis and measurement: essential steps defining evidencebased design. Healthcare Design, 4(1), 43-46.

Hamilton, D. K. (2003). The four levels of evidence-based practice. Healthcare Design, $3(4), 18-26$.

Hamilton, D. K. (2014). Research informed design, best practice, and fresh perspectives: can we all get along? HERD: Health Environments Research \& Design Journal, 7(3), 94-97.

Hamilton, D. K., \& Shepley, M. M. (2010). Design for critical care: An evidence-based approach: Routledge.

Hamilton, D. K., \& Watkins, D. H. (2008). Evidence-based design for multiple building types: Wiley. com.

Haq, S., Hill, G., \& Pramanik, A. (2005). Comparison of configurational, wayfinding and cognitive correlates in real and virtual settings. Paper presented at the 5th International Space Syntax Symposium. 
Haq, S., \& Pati, D. (2010). The Research-Design Interaction: Lessons Learned From an Evidence-Based Design Studio. HERD: Health Environments Research \& Design Journal, 3(4), 75-92.

Haq, S., \& Zimring, C. (2003). Just down the road a piece the development of topological knowledge of building layouts. Environment and Behavior, 35(1), 132-160.

Hartig, T., Evans, G. W., Jamner, L. D., Davis, D. S., \& Gärling, T. (2003). Tracking restoration in natural and urban field settings. Journal of environmental psychology, 23(2), 109-123.

Hathorn, K., \& Nanda, U. (2008). A guide to evidence-based art: Concord. CA: Center for Health Design.

Hendrich, A., Chow, M. P., Bafna, S., Choudhary, R., Heo, Y., \& Skierczynski, B. A. (2009). Unit-related factors that affect nursing time with patients: Spatial analysis of the time and motion study. HERD: Health Environments Research \& Design Journal, 2(2), 5-20.

Hillier, B. (1996). Space is the machine: a configurational theory of architecture.

Hilton, B. (1985). Noise in acute patient care areas. Research in Nursing \& Health, 8(3), 283-291.

Holstein, J. A., \& Gubrium, J. F. (2008). Handbook of constructionist research: Guilford Press.

Huelat, B. (2007). Wayfinding: Design for understanding. A Position Paper for the Environmental Standards Council of The Center for Health Design. California. The Center for Health Design.

Huelat, B. J. (2008). The Wisdom of Biophilia-Nature in Healing Environments. Journal of Green Building, 3(3), 23-35.

James, W. P., \& Tatton-Brown, W. (1986). Hospitals: design and development: Architectural Press. 
Johnson, P.-A. (1994). The Theory of Architecture: Concepts Themes \& Practices: John Wiley \& Sons.

Joseph, A., \& Kirk Hamilton, D. (2008). The Pebble Projects: coordinated evidencebased case studies. Building Research \& Information, 36(2), 129-145.

Joseph, A., \& Ulrich, R. (2007). Sound control for improved outcomes in healthcare settings. Concord, CA: Center for Health Design.

Kaplan, A. (1973). The conduct of inquiry: Transaction Publishers.

Kaplan, R., \& Kaplan, S. (1989). The experience of nature: A psychological perspective: CUP Archive.

Karro, J., Dent, A. W., \& Farish, S. (2005). Patient perceptions of privacy infringements in an emergency department. Emergency Medicine Australasia, 17(2), 117-123.

Kotzer, A. M., Zacharakis, S. K., Raynolds, M., \& Buenning, F. (2011). Evaluation of the built environment: Staff and family satisfaction pre-and post-occupancy of the Children's Hospital. HERD: Health Environments Research \& Design Journal, 4(4), 60-78.

Kramer, M., \& Schmalenberg, C. E. (2003). Magnet hospital nurses describe control over nursing practice. Western Journal of Nursing Research, 25(4), 434-452.

Kuhn, T. S. (2012). The structure of scientific revolutions: University of Chicago press.

Lane, P. (1990). A measure of clients' perceptions about intrusions of territory and personal space by nurses. Measurement of nursing outcomes. Measuring client self-care and coping skills, 199-218.

Lang, J. (1987). Creating architectural theory. The Role of The Behavioral Sciences In The Environmental Designs", Von Nostrand Reinhold Company, New York.

Lankford, M. G., Zembower, T. R., Trick, W. E., Hacek, D. M., Noskin, G. A., \& Peterson, L. R. (2003). Influence of role models and hospital design on the hand hygiene of health-care workers. Emerging infectious diseases, 9(2), 217. 
Latimer, H. S., Gutknecht, H., \& Hardesty, K. (2008). Analysis of hospital facility growth: Are we super-sizing healthcare? HERD: Health Environments Research \& Design Journal, 1(4), 70-88.

Leino-Kilpia, H., Välimäki, M., Dassen, T., Gasull, M., Lemonidou, C., Scott, A., \& Arndt, M. (2001). Privacy: a review of the literature. International Journal of Nursing Studies, 38, 663-671.

Malkin, J. (2008). A visual reference for evidence-based design: Center for Health Design.

Malone, E., Harmsen, C., Reno, K., Edelstein, E., Hamilton, D., \& Salvatore, A. (2008). An introduction to evidence based design: exploring healthcare and design (EDAC Study Guide Series, Vol: 1). Concord, CA: The Center for Health Design.

Marberry, S. O. (1995). Innovations in healthcare design: selected presentations from the first five symposia on healthcare design: John Wiley \& Sons.

Marcus, C. C. (1999). Hospitals: Typology of Outdoor Spaces. Healing gardens: Therapeutic benefits and design recommendations, 115.

Marcus, C. C. (2007). Healing gardens in hospitals. Interdisciplinary Design and Research e-Journal, 1(1).

Marcus, C. C., \& Barnes, M. (1999). Healing gardens: Therapeutic benefits and design recommendations: John Wiley \& Sons.

Marquardt, G. (2011). Wayfinding for people with dementia: a review of the role of architectural design. Health Environments Research \& Design Journal (HERD), 4(2).

Marshall, C., \& Rossman, G. (2006). Designing Qualitative Research. California: Sage Publications, Inc.

Maver, T. (1975). Three design paradigms: A tentative philosophy. DMG-DRS Journal, 9, 130-132. 
Maxwell, J. A. (2012). Qualitative research design: An interactive approach (Vol. 41): Sage publications.

McCullough, C. S. (2009). Evidence-based Design for healthcare facilities: Sigma Theta Tau International.

Mertens, D. M. (1998). Research methods in education and psychology: Integrating diversity with quantitative \& qualitative approaches.

Mlinek, E. J., \& Pierce, J. (1997). Confidentiality and privacy breaches in a university hospital emergency department. Academic Emergency Medicine, 4(12), 11421146.

Moore, G. T., \& Golledge, R. G. (1976). Environmental knowing: Theories, research and methods: Dowden.

Morgan, D., \&Stewart, N. . (1999). The physical environment of special care units: Needs of residents with dementia from the perspective of staff and family caregivers. Qualitative Health Research 9 (1), 105-119.

Mullins, J. S. (2011). Design of parametric software tools: optimizing future health care performance by integrating evidence-based knowledge in architectural design and building processes. Light in Engineering, Architecture and the Environment, 121, 37.

Nanda, U., Eisen, S., Zadeh, R., \& Owen, D. (2011). Effect of visual art on patient anxiety and agitation in a mental health facility and implications for the business case. Journal of Psychiatric and Mental Health Nursing, 18(5), 386-393.

Nanda, U., Pati, S., \& Nejati, A. (2015). Field Research and Parametric Analysis in a Medical-Surgical Unit. HERD: Health Environments Research \& Design Journal, 8(4), 41-57.

Newell, P. B. (1995). Perspectives on privacy. Journal of Environmental Psychology, 15(2), 87-104.

Newell, P. B. (1998). A cross-cultural comparison of privacy definitions and functions: A systems approach. Journal of Environmental Psychology, 18(4), 357-371. 
Nightingale, F. (1863). Notes on hospitals: Longman, Green, Longman, Roberts, and Green.

Norberg-Schulz, C. (1968). Intentions in architecture: MIT press.

Novicoff, W. M. (2013). Data-driven performance improvement in designing healthcare spaces. HERD: Health Environments Research \& Design Journal, 7(1), 79-84.

Nussbaumer, L. L. (2009). Evidence-based design for interior designers: Fairchild Books.

O'Neill, M. J. (1991). Effects of signage and floor plan configuration on wayfinding accuracy. Environment and Behavior, 23(5), 553-574.

Ortega-Andeane, P., \& Urbina-Soria, J. (1988). A case study of wayfinding and security in a Mexico City hospital. EDRA: Environmental Design Research Association, US, 19, 231-236.

Parrott, R., Burgoon, J. K., Burgoon, M., \& LePoire, B. A. (1989). Privacy between physicians and patients: more than a matter of confidentiality. Social Science \& Medicine, 29(12), 1381-1385.

Passini, R. (1992). Wayfinding in architecture (Vol. 4): John Wiley \& Sons Inc.

Pati, D. (2010). Testing differences before-and-after or among groups in healthcare design research. HERD: Health Environments Research \& Design Journal, 3(3), $11-18$.

Pati, D. (2011a). A framework for evaluating evidence in evidence-based design. HERD: Health Environments Research \& Design Journal, 4(3), 50-71.

Pati, D. (2011b). Generating Evidence from Day-to-Day Activities: Methodological Issues-Part 1. HERD: Health Environments Research \& Design Journal, 5(1), 120-124.

Pati, D. (2012). Generating Evidence from Day-To-Day Activities: Methodological Issues-Part 2. HERD: Health Environments Research \& Design Journal, 5(2), 117-121. 
Pati, D., Harvey Jr, T. E., \& Thurston, T. (2012). Estimating design impact on waste reduction: Examining decentralized nursing. Journal of Nursing Administration, 42(11), 513-518.

Pati, D., \& Nanda, U. (2011). Influence of positive distractions on children in two clinic waiting areas. HERD: Health Environments Research \& Design Journal, 4(3), 124-140.

Patton, M. Q. (2002). Qualitative research and evaluation methods: SAGE Publications, inc.

Peavey, E. K., Zoss, J., \& Watkins, N. (2012). Simulation and mock-up research methods to enhance design decision making. HERD: Health Environments Research \& Design Journal, 5(3), 133-144.

Pena, W. M., \& Parshall, S. A. (2012). Problem seeking: An architectural programming primer: John Wiley \& Sons.

Pérez-Carpinell, J., Camps, V. J., Trottini, M., \& Pérez-Baylach, C. M. (2006). Color memory in elderly adults. Color Research \& Application, 31(6), 458-467.

Philbin, M. K., \& Gray, L. (2002). Changing levels of quiet in an intensive care nursery. Journal of perinatology: official journal of the California Perinatal Association, 22(6), 455-460.

Pittet, D., Hugonnet, S., Harbarth, S., Mourouga, P., Sauvan, V., Touveneau, S., \& Perneger, T. V. (2000). Effectiveness of a hospital-wide programme to improve compliance with hand hygiene. The Lancet, 356(9238), 1307-1312.

Preiser, W. F. (2001). The evolution of post-occupancy evaluation: Toward building performance and universal design evaluation. Learning from our buildings: A state-of-the-practice summary of post-occupancy evaluation, 9-22.

Preiser, W. F., Rabinowitz, H. Z., \& White, E. T. (1988). Post-occupancy evaluation: Van Nostrand Reinhold company.

Proshansky, H. M. (1974). Environmental Psychology and the design professions. 
Randle, J., Clarke, M., \& Storr, J. (2006). Hand hygiene compliance in healthcare workers. Journal of Hospital Infection, 64(3), 205-209.

Rapoport, A. (1982). The meaning of the built environment: A nonverbal communication approach: University of Arizona Press.

Rapoport, A. (1987). On the cultural responsiveness of architecture. Journal of architectural education, 41(1), 10-15.

Rapoport, A. (2000). Science, explanatory theory and environment-behavior studies, in "Theoretical Perspectives in Environment-Behavior Research: Underlying Assumptions, Research Problems, and Mehtodologies", Edited by Seymour Wapner, Jack Demick, Takiji Yamamoto, Hirofumi Minami. 107-140.

Rapoport, A. (2005). Culture, architecture and design: Locke Science Publishing Company.

Reid, E. (2001). Factors affecting how patients sleep in the hospital environment. British Journal of Nursing, 10(14), 912-915.

Reiling, J. (2007). Safe by design: Designing safety in health care facilities, processes, and culture: Joint Commission Resources.

Rollins, J. A. (2004). Evidence-based hospital design improves health care outcomes for patients, families, and staff. Pediatric nursing, 30(4), 338.

Rooke, C., Tzortzopoulos, P., Koskela, L., \& Rooke, J. (2009). Wayfinding: embedding knowledge in hospital environments. HaCIRIC, Imperial College Business School, London, UK, 158-167.

Rousek, J., \& Hallbeck, M. (2011). The use of simulated visual impairment to identify hospital design elements that contribute to wayfinding difficulties. International Journal of Industrial Ergonomics, 41(5), 447-458.

Rousek, J. B., Koneczny, S., \& Hallbeck, M. S. (2009). Simulating visual impairment to detect hospital wayfinding difficulties. Paper presented at the Proceedings of the Human Factors and Ergonomics Society Annual Meeting. 
Rowe, P. G. (1991). Design thinking: MIT press.

Rubin, H. R., Owens, A. J., \& Golden, G. (1997). Status report (1998): An investigation to determine whether the built environment affects patients' medical outcomes: Center for Health Design.

Rubin, H. R., Owens, A. J., \& Golden, G. (1998). Status report (1998): An investigation to determine whether the built environment affects patients' medical outcomes: Center for Health Design.

Ruga, W. (1989). Designing for the six senses. Paper presented at the Journal of health care interior design: proceedings from the... Annual National Symposium on Health Care Interior Design. National Symposium on Health Care Interior Design (US).

Sarason, S. (2013). Social support: Theory, research and applications (Vol. 24): Springer Science \& Business Media.

Schwarz, B. B., R. (1999). Aging, autonomy, and architecture: Advances in assisted living: JHU Press.

Shepley, M., \& Davies, K. (2003). Nursing unit configuration and its relationship to noise and nurse walking behavior: An AIDS/HIV unit case study. AIA Academy Journal, 6, 12-14.

Shepley, M. M. (2002). Predesign and postoccupancy analysis of staff behavior in a neonatal intensive care unit. Children's Health Care, 31(3), 237-253.

Shepley, M. M., Bryant, C., \& Frohman, B. (1995). Validating a Building Prototype: A Post-Occupancy Evaluation of a Women's Medical Center. Journal of Interior Design, 21(2), 15-29.

Sherman, S. A., Varni, J. W., Ulrich, R. S., \& Malcarne, V. L. (2005). Post-occupancy evaluation of healing gardens in a pediatric cancer center. Landscape and Urban Planning, 73(2), 167-183.

Shumaker, S. A., \& Pequegnat, W. (1989). Hospital design, health providers, and the delivery of effective health care Advance in Environment, Behavior, and Design (pp. 161-199): Springer. 
Silverman, D. (2013). Doing qualitative research: A practical handbook: SAGE Publications Limited.

Solovy, A. (2002). "Home" improvement. H\&HN:Hospitals and Health Networks, 76 (12), 28.

Sommer, B., \& Sommer, R. (2002). A practical guide to behavioral research: Tools and techniques: Oxford University Press.

Stake, R. E., \& Savolainen, R. (1995). The art of case study research (Vol. 95004979): Sage publications Thousand Oaks, CA.

Stankos, M., \& Schwarz, B. (2007). Evidence-based design in healthcare: A theoretical dilemma. Interdisciplinary Design and Research e-Journal, 1(1).

Steptoe, A. E., \& Appels, A. E. (1989). Stress, personal control and health: John Wiley $\&$ Sons.

Sternberg, E. M. (2009). Healing spaces: The science of place and well-being: Harvard University Press.

Stetler, C. B., Brunell, M., Giuliano, K. K., Morsi, D., Prince, L., \& Newell-Stokes, V. (1998). Evidence-based practice and the role of nursing leadership. Journal of Nursing Administration, 28(7/8), 45-53.

Stichler, J. F. (2013). Applying Different Processes for Evidence-Based Design. HERD: Health Environments Research \& Design Journal, 7(1), 8-13.

Straus, E. W., \& Straus, A. (2006). Medical marvels: The 100 greatest advances in medicine: Prometheus Books.

Strauss, A., \& Corbin, J. (1998). Basics of qualitative research: Procedures and techniques for developing grounded theory. ed: Thousand Oaks, CA: Sage.

Strauss, A., \& Corbin, J. M. (1990). Basics of qualitative research:Grounded theory procedures and techniques: Sage Publications, Inc. 
Sturdavant, M. (1960). Intensive nursing service in circular and rectangular units. Hospitals, JAHA, 34 (14), 46-48.

Thomson, \& Goldin, A. (1975). The hospital: a social and architectural history: Yale, U.

Tofle, R. B., Schwarz, B., Yoon, S.-Y., Max-Royale, A., \& Des, M. (2004). Color In Healthcare Environments-A Research Report. San Francisco: Coalition for Health Environments Research.

Tolman, E. C. (1951). Purposive behavior in animals and men: Univ of California Press.

Topf, M. (2000). Hospital noise pollution: an environmental stress model to guide research and clinical interventions. Journal of Advanced Nursing, 31(3), 520-528.

Topf, M., \& Thompson, S. (2001). Interactive relationships between hospital patients' noise-induced stress and other stress with sleep. Heart \& Lung: The Journal of Acute and Critical Care, 30(4), 237-243.

Toulmin, S. (1992). Cosmopolis: The hidden agenda of modernity: University of Chicago Press.

Trites, D. K., Galbraith, F. D., Sturdavant, M., \& Leckwart, J. F. (1970). Influence of nursing-unit design on the activities and subjective feelings of nursing personnel. Environment and behavior.

Tzeng, S.-Y., \& Huang, J.-S. (2009). Spatial forms and signage in wayfinding decision points for hospital outpatient services. Journal of Asian Architecture and Building Engineering, 8(2), 453-460.

Ulrich, R. (1984). View through a window may influence recovery. Science(224), 224225.

Ulrich, R. S. (1979). Visual landscapes and psychological well-being. Landscape research, 4(1), 17-23.

Ulrich, R. S. (1981). Natural versus urban scenes some psychophysiological effects. Environment and behavior, 13(5), 523-556. 
Ulrich, R. S. (1991). Effects of interior design on wellness: theory and recent scientific research. Journal of Health Care Interior Design, 3(1), 97-109.

Ulrich, R. S. (1999a). Effects of gardens on health outcomes: Theory and research. Healing gardens: Therapeutic benefits and design recommendations, 27-86.

Ulrich, R. S. (1999b). on Health Outcomes: Theory and Research. Healing gardens: Therapeutic benefits and design recommendations, 27.

Ulrich, R. S. (2000). Evidence based environmental design for improving medical outcomes. Paper presented at the Proceedings of the Healing by Design: Building for Health Care in the 21st Century Conference, Montreal, Quebec, Canada.

Ulrich, R. S. (2001). Effects of healthcare environmental design on medical outcomes. Paper presented at the Design and Health: Proceedings of the Second International Conference on Health and Design. Stockholm, Sweden: Svensk Byggtjanst.

Ulrich, R. S., Berry, L., Quan, X., \& Turner Parish, J. (2010). A conceptual framework for the domain of evidence-based design. Health Environments Research \& Design Journal, 2012-2069.

Ulrich, R. S., \& Parsons, R. (1992). Influences of passive experiences with plants on individual well-being and health. The role of horticulture in human well-being and social development, 93-105.

Ulrich, R. S., Simons, R. F., Losito, B. D., Fiorito, E., Miles, M. A., \& Zelson, M. (1991). Stress recovery during exposure to natural and urban environments. Journal of environmental psychology, 11(3), 201-230.

Ulrich, R. S., Zimring, C., Zhu, X., DuBose, J., Seo, H.-B., Choi, Y.-S., . . Joseph, A. (2008). A review of the research literature on evidence-based healthcare design. HERD: Health Environments Research \& Design Journal, 1(3), 61-125.

Urlich, R., Zimring, C., Quan, X., Joseph, A., \& Choudhary, R. (2004). The role of the physical environment in the hospital of the 21 st century. The Center for Health Design. 
Valente, M., Potts, L. G., Valente, L. M., French-St George, M., \& Goebel, J. (1992). High-frequency thresholds: sound suite versus hospital room. Journal of the American Academy of Audiology, 3(4).

Van den Berg, A. E., Koole, S. L., \& van der Wulp, N. Y. (2003). Environmental preference and restoration:(How) are they related? Journal of environmental psychology, 23(2), 135-146.

Verderber, S. (2010). Innovations in hospital architecture: Taylor \& Francis.

Verderber, S., \& Fine, D. J. (2000). Healthcare architecture in an era of radical transformation: Yale University Press.

Viets, E. (2009). Lessons from evidence-based medicine: what healthcare designers can learn from the medical field. HERD: Health Environments Research \& Design Journal, 2(2), 73-87.

Watkins, N., Myers, D., \& Villasante, R. (2008). Mock-ups as "interactive laboratories": Mixed methods research using inpatient unit room mock-ups. HERD: Health Environments Research \& Design Journal, 2(1), 66-81.

Williams, A. M., Dawson, S., \& Kristjanson, L. J. (2008). Exploring the relationship between personal control and the hospital environment. Journal of clinical nursing, 17(12), 1601-1609.

Wolcott, H. F. (2001). Writing up qualitative research: Thousand Oaks, CA: Sage.

Yin, R. K. (2009). Case study research: Design and methods: Sage publications.

Zadeh, R. S., Shepley, M. M., \& Waggener, L. T. (2012). Rethinking efficiency in acute care nursing units: Analyzing nursing unit layouts for improved spatial flow. HERD: Health Environments Research \& Design Journal, 6(1), 39-65.

Zborowsky, T., Bunker-Hellmich, L., Morelli, A., \& O'Neill, M. (2010). Centralized vs. decentralized nursing stations: Effects on nurses' functional use of space and work environment. HERD: Health Environments Research \& Design Journal, 3(4), 1942. 
Zeisel, J. (1981). Inquiry by design: tools for environment-behaviour research: CUP Archive.

Zimring, C. (1994). A Guide to Conducting Healthcare Facility Visits: Center for Health Design.

Zimring, C., Augenbroe, G. L., Malone, E. B., \& Sadler, B. L. (2008). Implementing healthcare excellence: The vital role of the CEO in evidence-based design. HERD: Health Environments Research \& Design Journal, 1(3), 7-21.

Zimring, C., \& Bosch, S. (2008). Building the Evidence Base for Evidence-Based Design Editors' Introduction. Environment and behavior, 40(2), 147-150.

Zimring, C., Joseph, A., \& Choudhary, R. (2004). The role of the physical environment in the hospital of the 21st century: A once-in-a-lifetime opportunity. Concord, CA: The Center for Health Design.

Zimring, C. M., \& Reizenstein, J. E. (1980). Post-occupancy evaluation an overview. Environment and behavior, 12(4), 429-450.

Zuckerman, M. (1977). Development of a situation-specific trait-state test for the prediction and measurement of affective responses. Journal of consulting and clinical Psychology, 45(4), 513. 


\section{VITA}

Suining Ding is a professor at Indiana University Purdue University Fort Wayne where she is the program director for Interior Design Program. Suining is an accomplished author and an engaged scholar who has given numerous presentations on teaching pedagogy and scholarly research at national and international conferences. Her work also has appeared in books and journal articles. After sending her lovely daughter to Wellesley College in 2012, she embarked her doctoral studies. Since healthcare design research has always been intriguing to her and she has extensive practice experience in healthcare architecture, she passionately chose healthcare design as the cognate area for her doctoral studies and her dissertation research.

Suining attended The Ohio State University where she received her Master's degree in Interior Design. She also holds a Bachelor's degree in Architecture from Southeast University. She is a National Council of Interior Design Qualification (NCIDQ) certified Interior Designer. She also holds an Evidence-based Design Accreditation and Certification (EDAC) professional certification from the Center for Health Design. Additionally, she is a professional member of the American Society of Interior Designers (ASID). Before she started her teaching career, she enjoyed rewarding architectural practice experience which has been extremely beneficial to her dissertation research. 